\title{
Mesoporous silica nanomaterials for applications in catalysis, sensing, drug delivery and gene transfection
}

\author{
by
}

\section{Daniela Rodica Radu}

\begin{abstract}
A dissertation submitted to the graduate faculty in partial fulfillment of the requirements for the degree of DOCTOR OF PHILOSOPHY
\end{abstract}

\author{
Major: Chemistry \\ Program of Study Committee: \\ Victor Shang-Yi Lin, Major Professor \\ William S. Jenks \\ Marc D. Porter \\ Nicola L. Pohl \\ Brent H. Shanks
}

Iowa State University

Ames, Iowa

2004

Copyright $(\mathcal{C}$ Daniela Rodica Radu, 2004. All rights reserved. 


\section{Graduate College}

Iowa State University

This is to certify that the doctoral dissertation of

Daniela Rodica Radu

has met the dissertation requirements of Iowa State University

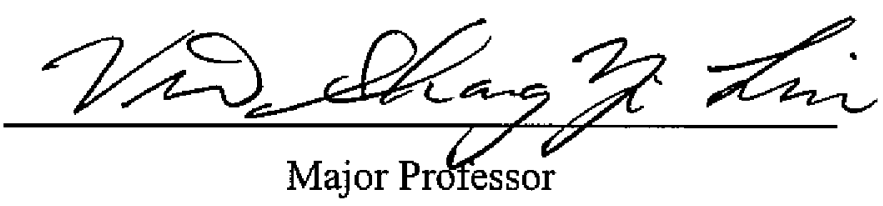

For the Major Program 


\section{DEDICATION}

To my children

"Float straight ahead and if the land you are looking for does not exist yet, be sure that God will create it for rewarding your courage."

Isabella of Castile to Christopher Columbus 


\section{TABLE OF CONTENTS}

LIST OF FIGURES $\quad$ ix

LIST OF TABLES $\quad$ XV

AKNOWLEDGEMENTS $\quad$ xvi

ABSTRACT xvii

CHAPTER 1. GENERAL INTRODUCTION

Introduction and Dissertation Organization $\quad, \quad 1$

Literature Review $\quad 4$

$\begin{array}{ll}\text { References } & 7\end{array}$

CHAPTER 2. FINE-TUNING THE DEGREE OF ORGANIC FUNCTIONALIZATION

OF MESOPOROUS SILICA NANOSPHERE MATERIALS VIA

AN INTERFACIALLY DESIGNED CO-CONDENSATION METHOD

Abstract

Introduction

Materials and Methods

Results and Discussion

Conclusions 
References

CHAPTER 3. OXIDATIVE POLYMERIZATION OF 1,4-DIETHYNYLBENZENE INTO HIGHLY CONJUGATED POLY(PHENYLENE BUTADTYNYLENE) WITHIN THE CHANNELS OF SURFACE-FUNCTIONALIZED MESOPOROUS SILICA AND ALUMINA MATERIALS

\begin{abstract}
Introduction

Materials and Methods

Results and Discussion

Conclusions

Acknowledgements

References

CHAPTER 4. ORGANOSULFONIC ACID-FUNCTIONALIZED MESOPOROUS SILICAS FOR THE ESTERIFICATION OF FATTY ACIDS
\end{abstract}

41

Abstract

Introduction

Materials and Methods

Results and Discussion 
$\begin{array}{ll}\text { Acknowledgements } & 60\end{array}$

$\begin{array}{ll}\text { References } & 60\end{array}$

CHAPTER 5. GATEKEEPING LAYER EFFECT: A POLY(LACTIC ACD)-COATED MESOPOROUS SILICA NANOSPHERE-BASED FLUORESCENCE PROBE FOR DETECTION OF AMINO-CONTAINING NEUROTRANSMITTERS

$\begin{array}{lr}\text { Abstract } & 63 \\ \text { Introduction } & 64 \\ \text { Materials and Methods } & 64 \\ \text { Results and Discussion } & 69 \\ \text { Conclusions } & 80 \\ \text { Acknowledgements } & 81 \\ \text { References } & 81\end{array}$

CHAPTER 6. REAL-TIME ATP IMAGING OF TUNABLE RELEASE FROM A MCM-41-TYPE MESOPOROUS SILICA NANOSPHERE-BASED DELIVERY SYSTEM

$\begin{array}{ll}\text { Abstract } & 84\end{array}$

$\begin{array}{ll}\text { Introduction } & 84\end{array}$

$\begin{array}{ll}\text { Materials and Methods } & 87\end{array}$

Results and Discussion $\quad 90$ 


$$
\text { vii }
$$

Conclusions

Acknowledgements

References

102

CHAPTER 7. INTRACELLULAR MESOPOROUS SILICA NANOSPHERE-BASED CONTROLLED RELEASE DELIVERY DEVICE
Abstract
Introduction
Materials and Methods
Results and Discussion
Conclusions
Acknowledgements
References
CHAPTER 8. A POLYAMIDOAMINE DENDRIMER-CAPPED MESOPOROUS
SILICA NANOSPHERE-BASED GENE TRANSFECTION REAGENT

Abstract

Introduction

Materials and Methods

Results and Discussion 
References

CHAPTER 9. GENERAL CONCLUSIONS

General Conclusions 


\section{LIST OF FIGURES}

\section{CHAPTER 1}

Figure 1-1. Schematics of MCM-41 type materials formation mechanism

\section{CHAPTER 2}

Figure 2-1. Schematic representation of the synthesis of organoalkoxysilane precursors

Figure 2-2. Schematic representation of the utilization of anionic organoalkoxysilane for controlling the functionalization of the MSN materials

Figure 2-3. Schematic representation of the utilization of anionic organoalkoxysilane for controlling the functionalization of the MSN materials

Figure 2-4. Powder XRD diffraction patterns of the MSN-SH, MSN-COOH and $\mathrm{MSN}-\mathrm{SO} 3 \mathrm{H}$ (blue) materials after treatment with disulfide reducing agent (DTT)

Figure 2-5. Nitrogen sorption isotherms of the MSN-SH, MSN-COOH and MSN-SO3H materials after treatment with disulfide reducing reagent DTT and pore size distributions of the MSN-SH, MSN-COOH and MSN-SO3H materials

Figure 2-6. Solid state ${ }^{13} \mathrm{C}$ CP-MAS NMR spectra of the MSN-SH, MSN-COOH, and MSN-SO3H

Figure 2-7. Schematic representation of the formation of thiol-functionalized 
mesoporous silica material (MSN-SO3H) via disulfide reduction with dithiothreitol (DTT)

\section{CHAPTER 3}

Figure 3-1. Schematic representation of $\mathrm{Cu}^{2+}$-functionalized mesoporous silica ( $\mathrm{Cu}-\mathrm{MCM})$ and alumina (Cu-MAL) catalysts for oxidative polymerization of 1,4-diethynylbenzene into conjugated oligo(phenylene butadiynylene)

Figure 3-2. Powder X-ray diffraction patterns of Cu-MCM before and after PPB polymerization and Cu-MAL before and after PPB polymerization

Figure 3-3. Absorbance measurements of polymeric material synthesized using catalysts on support or in solution

Figure 3-4. Nitrogen adsorption/desorption isotherms and the pore size distributions of the Cu-MCM and Cu-MAL materials before and after PPB polymerization within the mesoporous channels.

Figure 3-5. Normalized fluorescence emission spectra of 1,4-diethynylbenzene and the PPB-containing composite materials of Cu-MAL and Cu-MCM catalysts

Figure 3-6. ${ }^{13} \mathrm{C}$ CPMAS spectra of (a) structurally aligned PPB polymer catalyzed by Cu-MCM, (b) PPB polymer synthesized with Cu-MAL, and (c) bulk PPB

Figure 3-7. Figure 3-7. MALDI mass spectrometry mesurements of the PPB polymer synthesized within the mesoporous $\mathrm{Cu}-\mathrm{MCM}$ catalyst

\section{CHAPTER 4}

Figure 4-1. Organosulfonic acid functional groups used in the study 
Figure 4-2. Pore-size distribution curves for the mesoporous materials

Figure 4-3. Catalytic results for the esterification of palmitic acid in soybean oil with methanol

Figure 4-4. Effect of external mass transfer on the esterification of palmitic acid in soybean oil

Figure 4-5. Esterification of palmitic acid in soybean oil with methanol

\section{CHAPTER 5}

Figure 5-1. Schematic representation of a surface of MSN materials: Thiol-MSN and DH-MSN

Figure 5-2. Schematic representation of the synthesis of PLA-coated MSN-based fluorescence sensor system for detection of amine-containing neurotransmitters

Figure 5-3. ${ }^{1} \mathrm{H} \rightarrow{ }^{13} \mathrm{C} \mathrm{CPMAS},{ }^{29} \mathrm{Si}$ DPMAS and ${ }^{1} \mathrm{H} \rightarrow{ }^{29} \mathrm{Si}$ CPMAS spectra collected for Thiol-MSN , DH-MSN and PLA-MSN samples

Figure 5-4. Transmission electron micrograph (TEM) of an ultramicrotomed PLA-MSN material

Figure 5-5. Powder X-Ray diffraction patterns of thiol-MSN, DH-MSN, and PLA-MSN

Figure 5-6. BET nitrogen adsorption/desorption isotherms and BJH pore size distributions of DH-MSN and PLA-MSN materials

Figure 5-7. Particle size distribution and scanning electron micrographs of PLA-MSN

Figure 5-8. Kinetic measurements of the fluorescence detection of dopamine, tyrosine, and glutamic acid with OPTA-SS and PLA-MSN

Figure 5-9. HPLC chromatographs of the solution containing dopamine and glutamic 


\section{CHAPTER 6}

Figure 6-1. SEM and TEM micrographs of PAMAM dendrimer-capped MSN

Figure 6 -2 . Solid state ${ }^{13} \mathrm{C} \mathrm{CPMAS},{ }^{31} \mathrm{P}$ CPMAS,${ }^{29} \mathrm{Si}$ DPMAS, and ${ }^{29} \mathrm{Si}$ CPMAS spectra of ATP-loaded MSN material capped with G2.5 PAMAM dendrimers

Figure 6-3. Effect of disulfide-cleaving molecules on chemiluminescence signal

Figure 6-4. (A) Release of encapsulated ATP from MCM-type mesoporous nanospheres

Figure 6-4. (B) Release of encapsulated ATP from MCM-type mesoporous nanospheres

Figure 6-5. Effect of uncapping agent concentration on the magnitude of release of encapsulated ATP from MCM-type mesoporous nanospheres

Figure 6-6. Release of encapsulated ATP from dendrimer-capped MCM-41-type mesoporous nanospheres

\section{CHAPTER 7}

Figure 7-1. Schematic representation of Texas Red incorporated mesoporous silica nanospheres, T-MSN

Figure 7-2. Scanning electron micrographs (SEM) of the mesoporous silica nanospheres (MSN)

Figure 7-3. High-resolution transmission electron micrographs (TEM) of FTIC incorporate MCM-41 mesoporous silica nanospheres with amine functionality (F-MSN) 
xiii

Figure 7-4. Schematic representation of possible interaction of MSNs with HeLa cells 120

Figure 7-5. F-MSN internalization. Dosage study and Time dependence study 121

Figure 7-6. Fluorescent MSNs after endocytosis and cell mitosis - a dividing HeLa cell 122

Figure 7-7. Cellular application of F-MSN (a) F-MSN engaged in endocytosis

(b) F-MSNs inside of a HeLa cell

Figure 7-8. Doxorubicin delivery: Free doxorubicin delivered to HeLa Cells (a);

MSN Encapsulated doxorubicin delivery in HeLa Cells (b)

Figure 7-9. Cleavable versus non-cleavable caps: Cells incubated with Dox-MSNs and Cells incubated with Dox-ISP-MSNs

Figure 7-10. HPLC study of Doxorubicin release from Dox-MSNs

Figure 7-11. Kinetic study of Doxorubicin release

Figure 7-12. Transfection of neural glia (astrocytes) with pEGFP utilizing G2-MSN as a transfection vector

Figure 7-13. TEM micrograph of cotransfected HeLa cells

Figure 7-14. Confocal fluorescence images and phase contrast images of HeLa cells

$$
\text { (a) and } \mathrm{CHO} \text { cells(b) }
$$

Figure 7-15. Relative transfection efficiencies between several transfection reagents

\section{CHAPTER 8}

Figure 8-1. Schematic representation of a non-viral gene transfection

Figure 8-2. Schematic representation of a non-viral gene transfection system based on a Texas Red. (TR)-loaded, G2-PAMAM dendrimercapped MSN material complexed with an enhanced green fluorescence protein

(Aequorea victoria) plasmid DNA (pEGFP-Cl) 
Figure 8-3. Powder X-Ray diffraction patterns of purified ICP-MSN, G2-MSN, and Texas Red-loaded G2-MSN materials

Figure 8-4. BET nitrogen adsorption/desorption isotherms

Figure 8-5. $\quad{ }^{13} \mathrm{C}$ solid state CP-MAS NMR spectra of the ICP-MSN and G2-MSN materials

Figure 8-6. SEM (a) and TEM (300 kV) micrographs of the G2-MSN (b)

Figure 8-7. Complexation of G2-MSN with pEGFP-C1 DNA -electrophoresis study

Figure 8-8. Electrophoretic gel shifts of stability Studies of pEGFP-C1 DNA and G2-MSN-DNA Complex after Bam H1 treatment

Figure 8-9. Fluorescent microscopy images of HeLa cells treated with G2-MSN-DNA

Figure 8-10. Flow cytometry analysis of the transfection of pEGFP in HeLa cells with G2-MSN

Figure 8-11. Fhuorescence confocal micrographs of cells transfected by pEGFP-C1-coated G2-MSN system

Figure 8-12. TEM micrographs of G2-MSN-DNA complexes (black dots) endocytosed by Chinese hamster ovarian (CHO) (a), human cervical cancer (HeLa) (b), and neural glia (astrocytes) (c) cells

Figure 8-13. Cell growth of (a) HeLa and (b) CHO cells in the presence of G2-MSN and in the absence of G2-MSN 


\section{LIST OF TABLES}

Table 2-1. Structural properties of the organically functionalized MSN materials

Table 2-2. Elemental Analysis of the organically functionalized MSNs

Table 3-1. Powder XRD structural parameters of the series of $\mathrm{Cu}^{2+}$-materials

Table 4-1. Textural properties of the functionalized mesoporous silicas

Table 4-2. Comparison of the kinetic performance of the functionalized mesoporous silica catalysts

Table 5-1. Summary of ${ }^{13} \mathrm{C}$ CPMAS NMR data 72

Table 5-2. Summary of ${ }^{29}$ Si CPMAS NMR DATA 72

Table 5-3. Powder X-Ray diffraction results 75

Table 5-4. Nitrogen sorption isotherms 76

Table 5-5. HPLC analysis of dopamine and glutamic acid before and after the introduction of PLA-MSN

Table 6-1. Characteristics of release of encapsulated ATP from CdS-capped MCM-type mesoporous nanospheres for various reducing agents

Table 8-1. Powder X-Ray diffraction patterns 


\section{ACKNOWLEDGEMENTS}

I would like to express my appreciation for the whole support that I have received over the past few years from so many wonderful people.

Most importantly, I would like to express my gratitude and high appreciation to my supervisor, Professor Victor Shang-Yi Lin, for his commitment to guiding me through my doctoral research, for his wisdom, for his brilliant ideas and above all this, for his mentoring.

I am much indebted to my POS Committee members, Dr. William Jenks, Dr. Marc Porter, Dr. Nicola Pohl, and Dr. Brent Shanks, in no particular order, for having accepted to be with me through this trip and helping me with their excellent suggestions.

Many thanks to Dr. Janice Buss for her suggestions and friendship.

To my family, that tolerated my absence for such a long time, my forever worship.

Finally, I am expressing my special thanks to Dr. Cheng-Yu Lai, who brought color and inspiration to all this work.

The United States Government has assigned the DOE Report number IS-T 2497 to this thesis.

Notice: This document has been authored by the Iowa State University of Science and Technology under Contract No. W-7405-ENG-82 with the U.S. Department of Energy. The U.S Government retains a non-exclusive, paid-up, irrevocable, world-wide license to publish or reproduce the published form of this document, or allow others to do so, for U.S. Government purposes. 


\section{ABSTRACT}

Structurally well-defined mesoporous silica materials, such as MCM-type silicas with tunable pore size and narrow pore-size distribution have attracted much attention for their potential applications in adsorption, catalysis, separation, and sensing. Organofunctionalized MCM-41 silica pores could serve as synthetic scaffolds to mimic enzyme or antibody active sites for specific covalent and/or noncovalent interactions with target molecules. Herein, we designed and synthesized a fluorescence sensory system to study the molecular recognition events of biogenic molecules, such as dopamine and glucosamine, inside different functionalized mesoporous silica microenvironment.

We have also synthesized a poly(lactic acid) coated MCM-41-type mesoporous silica nanosphere (PLA-MSN) material that can serve as a fluorescence sensor system for the detection of amino-containing neurotransmitters in neutral aqueous buffer. Utilizing the PLA layer as a gatekeeper, we investigated the molecular recognition events between several structurally simple neurotransmitters, i.e., dopamine, tyrosine, and glutamic acid and a pore surface-anchored $o$-phthalic hemithioacetal (OPTA) groups. These OPTAs function as a fluorescence-sensing group that can react with the neurotransmitters with primary amine groups and form the corresponding fluorescent isoindole products. The poly(lactic acid) layer of the PLA-MSN sensor showed a unique "sieving" effect by regulating the rates of diffusion of the amino acid-based neurotransmitters into the sensor mesopores of the material.

An MCM-41 type mesoporous silica nanosphere-based (MSN) controlled-release delivery system has been synthesized and characterized using surface-derivatized cadmium sulfide (CdS) nanocrystals as chemically removable caps to encapsulate several 
xviii

pharmaceutical drug molecules and neurotransmitters inside the organically functionalized MSN mesoporous framework. We studied the stimuli-responsive release profiles of vancomycin- and adenosine triphosphate (ATP)-loaded MSN delivery systems by using disulfide bond-reducing molecules, such as dithiothreitol (DTT) and mercaptoethanol (ME), as release triggers. The biocompatibility and delivery efficiency of the MSN system with neuroglial cells (astrocytes) in vitro were demonstrated. In contrast to many current delivery systems, the molecules of interest were encapsulated inside the porous framework of the MSN not by adsorption or sol-gel types of entrapment but by capping the openings of the mesoporous channels with size-defined CdS nanoparticles to physically block the drugs/neurotransmitters of certain sizes from leaching out. We envision that this new MSN system could play a significant role in developing new generations of site-selective, controlled-release delivery nanodevices.

For reaching and repairing a damaged cell or for killing a cancer cell, a drug molecule -- no matter how potent -- has to enter the particular cell. Several carriers have been imagined and designed to facilitate the membrane penetration - all suffering from laborious synthesis and the requirement of highly specific targeting. However, for many applications such as local cancer therapy or in vitro gene transfection, an ideal carrier will be able to penetrate any type of cell and deliver the encapsulated molecule inside the cell body.

We have recently developed a new mesoporous silica nanosphere-based (MSN) transmembrane carrier that demonstrates ability to effectively transport molecules of interest through various cell membranes via endocytosis. Our system took advantage of the ordered mesoporous structure of MSN, where the nanometer-sized pores are large enough to accommodate/encapsulate pharmaceutical drugs and neurotransmitters. ${ }^{1}$ The drug-loaded 
mesopores were covalently capped in situ with either surface derivatized CdS nanocrystals or polyamido amine (PAMAM) dendrimers through a chemically cleavable linkage. The removable caps prevented the mesopore-encapsulated molecules from leaching. As a proof of principle, we studied the transmembrane activity of MSNs loaded with membrane impermeable fluorescent dyes on HeLa human cancer cell line, rat neuronal cells, and CHO cell line. The confocal fluorescence images, TEM micrographs, and flow-cytometer measurements showed that the MSNs were successfully engulfed by the cells without exhibiting cytotoxicity or mitosis blockage.

In the same context, as the ability to penetrate the cell membrane was demonstrated, we tried our system as gene carrier. The plasmid DNA of choice was pEGFP - encoding Green Fluorescent Protein. We successfully achieved Green Fluorescent Protein (GFP) gene expression in HeLa human cancer cell line and rat neuronal cells. Attached we present a collection of images illustrating the engulfed fluorescent silica in the cell body (the nuclei of the cells were blue stained). 


\section{CHAPTER 1. GENERAL INTRODUCTION}

\section{Introduction and Dissertation Organization}

The overall objective of this dissertation is to present the versatility of mesoporous silica nanomaterials for several applications described herein.

The dissertation is organized in eight chapters: the first chapter encloses a literature review, the chapters 2-8 consist of journal articles either published or submitted for publication and chapter 9 concludes this dissertation with summaries of the results and an outlook for future work.

Chapter 1 is an overview of nanostructured mesoporous sol-gel materials with emphasis on their application in catalysis, sensing and biology.

Chapter 2 presents a new method for fine tuning the amount of accessible functional groups on the internal surface of the mesopores in Mesoporous Silica Nanospheres (MSN) We developed a synthetic method that can fine tune the amount of chemically accessible organic functional groups on the pores surface of Mesoporous Silica Nanospheres (MSN). The principle of this method resides on exploiting electrostatic and size matching between the cationic alkylammonium head group of the CTAB surfactant with various anionic organoalkoxysilane precursors at the micelle-water interface in a base-catalyzed condensation reaction of silicate (a journal article accepted for publication). My personal contribution represents $55 \%$ of the presented research.

Chapter 3 describes the application of mesoporous silica nanomaterials in two catalysis applications. We demonstrated that a homogeneous coverage of mesopores with organic functional groups can be achieved through rational design/choice of organosilane 
precursors. By employing an ethylenediamine functional group for chelating $\mathrm{Cu}^{2+}$, a $\mathrm{Cu}-$ functionalized MSNs silica catalyst was used for the synthesis of polyalkynylene-based conducting polymer (molecular wire). My personal contribution represents $50 \%$ of the presented research.

Chapter 4 outlines the organically functionalized MSN for another catalytic application. Organosulfonic acid-functionalized mesoporous silicas were synthesized in a one-step approach of co-condensing inorganic-organic reagents in the presence of different surfactant templates with in situ oxidation of the thiol groups to the sulfonic acid groups. The resulting materials were tested for their catalytic performance in the esterification of fatty acid with methanol to produce methyl esters. The activity of the organosulfonic acidfunctionalized silicas in the esterification was compared to that of standard acidic resins. (published journal articles). My personal contribution represents $30 \%$ of the presented research.

Chapter 5 presents a sensing application of Mesoporous Silica Nanospheres (MSNs). We have synthesized a poly(lactic acid) coated mesoporous silica nanosphere (PLA-MSN) material that can serve as a fluorescence sensor system for detection of amino-containing neurotransmitters in neutral aqueous buffer. We investigated the molecular recognition events between several structurally simple neurotransmitters, i.e., dopamine, tyrosine, and glutamic acid and a pore surface-anchored o-phthalic hemithioacetal (OPTA) group, which functions as a fluorescence-sensing group that can react with the neurotransmitters with primary amine groups and form the corresponding fluorescent isoindole products. The poly(lactic acid) layer of the PLA-MSN sensor showed a unique "sieving" effect that regulates the rates of diffusion of the amino acid-based neurotransmitters into the sensor 
mesopores of the material (published journal article). My personal contribution represents $51 \%$ of the presented research.

Chapter 6 is focused on the application of MSNs in drug delivery. The mesoporosity of MSNs confer these materials properties of a sponge: they can soak impressive amounts of molecules in solution. However, the cannels being both-ends opened, the content is easily leaching. Consequently, we have developed a "capping" strategy. We examined bio-friendly molecules such as polyamidoamine dendrimers of generations $\mathrm{G} 2.5$ to $\mathrm{G} 4.5$ as the caps. The release profiles of the different capped MSNs were investigated. My personal contribution represents $20 \%$ of the presented research.

In Chapter 7 the drug delivery system employed MSNs loaded with Doxorubicin, an anticancer drug. The results demonstrated that these nano-Trojan horses have ability to deliver Doxorubicin to cancer cells and induce their apoptosis (submitted journal articles). My personal contribution represents $50 \%$ of the presented research.

Chapter 8 is devoted to the development of a gene transfection nanocarrier that has MSNs as a core of the nanocomposite. We exploited not only the mesopores but also the surface and the silica matrix of these beads for biological applications. A multifunctionalized, MSN-based transfection vector with G2-PAMAM dendrimers covalently attached to MSNs exterior surface was synthesized. The p-EGFP-C1 gene-coated MSN nanocomposite was able to transfect cancer cell lines, such as human HeLa and $\mathrm{CHO}$ cancer cell lines. The green fluorescent protein expression induced by the MSN system in these cells was monitored via fluorescent microscopy and confocal laser microscopy. The results indicated that the transfected cells exhibited less or none of the cytotoxicity commonly associated with the use other transfection methods. The gene carrier potential of MSNs by in 
transfecting primary cells and cotransfecting of two different genes was also investigated. My personal contribution represents $49 \%$ of the presented research.

The results indicated the versatility of this novel gene carrier for rationally designed gene therapy (published and submitted journal articles).

Finally, Chapter 9 is a brief conclusion of the dissertation with a general assessment of the accomplished goals as well as an overview of potential future applications.

\section{Literature Review}

Several versatile surfactant templated sol-gel pathways have been developed to prepare nanostructured porous materials and composites with different morphologies (e.g., monoliths, nanospheres, nanoparticles, and thin films), structures, compositions and properties. The synthetic conditions were systematically studied and optimized. The template effects on pore structure as well as synthetic process, especially template removal steps as well as the systematic functionalization, have been investigated. ${ }^{1-4}$

In the early nineties, ${ }^{1(a)}$ scientists from Mobil Oil Corporation synthesized ordered mesoporous materials of the M41S type, MCM-41 being one of the distinguished members of this family.

In M41S materials, a liquid crystal templating (LCT) mechanism is a process during which long chain surfactant molecules arrange themselves through micelle self-assembly to form liquid-crystalline phases, surrounded by inorganic oxides forming a framework to generate the formation of hexagonal, lamellar or cubic structures, as illustrated in Figure 1-1. 


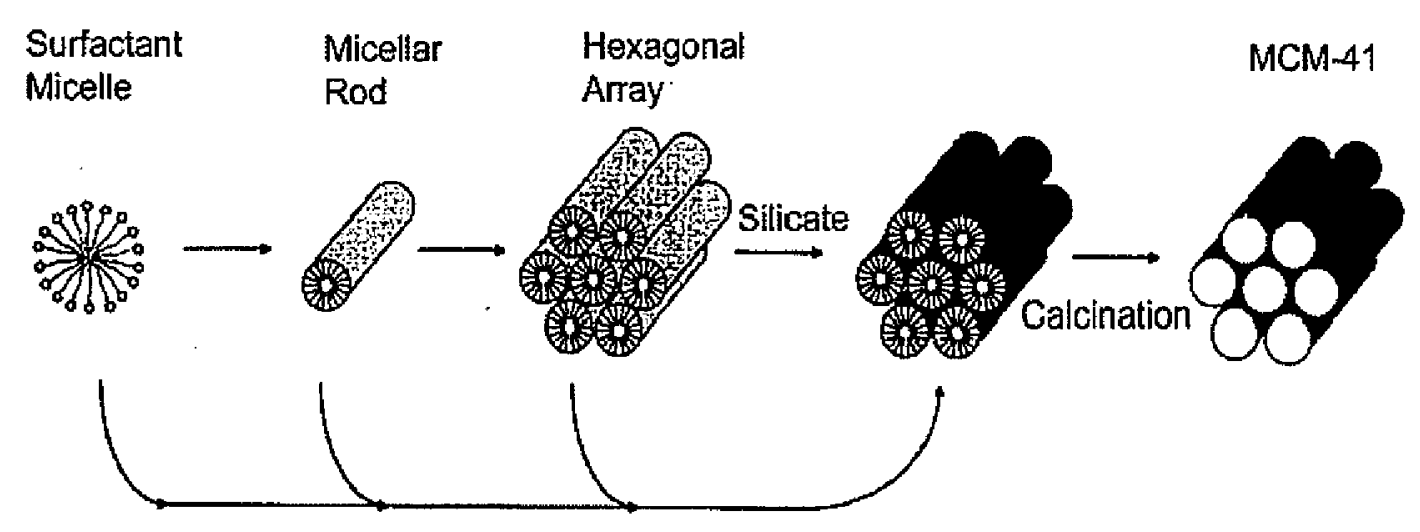

Figure 1-1. Schematics of MCM-41 type materials formation mechanism

This material possesses a porous system consisting of hexagonally arranged channels with diameters varying from 15 to $100 \AA$. MCM-41 has attracted the attention of scientists due to its elevated specific surface area, high thermal and hydrothermal stability, possibility of controlling its pore size and its hydrophobicity and acidity.

Also, recent advancements in utilizing organic surfactants or block copolymers as structure-directing templates for the syntheses of structurally well-defined mesoporous silica materials, such as MCM-48, ${ }^{\mathrm{I}(\mathrm{b})} \mathrm{SBA}-15,{ }^{2} \mathrm{MSU},{ }^{3}$ and FSM- $16,{ }^{4}$ has attracted much attention for their potential applications in sensing, ${ }^{5}$ catalysis, ${ }^{6}$ and drug delivery. ${ }^{7}$ Obviously, the realization of these applications greatly depends on the ability of functionalization of the interior and exterior surfaces of the mesoporous silicas with various organic functional groups.

Although a wide variety of synthetic approaches have been pursued and some significant progresses have been made, few would argue that the current state-of-the-art methods, such as post synthesis grafting ${ }^{8}$ and organosiloxane/siloxane co-condensation 
methods, ${ }^{9}$ need not to be improved in terms of controlling the amount and location of the incorporated functional groups on the surface of the mesoporous silica materials. For example, functional groups incorporated via the post synthesis grafting method typically congregate at the opening parts of porous channels resulting in an inhomogeneous surface coverage, ${ }^{10}$ whereas the amount of functional groups introduced by the organosiloxane/siloxane co-condensation method is yet to reach above $25 \%$ surface coverage without reaching an uniform coverage.

The composition and pore structures were thoroughly studied with various spectroscopic and microscopic methods such as IR, TGA, SEM, TEM, BET (gas sorption measurements), XRD and solid state NMR.

As part of one of the most active research areas in science, nanoscience, ${ }^{11}$ these materials has also raised great interest in the fields of microscale electronics, ${ }^{12-14}$ electrooptics, ${ }^{15}$ biosensors, ${ }^{16-18}$ etc. One particularly interesting application is the development of novel nanomaterials-based drug delivery systems. Traditionally, responsive polymer systems have been employed in such devices. ${ }^{19-20}$ For example, degradable polymers are synthesized in the presence of the drug molecule of interest. ${ }^{21}$ The resulting polymer/drug composite materials usually exhibit slow rates of drug release under normal conditions. Upon stimulation, the degradation of polymer matrix is accelerated, and the release of drug molecules is thereby enhanced. Drug delivery polymers that are responsive toward several types of stimulants, such as temperature, $\mathrm{pH}$, and magnetic/electric field, have been reported in the literature. $22-25$

In addition to polymer-based drug delivery systems, the organically functionalized MCM-type mesoporous silica materials ${ }^{26-27}$ offer several attractive features, such as stable 
mesoporous structures, large surface areas, tunable pore sizes and volumes, and well-defined surface properties, that are ideal for encapsulation of pharmaceutical drugs, proteins, ${ }^{28-32}$ and other biogenic molecules. ${ }^{33}$

Few approaches reported in literature have utilized solid silica nanoparticles as gene transfection vectors or enhancers. ${ }^{34-35}$ However, there are no precedent reports for utilization of mesoporous silica-based material in intracellular gene transfer. The two publications related to intracellular delivery: drug delivery and gene transfection have brought a new dimension to the applicability of MSNs. Virtually any drug within a size range compatible with the size of the meso-channels has potential to be encapsulated and further deliver intracellularly. In the same way, large polymeric molecules such as DNA and RNA that have ability to be electrostatically attached to the derivatized-MSN are delivered to cells.

In conclusion, mesoporous silica materials proved versatility in several applications, as will be showed in the current dissertation.

\section{References}

(1) (a) C. T. Kresge, M. E. Leonowicz, W. J. Roth, J. C. Vartuli, and J. S. Beck, Nature (London), 1992, 359, 710 ; (b) Beck, J.S.; Vartuli, J.C.; Leonowicz, M.E.; Kresge, C.T.; Schmitt, K.D.; Chu, C.T.W.; Olson, D.H.; Sheppard, E.W.; McCullen, S.B.; Higgins, J.B.; Schlenker, J.L. J. Am. Chem. Soc., 1992, 114, 10834.

(2) D. Zhao, J. Feng, Q. Huo, N. Melosh, G. H. Frederickson, B. F. Chmelka, and G. D. Stucky, Science (Washington, D. C.), 1998, 279, 548.

(3) S. A. Bagshaw, E. Prouzet, and T. J. Pinnavaia, Science (Washington, D. C.), 1995, $269,1242$. 
(4) S. Inagaki, A. Koiwai, N. Suzuki, Y. Fukushima, and K. Kuroda, Bull. Chem. Soc. Jpn., 1996, 69, 1449.

(5) (a) V. S. Y. Lin, C.-Y. Lai, J. Huang, S.-A. Song, and S. Xu, J. Am. Chem. Soc., 2001, 123, 11510. (b) D. R. Radu, C.-Y. Lai, J. W. Wiench, M. Pruski, and V. S. Y. Lin, J. Am. Chem. Soc., 2004, 126, 1640.

(6) (a) S. Huh, H.-T. Chen, J. W. Wiench, M. Pruski, and V. S. Y. Lin, J. Am. Chem. Soc,, 2004, 126, 1010. (b) A. Corma, Chem. Rev., 1997, 97, 2373. (c) J. M. Thomas, J. Mol. Catal. A, 1999, 146, 77. (e) D. Brunel, A. C. Blanc, A. Galarneau, and F. Fajula, Catal. Today, 2002, 73, 139, and references therein.

(7) (a) C.-Y. Lai, B. G. Trewyn, D. M. Jeftinija, K. Jeftinija, S. Xu, S. Jeftinija, and V. S. Y. Lin, J. Am. Chem. Soc., 2003, 125, 4451. (b) N. K. Mal, M. Fujiwara, Y. Tanaka, T. Taguchi, and M. Matsukata, Chem. Mater., 2003, 15, 3385.

(8) J. Liu, Y. Shin, Z. Nie, J. H. Chang, L.-Q. Wang, G. E. Fryxell, W. D. Samuels, and G. J. Exarhos, J. Phys. Chem. A, 2000, 104, 8328, and references therein.

(9) A. Stein, B. J. Melde, and R. C. Schroden, Adv. Mater. (Weinheim, Ger.), 2000, 12, 1403 , and references therein.

(10) M. H. Lim and A. Stein, Chem. Mater., 1999, 11, 3285.

(11) Wilson, M.; Kannangara, K.; Smith, G.; Simmons, M.; Raguse, B. Nanotechnology: Basic Science and Emerging Technologies; Chapman and Hall/CRC: Boca Raton, FL, 2002.

(12) Macucci, M.; Iannaccone, G.; Greer, J.; Martorell, J.; Sprung, D. W. L.; Schenk, A.; Yakimenko, I. I.; Berggren, K.-F.; Stokbro, K.; Gippius, N. Nanotechnology 2001, $12,136$. 
(13) Dai, L. In Perspectives of Fullerene Nanotechnology; Osawa, E., Ed.; Kluwer Academic Publishers: Dordrecht, Netherlands, 2002.

(14) Allan, G.; Delerue, C.; Krzeminski, C.; Lannoo, M. In Nanostructured Materials;

Knauth, P., Schoonman, J., Eds.; Kluwer Academic Publishers: Norwell, MA, 2002, pp 161.

(15) Krenn, J. R. Nature Mater. 2003, 2, 210.

(16) Cullum, B. M.; Vo-Dinh, T. Biomedical Photonics Handwork; CRC Press LLC: Boca Raton, FL, 2003.

(17) Lin, V. S. Y.; Lai, C.-Y.; Huang, J.; Song, S.-A.; Xu, S. J. Am. Chem. Soc. 2001, 123, 11510.

(18) Livage, J.; Coradin, T.; Roux, C. J. Phys.: Condensed Matter 2001, 13, R673.

(19) Uhrich, K. E.; Cannizzaro, S. M.; Langer, R. S.; Shakesheff, K. M. Chem. Rev. 1999, $99,3181$.

(20) Langer, R. Acc. Chem. Res. 1993, 26, 537.

(21) Li, Y.; Kissel, T. J. Controlled Release 1993, 27, 247.

(22) Peppas, N. A.; Huang, Y.; Torres-Lugo, M.; Ward, J. H.; Zhang, J. Annu. Rev. Biomed. Eng. 2000, $2,9$.

(23) Kost, J.; Langer, R. Adv. Drug Delivery Rev. 2001, 46, 125.

(24) Ishihara, K.; Kobayashi, M.; Ishimaru, N.; Shonohara, I. Polym. J. 1984, 16, 625.

(25) Fischel-Ghodsian, F.; Brown, L.; Mathiowitz, E.; Brandenburg, D.; Langer, R. Proc. Natl. Acad. Sci. U.S.A. 1988, 85, 2403.

(26) Stein, A.; Melde, B. J.; Schroden, R. C. Adv. Mater. (Weinheim, Germany) 2000, 12, 1403. 
(27) Sayari, A.; Hamoudi, S. Chem. Mater. 2001, 13, 3151.

(28) Vallet-Regi, M.; Ramila, A.; del Real, R. P.; Perez-Pariente, J. Chem. Mater. 2001, 13,308 .

(29) Munoz, B.; Ramila, A.; Perez-Pariente, J.; Diaz, I.; Vallet-Regi, M. Chem. Mater. $2003,15,500$.

(30) Ramila, A.; Munoz, B.; Perez-Pariente, J.; Vallet-Regi, M. J. Sol.-Gel Sci. Technol. 2003, 26, 1199.

(31) Mal, N. K.; Fujiwara, M.; Tanaka, Y.; Taguchi, T.; Matsukata, M. Chem. Mater. $2003,15,3385$.

(32) Diaz, J. F.; Balkus, K. J., Jr. J. Mol. Catal. B: Enzymatic 1996, 2, 115.

(33) Han, Y.-J.; Stucky, G. D.; Butler, A. J. Am. Chem. Soc. 1999, 121, 9897.

(34) Kisler, J. M.; Stevens, G. W.; O'Connor, A. J. Mater. Phys. Mech. 2001, 4, 89.

(35) Luo, D.; Saltzman, W. M. Nature Biotech. 2000, 18, 893 
CHAPTER 2. FINE-TUNING THE DEGREE OF ORGANIC FUNCTIONALIZATION OF MESOPOROUS SILICA NANOSPHERE MATERIALS VIA AN INTERFACIALLY DESIGNED CO-CONDENSATION METHOD

A paper accepted for publication in Chemical Communications

\author{
Daniela R. Radu, Cheng-Yu Lai, Jianguo Huang, Xu Shu, Victor S.-Y. Lin \\ Department of Chemistry, Iowa State University, Ames, Iowa
}

\begin{abstract}
A synthetic method that enables the fine tuning of the amount of chemically accessible organic functional groups on the pore surface of MCM-41 type mesoporous silica nanosphere (MSN) materials has been developed by electrostatically matching various anionic organoalkoxysilanes with the cationic cetyltrimethylammonium bromide micelles in a base-catalyzed condensation reaction of tetraethoxysilane.
\end{abstract}

\title{
Introduction
}

Recent advancements in utilizing organic surfactants or block copolymers as structure-directing templates for the syntheses of structurally well-defined mesoporous silica materials, such as MCM-41/48, ${ }^{1}$ SBA- $15,{ }^{2}$ MSU- $n,{ }^{3}$ and FSM-16, ${ }^{4}$ has attracted much attention for their potential applications in sensing, ${ }^{5}$ catalysis, ${ }^{6}$ and drug delivery. ${ }^{7}$ Obviously, the realization of these applications greatly depends on the ability of functionalization of the interior and exterior surfaces of the mesoporous silicas with various 
organic functional groups. Although a wide variety of synthetic approaches have been pursued and some significant progresses have been made, few would argue that the current state-of-the-art methods, such as post synthesis grafting ${ }^{8}$ and organosiloxane/siloxane cocondensation ${ }^{9}$ methods, need to be improved in terms of controlling the amount and location of the incorporated functional groups on the surface of the mesoporous silica materials. For example, functional groups incorporated via the post synthesis grafting method typically congregate at the opening parts of porous channels resulting in an inhomogeneous surface coverage, ${ }^{10}$ whereas the amount of functional groups introduced by the organosiloxane/siloxane co-condensation method is yet to reach above $25 \%$ surface coverage without destroying the structural integrity and the long-range periodicity of the synthesized materials. ${ }^{9,10}$ Herein, we report on a new co-condensation method that could generate organically functionalized, MCM-41 type of mesoporous silica nanosphere materials while controlling the surface concentration of organic functional groups.

\section{Materials and Methods}

\section{Materials}

3-Mercaptopropionic acid (99+\%), 2,2'-dipyridyl disulfide (98\%), (3mercaptopropyl)trimethoxysilane (MPTES) (95\%), 2-mercaptoethanesulfonic acid sodium salt (98\%), cetyltrimethylammonium bromide (CTAB), tetraethyl orthosilicate (TEOS, 96\%) and dithiothreitol (DTT) were purchased from Aldrich Chemical Co. (Milwaukee, WI). Acetic acid (Glacial), hydrochloric acid (37.4\%), sodium hydroxide, ethanol (anhydrous), methanol (HPLC grade), tetrahydrofuran (HPLC grade), hexanes (pesticide grade) and ethyl ether (anhydrous) were obtained from Fisher Scientific Co. (Pittsburgh, PA). Nanopure water 
was deionized to $18.0 \mathrm{M} \Omega-\mathrm{cm}$ in a Barnstead E-pure water purification system and used for the synthesis of MSN materials.

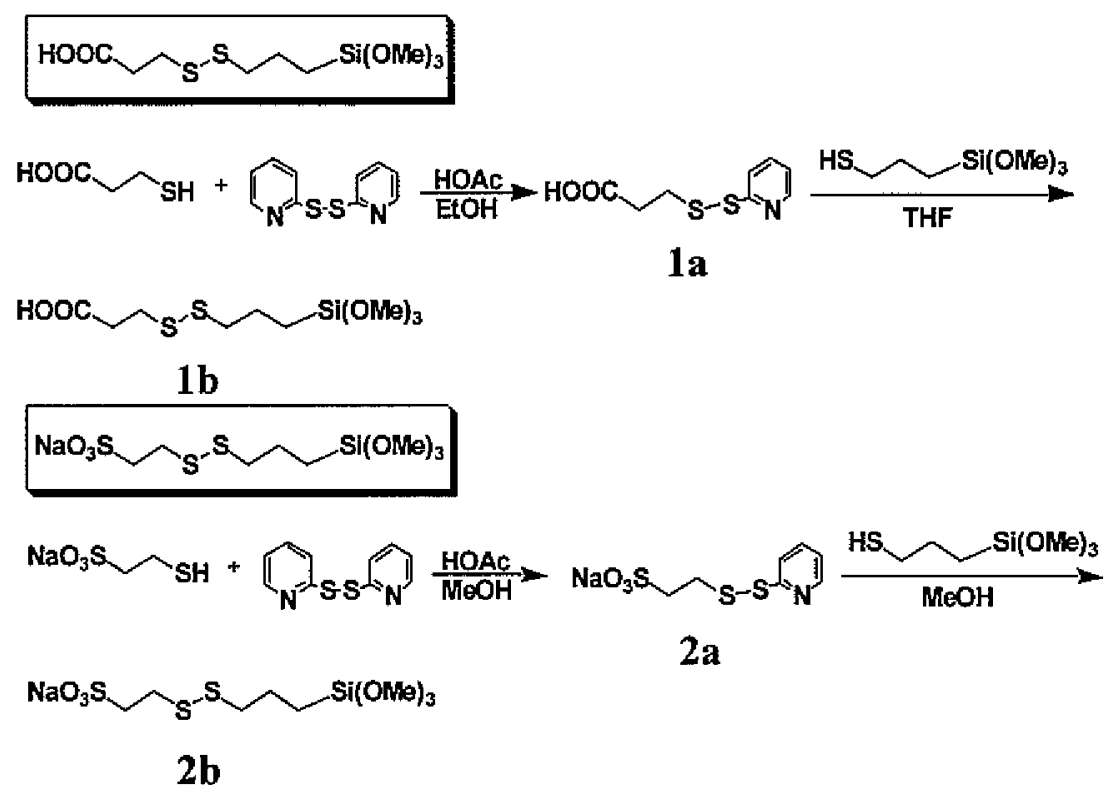

Figure 2-1. Schematic representation of the synthesis of organoalkoxysilane precursors

\section{Synthesis of organoalkoxysilane precursors}

\subsection{Synthesis of 2-[3-(trimethoxysilyl)-propyldisulfanyl]-propionic acid (1b)}

As depicted in Figure 2-1, 2-Carboxyethyl-2-pyridyl-disulfide, compound (1a), was prepared according to a procedure published by Carlsson. ${ }^{14}$ In a typical synthesis, $3.75 \mathrm{~g} \mathrm{(17}$ mmol) of 2,2'-dipyridyl disulfide (Aldrithiol-2) was dissolved in $30 \mathrm{~mL}$ of ethanol and a solution of $0.87 \mathrm{~mL}$ of mercaptopropionic acid in $5 \mathrm{~mL}$ ethanol was injected dropwise. After $20 \mathrm{~h}$ of stirring at room temperature, the crude yellow oil product was isolated by rotary evaporation. The purified product $(1.45 \mathrm{~g}$, yield $=40 \%)$ was obtained from an alumina column chromatography (eluent $\left.=\mathrm{CH}_{2} \mathrm{Cl}_{2} / \mathrm{EtOH} 3: 2 \mathrm{v} / \mathrm{v}\right)$. The product $1.45 \mathrm{~g}(6.8 \mathrm{mmol}$ ) is 
corresponding to $40 \%$ yield. The characterization of compound $1 \mathrm{a}$ is consistent with the literature reported data. ${ }^{14}$

2-[3-(trimethoxysilyl)-propyldisulfanyl]-propionic acid, compound (1b), was prepared by dissolving compound $1 \mathrm{a}(1.51 \mathrm{~g}, 7 \mathrm{mmol})$ in $30 \mathrm{~mL}$ THF, followed by a dropwise addition of MPTMS (1.1 g, $5.6 \mathrm{mmol})$. The resulting yellow solution was stirred under N2 atmosphere for $12 \mathrm{~h}$. After flash evaporation of the solvent, the yellow product was purified by silicagel column chromatography using EA/ hexane in 1:2 ratio as eluent. The purified product $(1 \mathrm{~g})$ was isolated with a $60 \%$ yield. $1 \mathrm{H}-\mathrm{NMR}\left(\mathrm{CDCl}_{3}\right), \delta 0.76(\mathrm{t}, 2 \mathrm{H}$, $\left.\mathrm{CH}_{2}(1)\right), 1.81\left(\mathrm{q}, 2 \mathrm{H}, \mathrm{CH}_{2}(2)\right), 2.71\left(\mathrm{t}, 2 \mathrm{H}, \mathrm{CH}_{2}(5)\right), 2.81\left(t, 2 \mathrm{H}, \mathrm{CH}_{2}(3)\right), 2.91\left(t, 2 \mathrm{H}, \mathrm{CH}_{2}(4)\right)$, $3.60\left(s, 1 \mathrm{H}, \mathrm{OCH}_{3}\right) ;{ }^{13} \mathrm{C}-\mathrm{NMR}\left(\mathrm{D}_{2} \mathrm{O}\right), \delta 10.25,13.69,23.75,34.83,36.98,42.26,180.99$.

\subsection{Synthesis 2-[3-(trimethoxysilyl)-propyldisulfanyl]-ethanesulfonic acid, (2b)}

As depicted in Fig. 2-1, 2,2'-dipyridyl disulfide (8.82 g, $40.0 \mathrm{mmol}$ ) was dissolved in $50.0 \mathrm{~mL}$ methanol, followed by an addition of $1.6 \mathrm{~mL}$ of glacial acetic acid as catalyst. To this mixture, 2-mercaptoethanesulfonic acid sodium salt $(3.82 \mathrm{~g}, 20.0 \mathrm{mmol})$ in $30.0 \mathrm{~mL}$ methanol was added dropwise in 30 min with stirring. The reaction mixture was protected from light and stirred at room temperature overnight, followed by solvent evaporation under vacuum. The crude product was purified by dissolving in a small amount of methanol, followed by recrystallization in ethyl ether and dried under vacuum to yield compound $2 \mathrm{a}$ $(5.14 \mathrm{~g}$, yield $=94.0 \%){ }^{1} \mathrm{H}-\mathrm{NMR}(300 \mathrm{MHz} ; \mathrm{DMSO}-\mathrm{d} 6), \delta 2.73\left(\mathrm{~m}, 2 \mathrm{H}, \mathrm{CH}_{2}\right), 3.02(m, 2 \mathrm{H}$, $\left.\mathrm{CH}_{2}\right), 7.24(d, 1 \mathrm{H}, \mathrm{ArH}), 7.81(m, 2 \mathrm{H}, \mathrm{ArH}), 8.45(d, 1 \mathrm{H}, \mathrm{ArH})$.

To synthesize 2-[3-(trimethoxysilyl)-propyldisulfanyl]-ethanesulfonic acid sodium salt (2b), compound $2 \mathrm{a}(1.36 \mathrm{~g}, 5.0 \mathrm{mmol})$ was dissolved in $20.0 \mathrm{~mL}$ of methanol with 1.0 $\mathrm{mL}$ of glacial acetic acid. To this mixture, (3-mercaptopropyl) trimethoxysilane $(0.95 \mathrm{~mL}$, 
$5.0 \mathrm{mmol}$ ) in $10.0 \mathrm{~mL}$ of methanol was added dropwise. The mixture was protected from light and stirred under nitrogen at room temperature overnight. The reaction was quenched and the solvent was evaporated under vacuum. The solid product was dissolved in a small amount of methanol, followed by ethyl ether precipitation. The purified product $(5.14 \mathrm{~g}$, yield $=74.7 \%$ ) was collected by filtration and dried under vacuum. $1 \mathrm{H}-\mathrm{NMR}(300 \mathrm{MHz}$;

$\left.\mathrm{D}_{2} \mathrm{O}\right) \delta 0.79\left(t, 2 \mathrm{H}, \mathrm{CH}_{2}(1)\right), 1.83\left(q, 2 \mathrm{H}, \mathrm{CH}_{2}(2)\right), 2.81\left(t, 2 \mathrm{H}, \mathrm{CH}_{2}(3)\right), 3.03\left(t, 2 \mathrm{H}, \mathrm{CH}_{2}(5)\right)$, $3.27\left(t, 2 \mathrm{H}, \mathrm{CH}_{2}(4)\right), 3.60\left(s, 7 \mathrm{H}, \mathrm{OCH}_{3}\right)$.

\section{Synthesis of MSN materials}

Three organically functionalized mesoporous silica materials, MSN-COOH, MSN$\mathrm{SO} 3 \mathrm{H}$, and MSN-SH, were prepared by adding an ethanolic solution (2 $\mathrm{mL}, 2.24 \mathrm{mmol}$ ) of CDSP-TMS, SDSP-TMS, and the commercially available MP-TMS, respectively, to an aqueous solution $(480 \mathrm{~mL})$ of CTAB $(2.74 \mathrm{mmol}), \mathrm{NaOH}(7.00 \mathrm{mmol})$, and TEOS $(22.40$ mmol) at $80^{\circ} \mathrm{C}$. The reaction mixture was stirred for $2 \mathrm{~h}$. The solid products were isolated by filtration and washed thoroughly with methanol. The surfactant-removed materials were obtained by refluxing $1 \mathrm{~g}$ of the MSN material in $170 \mathrm{~mL}$ of methanolic solution of $\mathrm{HCl}(1 \mathrm{M})$ for $12 \mathrm{~h}$. The resulting surfactant-removed material was isolated by filtration, washed extensively with methanol, and dried under vacuum. To obtain mesoporous silica material with free thiol groups, the surfactant extracted MSN material was added to $100.0 \mathrm{~mL}$ of $5 \%$ $\mathrm{NaHCO}_{3}$ (aq) containing a disulfide reducing agent, dithiothreitol (DTT) (1.88 g, $12.2 \mathrm{mmol}$ ). The mixture was stirred at room temperature for $4 \mathrm{~h}$. The white product was then filtered and washed with water and methanol, following by vacuum drying. 


\section{Characterization of the Organic Functionalization of the MSN Materials}

\subsection{Powder XRD}

Powder XRD diffraction patterns of MSN-COOH, MSN-SO3H, and MSN-SH are summarized in Table 2-1. The data were collected on a Scintag XRD 2000 X-Ray diffractometer using $\mathrm{Cu} \mathrm{Ka}$ radiation. Low angle diffraction with a $2 \theta$ range of 1 to $10^{\circ}$ was used to investigate the long-range order of the materials.

\subsection{Nitrogen Sorption Analysis}

Surface area (SA) and Median Pore Diameter (MPD) were measured using a Micromeritics ASAP2000 sorptometer. Samples were degassed at $90^{\circ} \mathrm{C}$ for $1 \mathrm{~h}$ and at 150 ${ }^{\circ} \mathrm{C}$ for $4 \mathrm{~h}$. Nitrogen adsorption and desorption isotherms of the MSN materials were obtained at $-196^{\circ} \mathrm{C}$. Specific surface areas and pore size distributions were calculated using the Brunauer-Emmett-Teller (BET) and Barrett-Joyner-Halenda (BJH) method, respectively.

\subsection{Scanning Electron Microscopy}

Particle morphology of these MSN materials was determined by scanning electron microscopy (SEM) using a JEOL 840A scanning electron microscope with $10 \mathrm{kV}$ accelerating voltage and $0.005 \mathrm{nA}$ of beam current for imaging. For obtaining the transmission electron microscopy (TEM) micrograph displayed in the main text, a small aliquot was taken from a suspension of MSN in methanol, and placed in a lacey carboncoated TEM grid, which was pulled through the suspension and allowed to dry in air. The specimen was given no further treatment, as it appeared stable under beam bombardment.

\subsection{Thermogravimetric Anaysis}

TGA curves were recorded using a TA Instruments TGA 2950 thermogravimetric analyzer with a temperature ramp of $5{ }^{\circ} \mathrm{C} /$ min under continuous flow of nitrogen (100 
$\mathrm{mL} / \mathrm{min}$ ). The percentage of weigh loss when heating the samples of MSNs in the range of 1$1000^{\circ} \mathrm{C}$ is concluded in Table 2-2. In general, three or four distinct weight loss TGA profiles were found, including methanol, organic functional groups, and a small weight loss due to the dehydration of the surface hydroxyl groups.

\section{$4.5{ }^{13}$ C Solid State NMR}

The ${ }^{13} \mathrm{C}$ spectra shown in the Figure. $2-5$ confirm the presence of the three organic functional groups in the MSN materials before the disulfide bond reductions. Solid-state ${ }^{13} \mathrm{C}$ CP-MAS NMR spectra were obtained at $75.47 \mathrm{MHz}$ on a Bruker MSL300 spectrometer equipped with Bruker $4 \mathrm{~mm}$ rotor MAS probe. Magic-angle sample spinning rate was maintained at $10 \mathrm{KHz}$. The NMR spectra consisted of between 2,000 and 6,000 acquisitions with cross polarization times of $3 \mathrm{~ms}$ and pulse repetition times of $15 \mathrm{~s}$. All chemical shifts reported are referenced to liquid $\mathrm{SiMe}_{4}$ (TMS).

\section{Quantification of chemically accessible surface-functionalized thiol coverage.}

All experiments were performed in triplicate, by reacting a predetermined amount of material (in the range of 20 to $25 \mathrm{mg}$ ) with a methanolic solution of excess $2,2^{2}$-dipyridyl disulfide (44 mg, $0.2 \mathrm{mmol}$ dissolved in $5 \mathrm{~mL}$ methanol)).

\section{Results and Discussion}

Our method involves the utilization of disulfide-containing organotrimethoxysilanes that have different anionic functional groups, such as 3-(3'-(trimethoxysilyl)-propyldisulfanyl)-propionic acid (CDSP-TMS), 2-[3-(trimethoxy-silyl)-propyl-disulfanyl]ethanesulfonic acid sodium salt (SDSP-TMS), and mercaptopropyl-trimethoxysilane (MP- 
TMS), to electrostatically match with cationic cetyltrimethylammonium bromide (CTAB) surfactant micelles in a $\mathrm{NaOH}$-catalyzed condensation reaction of tetraethoxysilane (TEOS) as shown in Figure 2-2. We were inspired by the recent reports by Larsen and Magid, ${ }^{11}$ where they observed the anionic lyotropic series (citrate $<\mathrm{CO}_{3}{ }^{2-}<\mathrm{SO}_{4}{ }^{2-}<\mathrm{CH}_{3} \mathrm{CO}_{2}{ }^{-}<\mathrm{F}^{-}<$ $\mathrm{OH}^{-}<\mathrm{HCO}_{2}{ }^{-}<\mathrm{Cl}^{-}<\mathrm{NO}_{3}{ }^{-}<\mathrm{Br}^{-}<\mathrm{CH}_{3} \mathrm{C}_{6} \mathrm{H}_{4} \mathrm{SO}_{3}{ }^{-}$) for interaction with the CTAB surfactant micelle based on the enthalpy of transfer of the salt from water to solutions of $0.1 \mathrm{M} \mathrm{CTAB}$. They concluded that anions less hydrated than $\mathrm{Br}^{-}$, such as sulfonate, will be able to replace $\mathrm{Br}^{-}$and bind tightly to the cetyltrimethylammonium head group of the CTAB molecule thereby effectively mitigating the repulsion between these cationic head groups and stabilizing the micelle structure. Also, several recent reports ${ }^{12}$ have also revealed that the long-range structure ordering of CTAB-templated mesoporous silicas could be improved by the additions of various anions. The tightly bound (less hydrated) anions, such as acetate and $\mathrm{BF}_{4}{ }^{\circ}$, became incorporated in the silicate matrix due to their ability to compete with the silicate anions in displacing $\mathrm{Br}^{-}$from the $\mathrm{CTAB}$ micelle.

In the present chapter, the different electrostatic matching effects of various anionic organoalkoxysilanes, such as thiolate-, carboxylate-, and sulfonate-containing organoalkoxysilanes, to CTAB micelles in governing the degree of organic functionalization of the MCM-41 type mesoporous silica materials are investigated.

Scheme 2-1.

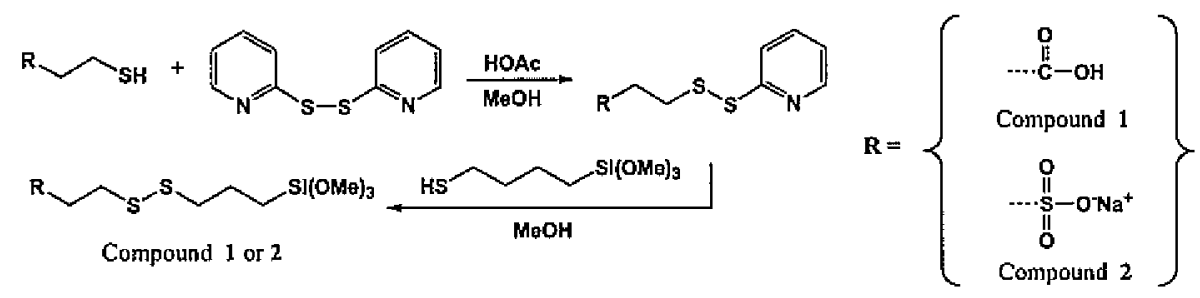


First, two disulfide-containing organotrimethoxysilanes (CDSP-TMS and SDSP-TMS) with carboxylic and sulfonic acid groups, respectively, were synthesized via a synthetic approach outlined in Scheme 2-1. The two compounds were synthesized via a simple thiol activation of 3-mercaptopropionic acid and 2-mercaptoethanesulfonic acid sodium salt with 2,2'-dipyridyl disulfide followed by a disulfide exchange reaction with mercaptopropyltrimethoxysilane. Three organically functionalized mesoporous silica materials, MSN$\mathrm{COOH}, \mathrm{MSN}-\mathrm{SO} 3 \mathrm{H}$, and MSN-SH, were prepared by adding an ethanolic solution $(2 \mathrm{~mL}$, $2.24 \mathrm{mmol}$ ) of CDSP-TMS, SDSP-TMS, and the commercially available MP-TMS, respectively, to an aqueous solution $\left(480 \mathrm{~mL}, 80^{\circ} \mathrm{C}\right)$ of $\mathrm{CTAB}(2.74 \mathrm{mmol}), \mathrm{NaOH}(7.00$ mmol), and TEOS ( $22.40 \mathrm{mmol}$, added at $80^{\circ} \mathrm{C}$ prior to the addition of organoalkoxysilanes). The reaction mixture was stirred for $2 \mathrm{~h}$. The solid products were isolated by filtration and washed thoroughly with methanol. Surfactant-removed materials were obtained with an acid extraction. All three materials exhibited spherical particle shape with an average particle diameter of $200 \mathrm{~nm}$ (Figure 2-2).

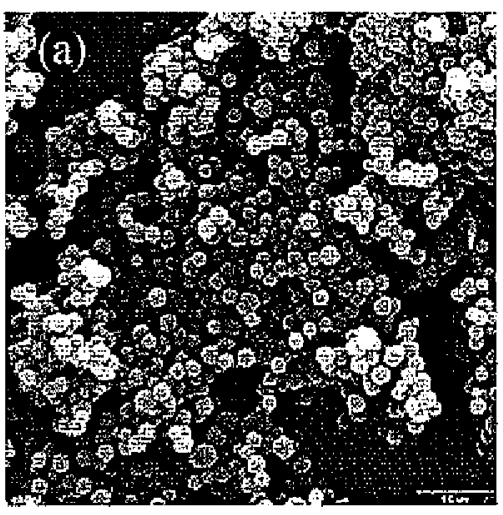

MSN-SH

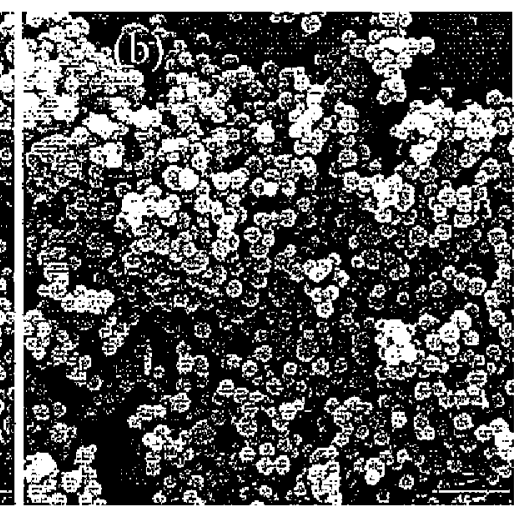

MSN-COOH

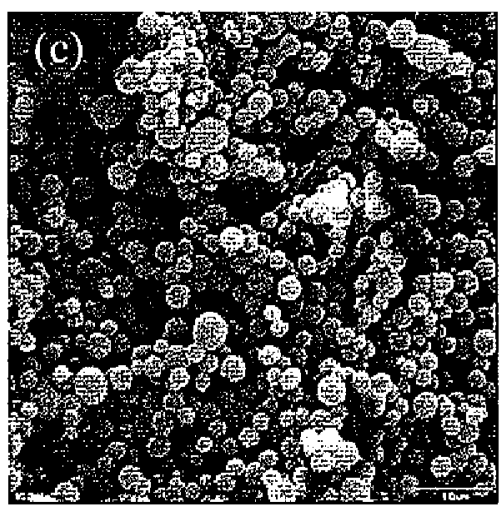

MSN-SO3H

Figure 2-2. SEM images of MSN-SH (a), MSN-COOH (b) and MSN-SO3H (c). All three materials exhibited spherical particle morphology, with an average particle diameter of $200 \mathrm{~nm}$. All images are presented using the same magnification (scale bar $=1 \mu \mathrm{m}$ ), 


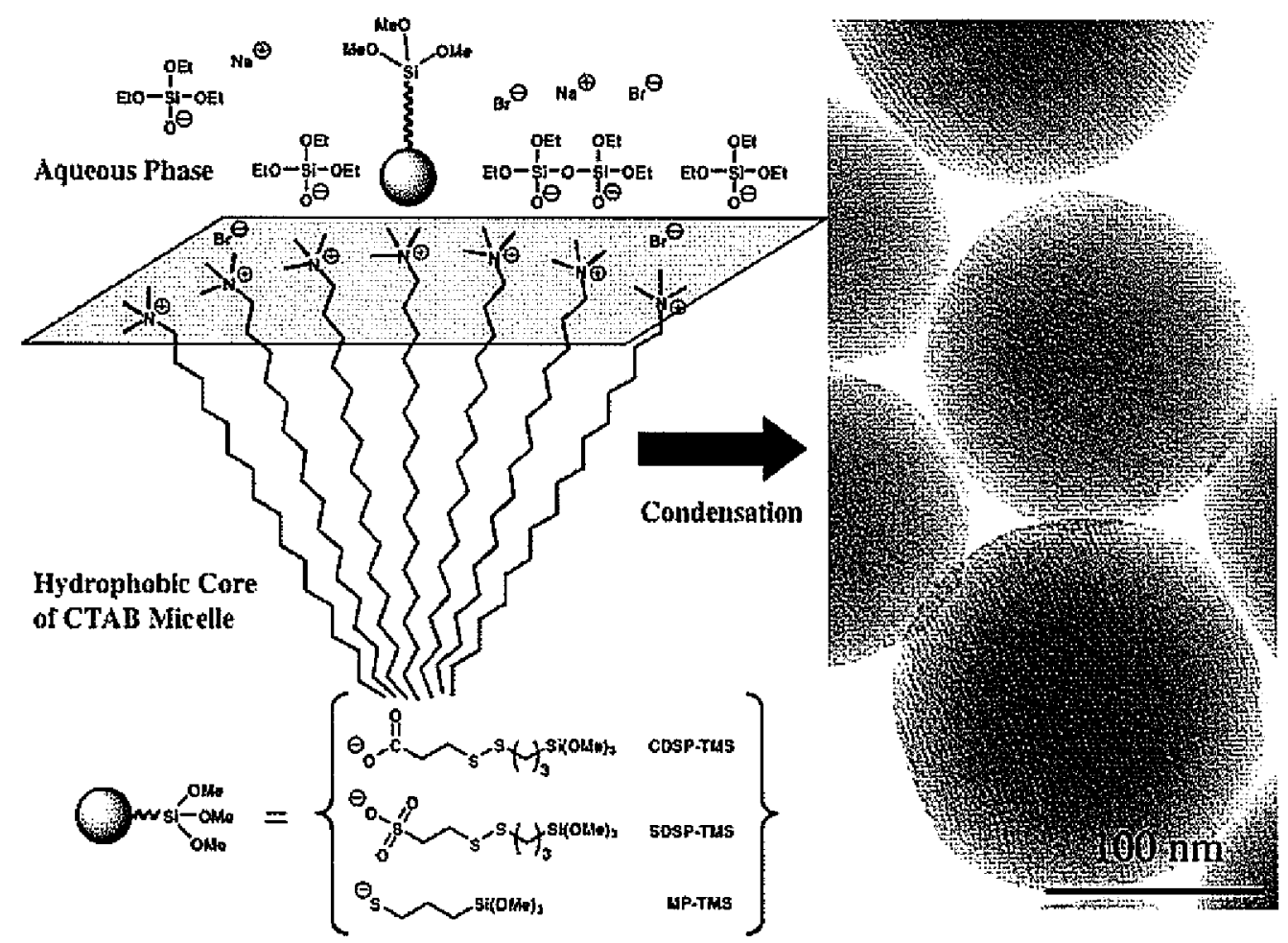

Figure 2-3. Schematic representation of the utilization of anionic organoalkoxysilane for controlling the functionalization of the MSN materials. The MCM-41 type mesoporous channels are illustrated by the parallel stripes shown in the TEM micrograph of the MSN-SH material.

The mesoporous structures of these organically functionalized MSN materials were determined by nitrogen adsorption-desorption surface analysis (BET isotherms and BJH pore size distributions), TEM, and powder X-ray diffraction (XRD) spectroscopy.

These materials exhibited diffraction patterns characteristic of hexagonal MCM-41 silicas, including (100), (110), and (200) peaks (Figure 2-3). In addition, all three MSN materials exhibited type IV BET isotherms with similar average BJH pore diameters (Figure 2-4 and Table 2-1). Hexagonally packed mesoporous channels were clearly observed in the TEM micrographs of these MSNs (Figure 2-1). 


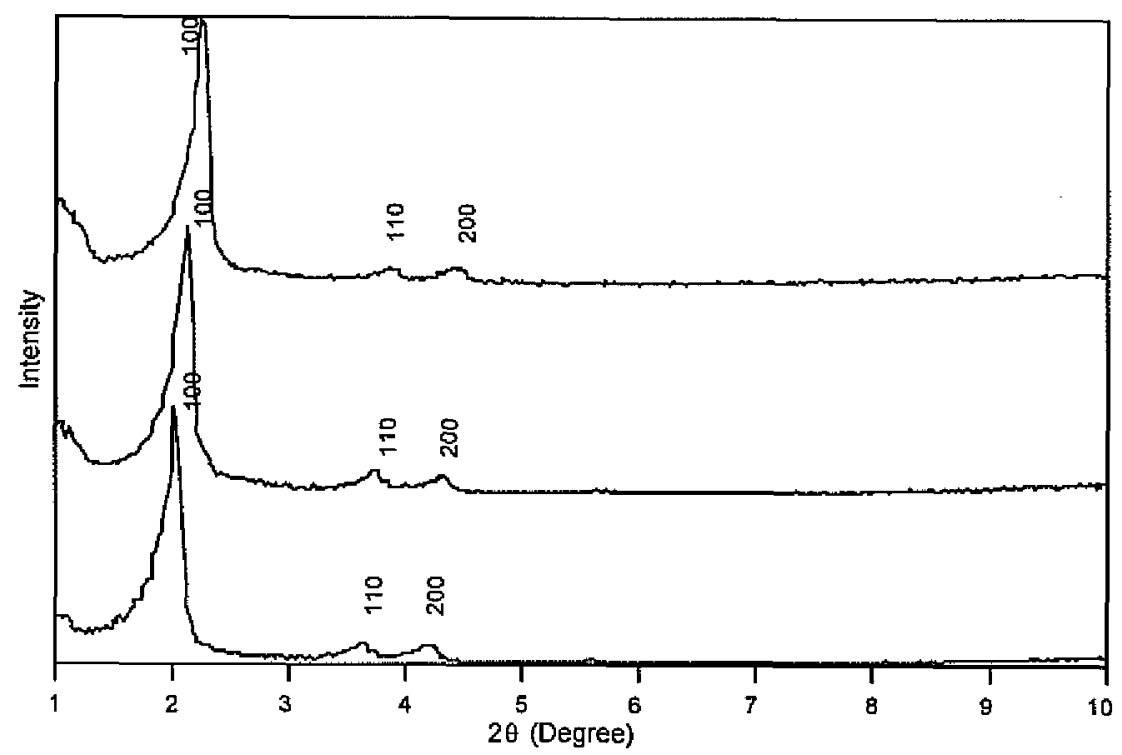

Figure 2-4. Powder XRD diffraction patterns of the MSN-SH (green), MSN-COOH (red) and MSN-SO3H (blue) materials after treatment with disulfide reducing agent (DTT).
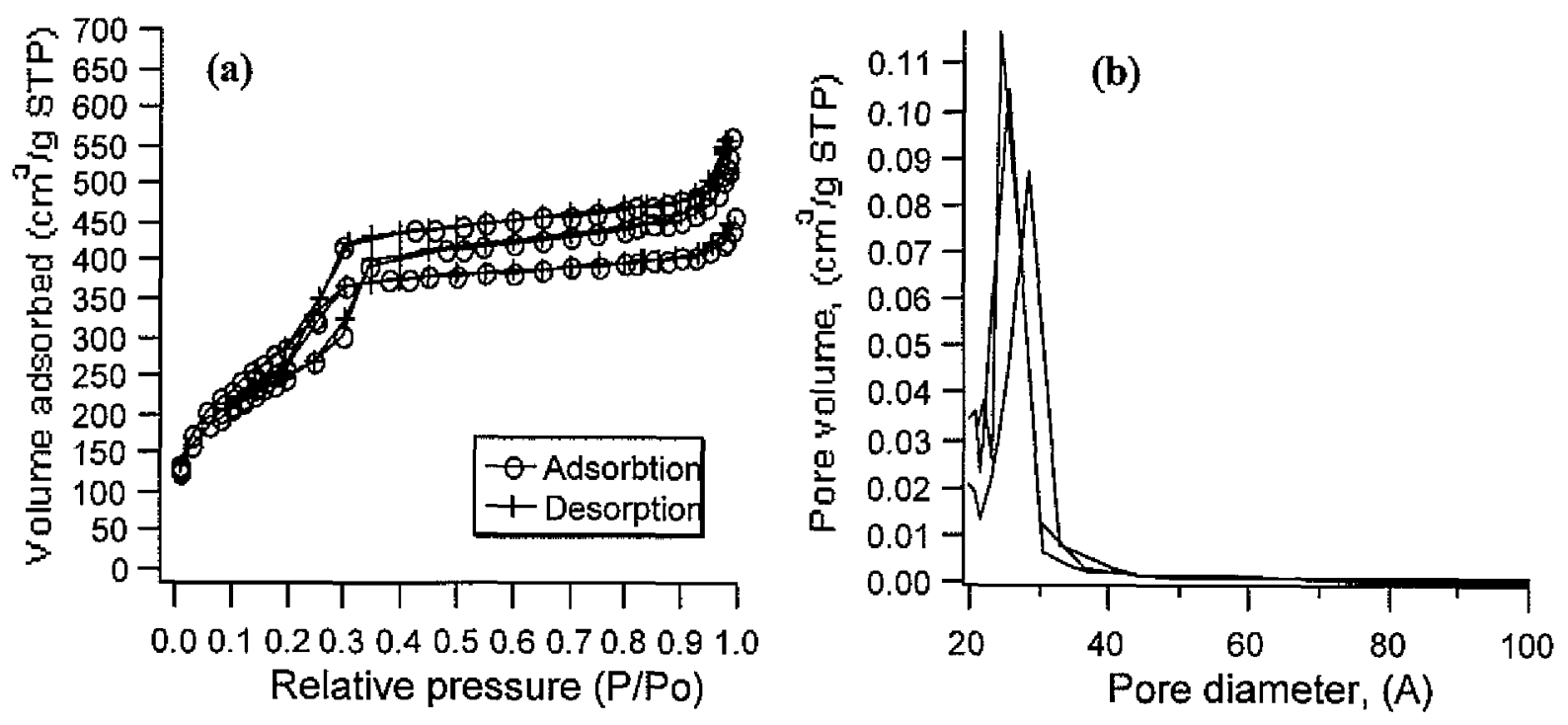

Figure 2-5. (a) Nitrogen sorption isotherms of the MSN-SH (green), MSN-COOH (red) and MSN-SO3H (blue) materials after treatment with disulfide reducing agent (DTT). (b) Pore size distributions of the MSN-SH, MSN$\mathrm{COOH}$ and MSN-SO3H materials. 


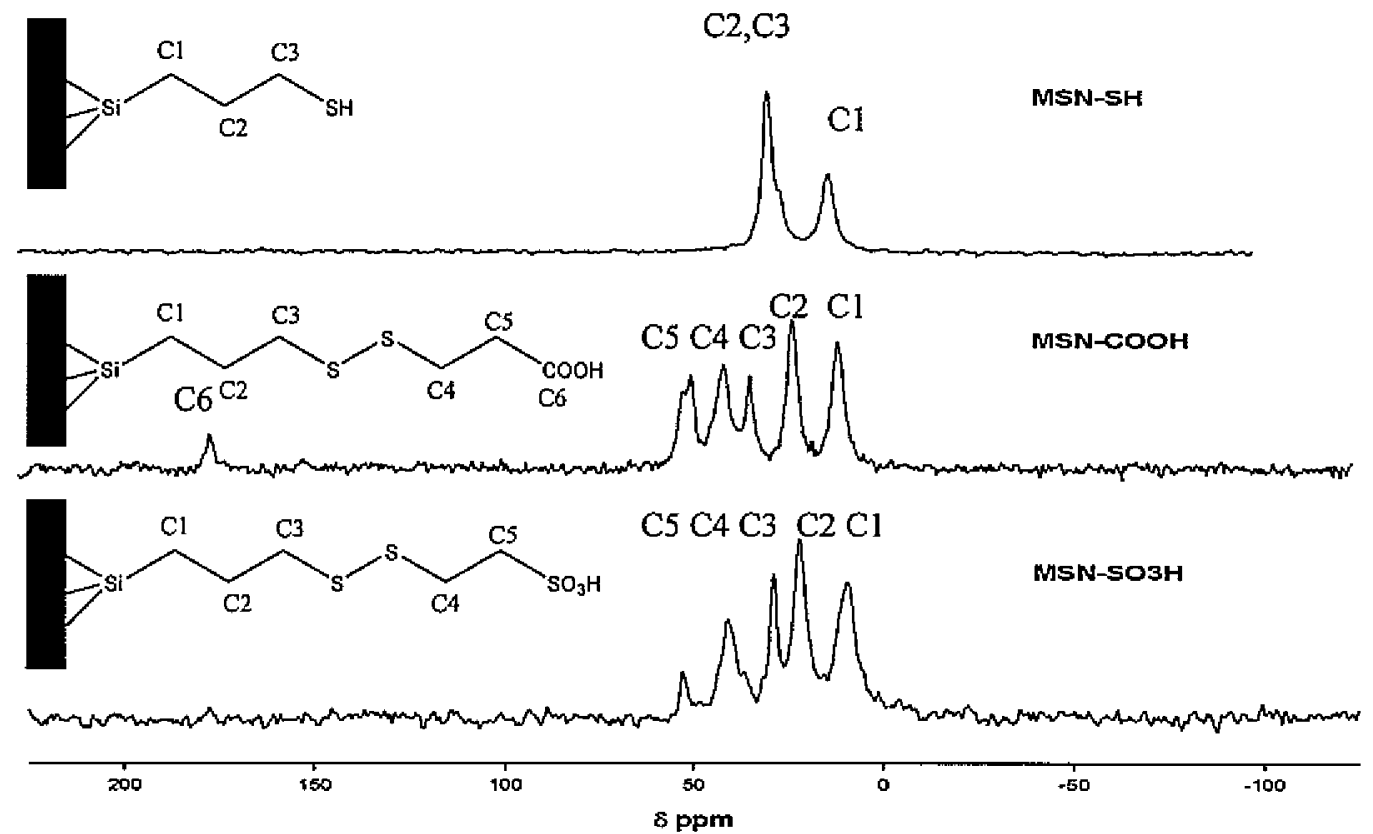

Figure 2-6. Solid state ${ }^{13} \mathrm{C}$ CP-MAS NMR spectra of the MSN-SH (up), MSN-COOH (middle) and MSN$\mathrm{SO} 3 \mathrm{H}$ (bottom).

The existence of the organic functional groups was confirmed by ${ }^{13} \mathrm{C}$ solid state NMR spectroscopy (Figure 2-6).

Table 2-1. Structural properties of the organically functionalized MSN materials.

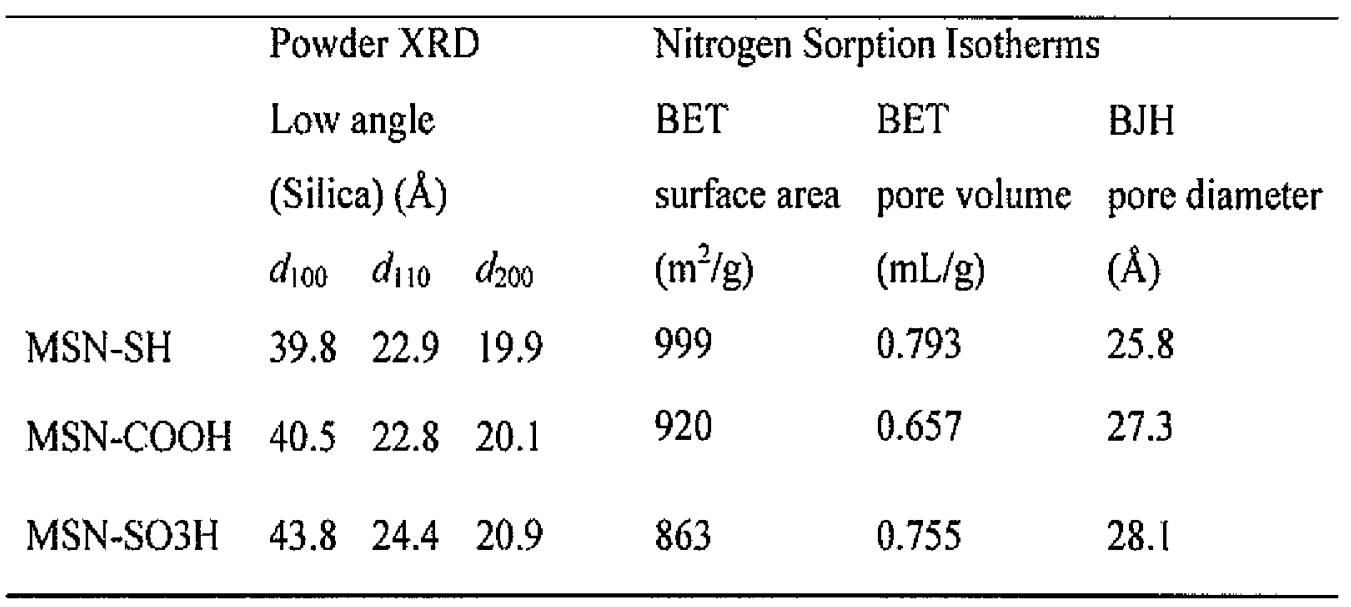

The nitrogen sorption isotherms of the three MSN materials exhibited a sharp step starting at ca. $p / p_{0}=0.38$, as shown in Figure $2-4 a$ with reversible type IV isotherms. (The inflection 
point is attributed to the commencement of pore filling from which the pore diameter can be roughly estimated).
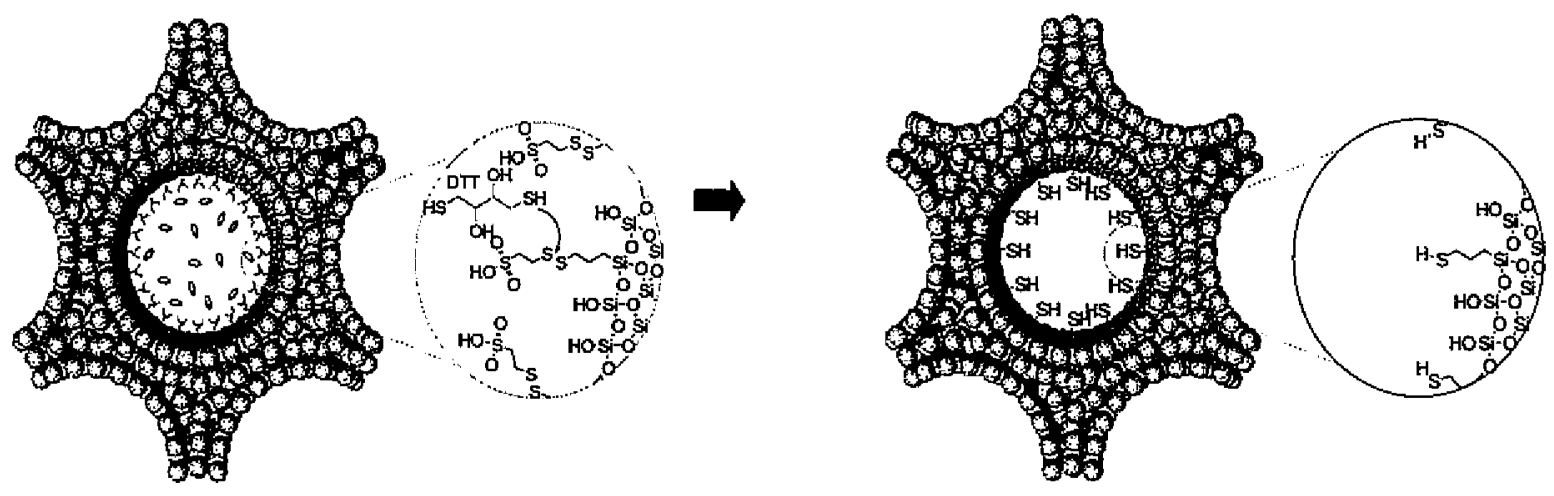

Figure 2-7. Schematic representation of the formation of thiol-functionalized mesoporous silica material (MSN$\mathrm{SO} 3 \mathrm{H}$ ) via disulfide reduction with dithiothreitol (DTT).

To quantify the amount of chemically accessible functional groups that are incorporated and oriented properly on the mesopore surfaces, we chemically converted the surface bound organic groups of the MSN-COOH and MSN-SO3H materials to thiol (-SH) by treating them with a disulfide reducing agent, dithiothreitol (DTT) as depicted in Fig. 2-6.

As shown in Scheme 2-2, reactions of the resulting free thiol-functionalized materials with the 2,2'-dipyridyl disulfide gave rise to 2-pyidyldithio-derivatized surface functional groups along with a 2-pyridothione compound as the side product.

Scheme 2-2

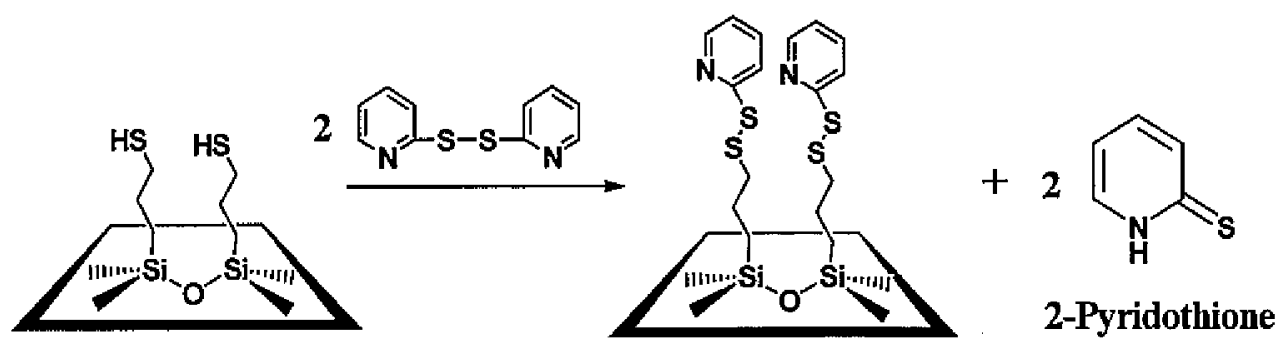


Given that every surface-bound thiol that reacted with the 2,2'-dipyridyl disulfide would yield one 2-pyridothione molecule in solution, the amount of chemically accessible surface thiol functionality of these three materials could be quantified by measuring the concentration (UV/Vis absorbance) of the 2-pyridothione $\left(\lambda_{\max }=343 \mathrm{~nm}, \varepsilon=8,080 \mathrm{M}^{-1}\right.$ $\left.\mathrm{cm}^{-1}\right)^{13}$ in the supernatants of these reactions. The results showed that the solution concentrations of 2-pyridothione increased in the order of MSN-SH $<\mathrm{MSN}-\mathrm{COOH}<\mathrm{MSN}$ $\mathrm{SO} 3 \mathrm{H}$, indicating that the surface concentration of the chemically accessible thiol functional group increases from MSN-SH $(0.56 \pm 0.01 \mathrm{mmol} / \mathrm{g}), \mathrm{MSN}-\mathrm{COOH}(0.97 \pm 0.01 \mathrm{mmol} / \mathrm{g})$, to MSN-SO3H $(1.56 \pm 0.01 \mathrm{mmol} / \mathrm{g})$. Interestingly, the elemental analyses of these materials showed a decreasing trend in sulphur values.

Table 2-2. Elemental Analysis of the organically functionalized MSNs

\begin{tabular}{cccc}
\hline Material & $\mathrm{C} \%$ & $\mathrm{H} \%$ & $\mathrm{~S} \%$ \\
MSN-SH & $13.23 \pm 0.01$ & $2.74 \pm 0.01$ & $10.09 \pm 0.01$ \\
MSN-COOH & $8.60 \pm 0.01$ & $2.33 \pm 0.01$ & $5.98 \pm 0.01$ \\
MSN-SO3H & $9.79 \pm 0.01$ & $2.60 \pm 0.01$ & $7.95 \pm 0.01$ \\
\hline
\end{tabular}

The weight $\%$ of sulfur and carbon among these materials (MSN-SH $>$ MSN-SO3H $>$ MSN-COOH) as summarized in Table 2-2.

In spite of a lower loading of organic functional groups in MSN-SO3H, the results suggested that the amount of the chemically accessible organic functional groups in MSN$\mathrm{SO} 3 \mathrm{H}$ is in fact higher than those of MSN-COOH and MSN-SH. Such a difference in the 
loading and spatial orientation of the organic functional groups could be attributed to the competition between the anionic species, i.e., $\mathrm{Br}^{-}$, silicates, and the anionic organoalkoxysilane precursors (CDSP-TMS, SDSP-TMS and MP-TMS), for the cationic surfactants (CTAB). Indeed, the least hydrated sulfonate group-containing SDSP-TMS gave rise to the highest loading of chemically accessible organic groups. Furthermore, relative to the carboxylate group, the thiolate offered less stabilization of the CTAB micelle aggregates, and therefore yielded the lowest loading.

\section{Conclusions}

Our results have shown that the extent of organic functionalization of MCM-41 silicas via co-condensation can be fine-tuned by carefully designing the interfacial electrostatic matching between the surfactant head groups and the desired organic functional group precursors.

\section{Acknowledgements}

This research was supported by the U.S. Department of Energy, Office of Basic Energy Sciences, through the Catalysis Science Grant No. AL-03-380-011 and NSF (CHE0239570).

\section{References}

(1). C. T. Kresge, M. E. Leonowicz, W. J. Roth, J. C. Vartuli, and J. S. Beck, Nature (London), 1992, 359, 710 . 
(2). D. Zhao, J. Feng, Q. Huo, N. Melosh, G. H. Frederickson, B. F. Chmelka, and G. D. Stucky, Science (Washington, D. C.), 1998, 279, 548.

(3). S. A. Bagshaw, E. Prouzet, and T. J. Pinnavaia, Science (Washington, D. C.), $1995,269,1242$.

(4). S. Inagaki, A. Koiwai, N. Suzuki, Y. Fukushima, and K. Kuroda, Bull. Chem. Soc. Jpn., 1996, 69, 1449.

(5). (a) V. S. Y. Lin, C.-Y. Lai, J. Huang, S.-A. Song, and S. Xu, J. Am. Chem. Soc., 2001, 123, 11510. (b) D. R. Radu, C.-Y. Lai, J. W. Wiench, M. Pruski, and V. S. Y. Lin, J, Am. Chem. Soc., 2004, 126, 1640.

(6). (a) S. Huh, H.-T. Chen, J. W. Wiench, M. Pruski, and V. S. Y. Lin, J. Am. Chem. Soc., 2004, 126, 1010. (b) A. Corma, Chem. Rev., 1997, 97, 2373. (c) J. M. Thomas, J. Mol. Catal. A, 1999, 146, 77. (e) D. Brunel, A. C. Blanc, A. Galarneau, and F. Fajula, Catal. Today, 2002, 73, 139, and references therein.

(7). (a) C.-Y. Lai, B. G. Trewyn, D. M. Jeftinija, K. Jeftinija, S. Xu, S. Jeftinija, and V. S. Y. Lin, J. Am. Chem. Soc, 2003, 125, 4451. (b) N. K. Mal, M. Fujiwara, Y. Tanaka, T. Taguchi, and M. Matsukata, Chem. Mater, 2003, 15, 3385.

(8). J. Liu, Y. Shin, Z. Nie, J. H. Chang, L.-Q. Wang, G. E. Fryxell, W. D. Samuels, and G. J. Exarhos, J. Phys. Chem. A, 2000, 104, 8328, and references therein.

(9). A. Stein, B. J. Melde, and R. C. Schroden, Adv. Mater. (Weinheim, Ger.), 2000, 12,1403 , and references therein.

(10). M. H. Lim and A. Stein, Chem. Mater., 1999, 11, 3285.

(11). (a) J. W. Larsen and L. J. Magid, J. Am. Chem. Soc., 1974, 96, 5774. (b) J. W. Larsen and L. J. Magid, J. Phys. Chem., 1974, 78, 834. 
(12). (a)K. J. Edler and J. W. White, Chem. Mater., 1997, 9, 1226. (b) A. Okabe, T. Fukushima, K. Ariga, M. Niki, and T. Aida, J. Am. Chem. Soc., 2004, 126, 9013.

(13). J. K. Yee, D. B. Parry, K. D. Caldwell, and J. M. Harris, Langmuir, 1991, 7, 307.

(14). Carlsson, J.; Drevin, H.; Axen, R. Biochem. J. 1978, 173, 723. 
CHAPTER 3. OXIDATIVE POLYMERIZATION OF 1,4-DIETHYNYLBENZENE INTO HIGHLY CONJUGATED POLY(PHENYLENE BUTADIYNYLENE) WITHIN THE CHANNELS OF SURFACE-FUNCTIONALIZED MESOPOROUS SILICA AND

\author{
ALUMINA MATERIALS \\ A paper published in the Journal of the American Chemical Society,
} 2002, 124, 9040-9041.

Victor S.-Y. Lin, Daniela R. Radu, Mi-Kyung Han, Weihua Deng, Shigeki Kuroki, Brent H. Shanks, and Marek Pruski

Department of Chemistry, Department of Chemical Engineering, and Ames Laboratory, Iowa State University, Ames, Iowa

\begin{abstract}
Properly functionalized and structurally ordered mesoporous materials, such as MCM-type silicas and aluminas, with tunable pore size and narrow pore-size distributions have attracted much attention for their potential applications as new catalytic scaffolds to direct and orient the conformation of desired products. For example, recent interest in encapsulation or synthesis or both of conducting polymers within the channels of MCM-41 has highlighted the future application of these materials as directional electron/energy transfer nanodevices. ${ }^{1}$ Several fundamental obstacles, such as low content and lack of the structural alignment of these polymer materials within the porous hosts, have yet to be overcome. Herein, we report the synthesis of $\mathrm{Cu}^{2+-}$-functionalized MCM-41 silica and
\end{abstract}


alumina, with different pore diameters, which can oxidatively catalyze the formation of a highly conjugated poly(phenylene butadiynylene) polymer (PPB), ${ }^{2}$ as depicted in Figure 3-1 . The alignment and extent of the conjugation of the conducting polymer within the mesoporous materials were characterized.

\section{Introduction}

Previous studies on the electronic properties of polyalkynylenebased conducting polymers, such as poly(phenylene ethynylene) (PPE) and PPB, demonstrated that these supermolecules have very high conductivity and charge/weight storage capability, when suitably doped. ${ }^{3}$ Utilizing the mesoporous channels as catalytic nano-reactors for the fabrication of highly conjugated polyalkynylenes will stabilize their architecture in the desired, aligned form.

Clearly, the rate and extent of polymerization within the mesoporous channels of MCM-41 directly depend on (1) the amount and spatial distribution of catalytic sites and (2) the diffusion rate of monomeric precursors and their local concentration near the catalytic sites. Both factors can be adjusted by varying the pore size and by tailoring the catalytic activity of the surface through proper functionalization. Several approaches to surface functionalization of mesoporous materials have been reported, including direct grafting, impregnation, and co-condensation. Direct grafting and impregnation to the as-synthesized MCM-41 silicas usually give rise to an inhomogeneous surface coverage of the functional groups. ${ }^{4}$ Most of the incorporated functional groups are located on the exterior surface or at the opening portion of the porous channels. In contrast, the co-condensation method yields a more homogeneous distribution of the functional groups within the mesopores. ${ }^{4}$ 
To examine how aforementioned factors influence the oxidative polymerization of 1,4-diethynylbenzene, we synthesized two mesoporous silica and alumina materials ( $\mathrm{Cu}-$ MCM and Cu-MAL, respectively) with different pore sizes and tested two different methods of $\mathrm{Cu}^{2+}$ surface functionalization.

Thus, we prepared the $\mathrm{Cu}^{2+}$-incorporated MCM-41 silica material (Cu-MCM) by cocondensation using a $\mathrm{Cu}^{2+}$-chelating molecule, $N$-[3(trimethoxysilyl)propyl]ethylenediamine, as the precursor, ${ }^{5}$ and utilize these materials as catalyst in 1,4-diethynylbenzene polymerization.

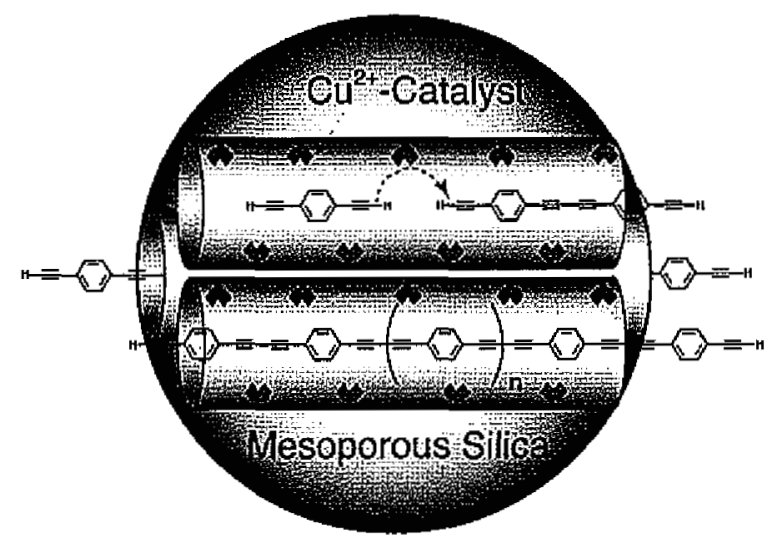

Figure 3-1. Schematic representation of $\mathrm{Cu}^{2+}$-functionalized mesoporous silica (Cu-MCM) and alumina (CuMAL) catalysts for oxidative polymerization of 1,4-diethynylbenzene into conjugated oligo(phenylene butadiynylene).

\section{Materials and Methods}

\section{Materials}

3-(2-aminoethylamino) propyltrimethoxysilane (AAPTS), copper(II) bromide $\left(\mathrm{CuBr}_{2}\right), n$-Cetyltrimethylammonium bromide (CTAB), tetraethylorthosilicate (TEOS) were 
all obtained from Aldrich and used without further purification. 1,4- diethynylbenzene was purchased from TCI America (Portland, OR) and used without further purification. Methanol $(99.8 \%)$ and $\mathrm{HCl}(37.3 \%)$ used in the experiments were purchased from Fisher Scientific. Nanopure water was obtained throughout a Barnstead E-pure water purification system.

\subsection{Synthesis of $\mathrm{Cu}-\mathrm{MCM}$ mesoporous silica nanosphere material}

Cetyltrimethylammonium bromide (CTAB, $\left.1.0 \mathrm{~g}, 2.74 \times 10^{-3} \mathrm{~mol}\right)$ was dissolved in $480 \mathrm{~mL}$ of nanopure water at room temperature. An aqueous solution of $\mathrm{NaOH}(2 \mathrm{M}, 3.5 \mathrm{~mL})$ was added dropwise to the CTAB solution. The temperature of the solution mixture was adjusted to $353 \mathrm{~K}$, followed by dropwise additions of both TEOS $\left(5 \mathrm{~mL}, 2.57 \times 10^{-2} \mathrm{~mol}\right)$ and a $15 \mathrm{~mL}$ of $0.087 \mathrm{M}$ methanol solution of $\mathrm{Cu}(\mathrm{AAPTS})_{2}{ }^{2+}$. The Cu(AAPTS $)_{2}{ }^{2+}$ complex solution was prepared in advanced by mixing a $15 \mathrm{~mL}$ of methanol solution of $\mathrm{CuBr}_{2}(249.0$ $\left.\mathrm{mg}, 1.3 \times 10^{-3} \mathrm{~mol}\right)$ and AAPTS $\left(0.488 \mathrm{~mL}, 2.57 \times 10^{-3}\right)$. The Cu(AAPTS $)_{2}{ }^{2+}$ complex solution was prepared in advanced by mixing a $15 \mathrm{~mL}$ methanolic solution of $\mathrm{CuBr}_{2}(249.0 \mathrm{mg}$, $\left.1.3 \times 10^{-3} \mathrm{~mol}\right)$ and AAPTS $\left(0.488 \mathrm{~mL}, 2.57 \times 10^{-3} / \mathrm{mol}\right)$. The color of the $\mathrm{Cu}^{2+}$ complex solution turned immediately blue upon the introduction of AAPTS. The mixture of CTAB, TEOS, and $\mathrm{Cu}(\mathrm{AAPTS})_{2}{ }^{2+}$ precursor was allowed to stir for $2 \mathrm{~h}$ giving rise to a blue suspension. This blue solid was isolated via filtration, washed extensively with hot ethanol, and dried at room temperature in air to yield the "as synthesized" Cu-MCM material. The "as synthesized" Cu-MCM material containing surfactant CTAB was dispersed in a $250 \mathrm{~mL}$ of $0.1 \mathrm{M}$ methanol solution of $\mathrm{HCl}$ and refluxed for $12 \mathrm{~h}$, followed by filtration and washed

with hot ethanol. Given that some $\mathrm{Cu}(\mathrm{AAPTS})_{2}{ }^{2+}$ might be demetallated and removed from the $\mathrm{Cu}-\mathrm{MCM}$ material due to the increased acidity during the surfactant removal, the material was re-suspended in a $100 \mathrm{~mL}$ of $0.1 \mathrm{M}$ ethanol solution of $\mathrm{CuBr}_{2}$ and stirred for $12 \mathrm{~h}$. The 
physiadsorbed $\mathrm{CuBr}_{2}$ was removed via a thorough wash with hot ethanol. The purified $\mathbf{C u}-$ MCM mesoporous silica nanospheres was placed under vacuum to remove the remaining solvent in the mesopores.

\subsection{Synthesis of Cu-MAL mesoporous alumina material}

The Cu-impregnated mesoporous alumina catalyst (Cu-MAL) was synthesized in a two-step process. First, the mesoporous alumina material was synthesized using the neutral templating approach of Bagshaw and Pinnavaia ${ }^{1}$ with Pluronic 64L (a polyethylene oxide/polypropylene oxide block copolymer surfactant) as the templating agent. The synthesized mesoporous alumina powder was calcined in air at $500^{\circ} \mathrm{C}$ for 6 hours. Copper was introduced to the calcined alumina using a cupric nitrate aqueous solution $(1 \mathrm{~mL}$ of $0.01 \mathrm{M} \mathrm{Cu}\left(\mathrm{NO}_{3}\right)_{2}$ with $0.75 \mathrm{~g}$ calcined mesoporous alumina). The $\mathrm{Cu}$-impregnated $\mathbf{C u}-\mathbf{M A L}$ sample was dried in air for $6 \mathrm{~h}$ and calcined at $500^{\circ} \mathrm{C}$ for $4 \mathrm{~h}$ under nitrogen.

\section{Quantification of catalytic $\mathrm{Cu}^{2+}$ in the $\mathrm{Cu}-\mathrm{MCM}$ material \\ 2.1 Quantification of catalytic $\mathrm{Cu}^{2+}$ in the $\mathrm{Cu}-\mathrm{MCM}$ material}

Surfactant-removed Cu-MCM material $(100 \mathrm{mg})$ was suspended in a $25 \mathrm{~mL}$ of methanol solution of $5 \mathrm{M} \mathrm{HCl}$ and stirred for $6 \mathrm{~h}$. The supernatant solution was isolated and neutralized with $\mathrm{NaOH}$ to reach $\mathrm{pH}$ 8.66. Excess of AAPTS was added to the $\mathrm{Cu}^{2+}$ methanol solution to form a blue solution of complex. The amount of $\mathrm{Cu}^{2+}$ was determined to be $5.2 \times 10^{-4} \mathrm{~mol} / \mathrm{g}$ of $\mathbf{C u}-\mathbf{M C M}$ by measuring the absorption $\lambda_{\max }\left(\varepsilon=129,000 \mathrm{~cm}^{-1} \mathrm{M}^{-1}\right)$ of $\mathrm{Cu}(\mathrm{AAPTS})_{2}{ }^{2+}$ complex at $585 \mathrm{~nm}$ in methanol. 


\subsection{Quantification of catalytic $\mathrm{Cu}^{2+}$ in the $\mathrm{Cu}-\mathrm{MAL}$ material}

The amount of $\mathrm{Cu}^{2+*}$ catalytic groups in the Cu-MAL material was estimated to be $1.33 \times 10^{-5} \mathrm{~mol} / \mathrm{g}$ of alumina based on the aforementioned amount of $\mathrm{Cu}\left(\mathrm{NO}_{3}\right)_{2}$ introduced to the mesoporous alumina sample.

\section{Oxidative polymerization of 1,4-diethynylbenzene using $\mathrm{Cu}-\mathrm{MCM}$ and $\mathrm{Cu}-\mathrm{MAL}$ catalyst materials}

A sample of Cu-MCM (250 mg) or Cu-MAL (100 mg) $\left(0.13 \mathrm{mmol}\right.$ of $\left.\mathrm{Cu}^{2+}\right)$ was dispersed in pyridine. A solution of 1,4-diethynylbenzene ( $250 \mathrm{mg}, 1.98 \mathrm{mmol})$ in $2 \mathrm{~mL}$ of pyridine was added to the suspension. The reaction mixture was allowed to reflux in air for $72 \mathrm{~h}$ to form the poly(phenylene butadiynylene) (PPB) polymer. The resulting brownish silica/polymer composite material was isolated by filtration and washed extensively with ethanol. The purified material was dried under vacuum to remove the adsorbed ethanol.

\section{Structure characterization and photophysical property measurements}

Powder XRD diffraction data were collected on a Scintag XRD 2000 X-Ray diffractometer using $\mathrm{Cu} \mathrm{K} \alpha$ radiation. Absorption spectra were measured on a HewlettPackard HP-8453 diode array UV Visible spectrometer. All fluorescence emission and excitation measurements were performed with a FluoroMax-2 spectrofluorometer at room temperature. Surface area (SA) and Median Pore Diameter (MPD) were measured using a Micromeritics ASAP2000 sorptometer. Sample preparation included degassing at $90^{\circ} \mathrm{C}$ for 1 $\mathrm{h}$ and at $150^{\circ} \mathrm{C}$ for $4 \mathrm{~h}$. Nitrogen adsorption and desorption isotherms of these materials were obtained at $-196^{\circ} \mathrm{C}$. Specific surface areas and pore size distributions were calculated using 
the Brunauer-Emmett-Teller (BET) and Barrett-Joyner-Halenda (BJH) method, respectively. Particle morphology of these materials was determined by scanning electron microscopy (SEM) using a JEOL 840A scanning electron microscope with $10 \mathrm{kV}$ accelerating voltage and $0.005 \mathrm{nA}$ of beam current for imaging. Matrix Assisted Laser Desorption ionization experiments were performed on a Bruker Proflex mass spectrometer (Bruker Analytical Systems, Inc. Billerica, MA), fitted with a delayed extraction capability. A $337 \mathrm{~nm}$ nitrogen laser was used with an attenuation of $30 \%$. The experiments were carried out with and without matrix. The matrix used was dihydroxybenzoic acid (DHB). A mass range of 20,000 was investigated.

(a)

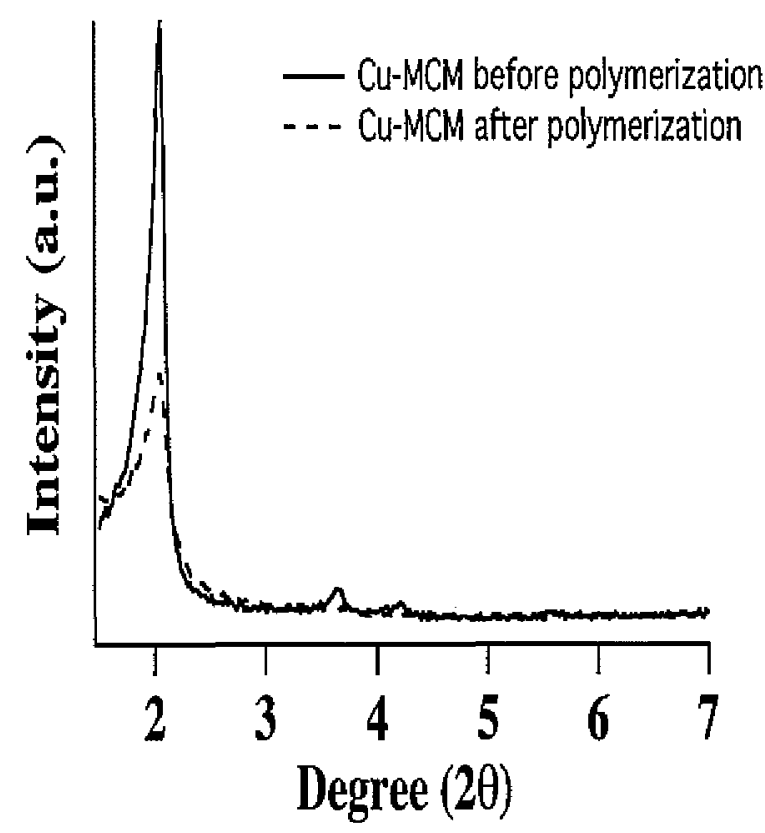

(b)

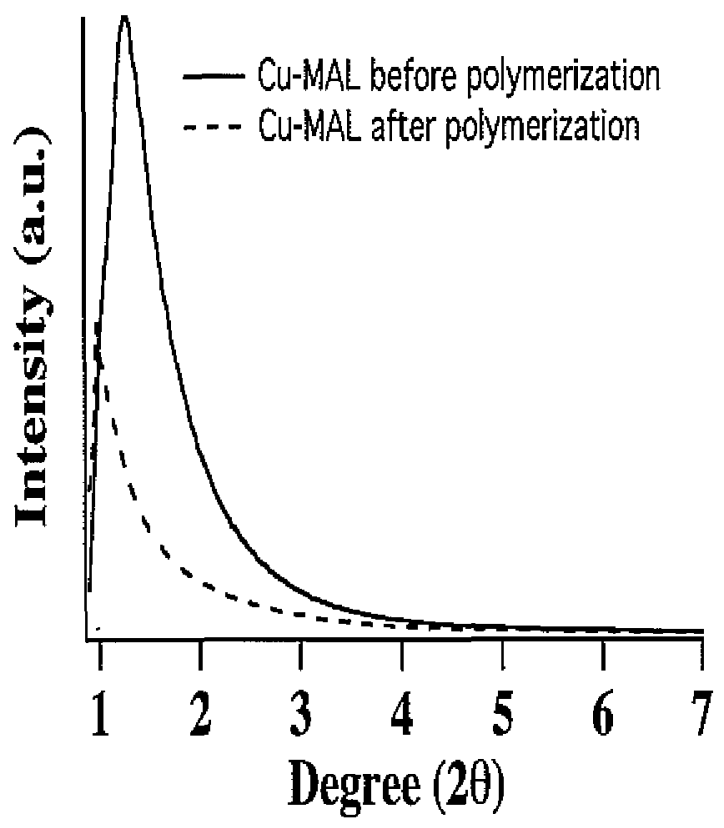

Figure 3-2. Powder X-ray diffraction patterns of (a) Cu-MCM before and after PPB polymerization and (b) Cu-MAL before and after PPB polymerization. 
Table 3-1. Powder XRD structural parameters of the series of $\mathrm{Cu}^{2+}$-functionalized mesoporous silica/alimina samples

\begin{tabular}{llll} 
Mesoporous catalyst & \multicolumn{3}{c}{ Low angle $(\AA)$} \\
& $d_{100}$ & $d_{110}$ & $d_{200}$ \\
\hline Surfactant removed Cu-MCM & 43.1 & 25.2 & 21.0 \\
Cu-MCM after PPB polymerization & 42.1 & 23.9 & 20.6 \\
Surfactant removed Cu-MAL & 66.8 & -- & -- \\
Cu-MAL after PPB polymerization & $88.2^{*}$ & -- & --
\end{tabular}

* Intensity is too low for accurate mesurement due to the shallow diffraction angle of $2 \theta$ of the Cu-MAL sample.

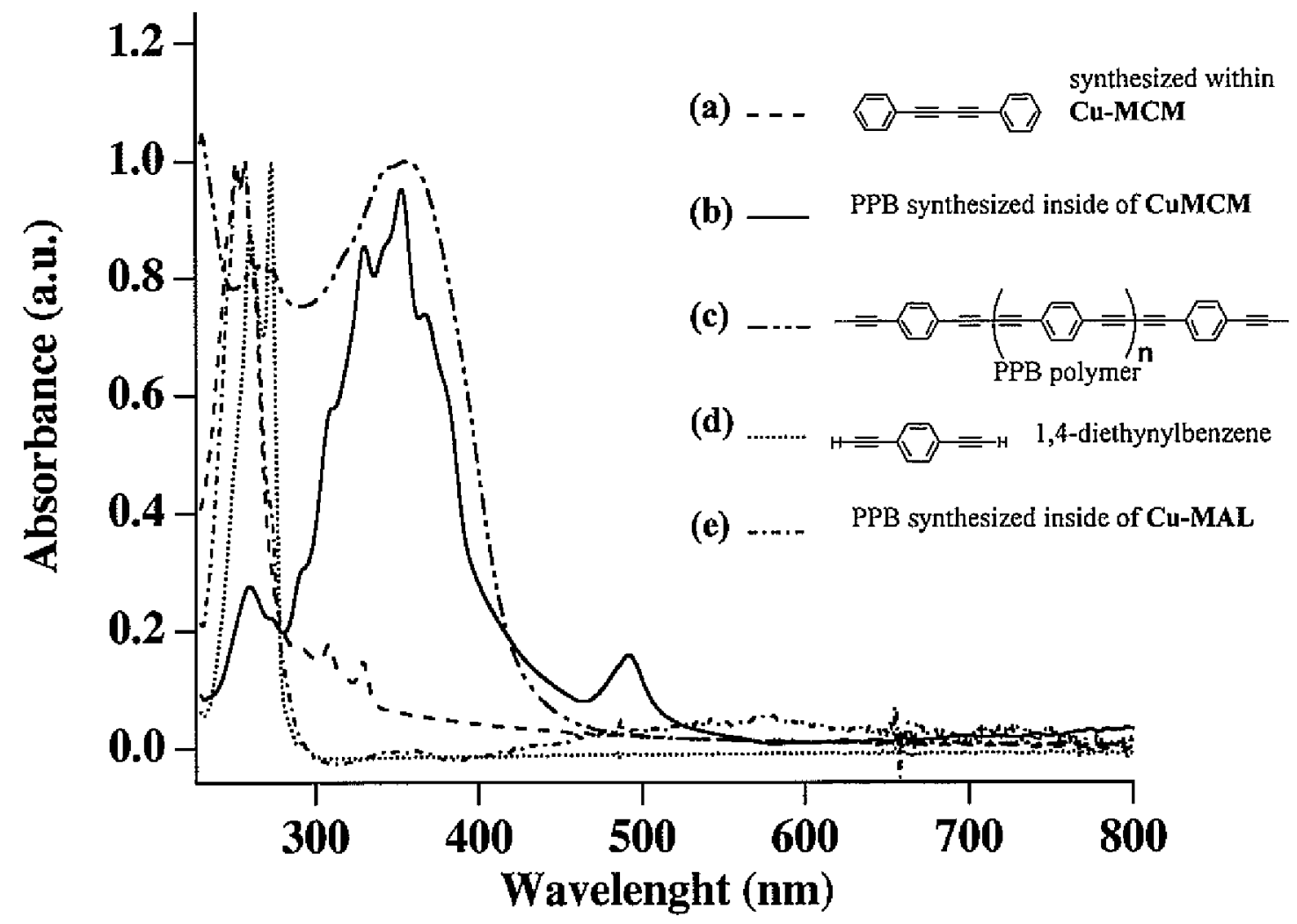

Figure 3-3. Absorbance measurements of polymeric material synthesized using catalysts on support or in solution 


\section{Results and Discussion}

The powder XRD (see Fig. 3-2), BET $\mathrm{N}_{2}$ sorption isotherm, and BJH pore-size distribution measurements indicated that the $\mathbf{C u}-\mathbf{M C M}$ contains a typical MCM-41-type of ordered cylindrical porous structure with a high surface area of ca. $655.0 \mathrm{~m}^{2} / \mathrm{g}$ and a BJH average pore diameter of ca. $25.6 \AA$ (Figure $3-4 a, b$ ).
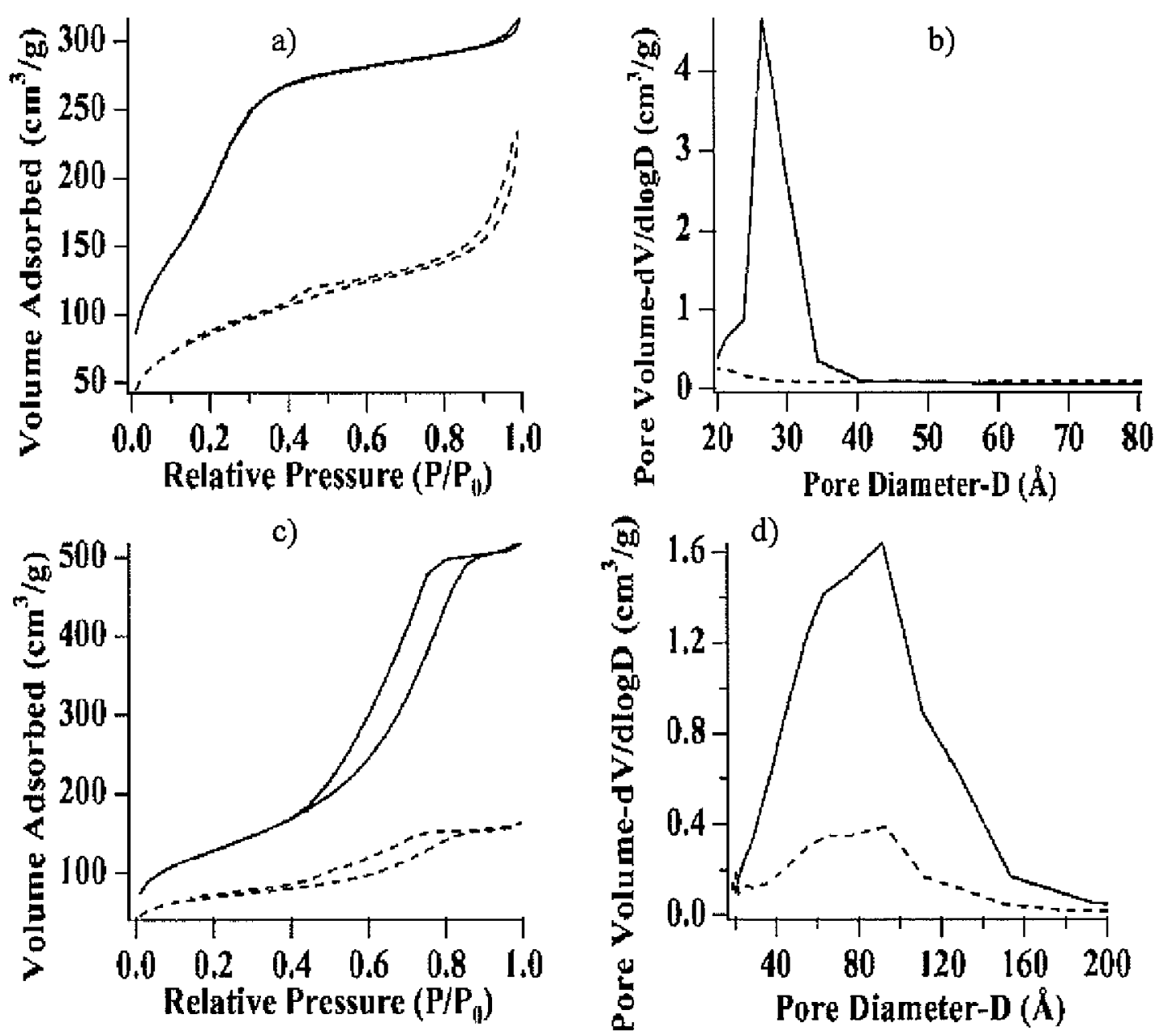

Figure 3-4. Nitrogen adsorption/desorption isotherms and the pore size distributions of the Cu-MCM, (a), (b), and Cu-MAL, (c), (d), materials before (solid line) and after (dashed line) PPB polymerization within the mesoporous channels. 
A mesoporous alumina catalyst was also synthesized using a method reported earlier ${ }^{6}$ followed by $\mathrm{Cu}$ impregnation (Cu-MAL). The mesoporous structure of $\mathrm{Cu}^{2+}$ - alumina catalyst was also characterized with aforementioned spectroscopic methods and exhibits a surface of ca. $448.0 \mathrm{~m}^{2} / \mathrm{g}$ and a BJH average pore diameter of ca. $68.0 \AA$ (Figure 3-2 c,d). The amounts of $\mathrm{Cu}^{2+}$ catalytic sites of both $\mathbf{C u}-\mathbf{M C M}$ and $\mathbf{C u}-\mathbf{M A L}$ were quantified to be ca. $5.2 \times 10^{-4}$ and $1.3 \times 10^{-5} \mathrm{~mol} / \mathrm{g}$, respectively. Our studies of 1,4-diethynylbenzene polymerization with the two $\mathrm{Cu}^{2+}$-functionalized mesoporous catalysts gave very different results. In the case of Cu-MCM, a $245-\mathrm{nm}$ bathochromic shift (emission $\lambda_{\max }=643.5 \mathrm{~nm}$ ) of the fluorescence emission spectra of the PPB polymer was observed after $56 \mathrm{~h}$ of refluxing in pyridine (Figure 3-3). The result indicates the effective $\pi$-conjugation length of the PPB polymer synthesized within the mesoporous channels of $\mathbf{C u}-\mathbf{M C M}$ is perhaps comparable to that of PPBs synthesized in homogeneous solutions. ${ }^{7}$ Interestingly, the oxidative polymerization using Cu-MAL showed two bathochromic-shifted fluorescence peaks $\left(\lambda_{\max }=472.5\right.$ and $\left.551.5 \mathrm{~nm}\right)$ under the same reaction conditions.

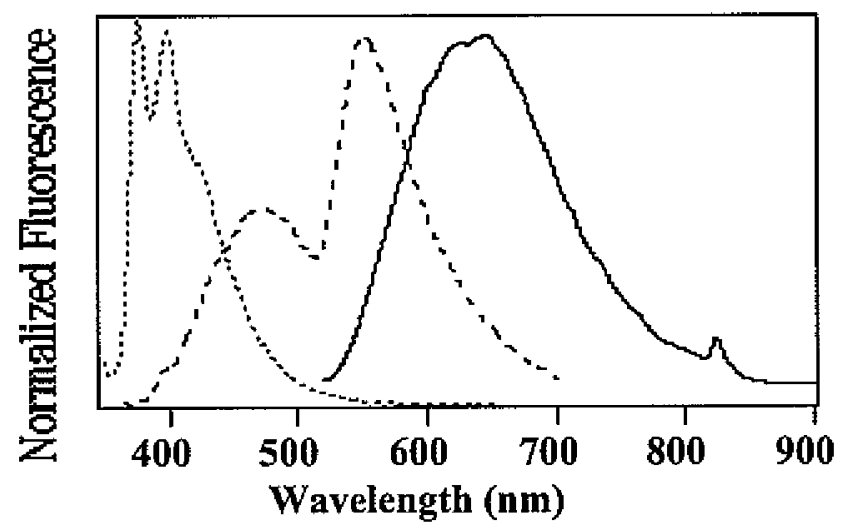

Figure 3-5. Normalized fluorescence emission spectra of 1,4-diethynylbenzene (dotted line) and the PPBcontaining composite materials of Cu-MAL and Cu-MCM catalysts (dashed and solid lines, respectively) after $56 \mathrm{~h}$ of polymerization. 
However, both shifts are significantly smaller than in the case of Cu-MCM. This spectral difference is consistent with smaller $\pi$-conjugation of the PPB polymer in the case of Cu-MAL. Other photophysical and MALDI mass spectroscopy measurements of the PPB polymers synthesized by both catalysts also confirmed the significant difference in the degree of polymerization. While the aforementioned results clearly established that the polymerization indeed occurred, direct evidence of the spatial arrangement of the synthesized structures has been obtained using ${ }^{13} \mathrm{C}$ solid-state NMR. The measurements were carried out using ${ }^{1} \mathrm{H} \rightarrow{ }^{13} \mathrm{C}$ cross polarization (CP) at $100.6 \mathrm{MHz}$ on a Chemagnetics Infinity spectrometer equipped with a $5 \mathrm{~mm}$ magic angle spinning (MAS) probe. Three representative ${ }^{13} \mathrm{C}$ spectra of the studied samples are shown in Figure 3-4.

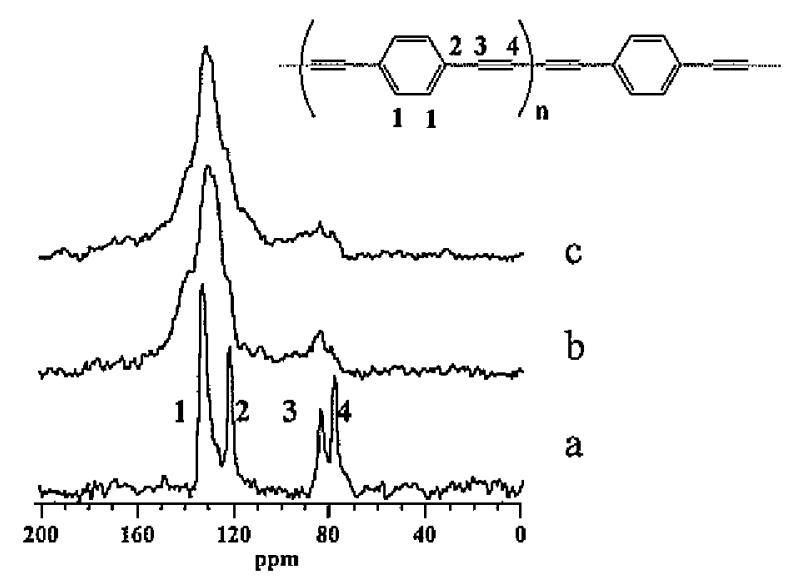

Figure 3-6. ${ }^{13} \mathrm{C}$ CPMAS spectra of (a) structurally aligned PPB polymer catalyzed by Cu-MCM, (b) PPB polymer synthesized with CuMAL, and (c) bulk PPB. The spectra were measured at room temperature, using $4680 \mathrm{scans}, 10 \mathrm{~s}$ intervals, sample rotation rate of $5 \mathrm{kHz}$, contact time of $2 \mathrm{~ms}, \mathrm{CW}$ ' $\mathrm{H}$ decoupling at $70 \mathrm{kHz}$ and sideband suppression (TOSS).

For estimating the average size of the oligomers we utilized MALDI-TOF mass spectrometry. The PPB sample was obtained by dissolving the MCM silica host in $50 \% \mathrm{HF}$ aqueous solution. The isolated PPB was dispersed in 50\% acetonitrile aqueous solution with 
$0.1 \%$ trifluoroacetic acid. The supernatant was mixed with dihydroxybenzoic acid (DHB) matrix (1:50 ratio) for MALDI measurement. The $\mathrm{M} / \mathrm{z}=2857.28$ peak corresponds to a PPB oligomer with 23 phenylene units and the $\mathrm{M} / \mathrm{z}=2886.25$ peak matches the molecular weight of a PPB oligomer with 22 phenylene units plus one DHB matrix molecule (Fig. 3-7).
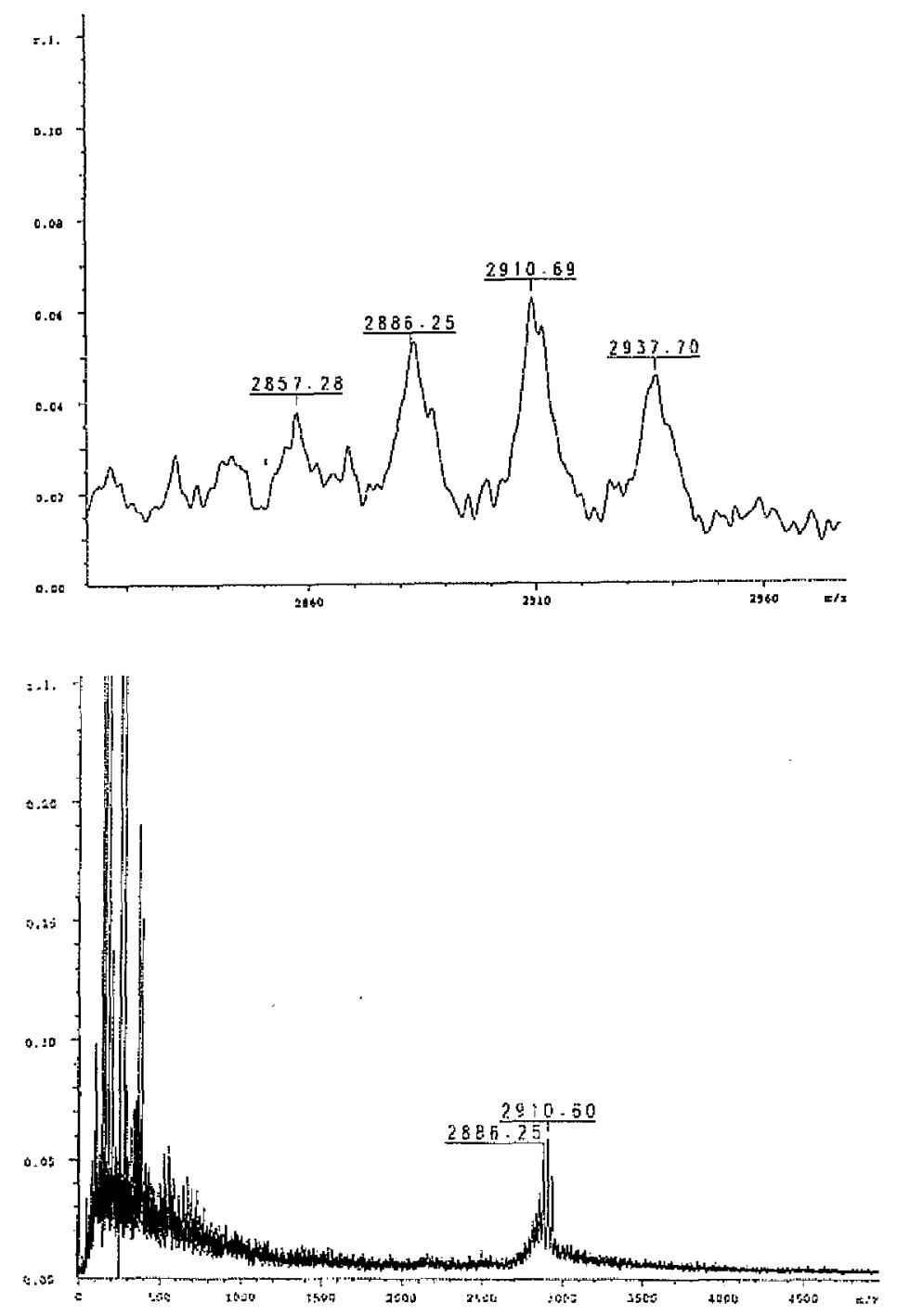

Figure 3-7. MALDI mass spectrometry mesurements of the PPB polymer synthesized within the mesoporous Cu-MCM catalyst. 
The spectrum of a sample catalyzed by $\mathbf{C u}-\mathbf{M C M}$ (a) is notably different from those of a randomly oriented polymer (c) and a polymer that was synthesized with the Cu-MAL material (b). The former is well resolved and consists of four resonance lines, which are assigned as shown in the figure.

The spectrum of bulk polymer exhibits considerable line broadening, with only two resolved bands at around 80 and $130 \mathrm{ppm}$, corresponding to $\mathrm{sp}$ and $\mathrm{sp}^{2}$ carbons, respectively. The observed broadening reflects the conformational heterogeneity in the three dimensional arrangements of polymeric chains. The same morphology is observed in the case of CuMAL. Additional significant differences are observed in spectra (b) and (c) with respect to (a): (i) both resonances are not only broader, but comprise more than two lines, and (ii) the intensities of $\mathrm{sp}^{2}$ and $\mathrm{sp}$ bands do not match the 3:2 ratio expected for PPB. These spectral features are consistent with considerable polydiacetylene-type cross-linking ${ }^{8}$ that occurred in the bulk polymer and Cu-MAL. In the case of Cu-MCM, the sharpness of the observed resonances and lack of cross-linking demonstrate that isolated molecular wires are formed within the parallel channels of MCM- 41 .

\section{Conclusions}

We have demonstrated that a linearly aligned conducting polymer can be catalytically synthesized within the porous channels of MCM-41 silica. Fluorescence and solid-state NMR provided spectroscopic evidence that the synthesis of extended polymeric chains with a high degree of alignment requires homogeneously distributed catalytic sites throughout the entire matrix. This type of homogeneity has been achieved via co-condensation of the catalytic groups in narrow pores. 


\section{Acknowledgments}

We thank the Biotechnology Office of ISU for startup funds and U.S. DOE, Office of BES, for support of this work through contract W-7405-Eng-82.

\section{References}

(1) (a) Cardin, D. J.; Constantine, S. P.; Gilbert, A.; Lay, A. K.; Alvaro, M.; Galletero, M. S.; Garcia, H.; Marquez, F. J. Am. Chem. Soc. 2001, 123, 3141. (b) Wu, C. G.; Bein, T. Science (Washington, D. C.) 1994, 264, 1757. (c) Tolbert, S. H.; Wu, J.; Gross, A. F.; Nguyen, T. Q.; Schwartz, B. J. Microporous Mesoporous Mater. 2001, 44-45, 445. (d) Nguyen, T.-Q.; Wu, J; Tolbert, S. H.; Schwartz, B. J. Adv. Mater. (Weinheim, Germany) 2001, 13, 609. (e) Schwartz, B. J.; Nguyen, T.-Q.; Wu, J.; Tolbert, S. H. Synth. Met. 2001, 116, 35. (f) Nguyen, T.-Q.; Wu, J.; Doan, V.; Schwartz, B. J.; Tolbert, S. H. Science (Washington, D. C.) 2000, 288, 652. (g) Bein, T. Stud. Surf. Sci. Catal. 1996, 102, 295. (h) Wu, C. G.; Bein, T. Stud. Surf. Sci. Catal. 1994, 84, 2269.

(2) Campbell, I. D.; Eglinton, G. Org. Synth. 1965, 45, 39.

(3) (a) Harriman, A.; Ziessel, R. Coord. Chem. Rev. 1998, 171, 331. (b) Donhauser, Z. J.; Mantooth, B. A.; Kelly, K. F.; Bumm, L. A.; Monnell, J. D.; Stapleton, J. J.; Price, D. W., Jr.; Rawlett, A. M.; Allara, D. L.; Tour, J. M.; Weiss, P. S. Science (Washington, D. C.) $2001,292,2303$.

(4) Stein, A.; Melde, B. J.; Schroden, R. C. Adv. Mater. 2000, 12, 1403 and references therein.

(5) (a) Karakassides, M. A.; Bourlinos, A.; Petridis, D.; Coche-Guerente, L.; Labbe, P. J. Mater. Chem. 2000, 10, 403. (b) Fryxell, G. E.; Liu, J.; Hauser, T. A.; Nie, Z.; Ferris, 
K. F.; Mattigod, S.; Gong, M.; Hallen, R.T. Chem. Mater. 1999, 11, 2148. (c) Dai, S.;

Burleigh, M. C.; Shin, Y.; Morrow, C. C.; Barnes, C. E.; Xue, Z. Angew. Chem., Int. Ed. 1999, 38, 1235.

(6) Bagshaw, S. A.; Pinnavaia, T. J. Angew. Chem., Int. Ed. Engl. 1996, 35, 1102.

(7) Kijima, M.; Kinoshita, I.; Shirakawa, H. J. Mol. Struct. 2000, 521, 279.

(8) Okada, S.; Peng, S.; Spevak, W.; Charych, D. Acc. Chem. Res. 1998, 31, 229

and references therein. 


\title{
CHAPTER 4. ORGANOSULFONIC ACID-FUNCTIONALIZED MESOPOROUS SILICAS FOR THE ESTERIFICATION OF FATTY ACDS
}

\author{
A paper published in Journal of Catalysis, 2003, 219, 329-336 \\ Isa K. Mbaraka, Daniela R. Radu, Victor S.-Y., Lin, and Brent H. Shanks \\ Departments of Chemical Engineering and Department of Chemistry \\ Iowa State University, Ames, lowa
}

\begin{abstract}
Organosulfonic acid-functionalized mesoporous silicas were synthesized in a one-step approach of co-condensing inorganic-organic reagents in the presence of different surfactant templates with in situ oxidation of the thiol groups to the sulfonic acid groups. The resulting materials were tested for their catalytic performance in the esterification of fatty acid with methanol to produce methyl esters. The performance of the functionalized mesoporous materials demonstrated a strong dependence on the median pore diameter of the catalyst as well as the acidic strength of the organosulfonic acid group. The activity of the organosulfonic acid-functionalized silicas in the esterification was compared to that of standard acidic resins. The results indicate the potential of rational catalysis design using organic-inorganic mesoporous materials.
\end{abstract}




\section{Introduction}

The transesterification of vegetable oils with short-chain alcohols (e.g. methanol and ethanol) to form alkyl esters has shown potential application as an intermediate for valueadded products (e.g. fatty alcohols) and biodiesel fuel..$^{1-5}$ The production of biodiesel has received extensive interest as a result of its desirable renewable, biodegradable, and nontoxic properties. $^{2-6}$ However, it is currently not cost competitive with conventional diesel fuel due to high raw material and production costs. To improve the economic outlook of biodiesel and alkyl esters in general, the feedstock selection becomes critical. In particular, oil feeds containing high free fatty acid content, such as found in beef tallow or yellow grease, are significantly less expensive than vegetable oils, such as soybean or rapeseed oil. ${ }^{1-7}$ These high free fatty acid feeds present significant processing problems in standard biodiesel manufacture since the free fatty acid is saponified by the homogeneous alkali catalyst used to transesterify triglycerides leading to a loss of catalyst as well as increased purification costs. ${ }^{8}$

One approach for improving the processing of high free fatty acid oils is to first esterify the free fatty acids to alkyl esters in the presence of an acidic catalyst. The pretreated oils in which the free fatty acid content is lowered to no more than $0.5 \mathrm{wt} \%$ can then be processed under standard transesterification reaction conditions. ${ }^{9}$ This pretreatment step has been successfully demonstrated using sulfuric acid. ${ }^{10}$ Unfortunately, use of the homogeneous sulfuric acid catalyst adds neutralization and separation steps as well as the esterification reaction to the process. Therefore, it would be desirable to perform the esterification pretreatment step with a heterogeneous acidic catalyst, which would significantly simplify the pretreatment process. 
Due to a combination of extremely high surface areas and flexible pore sizes, surfactant-templated mesostructured materials have been studied extensively. The physical and chemical properties of these mesoporous materials can be modified by incorporating functionalized organic groups, either by grafting on the preformed mesopore surface or by co-condensation during synthesis. ${ }^{1 t-13}$ Organic-inorganic hybrid mesoporous silicas functionalized with sulfonic acid groups have shown successful results for acid-catalyzed reactions. ${ }^{14,16}$ The direct co-condensation synthesis technique in which the mesostructure and functional group are simultaneously introduced, appears to be a desirable route for incorporating functional groups because it has been shown that it increases the concentration of the sulfonic groups in the mesoporous silica telative to grafting. ${ }^{15,17}$ One approach demonstrated previously involves one-step synthesis based on the simultaneous hydrolysis and condensation of tetraethoxysilane (TEOS) with (3-mercaptopropyl)trimethoxysilane (MPTMS) in the presence of template surfactant using in situ oxidation of the thiol groups with $\mathrm{H}_{2} \mathrm{O}_{2}$. Melero et al. has shown that the acid strength of the sulfonic groups in the mesoporous materials can be adjusted by choice of the organosulfonic precursor. ${ }^{18}$ For example, incorporation of a more electron-withdrawing group (e.g. phenyl group) with the sulfonic group will significantly increase the acidic strength of the resulting mesoporous material. Due to their large pore diameters, these acid-functionalized mesoporous silicas provide improved accessibility to large reactants such as fatty acids and its esters. ${ }^{16}$

Herein, is described the synthesis and utilization of silica mesoporous materials modified with sulfonic groups for the pretreatment esterification reaction of high free fatty acid oils. The results for the catalytic performance of the mesoporous materials are also compared to commercial acidic catalysts. 


\section{Materials and Methods}

\section{Materials Synthesis}

The mesoporous materials were synthesized following the procedures of Boessaert et al. and Melero et al. with only slight modification. ${ }^{16,18}$ Tetraethoxysilane (TEOS, 98\%, Aldrich) was used as the silica source. The mesoporous silicas were modified using (3mercapto-propyl)trimethoxysilane (MPTMS, 85\%, Fluka) without further treatment. The surfactants, n-dodecylamine (Aldrich), Pluronic L64 and Pluronic P123 (BASF Co., USA), were used as purchased to tailor the textural properties of the mesoporous materials. Mesoporous silica synthesized using the amine surfactant was denoted as HMS, while those synthesized with the tri-block copolymers were abbreviated SBA-15. ${ }^{12}$

\subsection{HMS-SO $\mathrm{H}_{3} \mathrm{H}$}

A molar composition of 0.08 TEOS, 0.02 MPTMS, $0.0275 n$-dodecylamine, 0.89 EtOH and $2.94 \mathrm{H}_{2} \mathrm{O}$ was used to synthesize $\mathrm{HMS}-\mathrm{SO}_{3} \mathrm{H}$. The amine was dissolved in an alcohol-water mixture prior to addition of the TEOS-MPTMS mixture. The mixture was aged for $24 \mathrm{~h}$ at room temperature under continuous stirring. The resulting solid product was filtered and air-dried. The template was extracted by refluxing in boiling EtOH for $24 \mathrm{~h}$. The thiol groups were oxidized with $\mathrm{H}_{2} \mathrm{O}_{2}(2.04 \mathrm{~g} / \mathrm{g}$ solid $)$ in a methanol-water mixture. The suspension was stirred at room temperature for $24 \mathrm{~h}$ followed by washing with EtOH and $\mathrm{H}_{2} \mathrm{O}$. The wet cake was acidified in $0.1 \mathrm{M} \mathrm{H}_{2} \mathrm{SO}_{4}$ for an additional $4 \mathrm{~h}$ before being washed thoroughly with $\mathrm{H}_{2} \mathrm{O}$. The product was finally dried at $20^{\circ} \mathrm{C}$.

\section{2 $\mathrm{SBA}-15-\mathrm{SO}_{3} \mathrm{H}$}

SBA-15- $\mathrm{SO}_{3} \mathrm{H}$ was prepared by dissolving $4 \mathrm{~g}$ of Pluronic (P123 or L64) in $125 \mathrm{~g}$ of $1.9 \mathrm{M} \mathrm{HCl}$ at room temperature under stirring with subsequent heating to $40{ }^{\circ} \mathrm{C}$ before 
adding TEOS. Approximately $45 \mathrm{~min}$ was allowed for prehydrolysis of TEOS prior to addition of the MPTMS- $\mathrm{H}_{2} \mathrm{O}_{2}$ solution. The resulting mixture with a molar composition of 0.0369 TEOS, $0.0041 \mathrm{MPTMS}$, and $0.0369 \mathrm{H}_{2} \mathrm{O}_{2}$ was stirred for $24 \mathrm{~h}$ at $40{ }^{\circ} \mathrm{C}$ and thereafter aged for $24 \mathrm{~h}$ at $100{ }^{\circ} \mathrm{C}$ under static condition. The product was collected and subjected to the same extraction method as previously described.

\subsection{SBA-15-ph-SO $\mathrm{S}_{3} \mathrm{H}$}

SBA-15-ph- $\mathrm{SO}_{3} \mathrm{H}$ mesoporous silica functionalized with benzenesulfonic acid groups was synthesized by dissolving Pluronic P123 (4 g) in $125 \mathrm{~mL}$ of $1.9 \mathrm{M} \mathrm{HCl}$ at room temperature while stirring. After complete dissolution, the solution was heated to $35^{\circ} \mathrm{C}$. TEOS $(8.76 \mathrm{~g})$ was added dropwise to the solution at a constant temperature of $35^{\circ} \mathrm{C}$. After a TEOS prehydrolysis of $45 \mathrm{~min}, 2.66 \mathrm{~mL}$ of 2-(4-chlorosulfonylphenyl)ethyltrimethoxysilane (CSPTMS) solution in methylene chloride (50\%, Gelest) was added dropwise (to prevent phase separation). The resulting mixture was stirred for $20 \mathrm{~h}$ at $35^{\circ} \mathrm{C}$ following by aging at $95^{\circ} \mathrm{C}$ for another $24 \mathrm{~h}$. The molar composition of the mixture for $4 \mathrm{~g}$ of copolymer was: 7.4 TEOS: 1 CSPTMS: $48 \mathrm{HCl}: 1466 \mathrm{H}_{2} \mathrm{O}$. The solid was isolated via filtration, washed extensively with methanol and dried in air. The surfactant template was removed by suspending the solid material in ethanol and refluxing for 48 hours. The sulfonyl chloride groups underwent hydrolysis in the acidic media of the reaction.

\section{Materials Characterization}

\subsection{Nitrogen Sorption Analysis}

The textural properties of the mesoporous materials were measured using the BET procedure. Nitrogen adsorption-desorption isotherms were taken at $77 \mathrm{~K}$ using a 
Micromeritics ASAP 2000 system. The ion capacities of the sulfonic acid groups in the functionalized mesoporous silica were quantified using $2 \mathrm{M} \mathrm{NaCl}(\mathrm{aq})$ as the ion-exchange agent. Approximately $0.05 \mathrm{~g}$ of the sample was added to $15 \mathrm{~mL}$ of the salt solution and allowed to equilibrate. Thereafter, it was titrated by dropwise addition of $0.01 \mathrm{M} \mathrm{NaOH}$ $(\mathrm{aq}) .15$

\subsection{Catalytic tests}

The reagents used for the catalytic test included palmitic acid (PA, $\geq 95 \%$, Sigma), refined soybean oil (SBO, Wesson) and methanol $(\mathrm{MeOH}, \geq 99.9 \%$, Fisher Scientific). A model high free fatty acid oil feed was simulated using $15 \%$ wt PA in SBO. The oil mixture was charged into the $100 \mathrm{~mL}$ reaction vessel with $\mathrm{MeOH}$ at a ratio of 1:20 w/w (PA: MeOH). The esterification reactions were performed in a stainless steel high-pressure batch reactor, Series 4565 Bench Top Mini Reactor (Parr Instrument Co., USA), fitted with mechanical stirrer and sample outlet. The reaction vessel was held at constant temperature with the aid of the heating mantle and integrated water-cooling system. Catalysts were screened using different loadings ( $5-20 \% \mathrm{w} / \mathrm{w}$ of the PA). The range of reaction temperature studied was 85 to $120^{\circ} \mathrm{C}$. Samples were drawn at hour intervals and their acid values were determined using the AOCS method Cd 3a-63.

The catalytic activities of the functionalized mesoporous silicas were compared with several commercial catalysts. These included homogeneous catalysts (sulfuric acid and ptoluenesulfonic acid, $\mathrm{TsOH}$ ) from Fisher Scientific and heterogeneous catalysts, Nafion NR50 (SA $=0.02 \mathrm{~m}^{2} / \mathrm{g}, \mathrm{H}^{+}$capacity $=0.8 \mathrm{mmol} / \mathrm{g}$, Alfa Aesar Co. USA) and Amberlyst-15 $\left(\mathrm{SA}=45 \mathrm{~m}^{2} / \mathrm{g}, \mathrm{Dp}=250 \AA, \mathrm{H}^{+}\right.$capacity $=4.7 \mathrm{mmol} / \mathrm{g}$, Rohm and Haas Co. USA). All experiments were performed at least twice to evaluate reproducibility. 


\section{Results and discussion}

The acidic functional groups utilized in the catalytic tests are schematized in Fig.4-1.

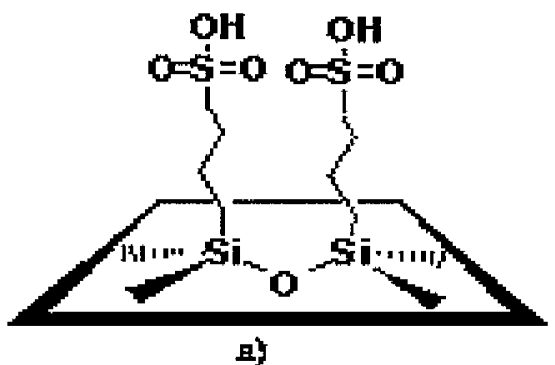

B)

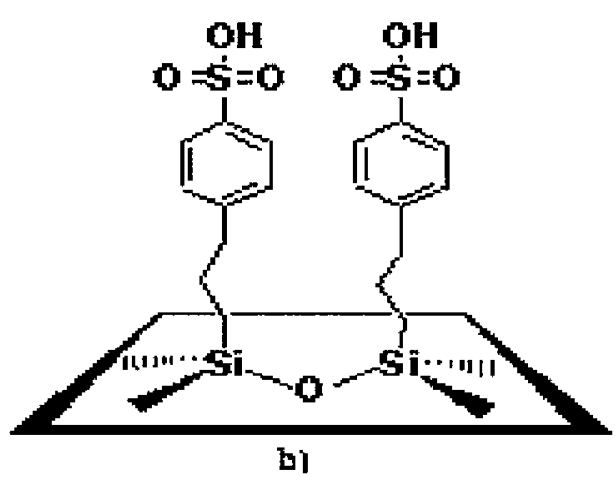

b)

Figure 4-1. Organosulfonic acid functional groups used in the study.

The textural properties of the functionalized mesoporous silicas synthesized for the current work are summarized in Table 4-1, where the suffix designates the surfactant used. The $N_{2}$ adsorption-desorption isotherms of the synthesized samples had the hysteresis behavior associated with mesoporous materials. ${ }^{11,14,19,20}$ The shape of the hysteresis loop indicated that the mesopores were disordered, which is a characteristic of mesoporous silica synthesized using nonionic surfactants as templates.

As seen in the table, the median pore diameter (MPD) of the mesoporous materials as determined by the $\mathrm{BJH}$ method was dependent on the surfactant template used, which is consistent with previous reports, and can be attributed to the size of the micelle structure formed during synthesis. ${ }^{11,21-23}$ For the propylsulfonic acid-functionalized samples, HMS$\mathrm{SO}_{3} \mathrm{H}-\mathrm{C} 12$ had the smallest MPD of $21 \AA$. The HMS material was formed from the cooperative self-assembly of the neutral primary amine, n-dodecylamine $\left(\mathrm{C}_{12}\right)$, with the neutral silica precursor. This procedure yielded mesoporous materials with worm-like pore structure and large wall thickness. ${ }^{19}$ The pore diameter of the FIMS material strongly depends 
on the length of the aliphatic carbon chain of the surfactant. The SBA-15 materials were synthesized using Pluronic L64 and P123, which are tri-block copolymers of polyethylene oxide-polypropylene oxide-polyethylene oxide, with molecular structure of $\mathrm{EO}_{13}-\mathrm{PO}_{30}-\mathrm{EO}_{13}$ and $\mathrm{EO}_{20}-\mathrm{PO}_{70}-\mathrm{EO}_{20}$, respectively ${ }^{1,20,24}$. The $\mathrm{SBA}-15-\mathrm{SO}_{3} \mathrm{H}-\mathrm{P} 123$ sample gave the largest MPD among the propylsulfonic acid-functionalized silicas. The larger MPD from the use of Pluronic P123 can be attributed to the lower EO:PO ratio of Pluronic P123 relative to Pluronic L64, 0.29 and 0.43, respectively. The decreased EO:PO ratio, which is as result of an increase in the molecular weight of the propylene oxide in the copolymer, increased the hydrophobicity of the resulting micelles. The increase in hydrophobicity of the micelles increased their size leading to an enlarged MPD in the resulting mesoporous material. ${ }^{11}$

The BET surface area of the samples was in the range reported in the literature for these types of mesoporous materials, which validates that the solvent extraction of the surfactant was successful. No clear relation between the surface areas of the functionalized mesoporous silica and the surfactant template was observed. Due to differences in preparation conditions, it was difficult to compare directly the surface area results with those reported in the literature.

The pore size distributions for the propylsulfonic acid-functionalized silicas as calculated from the BJH method are shown in Figure 4-2. The unimodal pore diameter distribution was consistent with that reported for organo-modified mesoporous silicas synthesized with nonionic surfactants. The pore volume followed the same trend with surfactant as was observed for the MPD. There was no apparent correlation between the pore volume and the BET surface area. 


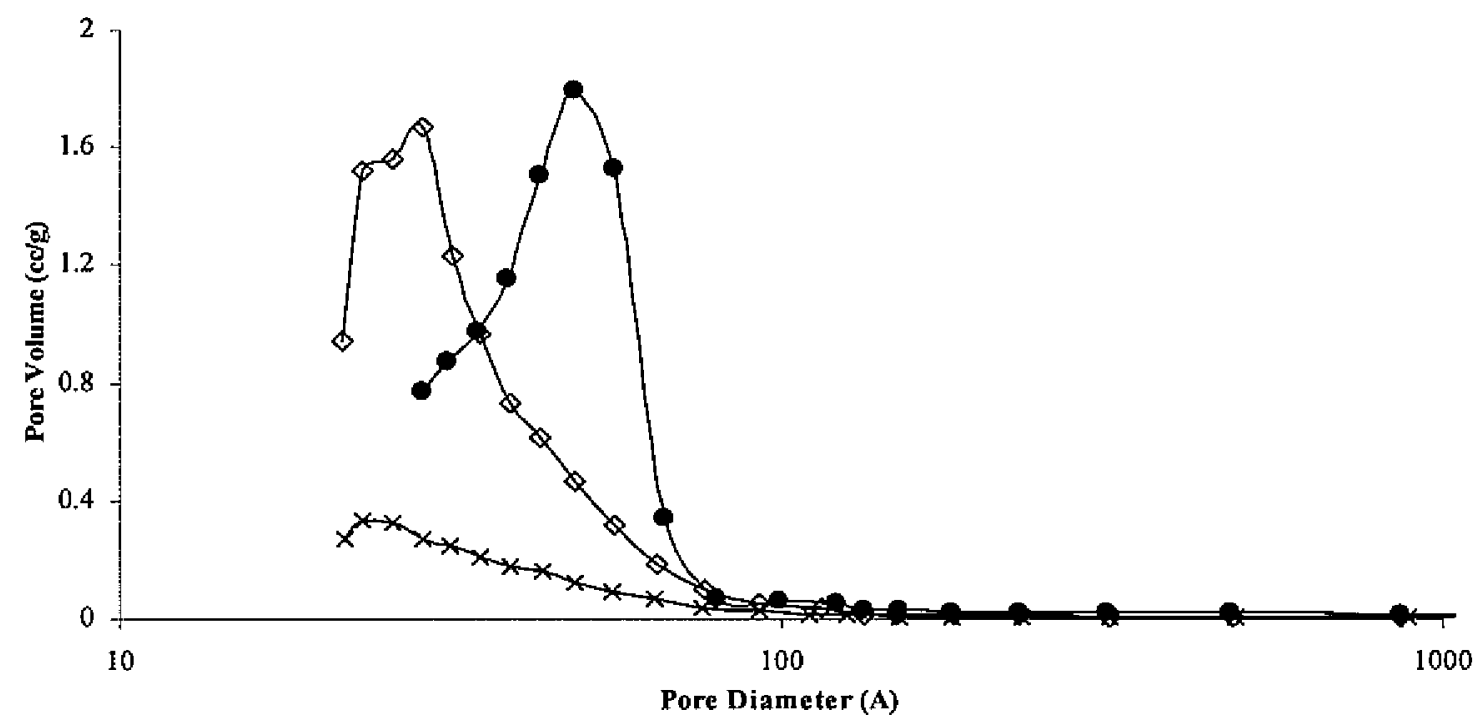

Figure 4-2 , Pore-size distribution curves for the mesoporous materials ( $\times$, HMS-SH-C12; $\diamond$ SBA-15-SH-L64; - SBA-15-SH-P123).

The number of sulfonic acid groups in the mesoporous silica, which were determined quantitatively using acid-base titration, are given in Table 4-1.

Table 4-1. Textural properties of the functionalized mesoporous silicas

\begin{tabular}{|c|c|c|c|c|c|}
\hline \multirow[b]{2}{*}{ Catalyst } & \multirow[b]{2}{*}{ Surfactant } & \multicolumn{3}{|c|}{ Textural properties } & \multirow[b]{2}{*}{$\begin{array}{c}\mathrm{H}^{+} \text {(mmol/ } \mathrm{g} \\
\text { sample) }\end{array}$} \\
\hline & & $\begin{array}{c}\mathrm{S}_{\mathrm{BET}} \\
\left(\mathrm{m}^{2} \mathrm{~g}^{-1}\right)\end{array}$ & $\begin{array}{c}\mathrm{V}_{\mathrm{p}} \\
\left(\mathrm{cm}^{3} \mathrm{~g}^{-1}\right)\end{array}$ & $\begin{array}{c}\mathrm{MPD} \\
(\AA)\end{array}$ & \\
\hline $\mathrm{HMS}-\mathrm{SO}_{3} \mathrm{H}-\mathrm{C} 12$ & $n$-dodecylamine & 550 & 0.30 & 22 & 0.60 \\
\hline $\mathrm{SBA}-15-\mathrm{SO}_{3} \mathrm{H}-\mathrm{L} 64$ & Pluronic L64 & 820 & 0.58 & 27 & 0.84 \\
\hline $\mathrm{SBA}-15-\mathrm{SO}_{3} \mathrm{H}-\mathrm{P} 123$ & Pluronic P123 & 735 & 0.67 & 35 & 1.44 \\
\hline SBA-15-ph-SO ${ }_{3} \mathrm{H}-\mathrm{P} 123$ & Pluronic P123 & 540 & 0.71 & 50 & 0.92 \\
\hline
\end{tabular}

It is noteworthy that the acid capacity of the materials was found to increase with increasing MPD. This result was unexpected given that equal concentrations of the MPTMS and the oxidation reagent were used in the synthesis of all the samples. This difference indicates that all of the sulfur must not reside in the sulfonic acid groups. It is possible that 
the oxidation process that converts the thiol in the MPTMS precursor to the sulfonic acid group may also be oxidizing some of the adjacent thiol groups to disulfides, which would not be reactive. ${ }^{25}$

The reaction performance of the functionalized mesoporous silicas was evaluated for the esterification of free fatty acids in a fatty acid/triglyceride mixture. A mixture of $15 \mathrm{wt} \%$ palmitic acid in soybean oil was used as the model high free fatty acid feed. This free fatty acid content is consistent with the value expected for a typical yellow grease. The transesterification of vegetable oil, which is performed with a homogeneous alkali catalyst such as sodium hydroxide or sodium methoxide, prefers a feedstock with $<0.5 \mathrm{wt} \%$ free fatty acid due to saponification of the free fatty acid with the alkali catalyst. Transesterification of oil feeds with higher concentrations of free fatty acid lead to low yields and high production cost due to this depletion of the catalyst and subsequent formation of soap, which increases purification costs. ${ }^{9}$ Pretreatment of a high free fatty acid oil via acid catalyzed esterification of the free fatty acid would provide a means for producing a feedstock that could be used in a standard transesterification reaction system. Therefore, the performance objective of the acid catalyst with the model feed was to decrease the palmitic acid content to less than $<0.5 \mathrm{wt} \%$. The esterification reaction was performed in excess methanol to favor the forward reaction, since the esterification of fatty acids with alcohol is extremely reversible. ${ }^{26}$

To provide a comparison basis for the functionalized mesoporous silicas, the esterification reaction was also performed with $\mathrm{H}_{2} \mathrm{SO}_{4}$ and two commercial acidic resins, Amberlyst-15 and Nafion. Shown in Figure 4-3 are the results for reaction studies performed at $85{ }^{\circ} \mathrm{C}$ with a methanol to palmitic acid ratio of $20: 1$ by weight. The figure gives the palmitic acid concentration by weight as a function of reaction time. 


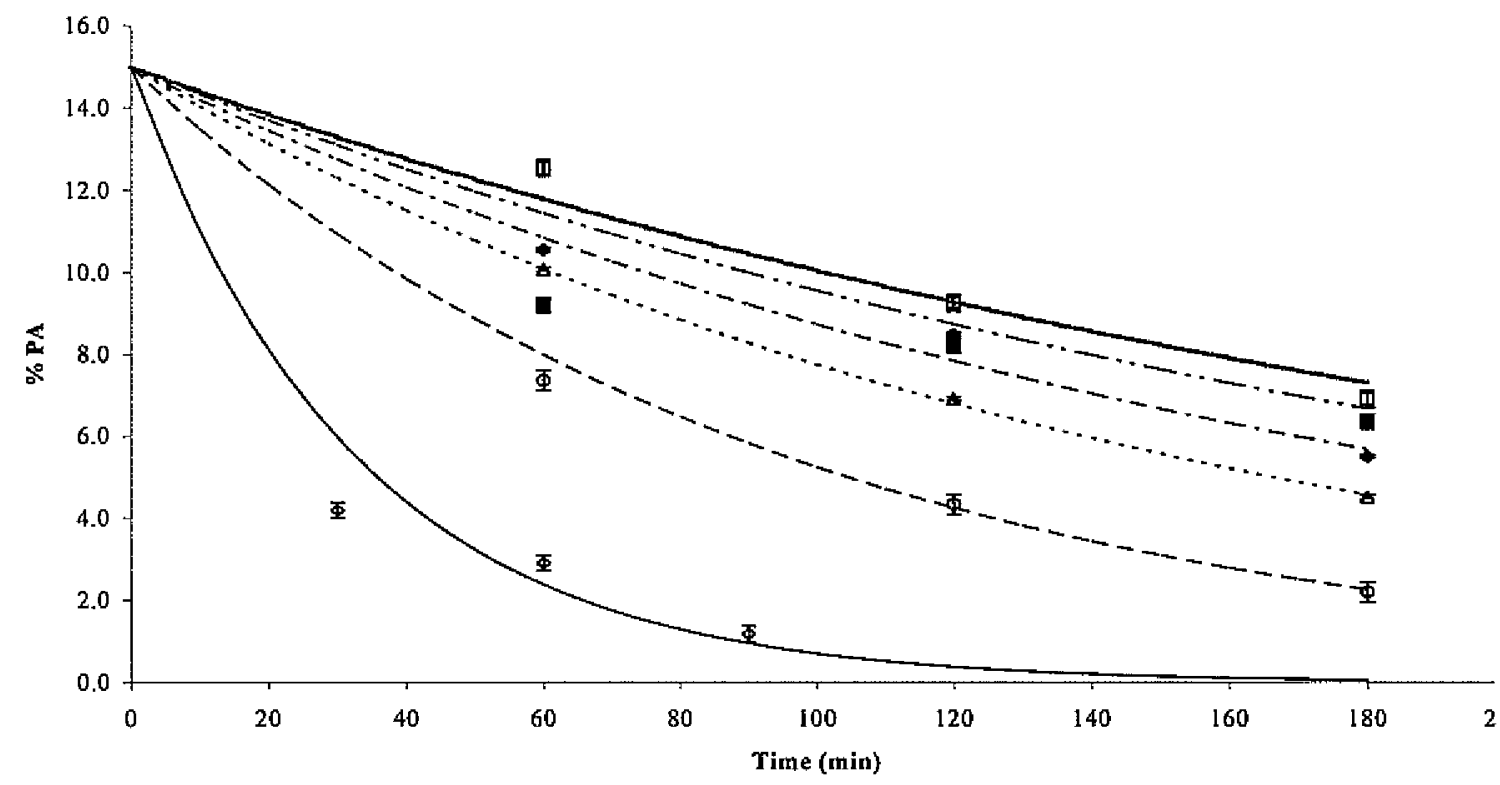

Figure 4-3. Catalytic results for the esterification of palmitic acid in soybean oil with methanol $\left(85^{\circ} \mathrm{C}\right.$; PA:MeOH=1:20; catalyst, $10 \%$ Amberlyst 15 -wet ( $\square$, Exp., =model), $10 \% \mathrm{HMS}_{-\mathrm{SO}} \mathrm{H}-\mathrm{C} 12$ (唋, Exp., -

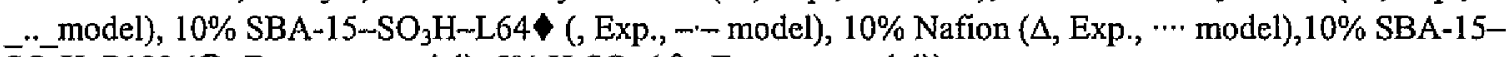
$\overline{\mathrm{S}} \mathrm{O}_{3} \mathrm{H}-\mathrm{P} 123\left(\mathrm{O}\right.$, Exp., -- model), $5 \% \mathrm{H}_{2} \mathrm{SO}_{4}(\diamond$, Exp., - model)).

A catalyst concentration of $10 \mathrm{wt} \%$ was used for all of the catalysts except $\mathrm{H}_{2} \mathrm{SO}_{4}$, which was used at only $5 \mathrm{wt} \%$ concentration. In addition to the experimental data, trend lines are given in the figure. The trend lines were determined by fitting the experimental data to a pseudo first order reaction model with respect to the palmitic acid concentration given that the methanol was in excess and the soybean oil was not significantly reacting. The model assumption is validated by the reasonable fit between the trend lines and experimental data. As can be seen from the Figure 4-3, the $\mathrm{H}_{2} \mathrm{SO}_{4}$ homogeneous catalyst was the most active with a conversion of more than $90 \%$ in less than $1.5 \mathrm{~h}$. The high activity of $\mathrm{H}_{2} \mathrm{SO}_{4}$ was consistent with results reported in the literature, whereas low as $5 \mathrm{wt} \%$ loading of the catalyst was reported to be sufficient to esterify free fatty acids to levels of less than $0.5 \mathrm{wt} \%{ }^{27}$ The 
kinetic model fit the $\mathrm{H}_{2} \mathrm{SO}_{4}$ data least well, which may be attributed to reaction inhibition due to the presence of water at high palmitic acid conversion.

Among the functionalized mesoporous silicas, SBA-15- $\mathrm{SO}_{3} \mathrm{H}-\mathrm{P} 123$ gave the highest catalytic activity and $\mathrm{HMS}-\mathrm{SO}_{3} \mathrm{H}-\mathrm{C} 12$ gave the least, with palmitic acid conversions of $85 \%$ and $55 \%$, respectively, after $3 \mathrm{~h}$. The higher activity with SBA-15-SO $3 \mathrm{H}-\mathrm{P} 123$ was consistent with the material having the largest number of active sites (1.44 mmol/g sample) as well as the largest pore diameter $(35 \AA)$. This observation was consistent with that reported by Bossaert et al. ${ }^{16}$ for the esterification of gylcerol with lauric acid using propylsulfonic acidfunctionalized mesoporous silica catalysts.

As seen in Figure 4-3, Amberlyst-15 despite its high exchange capacity gave the least catalytic activity with a conversion of $40 \%$, while the Nafion was intermediate relative to the mesoporous silica catalysts with a conversion of $70 \%$. Amberlyst- 15 is known to be an active catalyst in a number of esterification reactions and Nafion contains highly acidic sites, however, their low activity suggests that either their catalytic sites are not accessible or under the given reaction conditions they are not sufficiently reactive.

Since the superiority of the $\mathrm{H}_{2} \mathrm{SO}_{4}$ catalyst in the reaction may be attributable to external mass transfer limitation with the solid catalysts, the esterification reaction was performed at a range of agitation speeds. Shown in Figure 4-4 are the results for the SBA$15-\mathrm{SO}_{3} \mathrm{H}-\mathrm{P} 123$ catalyst, which was the most active solid catalyst. No significant differences in conversion rates were observed between the three stirring rates demonstrating that at the higher stirring rates that were used in the current study no significant external mass transfer limitations were experienced. 


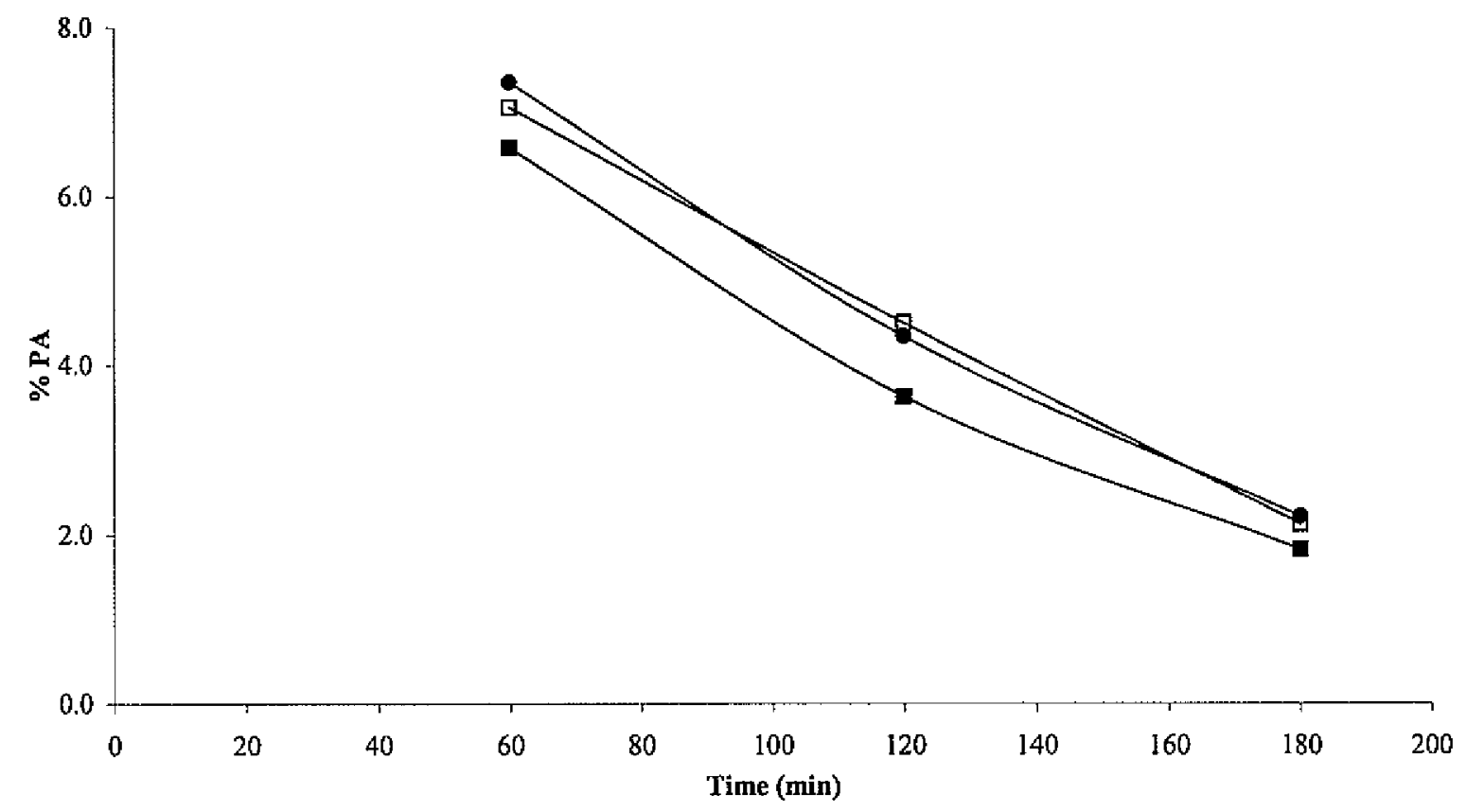

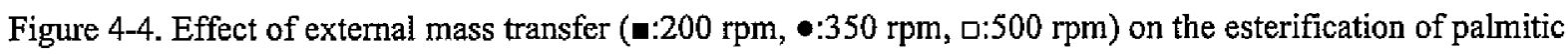
acid in soybean oil $\left(85^{\circ} \mathrm{C} ; \mathrm{PA}: \mathrm{MeOH}=1: 20\right.$, catalyst: $\left.10 \% \mathrm{SBA}-15-\mathrm{SO}_{3} \mathrm{H}-\mathrm{P} 123\right)$.

Determining the cause of the higher activity for the SBA- $15-\mathrm{SO}_{3} \mathrm{H}-\mathrm{P} 123$ catalyst requires understanding of the relative importance of its higher active site concentration and its larger MPD, since both of these attributes could be contributing to the improved performance. To better understand these features, the reaction was performed at a range of temperatures from $85-120^{\circ} \mathrm{C}$. These data were then used to calculate apparent activation energies for the catalysts. The apparent activation energies were calculated assuming a pseudo first order reaction with respect to the palmitic acid as discussed previously. The linear regressions fit for the resulting values $\left(\mathrm{R}^{2}>0.95\right)$ confirmed that the assumed first order kinetics were reasonable.

The calculated rate constants and apparent activation energies are summarized in Table 4-2 for the synthesized mesoporous silica catalysts as well as the Nafion. 
A temperature increase of $15-20^{\circ} \mathrm{C}$ caused a $2-3$ times increase in the rate constants, which is as expected for activated reactions. The apparent activation energy of the mesoporous catalysts decreased in the order of $\mathrm{HMS}-\mathrm{SO}_{3} \mathrm{H}-\mathrm{C} 12>\mathrm{SBA}-15-\mathrm{SO}_{3} \mathrm{H}-\mathrm{L} 64>$ SBA-15-SO 3 H-P123. It is significant to note that the apparent activation energy was found to decrease with increasing MPD. If internal diffusion was not significantly limiting the catalyst, the apparent activation energies for these catalysts should be the same since the identical propylsulfonic acid-functional group was the active site present in all of the catalysts. The importance of the propylsulfonic acid groups in the conversion reaction was validated by testing a mesoporous silica that contained a low level of grafted propylsulfonic acid groups $(0.02 \mathrm{mmol} / \mathrm{g})$. This catalyst was nearly inactive for the esterification reaction indicating that the silica has no significant esterification activity.

A likely cause of the decreased apparent activation energy with increase in MPD is the importance of activated diffusion. The impact of activated diffusion on reaction kinetics has been amply demonstrated with zeolitic catalysts in which the activation energy of diffusion is strongly dependent on temperature and follows an Arrhenius relationship. In these systems, activation energies of up to $84 \mathrm{~kJ} / \mathrm{mol}$ have been reported for activated diffusion. ${ }^{28}$ If the esterification reaction was limited by activated diffusion for the HMS$\mathrm{SO}_{3} \mathrm{H}-\mathrm{C} 12$ catalyst, subsequent increase in MPD as realized with the SBA-15 catalysts would lead to decreasing reaction limitation by activated diffusion. Therefore, the results in the current study appear to support the importance of activated diffusion in the esterification of palmitic acid with mesoporous materials having a MPD at least within the range of 22-35 $\AA$. 
In addition to the accessibility of the acidic sites, a potentially important characteristic is the strength of the acid site. A more acidic catalyst was synthesized by introducing a phenyl group within the organosulfonic acid (Figure 4-1.b). The phenyl group, which is more electronegative than the aliphatic carbon chain, would be expected to increase the acid strength of the sulfonic acid group within the catalyst. ${ }^{18}$ To diminish the possible effect of activated diffusion, arenesulfonic acid-functionalized mesoporous silica was synthesized using Pluronic P123, which would be expected to yield a larger MPD than from the other surfactants used in the study. The sample, which is denoted SBA-15-ph-SO 3 H-P123, had the textural properties and number of active site as given in Table 4-1. Despite the use of a common surfactant template, this material had a larger MPD and pore volume than the SBA$15-\mathrm{SO}_{3} \mathrm{H}-\mathrm{P} 123$ material.

Shown in Figure 4-5 is the catalytic activity of SBA-15-ph-SO $\mathrm{S}_{3} \mathrm{H}-\mathrm{P} 123$ for the esterification of palmitic acid relative to SBA-15-SO $\mathrm{H}-\mathrm{P} 123$ as well as the homogeneous catalysts, $\mathrm{H}_{2} \mathrm{SO}_{4}$ and p-toluene sulfonic acid (TsOH). SBA-15-ph-SO ${ }_{3} \mathrm{H}-\mathrm{P} 123$ had significantly higher activity than $\mathrm{SBA}-15-\mathrm{SO}_{3} \mathrm{H}-\mathrm{P} 123$ despite its lower number of acidic sites. In addition, it outperformed the esterification activity of the free $\mathrm{TsOH}$. While the overall conversion achieved using SBA-15-ph-SO $\mathrm{S}_{3} \mathrm{H}-\mathrm{P} 123$ was similar to $\mathrm{H}_{2} \mathrm{SO}_{4}$, the initial reactivity of the solid catalyst was higher than for $\mathrm{H}_{2} \mathrm{SO}_{4}$.

As discussed previously, the fit of the pseudo first order kinetic model to the $\mathrm{H}_{2} \mathrm{SO}_{4}$ data was inferior to the heterogeneous catalysts, which was attributed to reaction inhibition from water at the high conversion level. 


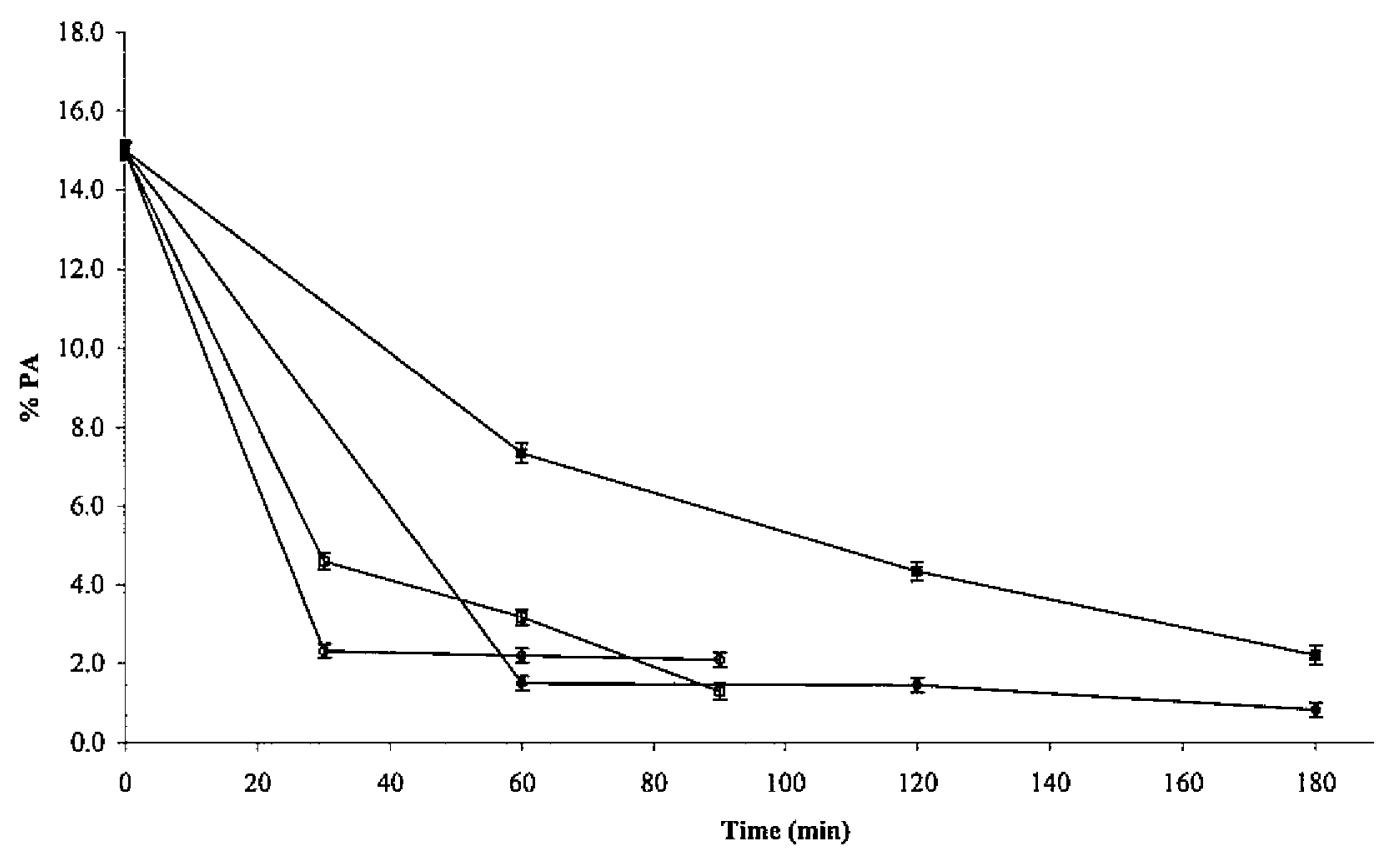

Figure 4-5. Esterification of palmitic acid in soybean oil with methanol $\left(85^{\circ} \mathrm{C} ; \mathrm{PA}: \mathrm{MeOH}=1: 20\right.$, catalyst: $\square$,

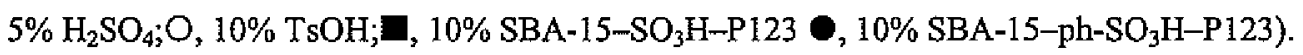

This effect was more pronounced in the reactions with free TsOH and SBA-15-ph$\mathrm{SO}_{3} \mathrm{H}-\mathrm{P} 123$, since both of these catalyst systems were very reactive. As such, the pseudo first order reaction trend lines are not included in Figure 4-5. Esterification of free fatty acids with methanol releases water that is known to limit the extent of the esterification reaction. Therefore, the low level of palmitic acid conversion after 60 minutes for the homogeneous catalysts and SBA-15-ph-SO ${ }_{3} \mathrm{H}-\mathrm{P} 123$ is likely due to the presence of water.

Comparison of the reaction performance of catalysts relative to a mass-based loading of the catalysts has limitations when catalysts with different number of active sites are considered. An apparent reactivity can be defined as the average turnover rate per total number of active sites. Since internal diffusion has been demonstrated to be significant in the mesoporous catalysts, the apparent reactivity can only represent an average turnover number 
that is convoluted with diffusion effects. For the current catalysts the number of active sites was defined by the $\mathrm{H}^{*}$ equivalents in the catalyst. Using this definition, the apparent reactivities for the catalysts at $85^{\circ} \mathrm{C}$ are given in Table 4-2. As can be seen from the table, SBA-15-ph-SO $\mathrm{S}_{3} \mathrm{H}-\mathrm{P} 123$ gave significantly higher apparent reactivity than any of the other catalysts, while the apparent reactivities for all of the propylsulfonic acid-functionalized silicas as well as the Nafion were comparable. The high apparent reactivity for SBA-15-ph$\mathrm{SO}_{3} \mathrm{H}-\mathrm{P} 123$ supports the conclusion that increasing the acidity of the sulfonic acid group enhances the reactivity of the material in the esterification reaction.

Table 4-2. Comparison of the kinetic performance of the functionalized mesoporous silica catalysts.

\begin{tabular}{|c|c|c|c|c|c|}
\hline \multirow[t]{2}{*}{ Catalyst } & \multicolumn{3}{|c|}{ Rate Constant $\left(\mathrm{min}^{-1}\right)$} & \multirow{2}{*}{$\begin{array}{c}\text { Apparent } \\
\text { Activation } \\
\text { Energy } \\
(\mathrm{kJ} / \mathrm{mol})\end{array}$} & \multirow{2}{*}{$\begin{array}{c}\begin{array}{c}\text { Apparent } \\
\text { Reactivity } \\
\left(\min ^{-1}\right)\end{array} \\
85^{\circ} \mathrm{C}\end{array}$} \\
\hline & $85^{\circ} \mathrm{C}$ & $100^{\circ} \mathrm{C}$ & $120^{\circ} \mathrm{C}$ & & \\
\hline Nafion & $6.6 \times 10^{-3}$ & $1.3 \times 10^{-2}$ & & $60 \pm 9$ & 0.16 \\
\hline HMS-SO ${ }_{3} \mathrm{H}-\mathrm{C} 12$ & $2.6 \times 10^{-3}$ & $9.0 \times 10^{-3}$ & $2.4 \times 10^{-2}$ & $75 \pm 10$ & 0.14 \\
\hline SBA-15-SO 3 H-L64 & $5.4 \times 10^{-3}$ & $1.3 \times 10^{-2}$ & $2.8 \times 10^{-2}$ & $55 \pm 5$ & 0.16 \\
\hline SBA-15-SO 3 H-P123 & $7.5 \times 10^{-3}$ & $1.5 \times 10^{-2}$ & $3.4 \times 10^{-2}$ & $40 \pm 1$ & 0.11 \\
\hline $\begin{array}{l}\text { SBA-15- } \mathrm{phSO}_{3} \mathrm{H}- \\
\mathrm{P} 123\end{array}$ & $1.7 \times 10^{-2}$ & & & & 0.68 \\
\hline
\end{tabular}

\section{Conclusions}

Organosulfonic acid-functionalized mesoporous silicas have been demonstrated to have higher reactivity than commercially available solid acid esterification catalysts for the conversion of fatty acids to methyl esters. Tailoring the textural properties of the catalyst structure and tuning the acidity of the active site can enhance the performance of the mesoporous materials. By choice of surfactant template, the pore diameter can be 
systematically increased to decrease internal mass transfer resistance. Due to the narrow pore size distribution of the mesoporous materials, the pore size effect on internal mass transfer could be definitively determined. Increasing the acidity of organosulfonic acid group was found to improve significantly that activity of the mesoporous catalyst for the fatty acid esterification reaction. Proper choice of the organosulfonic acid group produced a functionalized mesoporous silica with activity at least comparable to $\mathrm{H}_{2} \mathrm{SO}_{4}$. This work demonstrates the potential of organic-inorganic mesoporous materials for rational design of heterogeneous catalysts.

\section{Acknowledgements}

This work was financial supported by USDA though Iowa Biorenewable Technology and Byproduct Consortium. The synthesis of the SBA-15-ph-SO $3 \mathrm{H}-\mathrm{P} 123$ catalyst was supported by the United Soybean Board.

\section{References}

(1). Bender, M., Bioresource Technol. 1999, 70,81.

(2). Diasakou, M., Louloudi, A., and Papayannakos, N., Fuel , 1998, 77, 1297.

(3). Ogoshi, T., and Miyawaki, Y., J. Am. Oil. Chem. Soc. 1985, 62, 331.

(4). Suppes, G.J., Bockwinkel, K., Lucas, S., Botts, J.B., Mason, M.H., and Heppert, J.A., J. Am. Oil. Chem. Soc. 2001, 78, 139.

(5). Kildiran, G., Yucel, S.O., and Turkay, S., J. Am. Oil. Chem. Soc. 1996, 73, 225.

(6). Encinar, J.M., Gonzalez, J.F., Sabio, E., and Ramiro, M.J., Ind. Eng. Chem. Res. $1999,38,2927$. 
(7). Ma, F., Clements, L.D., and Hanna, M.A., Ind. Eng. Chem. Res. 1998, 37, 3768.

(8). Boocock, D.G.B., Konar, S.K., Mao, V., Lee, C., and Buligan, S., J. Am. Oil. Chem. Soc. 1998, 75, 1167.

(9). Basu, H.N., and Norris, M.E., U.S. Patent \#5,525,126, 1996.

(10). Koono, S., Moriya, O., Noguchi, T., and Okamura, H., E.P. Patent \# 566,047 1993.

(11). Zhao, D., Feng, J., Huo, Q., Melosh, N., Fredrickson, G.H., Chmelka, B.F., and Stucky, G.D., Science 1998, 279, 548.

(12). Stein, A., Melde, B.J., and Schodein, R.C., Adv. Mater, 2000, 12, 1403.

(13). Van Rhijn, W.M., De Vos, D.E., Bossaert W.D., and Jacobs P.A., Chem Comm.. $1998,317$.

(14). Diaz, I., Mohino, F., Perez-Pariente, J., Sastre, E., Wright, P., and Zhou, W., Stud. Surf. Sci. Catal. 2001, 135, 1248.

(15). Margolese, D., Melero, J.A., Chistiansen, S.C., Chmelka, B.F., and Stucky, G.D., Chem. Mater. 2000, 12, 2448.

(16). Bossaert W.D., De Vos, D.E., Van Rhijn, W.M., Bullen J., Grobet, P.J., and Jacobs P.A., J. Catal. 1999, 182, 156.

(17). Lin, V.S.-Y., Lai, C.-Y., Huang, J., Song, S.-A., and Xu, S., J. Am. Chem. Soc. $2001, I 23,11510$.

(18). Melero, J.A., Stucky, G.D., van Grieken, R., and Morales, G., J. Mater. Chem. $2002,12,1664$.

(19). Tanev, P.T., and Pinnavaia, J., Science 1995, $267,865$.

(20). Kruk, M., Jaroniec, M., Ko, C.H., and Ryoo, R., Chem. Mater. 2000, 12,1961. 
(21). Beck, J.S., Vartuli, J.C., Roth, W.J., Leonowicz, M.E., Kresge, C.T., Schmitt, K.D., Chu, C.T.W., Olson, D.H., Sheppard, E.W., McCullen, S.B., Higgins, J.B., and Schlenker, J.L., J. Am. Chem. Soc. 1992, 114, 10834.

(22). Beck, J.S., Vartuli, J.C., Kennedy, G.J., Kresge, C.T., Roth, W.J., and Schamm S.E., Chem. Mater. 1994, 6, 1816.

(23). Tanev, P.T, and Pinnavaia, J., Chem. Mater. 1996, 8, 2068.

(24). Ying, J.Y., Mehnert, C.P., and Wong, M.S., J. Angew. Chem. Int. Edu. 1999, 38, 56.

(25). Evans, B.J., Doi, J.T., and Musker, W.K., J. Org. Chem. 1990, 55, 2337.

(26). Freedman, B., Pryde, E.H., and Mounts, T.L., J. Am. Chem. Soc. 1984, 61,1638.

(27). Freedman, B., Butterfield, R.O., and Pryde, E.H., J. Am. Chem. Soc. 1986, 63,1375 .

(28). Bhatia, S., "Zeolite Catalysis: Principles and Applications." CRC Press, Florida, 1990. 
CHAPTER 5. GATEKEEPING LAYER EFFECT: A POLY(LACTIC ACID)-COATED MESOPOROUS SLICA NANOSPHERE-BASED FLUORESCENCE PROBE FOR DETECTION OF AMINO-CONTAINING NEUROTRANSMITTERS

A paper published in the Journal of American Chemical Society, 2004 126, 1640-1641

Daniela R. Radu, Cheng-Yu Lai, Marek Pruski, Jerzy Wiench, Victor S.-Y. Lin Department of Chemistry, Iowa State University and Ames Laboratory-USDOE, Ames, Iowa

\begin{abstract}
Selective functionalization of the exterior and interior surface of structurally uniform mesoporous materials, such as MCM- or SBA-type of silicas with different organic moieties ${ }^{2}$ allows precise regulation of the penetration of selective molecules with certain sizes and chemical properties into the nano-scale pores. Herein, we report the synthesis and characterization of a poly(lactic acid)-coated, MCM-41 type mesoporous silica nanosphere (PLA-MSN) material that can serve as a fluorescence sensor for selective detection of aminocontaining neurotransmitters under physiological condition. By utilizing the PLA layer as a gatekeeper to regulate the penetration of molecules in and out of the nano-scale pores, we investigated the molecular recognition events between several structurally simple neurotransmitters, i.e., dopamine, tyrosine, and glutamic acid and a pore surface-anchored $o$ phthalic hemithioacetal (OPTA) group.
\end{abstract}




\section{Introduction}

Synthesizing molecular receptors that can differentiate various extracellular amino acid-based neurotransmitters has long been a research challenge. For example, dopamine and glutamic acid are two essential neurotransmitters that are often simultaneously exchanged between various neural cells. ${ }^{1}$ Despite their importance in understanding interneuronal chemical communication, to the best of our knowledge, no synthetic molecular receptor has been reported in the literature that can distinguish dopamine from glutamic acid. In this chapter, we extend our sensor design strategy from providing a secondary interaction between similar targets to study the molecular recognition events to coating a poly(lactic acid) layer on MCM-41 type mesoporous silica nanosphere (PLA-MSN) to regulate the diffusion of detecting amino-containing neurotransmitters under physiological condition.

\section{Materials and Methods}

\section{Preparation of materials}

5,6-Epoxyhexyltriethoxysilane was purchased from Gelest, methanol and toluene were purchased from Fisher, and all other chemicals were purchased from Aldrich. All chemicals were used as received without further purification. Figure 5-1 illustrates schematic representation of the mesoporous silica nanosphere (MSN) materials functionalized with mercaptopropyl (Thiol-MSN) and bifunctionalized with dihydroxybexyl/mercaptopropyl (DH-MSN). 

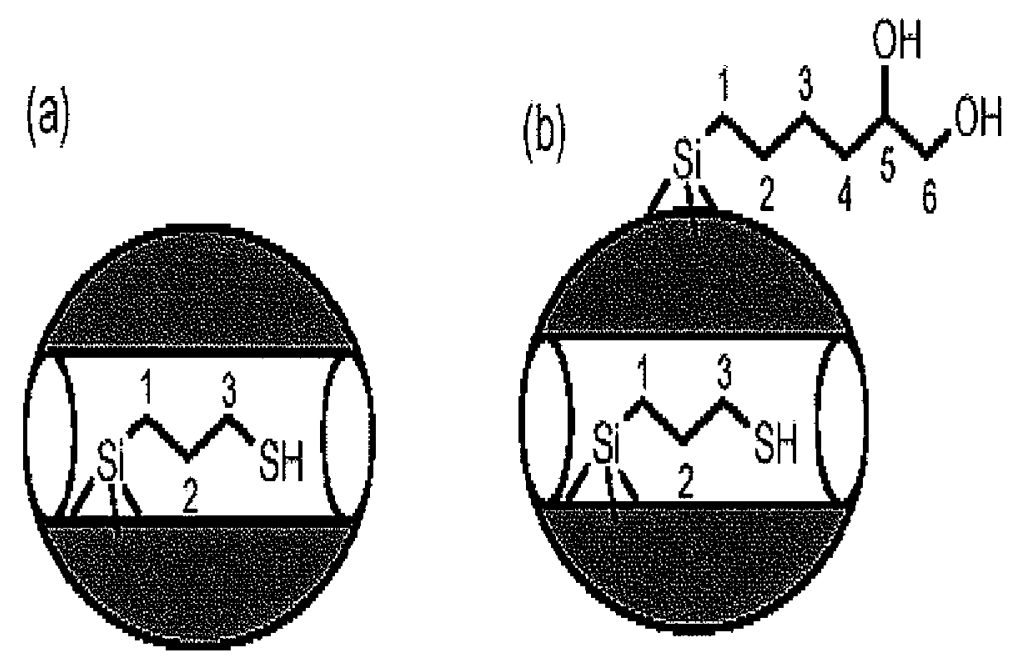

Figure 5-1. Schematic representation of a surface of MSN materials: Thiol-MSN (a) and DH-MSN (b).

\subsection{Synthesis of DH-MSN}

5,6-Epoxyhexyltriethoxysilane (EHTES, $1.0 \mathrm{mmol}$ ) was added to a toluene suspension $(80.0 \mathrm{~mL})$ of thiol-MSN $(1.0 \mathrm{~g})$. The reaction mixture was reffuxed overnight under nitrogen. The resulting material was filtered, washed extensively with toluene and methanol and dried under vacuum for $3 \mathrm{~h}$ at $25^{\circ} \mathrm{C}$. The 5,6-epoxyhexyl-grafted thiol-MSN material $(1.50 \mathrm{~g})$ was refluxed in a $162 \mathrm{~mL}$ methanol solution of hydrochloric acid (1.57 M) for $12 \mathrm{~h}$ to remove the $\mathrm{CTAB}$ template. The $\mathrm{HCl}$ methanol solution also converted the thiolMSN with epoxyhexyl groups to the desired 5,6-dihydroxyhexyl-coated thiol-MSN material (DH-MSN). The surfactant-removed DH-MSN $(1.00 \mathrm{~g})$ was treated with $80 \mathrm{~mL}$ water/methanol $(1 / 7)$ solution of sodium bicarbonate $(0.042 \mathrm{~g})$ for $4 \mathrm{~h}$ at room temperature to remove any unreacted, physisorbed EHTES. The purified material was dried under vacuum for $6 \mathrm{~h}$ at $60^{\circ} \mathrm{C}$. 


\subsection{Synthesis of PLA-coated thiol-MSN}

The purified DH-MSN material $(0.68 \mathrm{~g})$ was sonicated for $30 \mathrm{~min}$ in $10.0 \mathrm{~mL}$ anhydrous THF to disperse the particles uniformly. $L$-Lactide $(0.36 \mathrm{~g}, 2.50 \mathrm{mmol})$ was mixed with tin(II)-2-ethylhexanoate ( $\left.\mathrm{Sn}(\mathrm{oct})_{2}, 0.16 \mathrm{~mL}, 0.50 \mathrm{mmol}\right)$, in $15 \mathrm{~mL}$ anhydrous THF. The lactide/catalyst solution was added to the DH-MSN THF solution by injection under $N_{2}$. The reaction mixture was stirred for $72 \mathrm{~h}$ under $\mathrm{N}_{2}$ at $80^{\circ} \mathrm{C}$ to produce the PLA-coated thiolMSN.

\subsection{Synthesis of OPTA-SS material}

A fumed amorphous silica material $(0.2 \mathrm{~g})$ with a $200.0 \mathrm{~m}^{2} / \mathrm{g}$ BET surface area was added to a $20.0 \mathrm{~mL}$ toluene solution of 3-mercaptopropyltrimethoxysilane $(0.88 \mathrm{~mL}, 4.68$ mmol). The reaction mixture was refluxed over night under nitrogen. The resulting thiolgrafted solid silica was filtered and washed thoroughly with toluene, ethanol, and de-ionized water. The product was isolated by filtration and dried under vacuum for $12 \mathrm{~h}$. Chemically accessible thiol density was determined by measuring the solution concentration of the side product (pyridine-2-thione) generated from the reaction of the surface thiols with $2,2^{2}$ dipyridyl disulfide in THF. The surface-bound thiol functionality was then converted to $o$ phthalic hemithioacetal (OPTA) by reacting $85.0 \mathrm{mg}$ of material with $170.0 \mathrm{mg}$ (126.0 mmol) of phthalic dicarboxaldehyde (o-phtalaldehyde, OPA) in $10 \mathrm{~mL}$ methanol for $5 \mathrm{~h}$. After filtration, the material was extensively washed with methanol and dried under vacuum.

\section{Material Characterization}

Solid state NMR was used to characterize the mesoporous silica nanosphere (MSN) materials functionalized with mercaptopropyl (Thiol-MSN) and bifunctionalized with 
dihydroxyhexyl/mercaptopropyl (DH-MSN). The expected structures of these materials are illustrated in Figure 5-1. In addition, a PLA-coated sample (PLA-MSN), prepared from DHMSN, was examined. The samples were also analyzed by powder X-Ray diffraction and by measurements of nitrogen adsorption/desorption isotherms (see following Sections).

\subsection{Experimental conditions}

Solid-state nuclear magnetic resonance (NMR) of ${ }^{29} \mathrm{Si}$ and ${ }^{13} \mathrm{C}$ was used to (i) confirm the functionalization of MSN materials, (ii) determine their average molecular formulae, and (iii) provide evidence for polymerization of the lactide. The spectra were obtained at $9.4 \mathrm{~T}$ on a Varian/Chemagnetics Infinity spectrometer equipped with a doubly-tuned 5-mm magic angle spinning (MAS) probe. A sample rotation rate of $9 \mathrm{kHz}$ was used in all experiments. The method of variable amplitude cross polarization (CP) between $1 \mathrm{H}$ and the observed, diluted nuclei $\left({ }^{13} \mathrm{C}\right.$ or $\left.{ }^{29} \mathrm{Si}\right)$ was used to increase the sensitivity.2 During each $\mathrm{CP}$ period, the ${ }^{1} \mathrm{H}$ rf magnetic field was ramped between 16 and $40 \mathrm{kHz}$ using $2.4 \mathrm{kHz}$ increments, whereas the ${ }^{29} \mathrm{Si}$ (or ${ }^{13} \mathrm{C}$ ) rf field was maintained at a constant level of $36 \mathrm{kHz}$. The ${ }^{1} \mathrm{H}$ rf magnetic fields of $83 \mathrm{kHz}$ and $60 \mathrm{kHz}$ were used for initial excitation and during continuous wave (CW) decoupling, respectively. The measured values of $1 \mathrm{H}$ longitudinal relaxation time $T_{1}^{\mathrm{H}}$ did not exceed $1 \mathrm{~s}$, which allowed for repetition time of $1.2 \mathrm{~s}$ to be used in the CPMAS experiments. In the ${ }^{1} \mathrm{H} \rightarrow{ }^{13} \mathrm{C}$ CPMAS experiments, 6,000 free induction decays (FD's) were typically acquired using two different contact times of 0.4 or $1.5 \mathrm{~ms}$. The ${ }^{1} \mathrm{H} \rightarrow{ }^{29} \mathrm{Si} \mathrm{CPMAS}$ experiments used a contact time of $1 \mathrm{~ms}$ and 36,000 scans. All spectra were referenced to SiMe4. In spite of long relaxation times of ${ }^{29} \mathrm{Si}$ nuclei, the direct polarization (DPMAS) method was used for quantitative measurements of various silicon groups. During these measurements a $90^{\circ}$ excitation pulse of $2.1 \mu \mathrm{s}$ was followed by acquisition of the ${ }^{29} \mathrm{Si}$ FID 
under $\mathrm{CW}{ }^{1} \mathrm{H}$ decoupling at $65 \mathrm{kHz}$. The saturation recovery experiment, carried out with MCM-41 samples functionalized with allyl and 3-isocyanatopropyl groups, yielded the values of $T_{1}^{\mathrm{Si}}$ on the order of 50 to $65 \mathrm{~s}$ for $\mathrm{T}^{\mathrm{n}}$ groups and 30 to $45 \mathrm{~s}$ for $\mathrm{Q}^{\mathrm{n}}$ groups. Thus, a delay of $300 \mathrm{~s}$ between the scans was used to allow for full restoration of the equilibrium magnetization of ${ }^{29} \mathrm{Si}$ spins. An acquisition of $270 \mathrm{FDD}$ 's yielded the relative intensities of ${ }^{29} \mathrm{Si}$ resonances with an accuracy of $\pm 3 \%$.

\subsection{Powder X-Ray Diffraction}

Powder XRD experiments were performed on a Scintag XDS 2000 diffractometer using a $\mathrm{Cu} \mathrm{K \alpha}$ radiation source. Low angle diffraction with a $2 \theta$ range of 1 to $10^{\circ}$ was used to investigate the long-range order of the materials.

\subsection{Nitrogen adsorption/desorption isotherms}

The surface area and median pore diameter were measured using $N_{2}$ adsorption/desorption measurements in a Micromeritics ASAP 2000 BET surface analyzer system. The data were evaluated using the Brunauer-Emmett-Teller (BET) and BarrettJoyner-Halenda (BJH) methods to calculate the surface area and pore volumes/pore size distributions, respectively. Samples were prepared by degassing at $90{ }^{\circ} \mathrm{C}$ for $1 \mathrm{~h}$ and then at $150{ }^{\circ} \mathrm{C}$ for $4 \mathrm{~h}$.

\subsection{Particle size distribution and scanning electron micrograph of PLA-MSN}

Particle morphology of these materials was determined by scanning electron microscopy (SEM) using a Hitachi S4700 FE-SEM system with $10 \mathrm{kV}$ accelerating voltage and $0.005 \mathrm{nA}$ of beam current for imaging. 


\subsection{Transmission electron micrograph of PLA-MSN}

For transmission electron microscopy (TEM) studies, a small aliquot was taken from a suspension of methanol and placed in a lacey carbon-coated TEM grid, which was pulled through the suspension and allowed to dry in air. Thin sections of samples embedded in epoxy resin were obtained with ultramicrotomy $(60-80 \mathrm{~nm})$. The resulting sample was examined with a Philips model CM-30 TEM operated at $300 \mathrm{kV}$. The specimen was given no further treatment, as it appeared stable under beam bombardment.

\section{HPLC analysis of the competitive detection of PLA-MSN system in a mixture of dopamine and glutamic acid}

PLA-MSN nanoparticles ( $2 \mathrm{mg}$ ) were introduced to a pH 7.4 PBS buffer (10 $\mathrm{mM})$ solution of dopamine $(0.5 \mathrm{mM})$ and glutamic acid $(10 \mathrm{mM})$ at $25^{\circ} \mathrm{C}$. After $10 \mathrm{~min}$ of mixing, the suspension was centrifuged and the individual concentrations of dopamine and glutamic acid in the supernatant were analyzed by HPLC. All analyses were performed on a Hitachi LC/3DQMS HPLC system with a reverse phase C18 column (SUPELCOSIL LC-18-T 250 $\mathrm{mm} \times 4.6 \mathrm{~mm}, \mathrm{ID} 5 \mu \mathrm{m}$ packing, Aldrich). The UV absorption peak at $210 \mathrm{~nm}$ was used for the quantitative analyses of Glutamic acid and Dopamine. Flow rate of mobile phase was 1 $\mathrm{mL} / \mathrm{min}$. The mobile phase eluent consisted of a mixture of $0.1 \mathrm{M}$ potassium dihydrogen phosphate adjusted to $\mathrm{pH} 6.0$ (solvent A) and methanol (solvent B). The elution gradient program was as follows: $0 \min 100 \% \mathrm{~A}, 0 \% \mathrm{~B}, 9 \mathrm{~min} 100 \% \mathrm{~A}, 0 \% \mathrm{~B} ; 11 \mathrm{~min}, 70 \% \mathrm{~A}, 30 \% \mathrm{~B}$; $17 \min 70 \% \mathrm{~A}, 30 \% \mathrm{~B} ; 18 \mathrm{~min} 100 \% \mathrm{~A}, 0 \% \mathrm{~B}$. Finally, an additional 7 min was allowed for the column to return to the initial condition and re-equilibrate. The column temperature was set at room temperature and the injection volume of samples was $25 \mu \mathrm{L}$ for all analyses. 


\section{Results and Discussion}

We synthesized a mercaptopropyl-functionalized mesoporous silica nanosphere named thiol-MSN material with average pore diameter of $2.5 \mathrm{~nm}$ via our previously reported method. ${ }^{3 a, 4}$ As outlined in Figure 5-2, 5,6-epoxyhexyltriethoxysilane (EHTES) was grafted
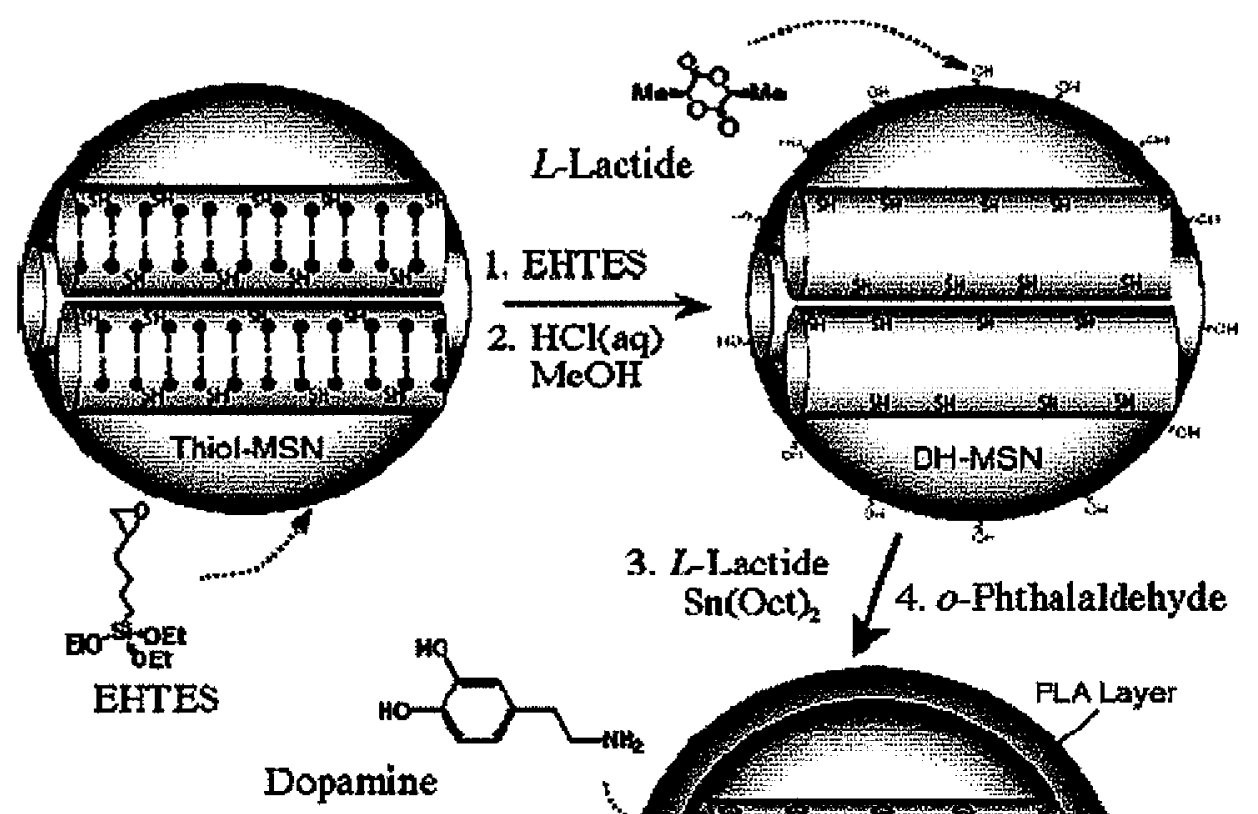

3. $L$-Lactide
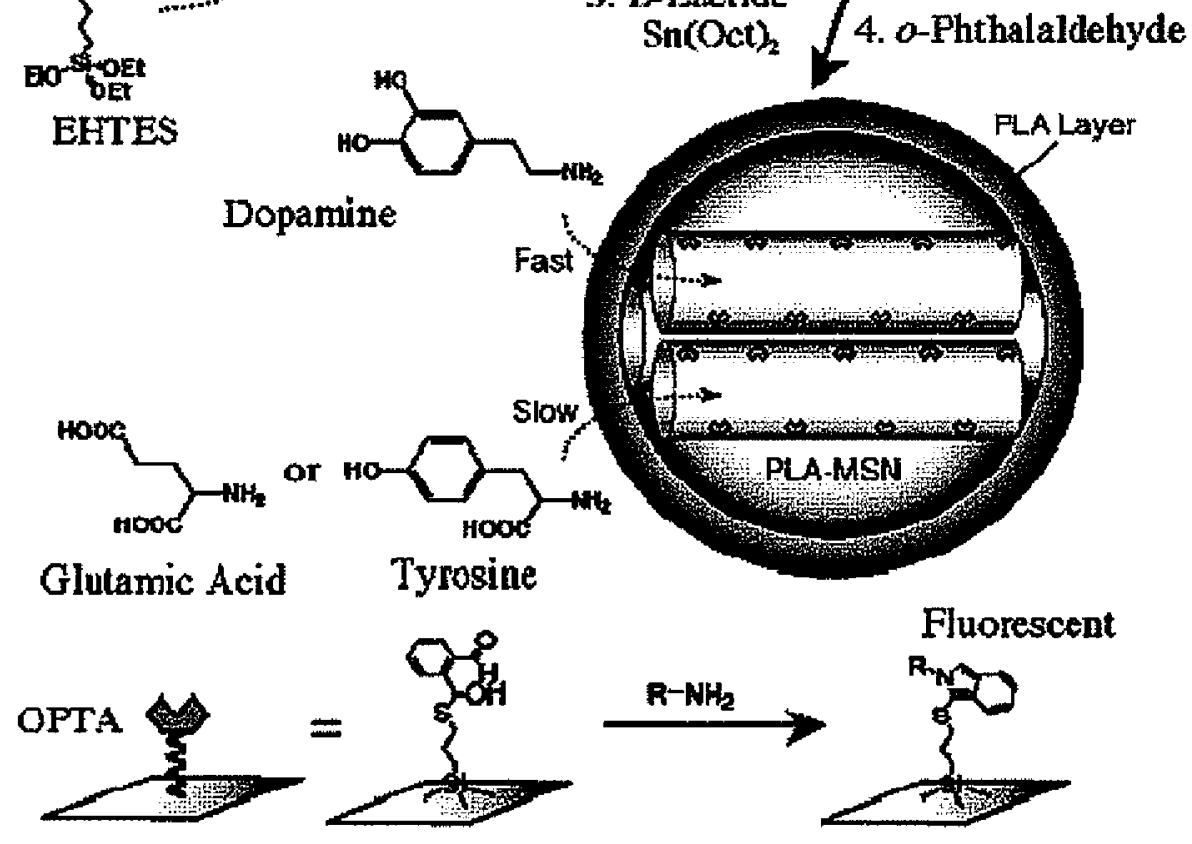

Figure 5-2. Schematic representation of the synthesis of PLA-coated MSNbased fluorescence sensor system for detection of amine-containing neurotransmitters, i.e., dopamine, glutamic acid, and tyrosine (R-NH2). (5,6epoxyhexyltriethoxysilane ) EHTES, cetyltrimethylammonium bromide(CTAB) surfactant $=\sim \sim \sim \sim$. 
onto the exterior surface of the thiol-MSN-containing cetyltrimethylammonium bromide (CTAB) surfactants inside the mesopores.

The resulting material was refluxed in a methanol solution of hydrochloric acid to remove the CTAB template and to convert the thiol-MSN with epoxyhexyl groups to a 5,6dihydroxyhexyl-coated thiol-MSN material (DH-MSN). ${ }^{5}$ Incorporation of the 5,6dihydroxyhexyl group was confirmed by ${ }^{29} \mathrm{Si}$ and ${ }^{13} \mathrm{C} \mathrm{CP}$ - and DP-MAS NMR spectroscopy (see below) and the surface coverage was measured to be $43 \%(2.1 \mathrm{mmol} / \mathrm{g})$.

Figure 5-3 shows the ${ }^{13} \mathrm{C}$ and ${ }^{29} \mathrm{Si}$ spectra acquired for Thiol-MSN, DH-MSN and PLA-MSN samples. The carbon chemical shifts $\delta_{C}$ corresponding to thiol, DH, and PLA functional groups are listed in Table 5-1, while Table 5-2 includes the chemical shifts $\delta_{S i}$ of $\mathrm{T}^{\mathrm{n}}$ and $\mathrm{Q}^{\mathrm{n}}$ silicone groups. In addition, Table 5-2 shows the relative concentrations of silicon groups, molecular formulae, and molar concentrations of organic functionalities obtained from the ${ }^{29} \mathrm{Si}$ DPMAS measurements. The ${ }^{13} \mathrm{C}$ NMR results demonstrated that the functionalization of mesopores was accomplished as intended. Only relatively small amounts of secondary and/or unreacted species were detected, as discussed below. The spectra were processed, deconvoluted and integrated using SpinSight NMR software by Varian/Chemagnetics. The observed resonances were assigned based on chemical shifts found in the liquid state spectra of the analogous compounds. Thus, the ${ }^{13} \mathrm{C}$ peaks at around 11 and $27 \mathrm{ppm}$ in thiol-MSN (Figure 5-3a) were assigned to carbons $\mathrm{C} 1$ and the superposition of $\mathrm{C} 2$ and $\mathrm{C} 3$, respectively, in the thiol functional group. ${ }^{4}$ Small quantities of two additional species were also detected in this sample. The resonance at around $50 \mathrm{ppm}$ was assigned to methoxy groups $\equiv \mathrm{SiOCH}_{3},{ }^{4}$ while the two resonances at 23 and $42 \mathrm{ppm}$ could represent the $\mathrm{C} 2$ and $\mathrm{C} 3$ carbons in disulfide functionality $\left(=\mathrm{SiCH}_{2} \mathrm{CH}_{2} \mathrm{CH}_{2} \mathrm{~S}\right)_{2}{ }^{5}$ 
The $\mathrm{C} 1$ carbon in disulfide yielded a peak at around $11 \mathrm{ppm}$, which overlapped with $\mathrm{C} 1 \mathrm{in}$ thiol. In the ${ }^{13} \mathrm{C}$ spectrum of DH-MSN (Figure 5-3a) the resonances representing thiol and disulfide functionalities were found in approximately $2: 1$ ratio. Five additional resonances were identified at around $72,69,55,36$, and $30 \mathrm{ppm}$. The peaks at $72,69,36$, and $30 \mathrm{ppm}$ represent carbons $\mathrm{C} 5, \mathrm{C} 6, \mathrm{C} 4$, and $\mathrm{C} 3$ of $\mathrm{DH}$ functionality. The resonances from $\mathrm{C} 1$ and $\mathrm{C} 2$ carbons of $\mathrm{DH}$, expected at positions around $23(\mathrm{C} 2)$ and $10(\mathrm{C} 1) \mathrm{ppm}$, overlap with those from disulfide and thiol groups. The small resonance at 55 corresponds most likely to $\mathrm{CH}_{2}$ carbon of $=\mathrm{SiOCH}_{2} \mathrm{CH}_{3}$ group, in which case the $\mathrm{CH}_{3}$ carbon would overlap with the resonance at around $13 \mathrm{ppm}$. It is also possible, however, that the peak at $55 \mathrm{ppm}$ is due to C5 carbon in unreacted EH groups. ${ }^{6}$ Spectrum (c) of PLA-MSN exhibits all resonances found in spectra (a) and (b) along with several new peaks representing the PLA coating, as shown in the last two columns of Table 1. It is also noted that the relative concentration of CTAB in all samples was below our detection limit of approximately $3 \%$.

Table 5-1. Summary of ${ }^{13} \mathrm{C}$ CPMAS NMR data

\begin{tabular}{lcllllll}
\hline Thiol & $\delta_{0}$ & disulfide & $\delta_{:}$ & $\mathrm{DH}$ & $\delta_{\mathrm{C}}$ & $\mathrm{PLA}-\mathrm{MSN}$ & $\delta_{1}$ \\
\hline $\mathrm{Cl}$ & 11.1 & $\mathrm{Cl}$ & 11.1 & $\mathrm{Cl}$ & 12.7 & $\mathrm{CH}$ & 16.4 \\
$\mathrm{C} 2$ & 27.3 & $\mathrm{C} 2$ & 23.2 & $\mathrm{C} 2$ & 23.2 & & 17.0 \\
$\mathrm{C} 3$ & 27.3 & $\mathrm{C} 3$ & 42.4 & $\mathrm{C} 3$ & 29.7 & $\mathrm{CH}$ & 70.1 \\
& & & & $\mathrm{C} 4$ & 36.5 & & 75.9 \\
& & & & $\mathrm{C} 5$ & 71.7 & $\mathrm{CO}$ & 170.1 \\
& & & & $\mathrm{C} 6$ & 68.9 & & 171.5 \\
& & & & & & 174.7 \\
\hline
\end{tabular}

The assignments of ${ }^{29} \mathrm{Si} \mathrm{NMR,} \mathrm{which} \mathrm{are} \mathrm{also} \mathrm{shown} \mathrm{in} \mathrm{Figure} \mathrm{5-3,} \mathrm{spectra} \mathrm{(d)} \mathrm{and}$ (g), are well established in the literature. ${ }^{3,4,7}$ The following silicone groups were found: $\mathrm{T}^{2}$ (at -58 ppm), $T^{3}$ (-67 ppm), $\mathrm{Q}^{2}$ (-93 ppm), $\mathrm{Q}^{3}$ (-102 ppm), and $\mathrm{Q}^{4}(-112 \mathrm{ppm})$. 
Table 5-2. Summary of 29Si CPMAS NMR DATA

\begin{tabular}{|c|c|c|c|c|c|c|c|}
\hline & $\begin{array}{l}\text { Relutive ex } \\
l^{2} \\
\left(-5 \text { ppun }^{2}\right)\end{array}$ & $\begin{array}{l}\gamma^{3} \\
\left(-67_{p p m}\right)\end{array}$ & $\begin{array}{l}1 \text { of silicon } \\
Q^{2} \\
(-93 \text { spunj }\end{array}$ & $\begin{array}{l}\text { groups [\%] } \\
Q^{3} \\
(-102 p p m)\end{array}$ & $\begin{array}{l}Q^{f} \\
(-112 \mathrm{ppm})\end{array}$ & $\mathrm{SC}[\mathrm{O} ;]^{(0)}$ & Average molecular lormula \\
\hline Thiol-MSN & 4 & 15 & 3 & 29 & 49 & $.37(2.7)$ & $\left(\mathrm{SiO}_{2}\right)_{100}\left(\mathrm{~L}_{2} \mathrm{O}\right)_{10}\left(\mathrm{C}_{3} \mathrm{I} \cdot \mathrm{Lg}_{\mathrm{g}} \mathrm{S}\right)_{19}$ \\
\hline DIL-MSN & $\hat{3}$ & 16 & I & 24 & 56 & $43(2.1)$ & $\left(\mathrm{SiO}_{2}\right)_{100}\left(\mathrm{I}_{2} \mathrm{O}\right)_{5}\left(\mathrm{C}_{3} \mathrm{H}_{8} \mathrm{~S}+\mathrm{C}_{6} \mathrm{H}_{14} \mathrm{O}_{2}\right)_{19}$ \\
\hline PLAA-MSN & 3 & 10 & I & 24 & 56 & +3 & \\
\hline
\end{tabular}

(a) $\mathrm{SC}$ - surlace coverage valculatcd using tollowing tequations: $\mathrm{SC}=\left(\mathrm{T}^{2}+\mathrm{T}^{3}\right) /\left(\mathrm{T}^{2}+\mathrm{T}^{3}+\mathrm{Q}^{2}+\mathrm{Q}^{3}\right)$. Note that NMR dalu represent the $S C$ "s of the entire surtite. According to our $\mathrm{N}_{2}$ adsomption measurenents. the exlernil surlace areat in the studied MSN's was approximately 30\%. Thus. the surface coverdge of internat pores in Thinl-MSN is in fae $40 \%$ higher. The values in parestheses represent the anounts of organic groups in mmol/g.

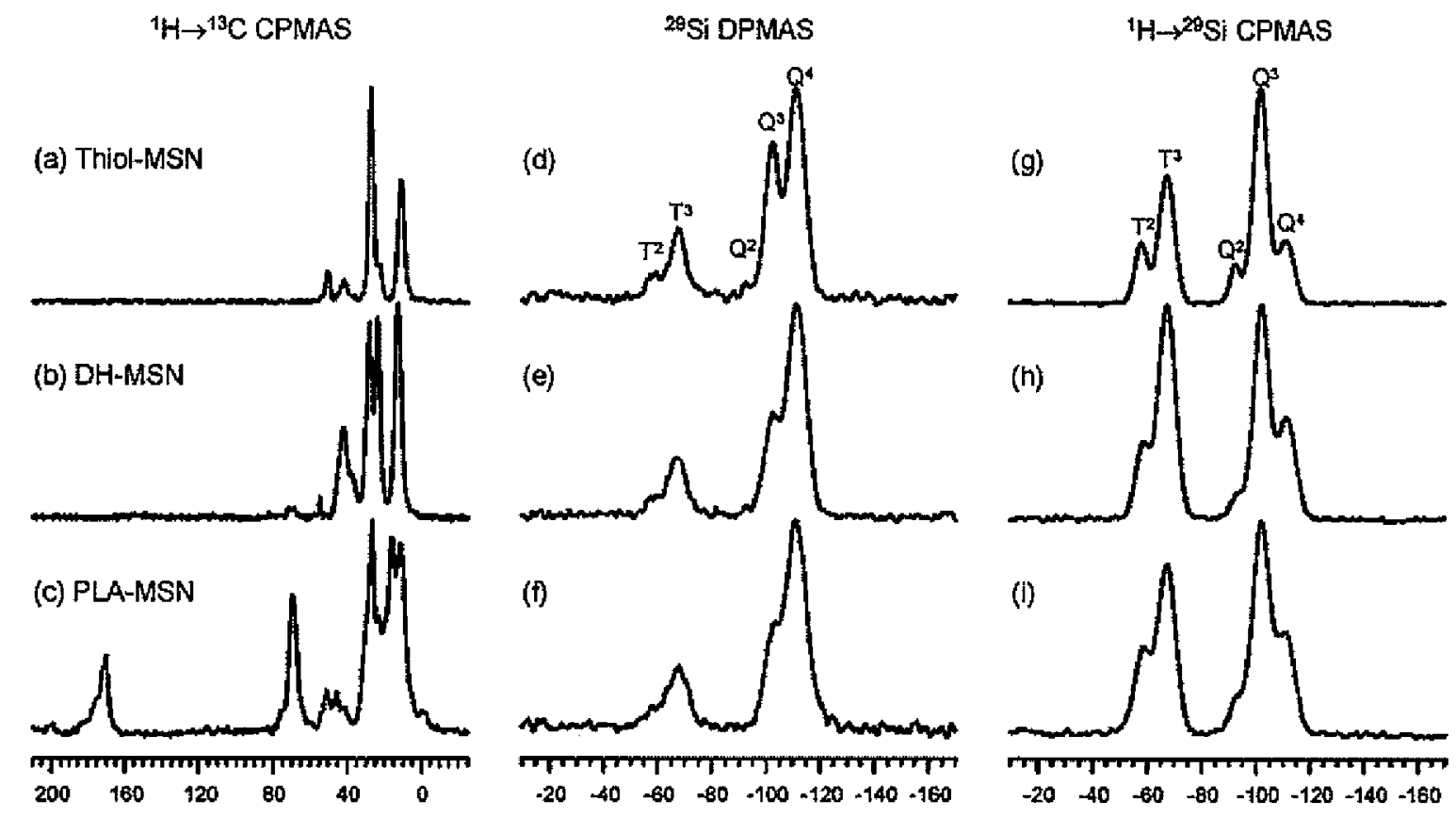

Figure 5-3. 'H $\rightarrow{ }^{13} \mathrm{C}$ CPMAS (a-c), ${ }^{29} \mathrm{Si}$ DPMAS (d-f) and ${ }^{1} \mathrm{H} \rightarrow{ }^{29} \mathrm{SiCPMAS}$ (g-i) spectra collected for ThiolMSN (a,d,g), DH-MSN (b,e,h) and PLA-MSN (c,f,i) samples. Following contact times (in ms) were used to collect the CPMAS spectra: $0.4(\mathrm{a}, \mathrm{b}), 1.5(\mathrm{c})$, and $1.0(\mathrm{~g}-\mathrm{i})$.

Surface coverage $(\mathrm{SC})$, calculated using equation: $\mathrm{SC}=\left(\mathrm{T}^{2}+\mathrm{T}^{3}\right) /\left(\mathrm{T}^{2}+\mathrm{T}^{3}+\mathrm{Q}^{2}+\mathrm{Q}^{3}\right)$, expresses amount of surface silicone atoms bonded to an organic group per total number of surface silicone atoms. Note that the ${ }^{29} \mathrm{Si}$ CPMAS spectra are not quantitative; they were 
merely used to facilitate the deconvolution of less intense resonances measured using DPMAS NMR.

The vacuum-dried DH-MSN material $(0.68 \mathrm{~g})$ was sonicated for $30 \mathrm{~min}$ in $10 \mathrm{~mL}$ of anhydrous THF to disperse the particles uniformly. L-Lactide $(0.36 \mathrm{~g}, 2.50 \mathrm{mmol})$ was mixed with a catalyst, tin(II) 2-ethylhexanoate (Sn(Oct) $)_{2}, 0.16 \mathrm{~mL}, 0.50 \mathrm{mmol}$ ), in $15 \mathrm{~mL}$ of anhydrous THF. The lactide/catalyst solution was added to the DH-MSN THF suspension via injection and stirred at $80^{\circ} \mathrm{C}$ for $72 \mathrm{~h}$ to yield the PLA-coated thiol-MSN material. The crude solid product was further purified by a method previously published by Langer's group. ${ }^{6}$ As shown in Figure 5-4, the average thickness (ca. $11 \mathrm{~nm}$ ) of the PLA layer was determined by transmission electron microscopy (TEM). The chemically accessible thiol density (0.22 mmol/g) of the purified PLA-MSN was measured by our previously published method. ${ }^{\text {ja }}$

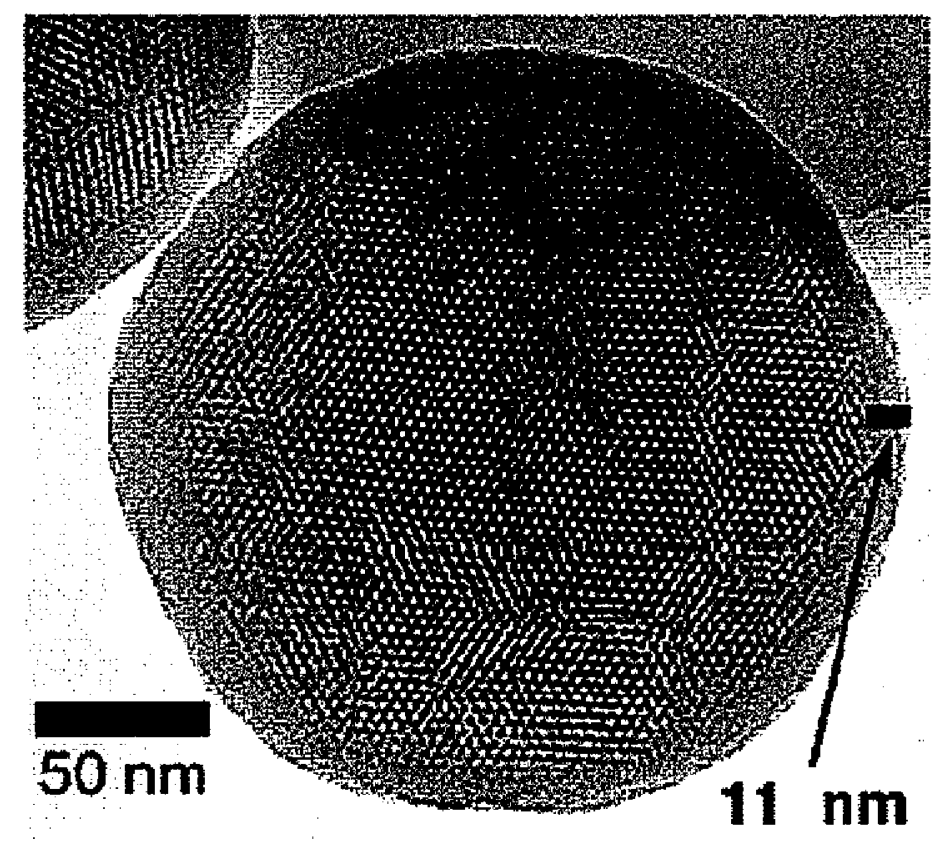

Figure 5-4. Transmission electron micrograph (TEM) of an ultramicrotomed PLA-MSN material. The layer of PLA can be visualized by the rim of amphorous structure surrounding the MCM-4l-type of MSN core with mesopores packed in a hexagonal symmetry. 
The mercaptopropyl functionality was then converted to the amine-sensitive OPTA group by reacting $85.0 \mathrm{mg}$ of PLA-coated thiol-MSN with $170.0 \mathrm{mg}(1.26 \mathrm{mmol})$ of phthalic dicarboxaldehyde (o-phthalaldehyde, OPA) in $10 \mathrm{~mL}$ of methanol solution for $5 \mathrm{~h}$. After filtration, the resulting material (PLA-MSN) was thoroughly washed with methanol and dried under vacuum. The morphology, particle size distribution, and the structure of organic functionalities of PLA-MSN were scrutinized by XRD, SEM, TEM, $\mathrm{N}_{2}$ sorption isotherms (From Figure 5-5 to 4-7).

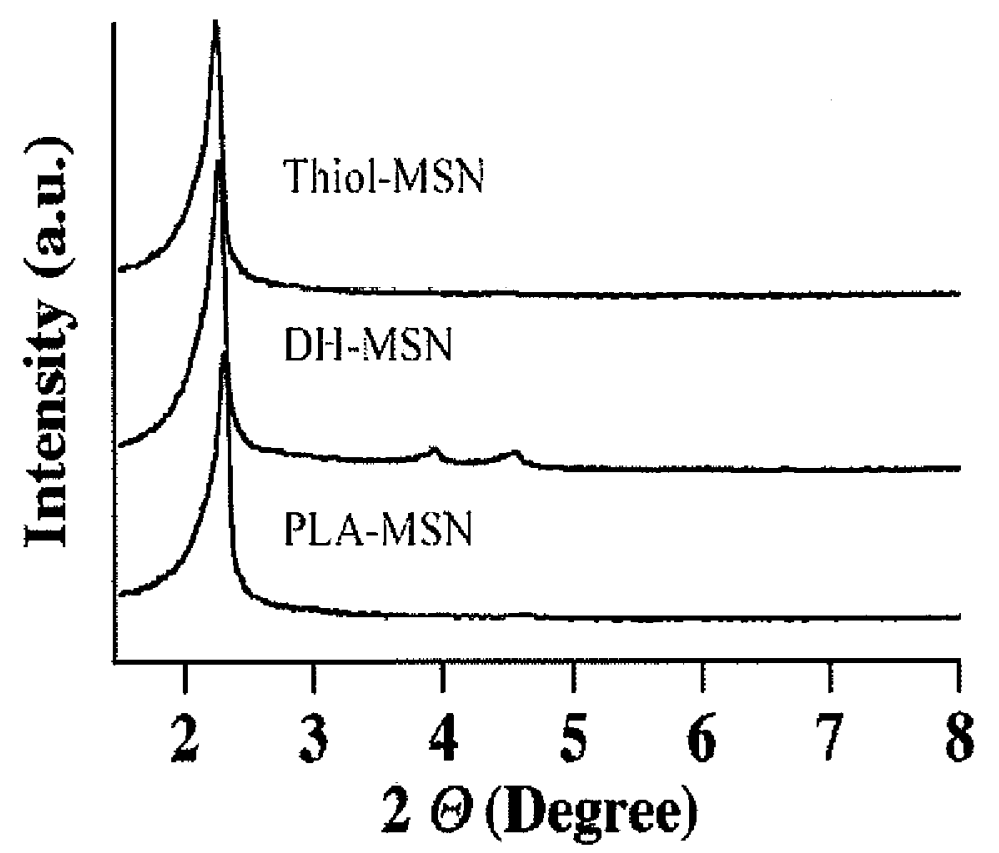

Figure 5-3. Powder X-Ray diffraction patterns of thiol-MSN, DH-MSN, and PLA-MSN. All three materials exhibit

Table 5-3. Powder X-Ray diffraction results

\begin{tabular}{llll}
\hline \multirow{2}{*}{ Sample } & \multicolumn{3}{l}{ Powder XRD Diffraction } \\
& $d_{100}(\hat{A})$ & $d_{2010}(A)$ & $d_{111}(\AA)$ \\
\hline Thiol-MSN & 20.26 & 11.50 & 10.00 \\
DII-MSN & 23.30 & 11.84 & 9.74 \\
PLA-MSN & 22.64 & 11.50 & 9.63 \\
\hline
\end{tabular}


The $\mathrm{N}_{2}$ sorption isotherms of thiol-MSN material were published in our previous papers. ${ }^{8}$ The details of nitorgen sorption analyses of the DH-MSN and PLA-MSN materials are outlined below.

Table 5-4. Nitrogen sorption isotherms.

\begin{tabular}{llll}
\hline \multirow{2}{*}{ Material } & BET & BET & B.IH \\
& Surface Area $\left(\mathrm{m}^{2} / \mathrm{g}\right)$ & Pore volume $(\mathrm{mL} / \mathrm{g})$ & Average Pore Diameter $(\AA)$ \\
\hline DH-MSN & 904.38 & 0.53 & 23.0 \\
PLA-MSN & 633.95 & 0.34 & 20.5 \\
\hline
\end{tabular}

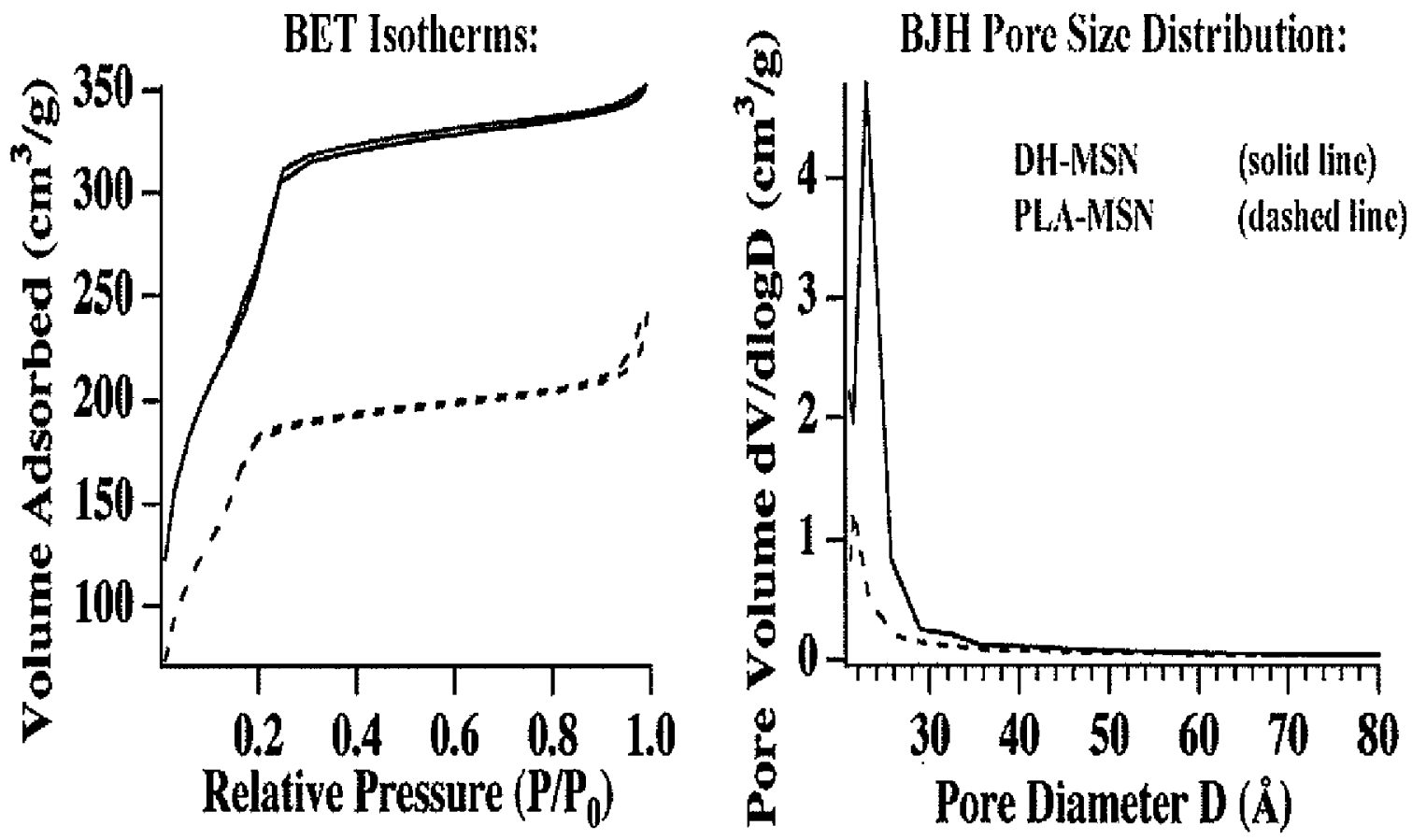

Figure 5-6. BET nitrogen adsorption/desorption isotherms and BJH pore size distributions of DH-MSN (solid line) and PLA-MSN (dashed line) materials. The BET isotherms of both DH-MSN and PLA-MSN materials didn't exhibit any hysteresis, which suggested the absence of the xerogel layer. 
(a)

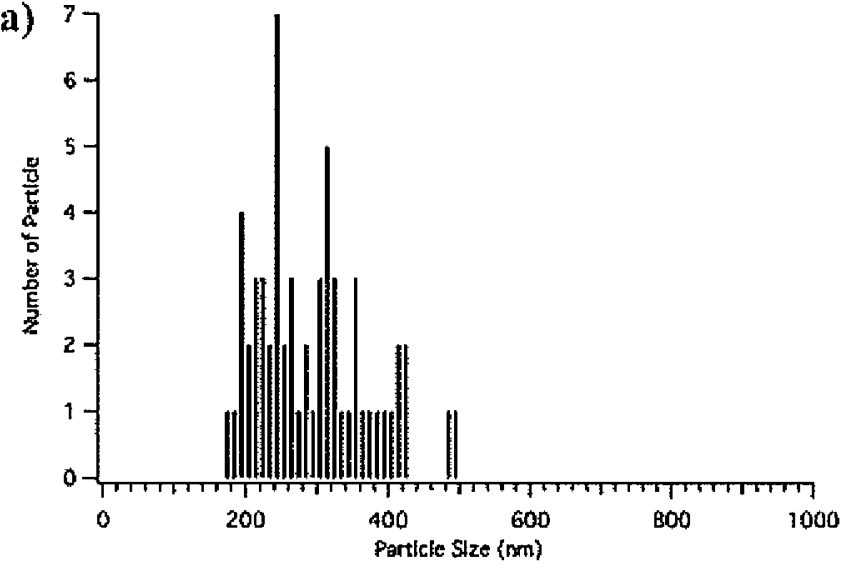

(b)

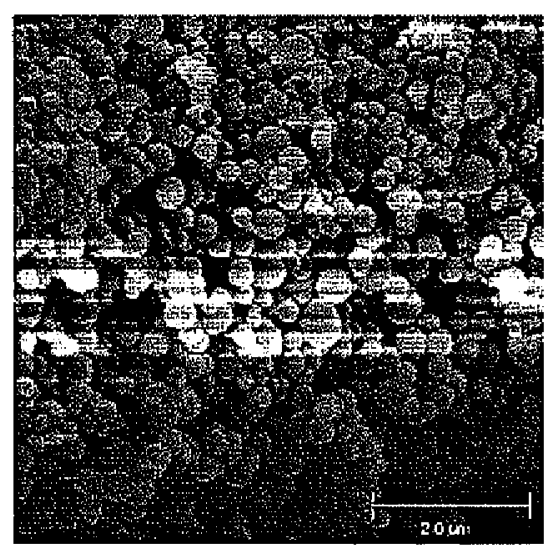

Figure 5-7. Particle size distribution (a) and scanning electron micrograph (b) of PLA-MSN. Polydispersity of PLA-MSN is approx. $160 \mathrm{~nm}$ (half width at half maximum of the particle size distribution).

To examine the gatekeeping effect of the PLA layer in our PLA-MSN system, we prepared and characterized an amorphous silica material grafted with the same OPTA functionality (OPTA-SS) as a control system. The surface coverage of the OPTA group was determined to be $0.08 \mathrm{mmol} / \mathrm{g}^{2 \mathrm{a}, 4}$ Both the OPTA-SS and our PLA-MSN materials were dispersed in $\mathrm{pH} 7.4$ PBS buffer $(10 \mathrm{mM})$ for the fluorescence-sensing experiments of neurotransmitters. In the case of OPTA-SS, dopamine, tyrosine, and glutamic acid ( $230 \mu \mathrm{M}$ each) reacted with the surface-bound OPTA groups rapidly, as evidence by the fluorescence emission data shown in Figure 5-8a. It is noteworthy that both tyrosine and glutamic acid reacted to the OPTA-SS with very similar rates and therefore could not be distinguished. In contrast, the reactions of these analytes $(230 \mu \mathrm{M})$ with our OPTA-derivatized PLA-MSN exhibited significantly different and lower reaction rates (Figure 5-8b), by a factor of 4,10 , and 57, respectively. In the case of dopamine, the lower reaction rate could be attributed to the additional diffusional penetration through the PLA layer into the OPTA-functionalized mesopores. Clearly, the reaction rates of tyrosine and glutamic acid were further slowed by 
the gatekeeping effect of the PLA layer on these two analytes. In addition, our study (Figure 5-8c) showed that the fluorescence intensity of OPTA-SS increased similarly with the increasing concentrations of all three neurotransmitters. However, in the case of the PLAMSN (Figure 5-8d), the dopamine binding gave the most significant increase of fluorescence intensities at all concentrations.

(a)

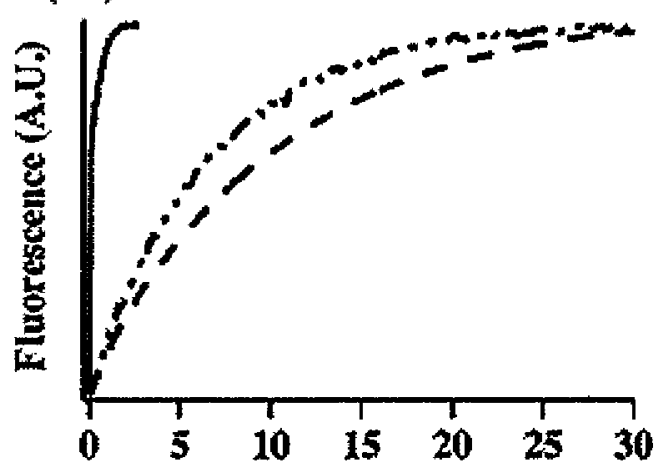

(c)

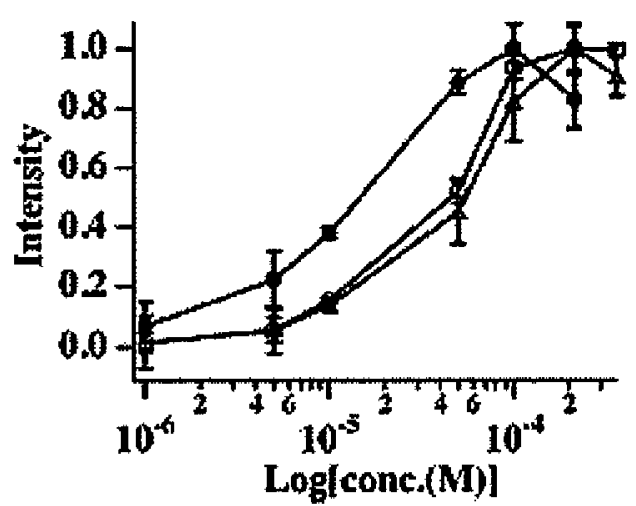

(b)
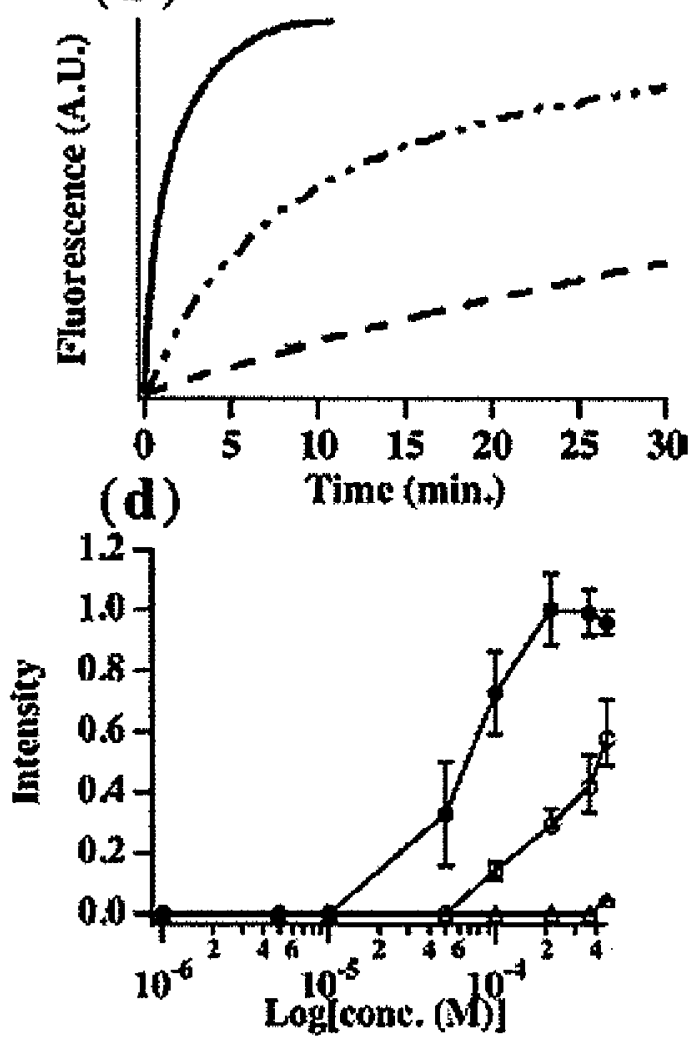

Figure 5-8. Kinetic measurements of the fluorescence detection of dopamine (s), tyrosine (- - - - - - ), and glutamic acid (- - ) with OPTA-SS (a) and PLA-MSN (b). Fluorescence increase of OPTA-SS (c) and PLAMSN (d) as a function of dopamine (b), tyrosine (O), and glutamic acid (4) concentrations. The fluorescence intensities were measured $5 \mathrm{~min}$ after the introduction of every concentration of each neurotransmitter. 
We also note that a similar set of kinetic and titration experiments performed on the DH-MSN material (without PLA) showed no evidence of the gatekeeping effect. To examine the substrate selectivity of our PLA-MSN system in the presence of a mixture of neurotransmitters, PLA-MSN nanoparticles ( $2 \mathrm{mg}$ ) were introduced to a pH 7.4 PBS buffer $(10 \mathrm{mM})$ solution of dopamine $(0.5 \mathrm{mM})$ and glutamic acid $(10 \mathrm{mM})$ at $25^{\circ} \mathrm{C}$.

After 10 min of mixing, the suspension was centrifuged, and the individual concentrations of dopamine and glutamic acid in the supernatant were analyzed by HPLC (Figure 5-9).

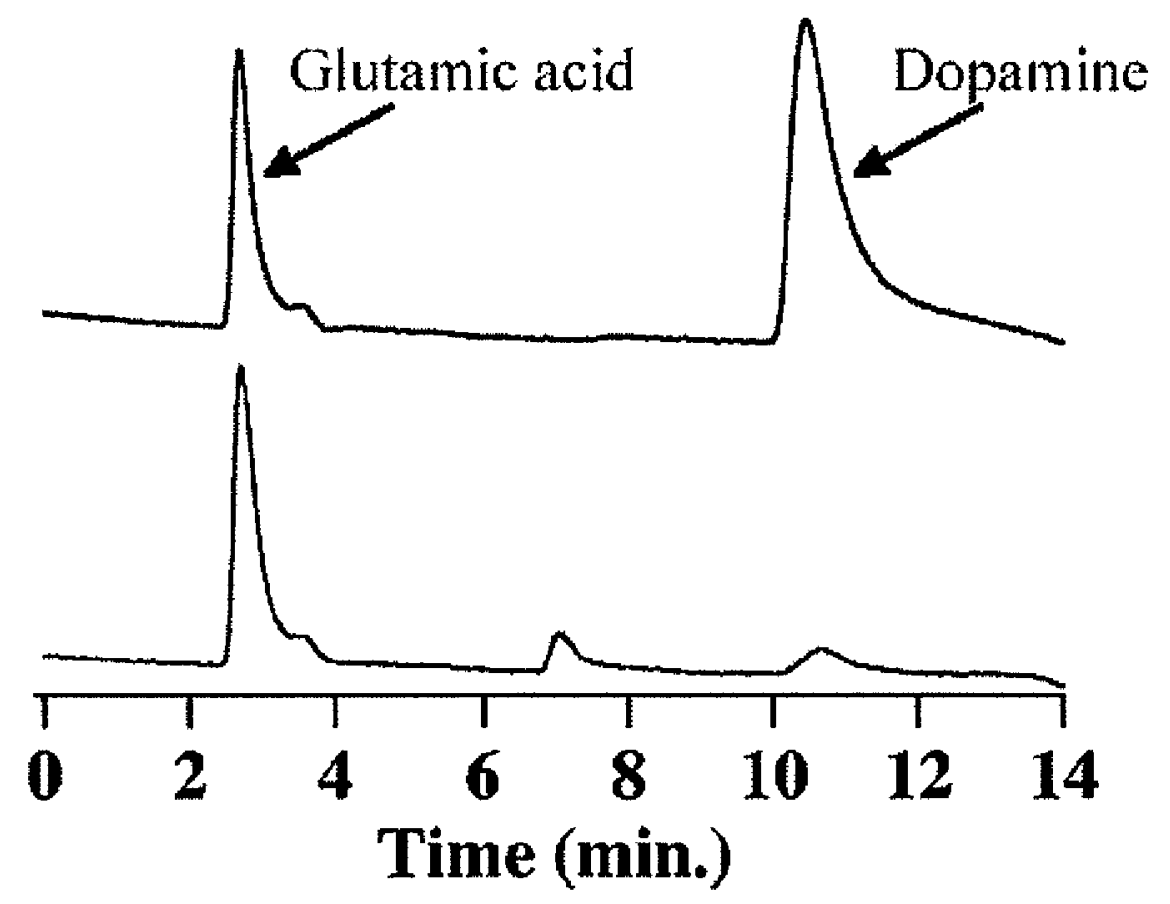

Figure 5-9. HPLC chromatographs of the solution containing dopamine $(0.5 \mathrm{mM})$ and glutamic acid $(10 \mathrm{mM})$ before (1) and after the introduction of PLA-MSN.

Given that the signal transduction mechanism of the PLA-MSN system is based on the covalent capture of substrates by the surface-bound OPTA groups, the different degrees of concentration decrease of these two analytes in solution would represent the selectivity of 
the PLA-MSN system. Despite the initial 20:1 concentration ratio between glutamic acid and dopamine, the results showed a $96 \%$ decrease of dopamine concentration, whereas only a $2 \%$ decrease of the concentration of glutamic acid was observed (Table 5-5).

Table 5-5. HPLC analysis of dopamine and glutamic acid before and after the introduction of PLA-MSN.

\begin{tabular}{|c|c|c|c|c|}
\hline & \multicolumn{2}{|c|}{ Dopamine } & \multicolumn{2}{|c|}{ Glutamic acid } \\
\hline & $\begin{array}{c}\text { Integrated Peak } \\
\text { Area }\end{array}$ & $\begin{array}{l}\text { Retention time } \\
\text { (min) }\end{array}$ & $\begin{array}{c}\text { Integrated Peak } \\
\text { Area }\end{array}$ & $\begin{array}{l}\text { Retention time } \\
\text { (min) }\end{array}$ \\
\hline $\begin{array}{l}\text { Befole } \\
\text { introduction of } \\
\text { PLA-MSN }\end{array}$ & 403270 & 10.54 & 140508 & 2.67 \\
\hline $\begin{array}{l}\text { After } 10 \text { min of } \\
\text { mixing with } \\
\text { PLA-MSN }\end{array}$ & 16499 & 10.72 & 138267 & 2.67 \\
\hline
\end{tabular}

The observed large difference in the rates of diffusion is most likely due to the different electrostatic, hydrogen bonding, and dipolar interactions between these neurotransmitters and the PLA layer in pH 7.4 buffer. The isoelectric points (pIs) of dopamine, tyrosine, and glutamic acid are 9.7, 5.7, and 3.2, respectively, whereas the pI of PLA is typically below $2.0,{ }^{7}$ which means the dopamine will be positively charged and the others will be negatively charged under our experimental conditions. Similar effects of pI have also been reported previously. ${ }^{8}$ For example, Blanco ${ }^{8}$ reported that proteins with low pI values, such as bovine serum albumin $(\mathrm{pI}=4.6)$ were released faster from a PLGA-based polymer than those with high pIs, such as lysozyme $(\mathrm{pI}=11.2)^{8 \mathrm{a}}$ 


\section{Conclusions}

We report on the synthesis and characterization of a poly-(lactic acid)-coated, MCM41-type mesoporous silica nanosphere (PLA-MSN) material as a fluorescence probe. By utilizing the PLA layer as a gatekeeper to regulate the penetration of molecules in and out of the nanoscale pores, we successfully select the molecular recognition events between several structurally simple neurotransmitters, i.e., dopamine, tyrosine, and glutamic acid and a pore surface-anchored o-phthalic hemithioacetal (OPTA) group.

\section{Acknowledgements}

This research was supported at Ames Laboratory by the U.S. DOE, office of BES, under contract W-7405-Eng-82 and by the NSF (CHE-0239570).

\section{References}

(1). Sawa, A.; Snyder, S. H. Science (Washington, DC) 2002, 296, 692 and references therein.

(2). (a) Stucky, G. D.; Zhao, D.; Yang, P.; Lukens, W.; Melosh, N.; Chmelka, B. F. Stud. Surf. Sci. Catal. 1998, 117, 1. (b) Dai, S.; Burleigh, M. C.; Shin, Y.; Morrow, C. C.; Barnes, C. E.; Xue, Z. Angew. Chem., Int. Ed. 1999, 38, 1235. (c) Stein, A.; Melde, B. J.; Schroden, R. C. AdV. Mater. (Weinheim, Ger.) 2000, 12, 1403.

(3). (a) Lin, V. S.-Y.; Lai, C.-Y.; Huang, J.; Song, S.-A.; Xu, S. J. Am. Chem. Soc. 2001, 123, 11510. (b) Simons, S. S., Jr.; Johnson, D. F. Anal. Biochem. 1978, 90, 705. 
(4). (4) Lai, C.-Y.; Trewyn, B. G.; Jeftinija, D. M.; Jeftinija, K.; Xu, S.; Jeftinija, S.; Lin, V. S.-Y. J. Am. Chem. Soc. 2003, 125, 4451.

(5). (a) Jogikalmath, G.; Stuart, J. K.; Pungor, A.; Hlady, V. Colloids Surf., A 1999, 154, 53-64. (b) Park, Y.-I.; Nagai, M. Solid State Ionics 2001, 145, 149.

(6). Choi, I. S.; Langer, R. Macromolecules 2001, 34, 5361

(7). Gomez-Lopera, S. A.; Plaza, R. C.; Delgado, A. V. J. Colloid Interface Sci. 2001, 240,40 .

(8). (a) Blanco, D.; Alonso, M. J. Eur. J. Pharm. Biopharm. 1998, 45, 285. (b) Dalmia, A.; Liu, C. C.; Savinell, R. F. J. Electroanal. Chem. 1997, 430, 205. (c) O'Brien, K. B.; Esguerra, M.; Klug, C. T.; Miller, R. F.; Bowser, M. T. Electrophoresis $\mathbf{2 0 0 3}, 24,1227$.

(9). Mora, F.; del Arco, A.; Segovia, G. J. Physiol. Biochem. 2001, 57, 97-104.

(10). (a) Yee, J. K.; Parry, D. B.; Caldwell, K. D.; Harris, J. M. Langmuir 1991, 7, 307313. (b) Millot, M. C.; Sebille, B.; Mahieu, J. P. J. Chromatogr. 1986, 354, 155167.

(11). (a) Yee, J. K.; Parry, D. B.; Caldwell, K. D.; Harris, J. M. Langmuir 1991, 7, 307313. (b) Millot, M. C.; Sebille, B.; Mahieu, J. P. J. Chromatogr. 1986, 354, $155-$ 167.

(12). (a) Pines, A.; Gibby, M. G.; Waugh, J. S. J. Chem. Phys. 1973, 59, 569-590. (b) Peersen, O. B.; Wu, X.; Kustanovich, I.; Smith, S. O. J. Magn. Reson. A 1993, $104,334-339$.

(13). Huh, S.; Wiench, J. W.; Yoo, J.-C.; Pruski, M.; Lin, V. S. Y. Chem. Mater. 2003, $15,4247-4256$ 
(14). Maciel, G. E.; Sindorf, D. W.; Bartuska, V. J. J. Chromatogr. 1981, 205, 438-443.

(15). Freeman, F.; Angeletakis, C. N. J. Org. Chem. 1982, 47, 4194-4200.

(16). Grant, D. M.; Paul, E. G. J. Am. Chem. Soc. 1964, 86, 2984-2990. 
CHAPTER 6. REAL-TIME ATP IMAGING OF TUNABLE RELEASE FROM A MCM-41TYPE MESOPOROUS SILICA NANOSPHERE-BASED DELIVERY SYSTEM

\title{
A paper submitted to Chemistry of Materials
}

Jason A. Gruenhagen, Cheng-Yu Lai, Daniela R. Radu, Victor S.-Y. Lin, and Edward S.

Yeung

Ames Laboratory-USDOE and Department of Chemistry, Iowa State University, Ames, Iowa

\begin{abstract}
We designed a mesoporous silica nanosphere (MSN) material with tunable release capability for drug delivery applications. Adenosine 5-triphosphate (ATP) molecules were encapsulated within the MSNs by immersing dry nanospheres in aqueous solutions of ATP followed by capping of the mesopores with chemically removable caps, such as CdS nanoparticles and poly(amido amine) dendrimers (PAMAM), via a disulfide linkage. We employed luciferase chemiluminescence imaging to investigate the kinetics and mechanism of the ATP release with various disulfide-reducing agents as uncapping triggers. By varying the chemical nature of the "cap" and "trigger" molecules in our MSN system, we discovered that the release profiles could indeed be regulated in a controllable fashion.
\end{abstract}

\section{Introduction}

Nanomaterials ${ }^{1}$ research has attracted much attention recently for their potential applications in electronics, ${ }^{2-4}$ electro-optics, ${ }^{5}$ biosensors, ${ }^{6-8}$ etc. One particularly interesting 
application is the development of novel nanomaterials-based drug delivery systems. Traditionally, responsive polymer systems have been employed in such devices. ${ }^{9,10}$ For example, degradable polymers are synthesized in the presence of the drug molecule of interest. ${ }^{11}$ The resulting polymer/drug composite materials usually exhibit slow rates of drug release under normal conditions. Upon stimulation, the degradation of polymer matrix is accelerated, and the release of drug molecules is thereby enhanced. Drug delivery polymers that are responsive toward several types of stimulants, such as temperature, $\mathrm{pH}$, and magnetic/electric field, have been reported in the literature. ${ }^{12-15}$

In addition to polymer-based drug delivery systems, the organically functionalized MCM-type mesoporous silica materials ${ }^{16,17}$ offer several attractive features, such as stable mesoporous structures, large surface areas, tunable pore sizes and volumes, and well-defined surface properties, that are ideal for encapsulation of pharmaceutical drugs, ${ }^{18-21}$ proteins, ${ }^{22-26}$ and other biogenic molecules. ${ }^{27}$ We have recently reported the synthesis and characterization of a unique drug delivery system, which is based on a mesoporous silica nanosphere (MSN) material and surface-derivatized CdS nanocrystals. ${ }^{27}$ In contrast to many current polymerbased delivery systems, the molecules of interest were encapsulated inside the porous framework of the MSN not by adsorption or sol-gel types of entrapment, but by covalently capping the openings of the mesoporous channels with size-defined CdS nanocrystals to physically block the drugs from leaching out. Drug molecules loaded into the pores were released by the addition of disulfide bond-reducing molecules as "uncapping triggers". The rate of release was controlled by the concentration of the trigger molecules. Prior to uncapping, the CdS-capped MSN system exhibited negligible release of drug molecules. The "zero release" feature along with the ability to tune the rate of release by varying stimulant 
concentrations are important prerequisites for developing delivery systems for many sitespecific applications, such as delivery of highly toxic anti-tumor drugs, hormones, and neurotransmitters to certain cell types and tissues. To investigate the release mechanism and kinetics, we monitored the dithiothreitol- (DTT) and mercaptoethanol- (ME) triggered release of ATP and vancomycin from the CdS-capped MSN system utilizing high performance liquid chromatography (HPLC). ${ }^{27}$ While successful, HPLC was only sensitive for detecting drug release on the hour timescale, which cannot provide the detailed temporal profile of release.

To gain further insight on how the release mechanism and kinetics can be fine tuned by the chemical nature of the "cap" and "trigger" molecules in our MSN system, we report herein on the synthesis and characterization of a new adenosine triphosphate (ATP) loaded MSN material capped with poly(amido amine) dendrimers (PAMAM). ${ }^{28-30}$ As depicted in Scheme 6-1, a highly sensitive method of ATP chemiluminescence imaging was used to monitor the release of ATP from MSN materials capped with PAMAM dendrimers or CdS nanoparticles that are triggered by three different disulfide reducing agents, i.e., DTT, ME, and tris(2-carboxyethyl)phosphine (TCEP) ${ }_{2}^{31}$ in real time. The imaging method was based on our previously reported luminescence imaging assay by detecting the ATP-induced chemiluminescence of luciferase in situ. ${ }^{32}$ Through use of an intensified charge-coupled device (iCCD) camera attached to a microscope, real-time imaging of release of ATP from glial cells with a detection limit of $10^{-8} \mathrm{M}$ was achieved. ${ }^{33}$ By using this highly sensitive and selective imaging method, we investigated the effects of the aforementioned uncapping triggers in regulating the magnitudes and kinetics of ATP release from the two MSN materials capped with CdS nanoparticles and PAMAM dendrimers.

\section{Materials and Methods}




\section{Chemicals}

Firefly luciferase (from Photinus pyralis) was obtained from R \& D Systems (Minneapolis, MN). All other chemicals were from Aldrich (Milwaukee, WI) and Sigma (St. Louis, MO) and used as received. Low ionic strength HEPES buffer contained $10 \mathrm{mM}$ 4-(2hydroxyethyl)-1-piperazineethanesulfonic acid (HEPES), $5 \mathrm{mM} \mathrm{KCl}$, and $5 \mathrm{mM} \mathrm{NaCl}(\mathrm{pH}=$ 7.75). Chemiluminescence imaging solution was comprised of low ionic strength HEPES buffer with $100 \mu \mathrm{g} / \mathrm{mL}$ firefly luciferase and $205 \mu \mathrm{M}$ D-luciferin. Nanopure water (18.1 $\mathrm{MHz}$ ) prepared from a Barnstead E-pure water purification system was employed throughout. PBS buffer (10 mM, pH 7.4) solutions with the total ionic strength of $0.06 \mathrm{M}$ were prepared and used as the solvent for all the loading experiments.

\section{Loading of ATP into the mesoporous framework of linker-MSN and the capping} of the mesopores with mercaptoacetic acid-functionalized CdS nanoparticles 2-(Propyldisulfanyl)ethylamine-functionalized MSN (linker-MSN) and mercaptoacetic acid-derivatized cadmium sulfide (CdS) nanoparticles were synthesized and purified as described previously. ${ }^{27}$ The purified linker-MSN material (100 mg) was incubated in a $10 \mathrm{mM}$ PBS buffer $(0.60 \mathrm{~mL}, \mathrm{pH} 7.4)$ solution of ATP $(5 \mathrm{mM})$ for $24 \mathrm{~h}$. The mercaptoacetic acid-functionalized CdS nanoparticles $(0.15 \mathrm{mmol})$ were dissolved in $2 \mathrm{~mL}$ of the aforementioned PBS buffer with ATP (5 mM). 1-[3-(Dimethylamino)propyl]-3ethylcarbodiimide hydrochloride (EDC, $57.5 \mathrm{mg}, 0.30 \mathrm{mmol}$ ) was added to the CdS/ATP solution. The resulting solution of CdS was then added to the MSN/ATP suspension. The reaction mixture was stirred at room temperature for $24 \mathrm{~h}$. The suspension was centrifuged at $12000 \mathrm{rpm}$ for $3 \mathrm{~min}$. The precipitates (ATP-loaded, CdS-capped MSNs) were isolated and 
dried under vacuum. Previous to each ATP imaging experiment, ATP-loaded MSN (10 mg) was redispersed in $1.5 \mathrm{~mL}$ of PBS buffer ( $\mathrm{pH}$ 7.4), followed by repeating wash/sonication/centrifugation cycles for five times to remove physisorbed ATP molecules from the exterior surface of the material.

\section{Loading of ATP into the mesoporous framework of linker-MSN and the capping of the mesopores with G2.5 or G4.5 PAMAM dendrimer}

The purified linker-MSN material (100 mg) was incubated in the aforementioned PBS buffer solution ( $0.7 \mathrm{~mL}, \mathrm{pH} 7.4$ ) of ATP ( $5 \mathrm{mM}$ ) for $24 \mathrm{~h}$. The G2.5 and G4.5 PAMAM dendrimers were purchased from Aldrich as $10 \%$ and $5 \% \mathrm{w} / \mathrm{w}$ methanol solutions, respectively. In a typical experiment, $2 \mathrm{~mL}$ of G2.5 or G4.5 PAMAM dendrimer-containing methanol solution was first evaporated, followed by the addition of $2 \mathrm{~mL}$ of PBS buffer containing EDC (30 $\mathrm{mg}, 0.16 \mathrm{mmol})$ to re-dissolve and activate the PAMAM dendrimers. The resulting PAMAM solution was then added to the MSN with ATP (5mM) suspension. The reaction mixture was stirred at room temperature for $24 \mathrm{~h}$. The resulting precipitates (ATP- loaded, G2.5 or G4.5-capped MSNs) were isolated and purified via the same washing procedures described above.

\section{Scanning and transmission electron microscopy}

Particle morphology of these materials was determined by scanning electron microscopy (SEM) using a JEOL 840A scanning electron microscope with $10 \mathrm{kV}$ accelerating voltage and $0.005 \mathrm{nA}$ of beam current for imaging. For transmission electron microscopy (TEM) studies, a small aliquot of ATP-loaded MSN was placed between two clean glass slides. Slides were rubbed back and forth to break up larger clumps. The resulting

powder was washed into a Petri dish with acetone. The mixture was stirred and ultrasonically 
agitated. While still in suspension, a lacey carbon-coated TEM grid was pulled through the suspension. The grid was allowed to dry in air and then examined in an Amray 1845 FE-SEM followed by examination with a Philips model CM-30 TEM operated at $300 \mathrm{kV}$ with 69000 to 340000 electron optical magnification. The specimen was given no further treatment, as it appeared stable under beam bombardment.

\section{ATP imaging}

ATP imaging was performed on the stage of an inverted microscope (Axiovert 100 TV, Zeiss, Germany). Chemiluminescence signal was collected with a Zeiss Apochromat 20X microscope objective $(\mathrm{NA}=0.75)$ and detected with an $\mathrm{iCCD}(\mathrm{EEV} 576 \times 384$ pixels CCD chip, Roper Scientific, Trenton, NJ) attached to the camera mount of the microscope. Nanosphere bulk samples were incubated in imaging solution for at least four hours prior to conducting experiments. The nanospheres were centrifuged down and the supernatant was replaced with fresh imaging solution. Images were collected at a frequency of $0.80 \mathrm{~Hz}$ with $1000 \mathrm{~ms}$ exposure times. All experiments were performed at room temperature.

\section{Data presentation/analysis}

Chemiluminescence signal was obtained and processed with Winview32 software (Roper Scientific). The number of pixels over a threshold value was tabulated for each particle and each frame of data. The ATP concentrations were calculated from a calibration curve obtained with the identical imaging parameters. Displayed images are the average of 50 frames for clarity. 


\section{Results and Discussion}

Characteristics of end-capped mesoporous silica nanospheres. The synthesis and characterization of ATP-loaded, CdS-capped MSN material (CdS-MSN) were described in our previous report. ${ }^{27}$ (see Scheme 6-1).

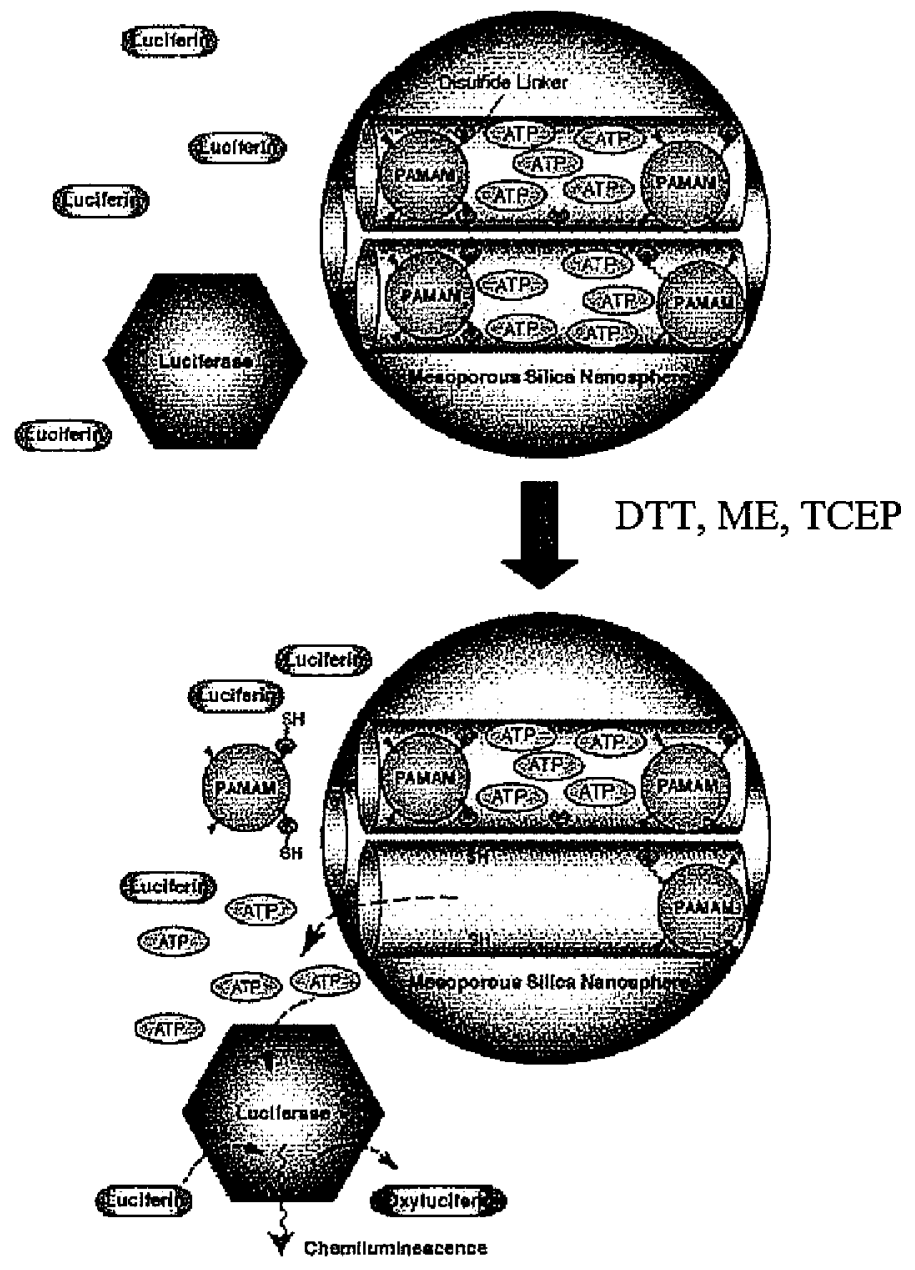

Scheme 6-1.

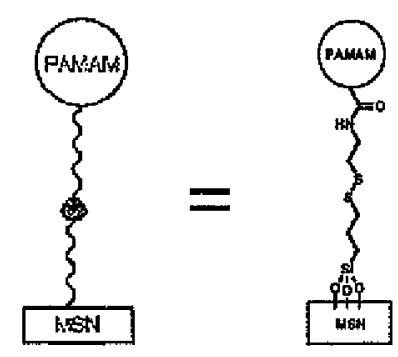


As shown in Figure 6-1A, the G4.5 PAMAM dendrimer-capped MSN (PAMAMMSN) material consists of spherical-shaped nanoparticles with an average particle diameter of $200 \mathrm{~nm}$.
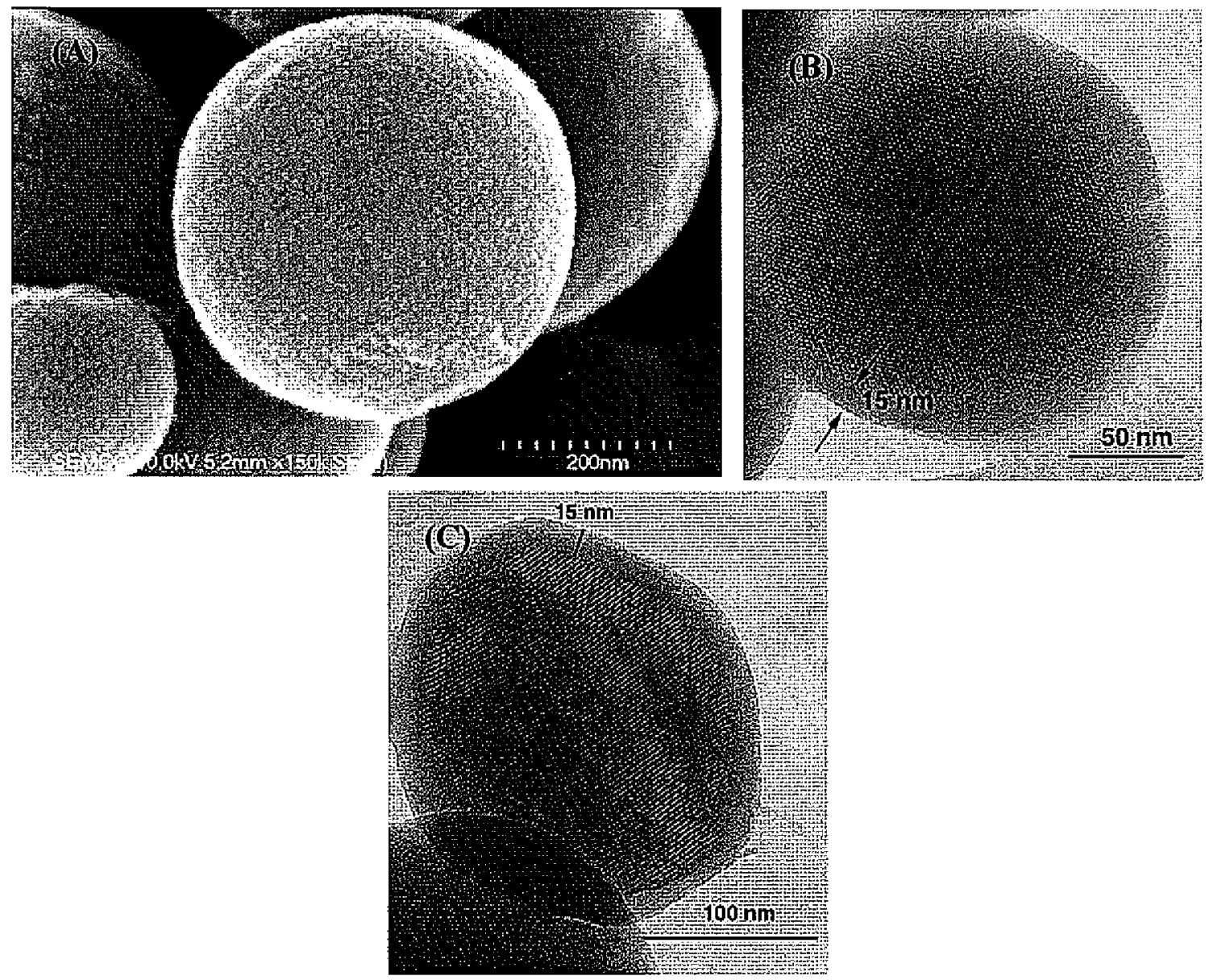

Figure 6-1. SEM $(A)$ and TEM $(B, C)$ micrographs of PAMAM dendrimer-capped MSN. The channel structure is revealed as the hexagonally packed dots shown in $\mathrm{B}$. The lines traversing the entire particle in $\mathrm{C}$ are the pores, as viewed perpendicular to the pore axis. Also visible is the PAMAM dendrimer coating along the entire perimeter of the particle. 
The MCM-41 type of mesoporous channel structure of the PAMAM-MSN was visualized with the linear pores $(2.3 \mathrm{~nm}$ in diameter) traversing their entire length and the hexagonally array of mesopores shown in the transmission electron micrographs (Figure 1B and C). An even layer of G4.5 dendrimers coated on the exterior surface of MSN material was clearly observed in the TEM micrographs (Figure 6-1B and 6-1C). As shown in Figure 6-2, the presence of the PAMAM dendrimers and ATP molecules in our MSN delivery system was also confirmed by the solid state CP- and DP-MAS ${ }^{13} \mathrm{C},{ }^{31} \mathrm{P}$, and ${ }^{29} \mathrm{Si}$ NMR spectroscopy described in our prior reports. ${ }^{27,34-37}$
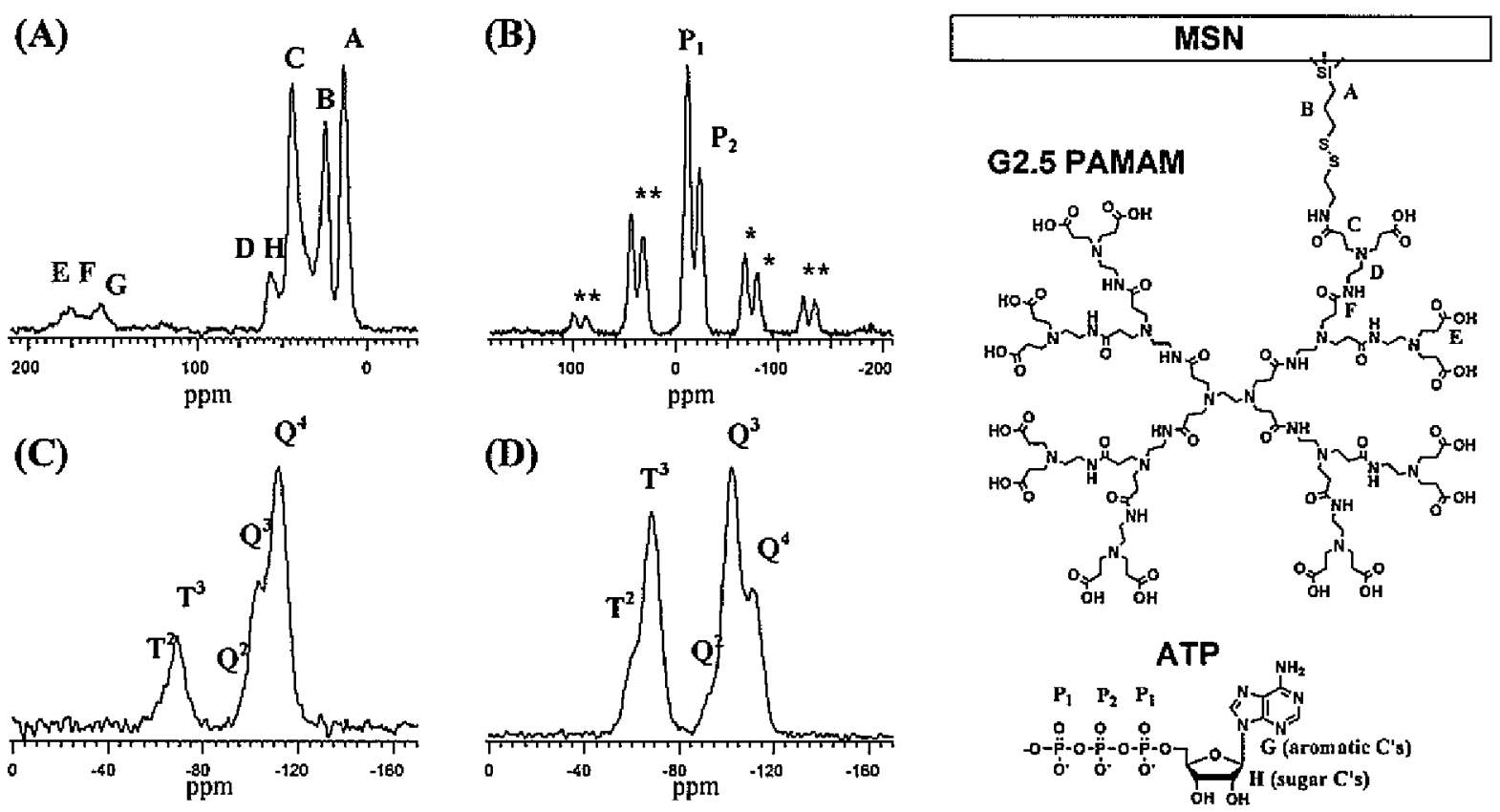

Figure 6-2. Solid state ${ }^{13} \mathrm{C}$ CPMAS (A), ${ }^{31} \mathrm{P}$ CPMAS (B), ${ }^{29} \mathrm{Si}$ DPMAS (C), and ${ }^{29} \mathrm{Si}$ CPMAS (D) spectra of ATP-loaded MSN material capped with G2.5 PAMAM dendrimers. ${ }^{29}$ Si CPMAS spectrum was acquired by using $1 \mathrm{~ms}$ contact time. * are spinning side bands.

Chemiluminescent imaging of ATP release was chosen for the following reasons: (1) The method is extremely sensitive since luciferase has a luminescence efficiency of $0.88 .^{38}$ 
(2) The reaction kinetics of luciferase catalyzed ATP chemiluminescence are exceedingly rapid. ${ }^{39}$ (3) The luciferase enzyme employed in ATP imaging measures approximately $5.5 \times$ $6.5 \times 8.1 \mathrm{~nm}$ in size $\mathrm{s}^{40}$ and therefore cannot enter the uncapped pores of the nanospheres. This ensures that any detected chemiluminescence must result from release of ATP from the MSNs. (4) There is no interference from the fluorescent MSNs.

Compatibility of ATP imaging and the MSN-based drug delivery system. Though detection of ATP via firefly luciferase-catalyzed chemiluminescence is highly specific for ATP, experiments were conducted to ensure that the uncapping molecules did not interfere with the detection scheme. Excessive concentrations of these agents could diminish the activity of firefly luciferase.

As depicted in Figure 6-3A, the chemiluminescence from injection of a 66 nM ATP standard was four times lower for luciferase containing $500 \mu \mathrm{M} \mathrm{ME}$ than for luciferase without ME. In our previous report, ${ }^{27} 1 \mathrm{mM} \mathrm{ME}$ was employed to remove the CdS caps from their nanospheres. Thus, it was not a suitable uncapping agent for use with our detection scheme.

As illustrated in Figure 3A, addition of $10 \mathrm{mM}$ DTT to luciferase imaging solution also caused a significant reduction in chemiluminescence from injected ATP standards. In this case, however, the reduction in signal was only by a factor of 2 . Previous experiments demonstrated that DTT concentrations of $0.1-10 \mathrm{mM}$ were effective in uncapping the CdScapped nanospheres. ${ }^{27}$ Therefore, further experiments were conducted to determine if lower concentrations of DTT also interfered with detection of ATP. In Figure 6-3B, DTT concentrations of $20 \mathrm{mM}, 10 \mathrm{mM}$, and $5 \mathrm{mM}$ showed progressively less interference with the detection of ATP chemiluminescence. Finally, I mM DTT did not interfere with our 
detection scheme significantly. Thus, DTT was employed as the uncapping agent in our initial experiments.

Based on work by Whitesides and coworkers, ${ }^{31}$ TCEP is a biocompatible disulfide bond-cleaving molecule and is widely used in cell cultures. Thus, we also examined the effect of TCEP as an uncapping trigger. As shown in Figure 6-3A, 5 mM TCEP did not cause any significant interference with the detection of injected ATP standards. Since only $100 \mu \mathrm{M}$ TCEP was necessary to induce significant uncapping of the nanospheres, ${ }^{27}$ this compound was applicable for our experiments.
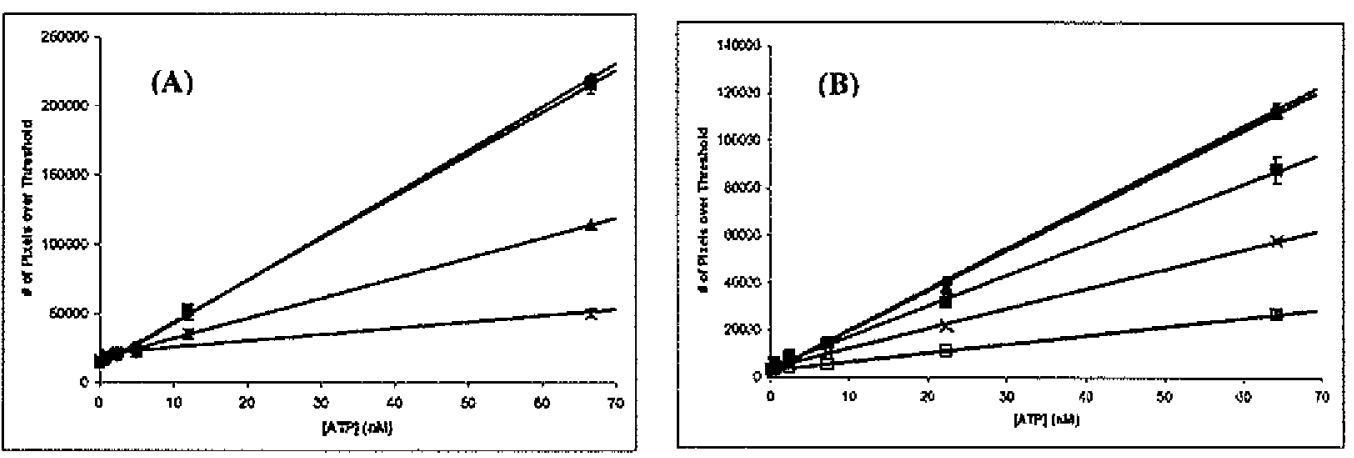

Figure 6-3. Effect of disulfide-cleaving molecules on chemiluminescence signal. Chemiluminescence signal from ATP standards was collected as detailed in the experimental section. (A) ATP standards were injected into imaging solution containing $5 \mathrm{mM} \operatorname{TCEP}(v), 10 \mathrm{mM}$ DTT $(\sigma), 1 \mathrm{mM} \mathrm{ME}(\mathbf{X})$, and imaging solution only $(\lambda)$. (B) ATP standards were injected into imaging solution containing DTT concentrations of $20 \mathrm{mM}(\square), 10 \mathrm{mM}$ $(\mathrm{X}), 5 \mathrm{mM}(v), 1 \mathrm{mM}(\sigma)$, and $0 \mathrm{mM}(\lambda)$.

In Figure 6-3A, the control experiment (no uncapping agent present) provides a calibration curve for the detection of ATP from luciferase-catalyzed chemiluminescence. The limit of detection was calculated to be $0.5 \mathrm{nM}$ ATP, and the signal was linear over two orders of magnitude (0.5-66 nM ATP; $\left.\mathrm{R}^{2}=0.9997\right)$. 
Detection of release of encapsulated ATP from CdS-MSN. Prior to the release experiments, the MSN particles were first thoroughly rinsed with a high ionic strength buffer to remove most of the physisorbed ATP. The nanospheres were then bathed in the imaging solution containing luciferase for $4 \mathrm{~h}$, where the remaining physisorbed ATP was broken down enzymatically into ADP and inorganic phosphate.

Prior to uncapping with DTT, the purified MSN generated no significant ATP release. In contrast, upon addition of $10 \mathrm{mM}$ DTT, significant levels of ATP were released from the MSNs. Figure 6-4A depicts nine frames of chemiluminescence data obtained from a representative experiment. The optical image shows an aggregate of MSNs in the lower right region. The maximal ATP release was observed $129 \mathrm{~s}$ after stimulation, as illustrated in the signal profile in Figure 6-4B.

(A)

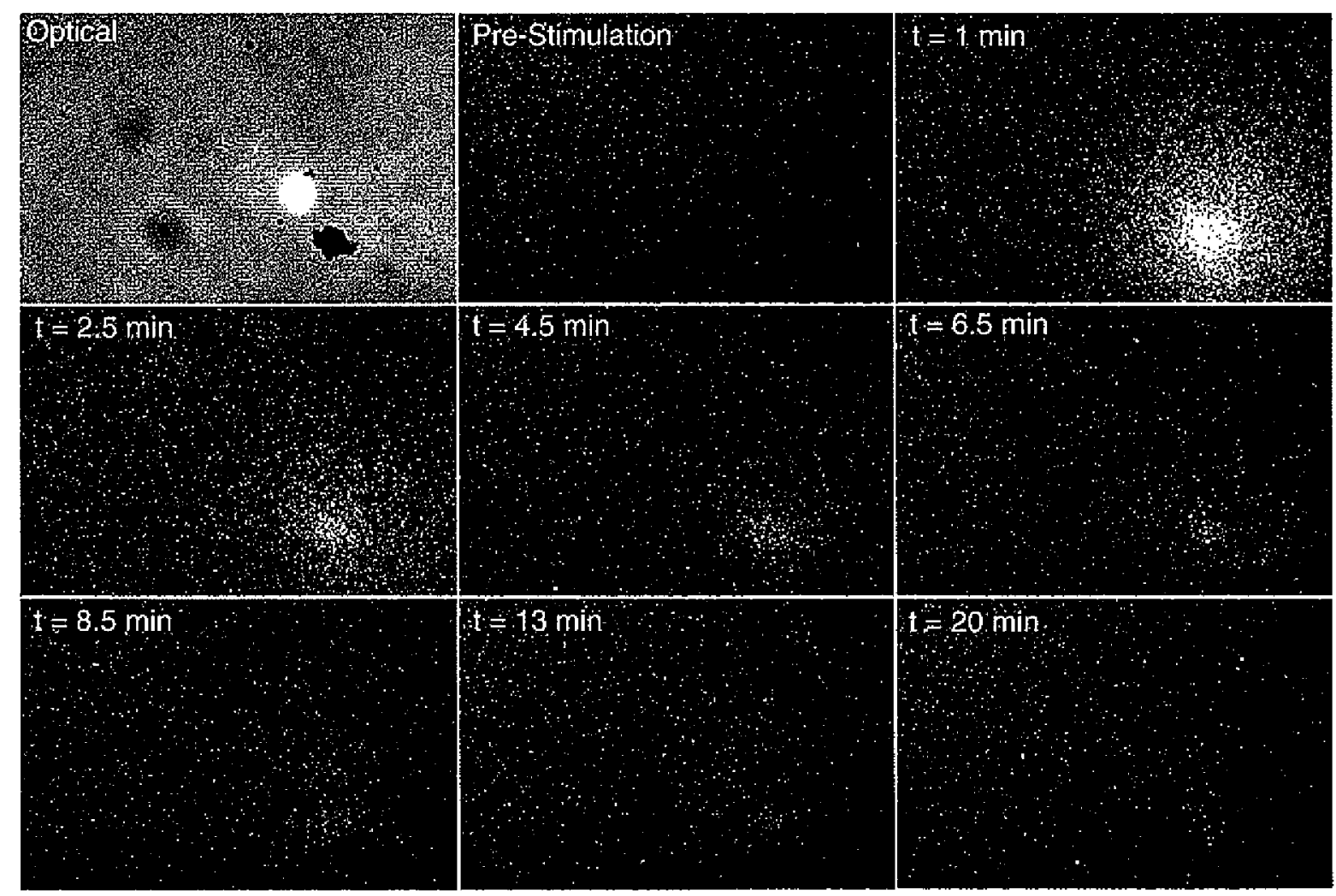


(B)

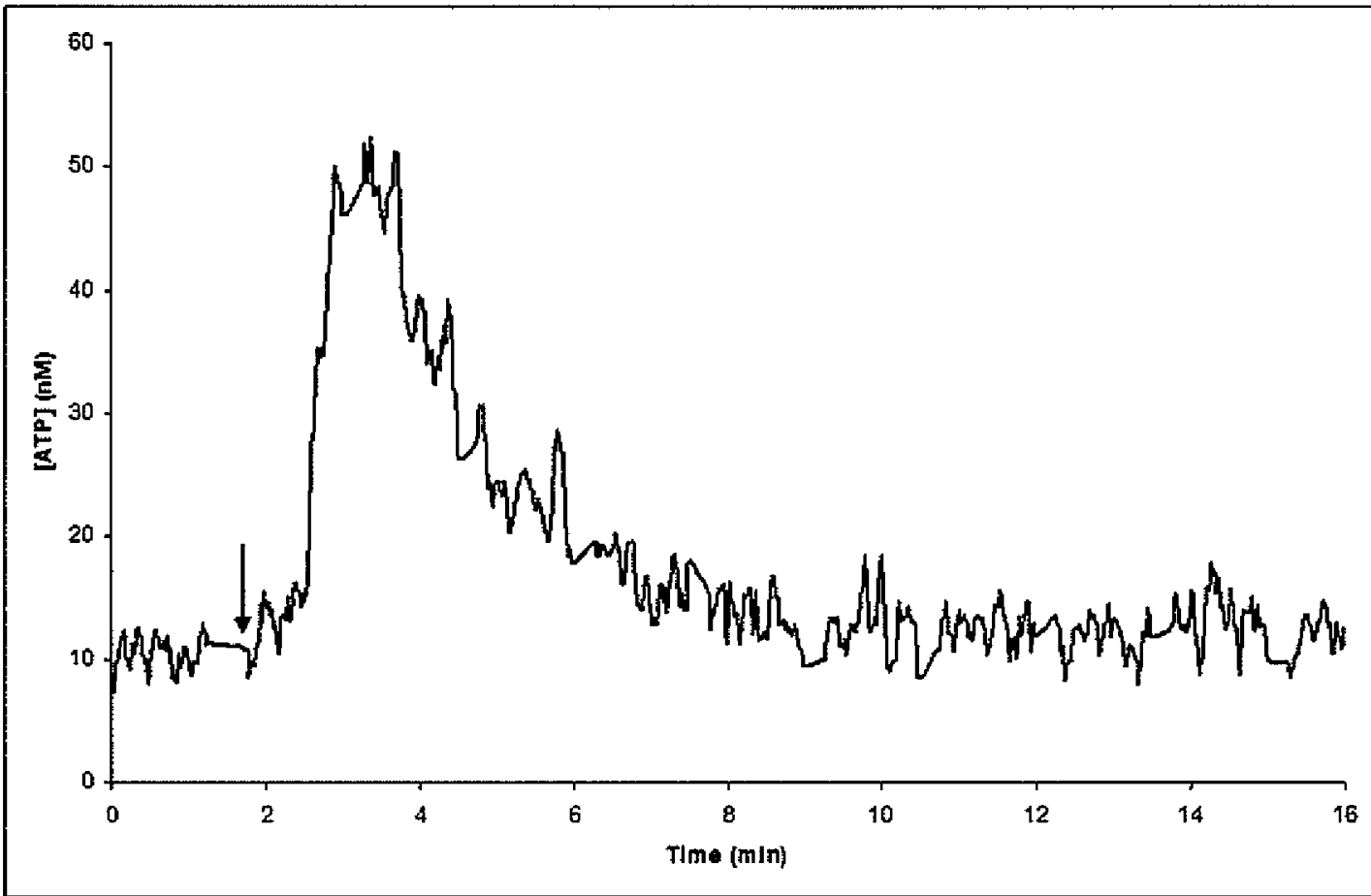

Figure 6-4. Release of encapsulated ATP from MCM-type mesoporous nanospheres. Chemiluminescence signal from ATP release was collected as detailed in the experimental section. (A) 1st frame-optical image of CdScapped MCM-type mesoporous nanosphere aggregate. Other frames-chemiluminescence images depicting release of encapsulated ATP from the nanospheres stimulated with $5 \mathrm{mM}$ DTT. (B) Time course for release of ATP from (A). Arrow indicates point of stimulation.

The magnitude of the ATP signal rose quickly in an initial burst and then quickly decreased again. The rate of signal decline slowed greatly approximately 3-4 min after stimulation, and the magnitude of release approached pre-stimulation levels 8-10 min after stimulation.

As previously observed via HPLC, the majority of the ATP which is released is detected in the first hour after stimulation with DTT ${ }^{27}$ The results here suggest that in fact the majority of release occurs in the first few min after uncapping. The initial peak in the 
signal likely represents release of a pool of free ATP near the opening of the pores. Additionally, the release following the initial burst $(3-10 \mathrm{~min})$ is likely associated with diffusion of free ATP from the center of the particle through the pores to the extracellular solution. Finally, the very low-level release detected previously over a period of days would correspond to release of physisorbed ATP from within the pores. Given that the mesopore surface was functionalized with 2-(propyldisulfanyl)ethylamine groups, the electrostatic adsorption of ATP within the pores would be expected. The combined data obtained by HPLC and ATP chemiluminescence imaging describe the complete release profile for the MSNs. The results further illustrate how these two methods complement one another.

Comparison of uncapping of MSNs by DTT and TCEP. As TCEP was the most compatible reducing agent for use with our detection system, it was also utilized for uncapping ATP-loaded CdS-MSNs. Surprisingly, the amount of ATP released was attenuated while the temporal maximum of release was extended compared to stimulation of identical MSN material with DTT, as illustrated in Table 6-1. These results indicate that TCEP cannot cleave the disulfides bonds securing the CdS caps to the MSNs as quickly as can DTT. Several explanations can be proposed for this phenomenon. First and foremost, since the reducing power of DTT is greater than that of TCEP ${ }^{31}$ the rate of disulfide cleavage for the linkers is likely slower for TCEP than DTT. Thus the rate of CdS nanocrystal release and subsequent ATP release would be delayed. Another possible explanation of this phenomenon is the charge of TCEP. The CdS nanocrystals are derivatized with carboxylic acid moieties and are thus negatively charged across their entire surface. TCEP is also negatively charged while DTT is neutral in charge in the imaging solution. Therefore, DTT can more easily diffuse into the nanosphere structure to reach and cleave the disulfide linkers. Finally, since 
TCEP is larger than DTT, its diffusion through the CdS nanocrystal caps could be sterically hindered. The actual basis for the attenuated release of ATP in the case of TCEP stimulation likely is a combination of the above. Further investigation of the stimulant diffusion and reaction kinetics would be necessary to pinpoint the reason.

\section{Effect of DTT concentration on release of encapsulated ATP from CdS-MSN.}

We examined the effect of varying the concentration of uncapping agent on the magnitude of ATP release. DTT concentrations from $5 \mu \mathrm{M}$ to $5 \mathrm{mM}$ were added to CdS-MSNs. The $5 \mathrm{mM}$ DTT was employed to ensure complete uncapping of the nanospheres, though it decreased the luminescence efficiency as demonstrated above. This was compensated for by employing the calibration curve for imaging solution containing $5 \mathrm{mM}$ DTT to determine the ATP concentration. As depicted in Figure 6-5, the magnitude of ATP release varied with DTT concentration. $5 \mathrm{mM} \mathrm{DTT}$ induced release of $32.9 \pm 1.6 \mathrm{nM}$ ATP compared to only $8.0 \pm 2.9$ nM ATP for $5 \mu \mathrm{M}$ DTT.

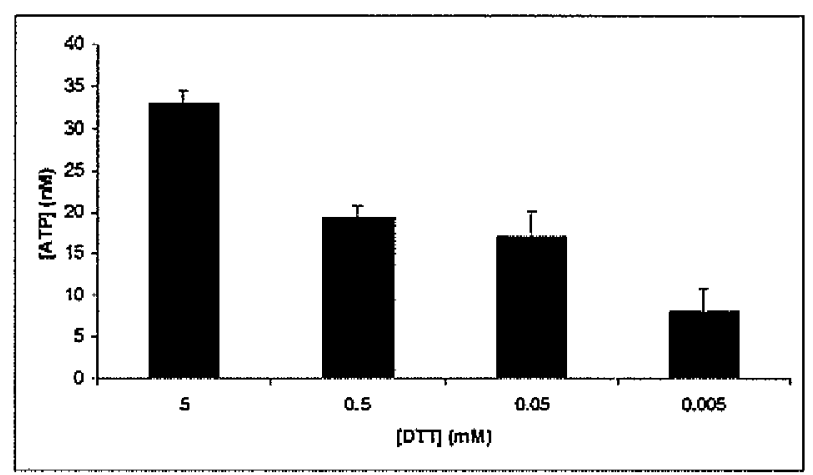

Figure 6-5. Effect of uncapping agent concentration on the magnitude of release of encapsulated ATP from MCM-type mesoporous nanospheres. Chemiluminescence signal from ATP release was collected as detailed in the experimental section. 
Thus the lower concentrations of DTT were unable to completely uncap all of the MSN pores or, at least, were unable to uncap all of the pores simultaneously. These results corroborate those obtained previously with HPLC. ${ }^{27}$

Release of ATP from PAMAM-MSN. To investigate the influence of different capping moieties on the release kinetics, the release of ATP from MSNs capped with PAMAM dendrimers was also studied. Two types of PAMAM dendrimers (generations 2.5 and 4.5) have been successfully attached to cap the pores of the linker-functionalized MSN. When stimulated with $5 \mathrm{mM}$ DTT, release of ATP was detected from both types of PAMAM-MSNs. The release profiles are displayed in Figure 6-6 for generation 2.5 and generation 4.5 PAMAM-MSNs. These release profiles were smoothed by averaging the release for all 50 frames of each imaging file.

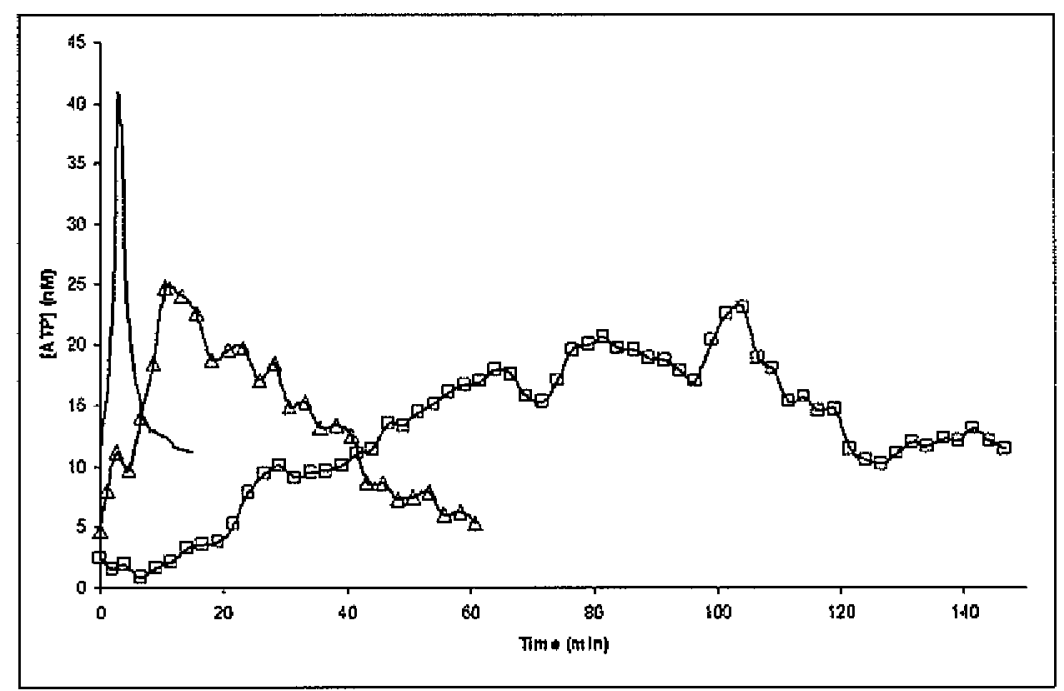

Figure 6-6. Release of encapsulated ATP from dendrimer-capped MCM-41-type mesoporous nanospheres. Chemiluminescence signal from ATP release was collected as detailed in the experimental section. Plots depict release stimulated with $5 \mathrm{mM}$ DTT at time $=2 \min$ for generation 2.5 PAMAM dendrimer-capped particles $(\square)$, generation 4.5 PAMAM dendrimer-capped particles $(\Delta)$ and CdS nanocrystal-capped particles (solid line). 
Also depicted in Figure 6-6 is the release profile previously shown in Figure 6-4B for DTT stimulation. For comparison purposes, this profile was processed identically to those for dendrimer-MSNs.

Table 6-1. Characteristics of release of encapsulated ATP from CdS-capped MCM-type mesoporous nanospheres for various reducing agents.

\begin{tabular}{ccc}
\hline Uncapping Agent & Release Maximum $(\min )$ & Release Maximum (nM ATP) \\
\hline $5 \mathrm{mM}$ DTT & $1.8 \pm 0.8$ & $32.1 \pm 9.8$ \\
$5 \mathrm{mM}$ TCEP & $8.0 \pm 2.3$ & $4.5 \pm 0.8$ \\
\hline
\end{tabular}

Upon stimulation with DTT, the generation 2.5 PAMAM-MSN showed no immediate release of ATP. Only after 20-30 min was a small amount of release observed from the nanospheres. This ATP release slowly increased to a maximum approximately $1.5 \mathrm{~h}$ after stimulation and slowly decreased back towards baseline levels. For nanospheres with generation 4.5 dendrimer caps, release occurred more quickly. ATP signal began 5 min after the addition of DTT, and maximum release was observed $11 \mathrm{~min}$ after stimulation. For both types of dendrimer-capped nanospheres, the maximum amount of release was smaller and the time required was longer than those of CdS-MSNs.

Apparently, the PAMAM dendrimer caps are more flexible than the CdS nanocrystal caps. After forming one link to the nanosphere, it is possible that a dendrimer can flex slightly and form additional bonds to the opening of the MSN pore. The CdS nanocrystals, on other hand, are solid particles and perhaps lack flexibility and therefore may form fewer bonds to the nanosphere. Hence, in the case of PAMAM-MSN, more disulfide bonds would need to be broken in order to release the dendrimer caps upon stimulation. Additionally, with 
more bonds formed, the dendrimer caps would be held tighter to the nanosphere allowing less room for the reducing agents to diffuse into the pores to reach the disulfide linkers. In fact, the generation 2.5 PAMAM is smaller in size than the $2.3 \mathrm{~nm}$ diameter pores of the MSN. Therefore, these dendrimers could diffuse into and bind inside the pores. Thus, each pore could be bound by more than one generation 2.5 dendrimer capping molecule. This would decrease the rate of capped ATP release significantly, as was observed in our experiments.

Upon further examination of Figure 6, it appears that the total released ATP from the PAMAM-MSN is actually greater than that of the CdS-MSN. As observed via TEM images in an earlier report, ${ }^{27}$ the capping efficiency for CdS nanocrystals is only $57 \%$. In contrast, the dendrimer-capped particles have a capping efficiency of nearly $100 \%$. This indicates that though the nanospheres were loaded with the same concentration of ATP, the dendrimercapped particles contain more ATP than the CdS-capped particles. Thus, more ATP is present to be released upon introduction of DTT.

\section{Conclusions}

Real-time imaging of ATP release via luciferase-catalyzed chemiluminescence is a highly sensitive and selective method. We applied this imaging technique to the study of ATP release from mesoporous silica nanospheres end-capped with CdS nanocrystals and PAMAM dendrimers. The kinetics revealed a pulse-type release from CdS-capped particles upon uncapping. In contrast, the dendrimer-capped nanospheres exhibited release of ATP in a more gradual and plateau-like profile. Understanding the release mechanisms and release kinetics of these systems will aid in the development of more advanced particle designs. By varying the capping molecules as well as the uncapping triggers, we envision that the release profile 
of a drug of interest can be fine-tuned depending on whether a high concentration, one-time drug release or a lower level, continuous drug release treatment is desired.

\section{Acknowledgments}

The authors would like to thank Dr. M. Pruski and Dr. J. W. Wiench for their help in solid state NMR measurements, and Brian G. Trewyn for assistance in sample preparation and helpful discussions. V.S.-Y. L. thanks NSF (CHE-0239570) for support. E.S.Y. thanks the Robert Allen Wright Endowment for Excellence for support. The Ames Laboratory is operated for the U.S. Department of Energy by Iowa State University under Contract No. W7405-Eng-82. This work was supported by the Director of Science, Office of Basic Energy Sciences, Division of Chemical Sciences.

\section{References}

(1) Wilson, M.; Kannangara, K.; Smith, G.; Simmons, M.; Raguse, B. Nanotechnology: Basic Science and Emerging Technologies; Chapman and Hall/CRC: Boca Raton, FL, 2002.

(2) Macucci, M.; Iannaccone, G.; Greer, J.; Martorell, J.; Sprung, D. W. L.; Schenk, A.; Yakimenko, I. I.; Berggren, K.-F.; Stokbro, K.; Gippilus, N. Nanotechnology 2001, 12, 136.

(3) Dai, L. In Perspectives of Fullerene Nanotechnology; Osawa, E., Ed.; Kluwer Academic Publishers: Dordrecht, Netherlands, 2002. 
(4) Allan, G.; Delerue, C.; Krzeminski, C.; Lannoo, M. In Nanostructured Materials;

Knauth, P., Schoonman, J., Eds.; Kluwer Academic Publishers: Norwell, MA, 2002, 161.

(5) Krenn, J. R. Nature Mater. 2003, 2, 210.

(6) Cullum, B. M.; Vo-Dinh, T. Biomedical Photonics Handwork; CRC Press LLC: Boca Raton, FL, 2003.

(7) Lin, V. S. Y.; Lai, C.-Y.; Huang, J.; Song, S.-A.; Xu, S. J. Am. Chem. Soc. 2001, 123, 11510.

(8) Livage, J.; Coradin, T.; Roux, C. J. Phys.: Condensed Matter 2001, 13, R673.

(9) Uhrich, K. E.; Cannizzaro, S. M.; Langer, R. S.; Shakesheff, K. M. Chem. Rev. (Washington, D. C.) 1999, 99, 3181.

(10) Langer, R. Acc. Chem. Res. 1993, 26, 537.

(11) Li, Y.; Kissel, T. J. Controlled Release 1993, 27, 247.

(12) Peppas, N. A.; Huang, Y.; Torres-Lugo, M.; Ward, J. H.; Zhang, J. Annu. Rev. Biomed. Eng. 2000, 2, 9 .

(13) Kost, J.; Langer, R. Adv. Drug Delivery Rev. 2001, 46, 125.

(14) Ishihara, K.; Kobayashi, M.; Ishimaru, N.; Shonohara, I. Polym. J. 1984, 16, 625.

(15) Fischel-Ghodsian, F.; Brown, L.; Mathiowitz, E.; Brandenburg, D.; Langer, R. Proc. Natl. Acad. Sci. U.S.A. 1988, 85, 2403.

(16) Stein, A.; Melde, B. J.; Schroden, R. C. Adv. Mater. (Weinheim, Germany) 2000, 12, 1403.

(17) Sayari, A.; Hamoudi, S. Chem. Mater. 2001, 13, 3151. 
(18) Vallet-Regi, M.; Ramila, A.; del Real, R. P.; Perez-Pariente, J. Chem. Mater. 2001, 13,308 .

(19) Munoz, B.; Ramila, A.; Perez-Pariente, J.; Diaz, I.; Vallet-Regi, M. Chem. Mater. $2003,15,50$.

(20) Ramila, A.; Munoz, B.; Perez-Pariente, J.; Vallet-Regi, M. J. Sol.-Gel Sci. Technol. 2003, 26, 1199.

(21) Mal, N. K.; Fujiwara, M.; Tanaka, Y.; Taguchi, T.; Matsukata, M. Chem. Mater. 2003, 15, 3385 .

(22) Diaz, J. F.; Balkus, K. J., Jr. J. Mol. Catal. B: Enzymatic 1996, 2, 115.

(23) Han, Y.-J.; Stucky, G. D.; Butler, A. J. Am. Chem. Soc. 1999, 121, 9897.

(24) Kisler, J. M.; Stevens, G. W.; O'Connor, A. J. Mater. Phys. Mech. 2001, 4, 89.

(25) Yiu, H. H. P.; Wright, P. A.; Botting, N. P. Microporous Mesoporous Mater, 2001, $44-45,763$.

(26) Takahashi, H.; Li, B.; Sasaki, T.; Miyazaki, C.; Kajino, T.; Inagaki, S. Microporous Mesoporous Mater. 2001, 44-45, 755.

(27) Lai, C.-Y.; Trewyn, B. G.; Jeftinija, D. M.; Jeftinija, K.; Xu, S.; Jeftinija, S.; Lin, V. S. Y. J. Am. Chem. Soc. 2003, 125, 4451.

(28) Tomalia, D. A.; Baker, H.; Dewald, J.; Hall, M.; Kallos, G.; Martin, S.; Roeck, J.; Ryder, J.; Smith, P. Macromolecules 1986, 19, 2466.

(29) Roberts, J. C.; Bhalgat, M. K.; Zera, R. T. J. Biomed. Mater. Res. 1996, 30, 53.

(30) Tang, M.; Redemann, C. T.; Szoka, F. C., Jr. Bioconjugate Chem. 1996, 7, 703.

(31) Burns, J. A.; Butler, J. C.; Moran, J.; Whitesides, G. M. J. Org. Chem. 1991, 56, 2648. 
(32) Gould, S. J.; Subramani, S. Anal. Biochem. 1988, 175, 5.

(33) Wang, Z.; Haydon, P. G.; Yeung, E. S. Anal. Chem. 2000, 72, 2001.

(34) Huh, S.; Chen, H.-T.; Wiench, J. W.; Pruski, M.; Lin, V. S. Y. J. Am. Chem. Soc. 2004, 126, 1010 .

(35) Huh, S; Wiench, J. W.; Trewyn, B. G.; Song, S.; Pruski, M.; Lin, V. S. Y. Chem. Commun. (Cambridge) 2003, 2364.

(36) Huh, S.; Wiench, J. W.; Yoo, J.-C.; Pruski, M.; Lin, V. S. Y. Chem. Mater. 2003, 15, 4247.

(37) Radu, D. R.; Lai, C.-Y.; Wiench, J. W.; Pruski, M.; Lin, V. S. Y. J. Am. Chem. Soc. 2004, 126,1640 .

(38) Chiu, N. H. L.; Christopoulos, T. K. Clin. Chem. 1999, 45, 1954.

(39) McElroy, W. D.; DeLuca, M. Bioluminescence and Chemiluminescence: Basic Chemistry and Analytical Applications; Academic Press: New York, 1981.

(40) Conti, E.; Franks, N. P.; Brick, P. Structure 1996, 4, 287. 


\title{
CHAPTER 7. INTRACELLULAR MESOPOROUS SIICA NANOSPHERE-BASED CONTROLLED RELEASE DELIVERY DEVICE
}

\author{
A paper to be submitted to Nature Biotechnology
}

\author{
Cheng-Yu Lai, Daniela R. Radu and Victor S.-Y. Lin
}

Department of Chemistry, Iowa State University, Ames, Iowa

\begin{abstract}
Silica mesoporous nanomaterials have been utilized in various applications. For applying these materials in biology, they have to fulfill several prerequisites: a) narrow size distribution within a safe size-range defined from $100 \mathrm{~nm}$ to $1 \mu \mathrm{m}$ for biocompatibility reasons; b) versatility in exterior particle surface modifications for receptor targeting purposes or simply for improving particles biocompatibility; c) high chemical and thermal stabilities for increased feasibility. We are reporting on a intracellular delivery nano-vehicle that successfully responded to all these prerequisites and further proved pluripotency in biological applications. In the present work, the mesoporous silica nanospheres (MSNs) have been utilized for: drug delivery by encapsulating Doxorubicin inside the mesopores and controlled release of the drug in HeLa cancer cells and for transfection of different types of cells such as cancer cell lines: HeLa human cervical cancer and CHO Chinese hamster ovarian cells as well as primary cells such as neurons and glia.
\end{abstract}




\section{Introduction}

The developing of systems for investigation/intervention in cellular phenomena implies downsizing the components of the system to match the size of the cellular components. In the present work, we developed a nanocomposite Mesoporous Silica Nanosphere (MSN)-based system that is functioning as a cellular vehicle endowed with the ability of carrying exogenous molecules in the cytosol. The research performed in developing built-in delivery properties for pharmaceutical drugs is still relying on specialized synthesis for each particular group of molecules. Consequently, the development of delivery systems is as important as the development of the drugs. Several types of polymers were employed to perform the intracellular delivery task. Often, polymeric systems are too specialized on particular applications ${ }^{1}$ whereas supramolecular assemblies such as dendritic boxes are still suffering from lack of controlled release as well as limited loading capacity. In terms of silica mesoporous materials utilization, other than MSN, the application of such materials in the biological field, e.g. in drug delivery, was disappointing due to their low biocompatibility (irregular shape and size, out-ranging the biocompatible size). To respond to all prerequisites related to biotechnological applications, several modifications of mesoporous silica materials have been achieved by different research groups. ${ }^{2}$ Several organic-group modified mesoporous silica materials have been synthesized by in situ co-condensation of organosilane

precursors and a silica source, e.g. tetraethyl orthosilicate (TEOS), in the presence of a templating surfactant. However, there were no morphological improvements reported, that would allow the successful of these materials use in drug delivery. In our recently published work, ${ }^{3}$ we have been reporting morphological as well surface modifications of mesoporous

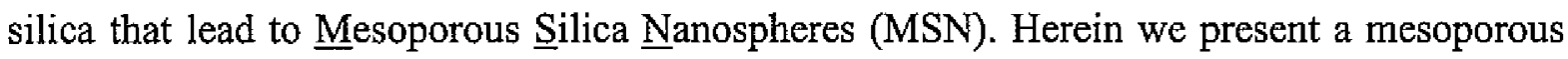


silica nanospherical device that has ability to encapsulate and controlled release to HeLa cervical cancer cells an antineoplastic antibiotic--Doxorubicin--proving an incommensurable potential in applications in drug delivery to living systems. As therapeutic methods extend their field from simple drug molecules to polymeric proteins and genes, virtually, our system, with mesopores in the range of $2-4 \mathrm{~nm},{ }^{4}$ would not have the internal capacity necessary for encapsulating the drugs. However, the engineering of the surface with functionalities that enable it to electrostatically bind these aforementioned molecules allows the system to deliver their cargo. We demonstrated that HeLa human cancer cells, $\mathrm{CHO}$ murine cancer cells, and primary cells such as astroglia can be transfected and cotransfected by using MSNs as gene carriers.

\section{Materials and Methods}

1. Materials: 3-Aminopropyltrimethoxysilane (APTES), $n$-cetyltrimethylammonium bromide (CTAB), 3-mercaptopropyltrimethoxysilane (MPTES), sodium sulfide, and tetraethoxylsilane (TEOS) were all obtained from Aldrich and used without further purification. Nanopure water $(18.1 \mathrm{MHz})$ prepared from a Barnstead E-pure water purification system was employed throughout. Fluorescein 5-isothiocyanate (FITC) and Texas Red sulfonyl chloride were purchased from Molecular Probe (Eugene, OR.).

\section{Materials Synthesis}

\subsection{Synthesis of G2 -MSN ${ }^{5}$}

$N$-(3-triethoxysilylpropyl)-4,5-dihydroimidazole was purchased from Gelest, and all other chemicals were purchased from Aldrich. All chemicals were used as received without 
further purification. The role of imidazole group is associated with the ability of weak bases to confer the buffer capacity necessary for manipulating the endosomal $\mathrm{pH}$.

Hexagonally ordered IMI-MSN was prepared by the following procedure: $N$ Cetyltrimethylammonium bromide (CTAB, $1.00 \mathrm{~g}, 2.74 \times 10^{-3} \mathrm{~mol}$ ) was dissolved in $480 \mathrm{~mL}$ of Nanopure water. $\mathrm{NaOH}(\mathrm{aq})(2.00 \mathrm{M}, 3.50 \mathrm{~mL})$ was added to CTAB solution and the solution temperature was adjusted to $353 \mathrm{~K}$. At this temperature, TEOS $\left(5.00 \mathrm{~mL}, 2.57 \times 10^{-2}\right.$ mol) was introduced dropwise to the surfactant solution, followed by the dropwise addition of $N$-(3-triethoxysilylpropyl)-4,5-dihydroimidazole $\left(0.928 \mathrm{~mL}, 5.13 \times 10^{-3} \mathrm{~mol}\right)$, both additions being performed under vigorous stirring. The mixture was allowed to stir for $2 \mathrm{~h}$ to give rise to a white precipitate: template-containing IMI-MSN. The solid product was filtered, washed with deionized water and methanol, and dried in air. To remove the surfactant template (CTAB), $1.50 \mathrm{~g}$ of as-synthesized IMI-MSN was refluxed for $24 \mathrm{~h}$ in a solution of $9.0 \mathrm{~mL}$ of $\mathrm{HCl}(37.4 \%)$ and $160.00 \mathrm{~mL}$ of methanol followed by extensive wash with deionized water and methanol. The resulting surfactant-removed IMI-MSN material was placed under high vacuum to remove the remaining solvent from the mesopores. The surfactant-free IMI-MSN material was placed under high vacuum to remove the remaining solvent from the mesopores. IMI-MSN $(1.00 \mathrm{~g})$ was refluxed for $20 \mathrm{~h}$ in $80.00 \mathrm{~mL}$ of anhydrous toluene with $0.25 \mathrm{~mL}(1.00 \mathrm{mmol})$ of 3-isocyanatopropyltriethoxysilane to yield the 3-isocyanatopropyl-functionalized MSN (ICP-MSN) material.

The purified ICP-MSN $(0.15 \mathrm{~g})$ was added to anhydrous ethanol $(3.00 \mathrm{~mL})$. A second-generation (G2) polyamidoamine dendrimer (PAMAM, $2.00 \mathrm{~mL}, 0.11 \mathrm{mmol}$ ) was then added to the ICP-MSN ethanol solution. The amino groups of the G2-PAMAM were allowed to react with the ICP functional groups present on the surface of MSN for $20 \mathrm{~h}$ at 
room temperature to yield the G2-PAMAM-capped MSN material (G2-MSN). The resulting G2-MSN material was filtered and washed thoroughly with ethanol, methanol and acetone and dried under high vacuum.

\subsection{Synthesis of dye-Incorporated MSN (F-MSN and T-MSN): ${ }^{5}$}

For synthesizing dye incorporated MSNs, fluorescein isocyanate ( $3 \mathrm{~mL}$ of $8 \mathrm{mM} \mathrm{DMF}$ solution to allow the fluorescent dye to be embedded inside the silica matrix, $2.4 \times 10^{-5} \mathrm{~mol}$, Molecular Probe) was first covalently attached to the coupling agent 3aminopropyltriethoxysilane $\left(0.9 \mathrm{~mL}, 5.1 \times 10^{-3} \mathrm{~mol}\right.$, APTES $)$ by addition of the amine group to the FTIC group in anhydrous DMF solution. For Texas-Red doped MSNs, Sulforhodamine 101 sulfonyl chloride solution ( $3 \mathrm{~mL}$ of $8 \mathrm{mM}$ DMF solution, $2.4 \times 10^{-5} \mathrm{~mol}^{\text {, Texas }} \operatorname{Red}^{\mathrm{TM}}$, Molecular Probe) was added to 3-mercaptopropyltrimethoxysilane $\left(0.97 \mathrm{~mL}, 5.13 \times 10^{-3} \mathrm{~mol}\right.$, MPTES) to allow the reaction between the mercapto group and the sulfonyl chloride and both mixtures were stirred for $4 \mathrm{~h}$ under nitrogen atmosphere. After 4 hour later, this mixture was added dropwise immediately after TEOS addition, the rest of conditions being identical with the aforementioned preparation. The resulting FTIC-MSN/Texas Red-MSN materials were filtered and washed thoroughly with ethanol, methanol and acetone and dried under high vacuum. To remove the surfactant template (CTAB), $1.50 \mathrm{~g}$ of as-synthesized FTIC-MSN or Texas Red-MSN was refluxed for $24 \mathrm{~h}$ in a solution of $9.0 \mathrm{~mL}$ of $\mathrm{HCl}(37.4 \%)$ and 160.00 $\mathrm{mL}$ of methanol followed by extensive wash with deionized water and methanol. The resulting surfactant-removed FTIC-MSN or Texas Red-MSN material was placed under high vacuum to remove the remaining solvent from the mesopores. To ensure the complete removal of FTIC or Texas Red molecules physisorbed on the surface of MSN, a Soxhlet 
extraction in ethanol was performed for $20 \mathrm{~h}$. The resulting solid was filtered and dried in air.

\section{Characterization of ICP-MSN and G2-MSN ${ }^{5}$}

\subsection{Powder X-Ray Diffraction}

Powder XRD experiments were performed on a Scintag XDS 2000 diffractometer using a $\mathrm{Cu} \mathrm{K} \alpha$ radiation source. Low angle diffraction with a $2 \theta$ range of 1 to $10^{\circ}$ was used to investigate the long-range order of the materials.

\subsection{Nitrogen adsorption/desorption isotherms}

The surface area and median pore diameter were measured using $\mathrm{N}_{2}$ adsorption/desorption measurements in a Micromeritics ASAP 2000 BET surface analyzer system. The data were evaluated using the Brunauer-Emmett-Teller (BET) and BarrettJoyner-Halenda $(\mathrm{BJH})$ methods to calculate the surface area and pore volumes/pore size distributions, respectively. Samples were prepared by degassing at $90^{\circ} \mathrm{C}$ for $1 \mathrm{~h}$ and then at $150^{\circ} \mathrm{C}$ for $4 \mathrm{~h}$.

\subsection{Solid-state ${ }^{13}$ C CP-MAS NMR}

Solid-state ${ }^{13} \mathrm{C}$ CP-MAS NMR spectra were obtained at $75.47 \mathrm{MHz}$ on a Bruker MSL300 spectrometer equipped with Bruker 4mm rotor MAS probe. Magic-angle sample spinning rate was maintained at $10 \mathrm{kHz}$ for ${ }^{13} \mathrm{C}$ in order to minimize the spin band due to the high anisotropic chemical shifts of aromatic carbons. The NMR spectra consisted of 5,000 to 20,000 acquisitions with cross polarization times of $3 \mathrm{~ms}\left({ }^{13} \mathrm{C}\right)$ and pulse repetition times of $15 \mathrm{~s}\left({ }^{13} \mathrm{C}\right)$. All chemical shifts reported are referenced to liquid $\mathrm{Me}_{4} \mathrm{Si}$ (TMS). 


\subsection{Scanning and Transmission Electron Micrographs (SEM and TEM) of G2-} MSN

Particle morphology of these materials was determined by scanning electron microscopy (SEM) with $10 \mathrm{kV}$ accelerating voltage and $0.005 \mathrm{nA}$ of beam current for imaging. For transmission electron microscopy (TEM) studies, a small aliquot was taken from a suspension of methanol and placed in a lacey carbon-coated TEM grid, which was pulled through the suspension and allowed to dry in air. Thin sections of samples embedded in epoxy resin were obtained with ultramicrotomy $(60-80 \mathrm{~nm})$. The resulting sample was examined with a Philips model CM-30 TEM operated at $300 \mathrm{kV}$. The specimen was given no further treatment, as it appeared stable under beam bombardment.

\section{Cell Growth Studies}

To further demonstrate the in vitro biocompatibility of the G2-MSN, growth studies were performed for HeLa and CHO cells. Two series of experiments were designed for both types of cells: one series studied the natural cells growth (without MSNs) and the other was monitored after MSNs application. All experiments were performed in triplicate. To ensure enough space and media for cell growing, the cells were seeded in T-25 flasks. In the experiments without MSNs, 18 flasks were loaded with the same amount of cells for each cell type. After allowing $24 \mathrm{~h}$ for cell adhesion, the cells were analyzed everyday ( 3 flasks per day) for 6 days. The cells were trypsinized and counted by using a Guava ViaCount(B) assay (Guava Technologies, Inc, USA). In the experiments with G2-MSNs, the cells were seeded for $24 \mathrm{~h}$ prior to the incubation with MSNs at $0.1 \mathrm{mg} / \mathrm{mL}$ concentration in DMEM + $10 \% \mathrm{CS}$ (calf serum) and antibiotics for $4 \mathrm{~h}$. After the $4 \mathrm{~h}$ incubation, the cells were washed 
twice with PBS buffer and incubated for another 6 days. The aforementioned cell counting procedures were followed. All experiments were performed in triplicate ( 3 flasks /day). During the 6-day growth period, the cells were periodically examined under a phase contrast microscope. The cells were added with fresh media every other day or upon $\mathrm{pH}$ fluctuations (Phenol Red dye was used as $\mathrm{pH}$ indicator). The doubling times of the cell density of HeLa cells without and with MSNs were calculated from the semilog plots to be $20 \mathrm{~h}$ and $24 \mathrm{~h}$, respectively. The doubling times of $\mathrm{CHO}$ cells without and with MSNs were calculated to be $21 \mathrm{~h}$ and $24 \mathrm{~h}$, respectively. $\left(\mathrm{R}^{2}>97 \%\right.$ in the case of HeLa cells, whereas $\mathrm{R}^{2}>97.6 \%$ for CHO cells).

\subsection{Endocytosis Mapping of Cells}

For cell mapping studies, the cells were seeded with dye doped MSNs (such as FTICMSN) at $0.1 \mathrm{mg} / \mathrm{mL}$ concentration in DMEM $+10 \% \mathrm{CS}$ (calf serum) and antibiotics for $4 \mathrm{~h}$. After the $4 \mathrm{~h}$ incubation, the cells were washed twice with PBS buffer and incubated for another $24 \mathrm{~h}$. Before imaging, the samples were washed three times with PBS buffer and fixed with formaldehyde in PBS (3.7\%). After washing again with PBS, images were captured by confocal microscope.

\section{Gene Transfection Experiments of DNA-coated G2-MSNs ${ }^{5}$ \\ 5.1 Transfection procedures}

Human cervical cancer (HeLa) and Chinese Hamster Ovarian (CHO) cell lines were obtained from American Tissue Culture Collection (ATCC). Astrocyte Cells are donated from Dr. Srdija Jeftinija at Iowa State University. HeLa and CHO cells were maintained in T75 flasks using DMEM (Dulbbecco's modified Eagle's medium) supplemented with 10\% 
calf serum, $2 \mathrm{mM} \mathrm{L}$-glutamine, $100 \mathrm{U} / \mathrm{mL}$ penicillin, $100 \mu \mathrm{g} / \mu \mathrm{L}$ streptomycin, and $1 \mu \mathrm{g} / \mu \mathrm{L}$ gentamycin. Astrocytes cells were in Eagle's minimum essential medium (EMEM) containing $10 \%$ serum. All cells were passaged when its confluence is reaching $90 \%$ of the plates. pDsRed1-N1 and pEGFP-C1 plasmids (Clontech, Palo Alto, CA) were used as reporter proteins. All plasmids were amplified in the $E$. coli strain DH5 $\alpha$ and purified according to the manufacturer's protocol (Qiagen, USA). The isolated DNA was resuspended in TrisEDTA $(\mathrm{pH} 8.0)$ at a concentration of $1 \mu \mathrm{g} / \mu \mathrm{L}$.

HeLa and CHO cells were first seeded onto 24 -well plates $\left(6 \times 10^{4}\right.$ cells per well, in $0.6 \mathrm{~mL}$ growth medium) $24 \mathrm{~h}$ prior to the experiment. Astrocytes were deposited on 24 wells $\left(7 \times 10^{4}\right.$ cells per well, in $1.0 \mathrm{~mL}$ growth medium).

In a typical transfection experiment, $1 \mu \mathrm{g}$ of each plasmid DNA encoding GFP and RFP were added to $10 \mu \mathrm{g}$ of G2-MSN suspension obtained by dispersing the nanosphere material in $30 \mu \mathrm{L}$ of HEPES buffer solution (10 mM HEPES, $\mathrm{pH} 7.4)$. The complex mixture was incubated for $2 \mathrm{~h}$ at $4{ }^{\circ} \mathrm{C}$. To further compact the DNA bound to the G2-MSN for more gene transfection efficiency and protection of the DNA from enzymatic degradation, the G2MSN were incubated with $30 \mu \mathrm{L}$ of $100 \mathrm{mM} \mathrm{CaCl}_{2}$ aqueous solution for another $2 \mathrm{~h}$. The G2-MSN/DNA suspension was further added to the cells cultured on 24-well plates and incubated for $4 \mathrm{~h}$ at $37^{\circ} \mathrm{C}$ and each well contained $0.6 \mathrm{~mL}$ DMEM (free of $\mathrm{Ca}^{2+}$ and $\mathrm{Mg}^{2+}$ ) and consequently the addition of the complex resulted in a final $\mathrm{CaCl}_{2}$ concentration of 4.5 $\mathrm{mM}$. After $4 \mathrm{~h}$, the transfection mixture was removed by washing the transfected cells with PBS buffer and cultured with DMEM supplemented with $10 \%$ calf serum (CS) and antibiotics. The cultures were maintained for 2 days to monitor gene expression. 
To compare the transfection efficiency of our G2-MSN system with other commercially available transfection reagents, three different reagents, PolyFect ${ }^{\circledR}$ and SuperFect ${ }^{(Q i a g e n, ~ V a l e n c i a, ~ C a l i f o r n i a) ~ w e r e ~ u s e d ~ t o ~ t r a n s f e c t ~ t h e ~ a f o r e m e n t i o n e d ~ c e l l ~}$ types under the same experimental condition. First, 16 and $10 \mu \mathrm{L}$ of the stock solutions of PolyFect $^{\oplus}(2 \mathrm{mg} / \mathrm{mL})$ and SuperFect ${ }^{\circledR}(3 \mathrm{mg} / \mathrm{mL})$, respectively, were added to a $60 \mu \mathrm{L}$ of serum-free medium (DMEM) containing $1 \mu \mathrm{g}$ pEGFP-Cl and $1 \mu \mathrm{g}$ pDsRed1-N1 ( 1 to 1 ratio). The solutions were incubated at room temperature for $15 \mathrm{~min}$ to allow the formation of stable complexes between DNA molecules and transfection reagents. The complexes were then added to a culture of cells in a 24 well plate with a cell density of $6 \times 10^{4}$ cells/well that contained $700 \mu \mathrm{l}$ of pre-warmed DMEM $+10 \% \mathrm{CS}$ medium and antibiotics. After $4 \mathrm{~h}$ of incubation, the transfection medium was discarded and replaced with fresh growth medium (DMEM $+10 \% \mathrm{CS}$ medium and antibiotics). The cells were evaluated for expression of the GFP and RFP by flow cytometry after $48 \mathrm{~h}$ post-transfection.

\subsection{Flow Cytometric Analysis of transfected cells ${ }^{5}$}

Flow cytometric measurements were performed immediately after collection of cultured cells. All cells were trypsinized and resuspended in $0.5 \mathrm{~mL}$ of PBS before the FACS analysis. Positive and negative control experiments utilizing cultures of untransfected cells (cells only) and "mock"-transfected cells (cells incubated with MSNs without DNA plasmid) were measured with an EPICS-ALTRA flow cytometer (Beckman Coulter, Miami, FL), using a $488 \mathrm{~nm}$ laser for GFP and RFP excitation. GFP fluorescence was detected using PMT2 in conjunction with a $525 \mathrm{~nm}$ band-pass filter and RFP fluorescence used PMT3 in conjunction with a $583 \mathrm{~nm}$ band-pass filter. An electronic gate was set around cells based on the forward and side scatter properties of the population and a minimum of 10,000 gated events per 
sample were collected and stored in list mode files. Data analysis was performed with FlowJo software (Tree Star, Ashland, OR). All experiments were performed in quadruplicate. Untransfected cells were used for background calibration. The average transfection efficiencies of different transfection reagent systems on HeLa cells were summarized on Figure 7-13 and 7-15.

\subsection{Confocal Microscopy Imaging of Trasnfected Cells ${ }^{5}$}

HeLa and CHO cells were grown on coverslips in a 24-well culture plate. All of the samples were washed three times with PBS buffer and fixed with formaldehyde in PBS (3.7 \%). After washing again with PBS, images were captured on an inverted Nikon Eclipse microscope connected to a Prairie Technologies (Middleton, WI) Scanning Laser Confocal Microscope controlled by Prairie Technologies software. Images were analyzed using Metamorph software (Universal Imaging, West Chester, PA). The samples were imaged by FTIC channel for GFP and TRIC channel for Ds-Red.

\subsection{Transmission Electron Micrographs of G2-MSN transfected Cells ${ }^{5}$}

To study the endocytosis of G2-MSN, cells were fixed 4 and $24 \mathrm{~h}$ after a typical transfection experiment with $2 \%$ glutaraldehyde/2\% paraformaldehyde in PBS buffer and incubated overnight at $4^{\circ} \mathrm{C}$ to visualize the location of MSNs. After washing with PBS, cells were dehydrated with graded ethanol and coated with $2 \%$ osmium tetroxide (Aldrich). TEM samples were sectioned in epoxy resin by microtome and developed using $2 \%$ uranyl acetate and $0.04 \%$ lead citrate. 


\section{Results and Discussion}

MSNs biocompatibility study. The application of our system directly to living cells involves two preliminary steps: successful derivatization of MSNs for the desired application and biocompatibility screening. To monitor the interaction of the MSN beads with the cellular environment we have prepared dye-doped particles, by incorporating fluorescent dyes inside the silica matrix. This embedding was performed in situ, during the synthesis of the material. ${ }^{6}$ As flow cytometry instruments are often using lasers $\mathrm{Kr}$ and Ar lasers, the fluorescent dyes of choice were derivatives of fluorescein and of Texas Red. The synthesis of the particles: fluorescein modified (F-MSN) and Texas Red modified (T-MSN), involve a slight modification.
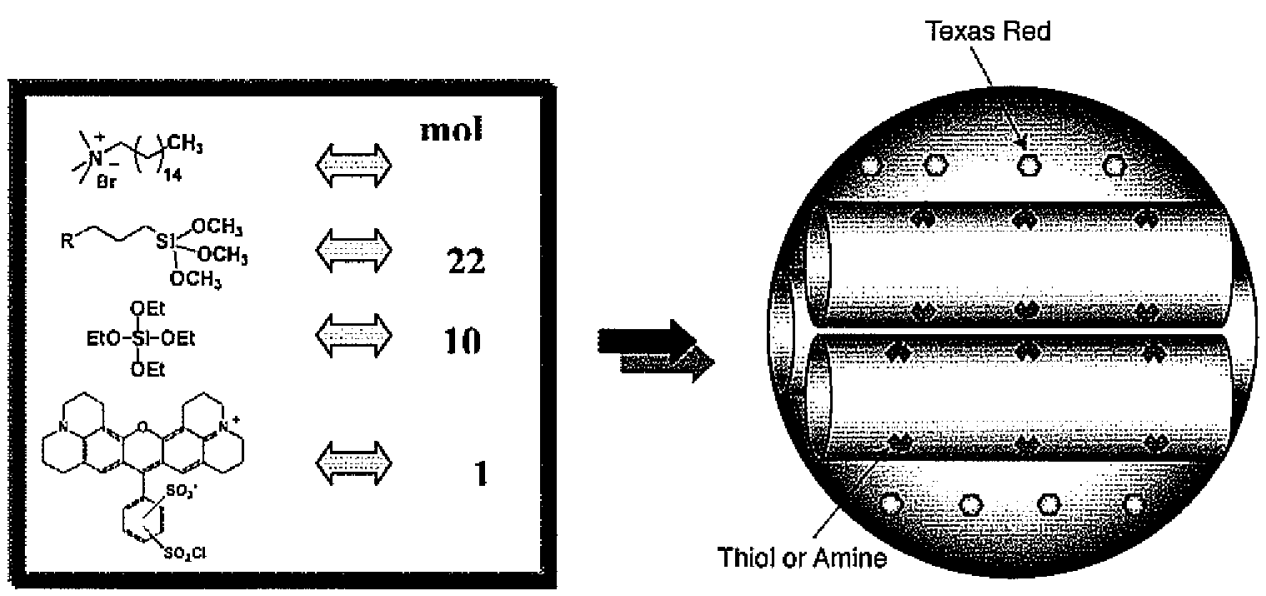

Figure 7-1. Schematic representation of Texas Red incorporated mesoporous silica nanospheres, T-MSN.

The synthetic pathway proposed in our previously published work resulted in morphological changes from polydisperse particles with irregular shape to nanospheres with high monodispersity (average diameter of $200 \mathrm{~nm}$ ). The particles synthesized with 
fluorescent dyes were maintaining this morphology as suggested in Figure 7-1 and showed in the SEM images in Figure 7-2.
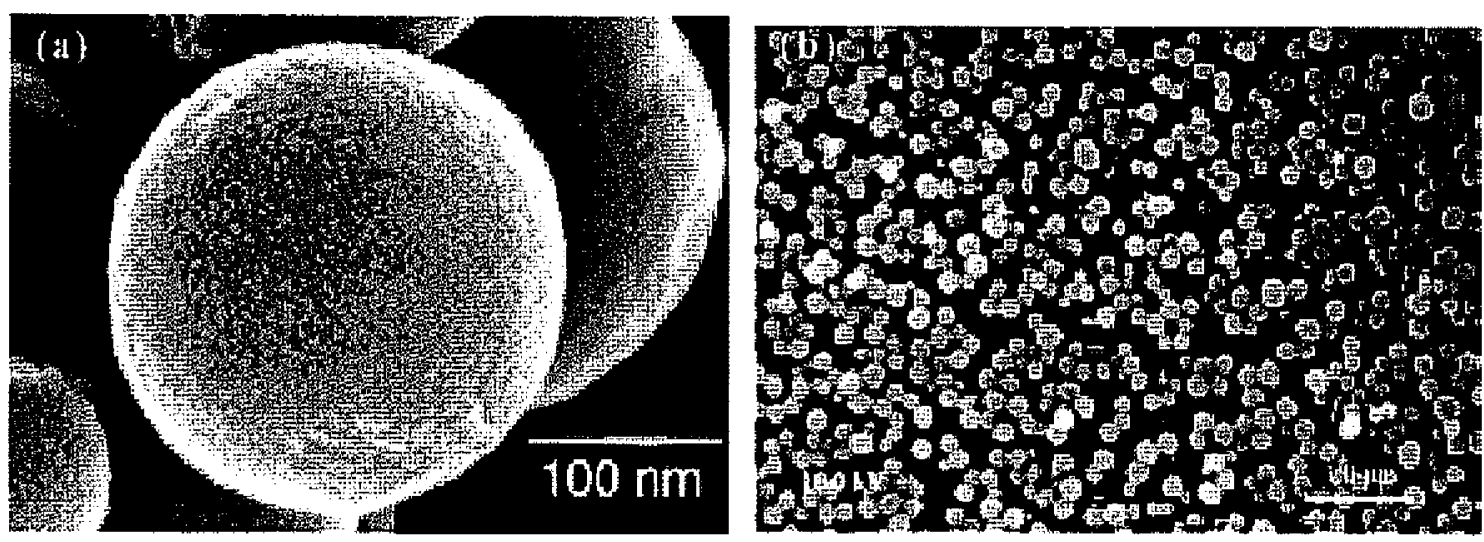

Figure 7-2 Scanning electron micrographs (SEM) of the mesoporous silica nanospheres (MSN). Scale bars = $100 \mathrm{~nm}(\mathrm{a})$ and $1.0 \mu \mathrm{m}(\mathrm{b})$.

The TEM micrographs in Figure 7-3 also show that the synthetic modifications of FMSN and T-MSN did not affect the well organized mesoporosity characteristic to nonfunctionalized materials.
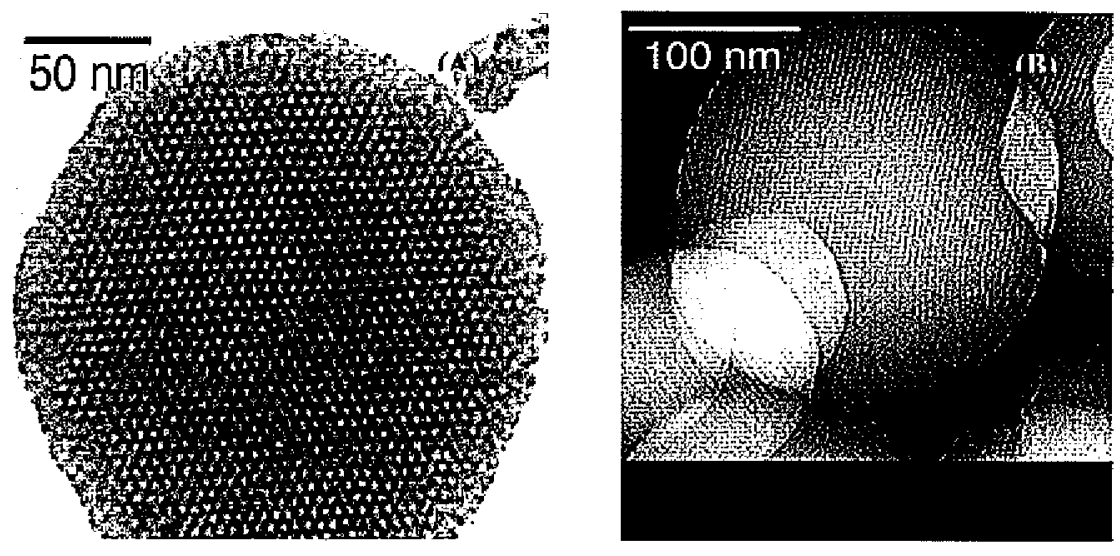

Figure 7-3. High-resolution transmission electron micrographs (TEM) of FTIC incorporated MCM-41 mesoporous silica nanospheres with amine functionality (F-MSN).

The fluorescence of the materials was concluded by suspending aliquots of material in water and monitoring their fluorescent signal. A very high stability of the signal with time 
was observed, while the emission profile was similar with that belonging to the Texas Red monitored in water solution. Based on this observation we concluded that the covalent linkage between the fluorophores and the silica matrix prevented the undesired fluorophoreleaching problem.

The biocompatibility screening was performed by applying the two fluorescent materials, F-MSN and T-MSN, to HeLa and CHO cancer cell lines. To evaluate the influence of fluorescent MSNs treatment on cells behavior, growth studies were performed for HeLa and CHO cells. The study concluded that after application of the MSNs, the cells followed their homeostatic behavior. Furthermore, embedding a fluorescent dye within the matrix, although was designed for biocompatibility study, do not harm the mesostructure and consequently, the future applications for drug and gene can use this third dimension of the MSNs for tracking purposes. ${ }^{7}$

The biocompatibility study is including the observation of cellular fate as a function of time and amount of material that was applied. Eventually, these observations are essential to decide the type and extent of the applications. There are two hypotheses in MSNs application to the cell: an extracellular attachment on the cell membrane or an endocytic uptake. Whereas the first hypothesis would not be of real interest, the practical applicability of the second: MSN uptake inside the cells--whether is related to analytical determinations or delivery applications--would be always dependent of the amount of the material that is engulfed by a specific cell, as well as to the period of time that is necessary for the MSN to be internalized by the cell.

To investigate the aforementioned parameters, we performed a cellular uptake study of the material on HeLa and CHO cells. The dosage study experiments were designed to 
determine the maximum amount of material that can be incorporated by a cell. Fluoresceindoped, F-MSNs, were used for the study, enabling flow-cytometry assessment of the fluorescence. The cells at visual confluency were treated with incremental amounts of material. Flow cytometry measurements were performed for a predetermined population of cells. Each set of cell cultures contained increasing amounts of material. To establish which of the aforementioned hypotheses is true, after measuring the fluorescence coming from samples, we added a fluorescence quencher, Trypan Blue, to each sample test tube. In this way, by measuring the fluorescence before and after quencher addition we can assess the location of the material in respect with the cell membrane. The first hypothesis, that the MSNs are located on the outer side of the membrane of the cells, was easy eliminated because the cells kept the same fluorescence level after Trypan Blue addition (Figure 7-4). This observation allows us to conclude that the material is completely engulfed by the cells. ${ }^{8}$

a)

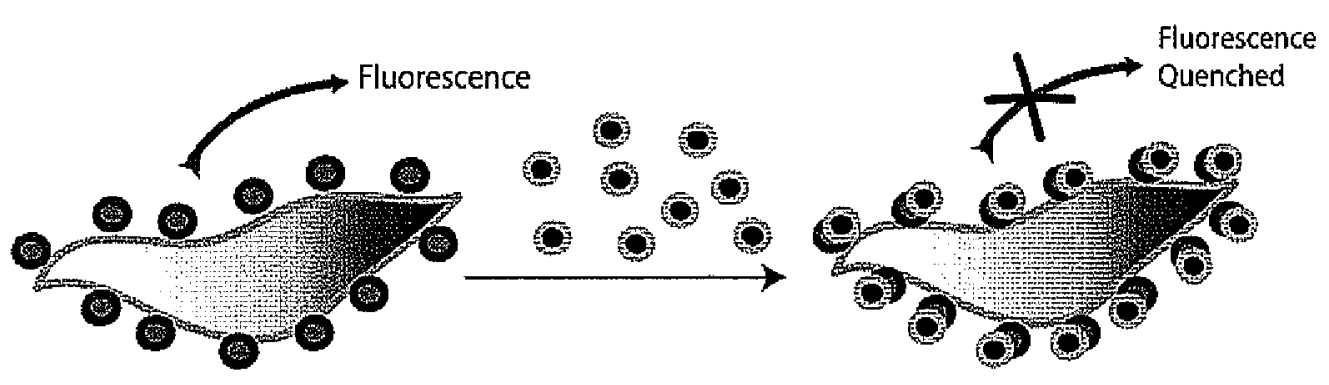

b)

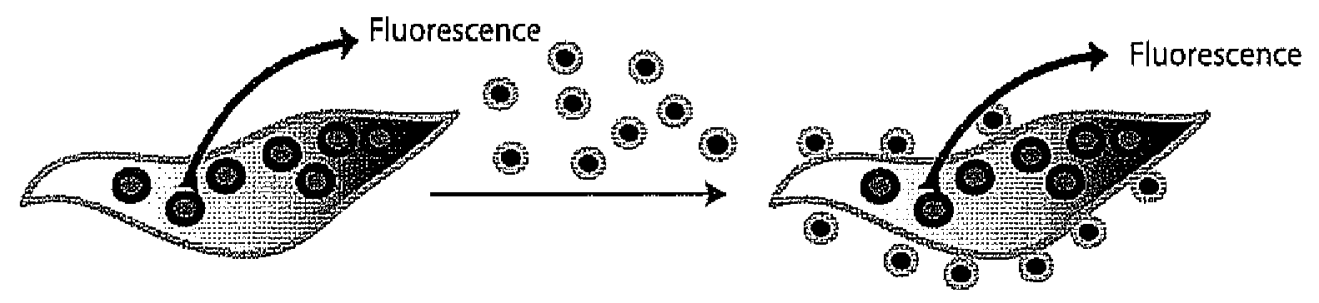

Figure. 7-4. Schematic representation of possible interaction of MSNs with HeLa cells: Hypothesis 1: MSNs are located primarily outside of the cell and the addition of Trypan Blue causes the fluorescence quenching a); Hypothesis 2: MSNs are located primarily inside of the cells resulting; no quenching 
The results, plotted in Figure 7-5, concluded that the maximum amount of MSNs engulfed by cells attained plateau at a dosage of $0.1 \mathrm{mg}$ for $10^{5}$ cells. As this uptake amount was observed after $12 \mathrm{~h}$ of incubation, we further determined the minimum amount of time for incorporating the aforementioned dose $(0.1 \mathrm{mg})$ for $10^{5}$ cells. The kinetic study was performed for $12 \mathrm{~h}$ and revealed that after the first $4 \mathrm{~h}$, the mean fluorescence became stationary. Together with the TEM micrographic evidence, this observations lead to the final conclusion that the whole material was internalized in $4 \mathrm{~h}$, in the established conditions.
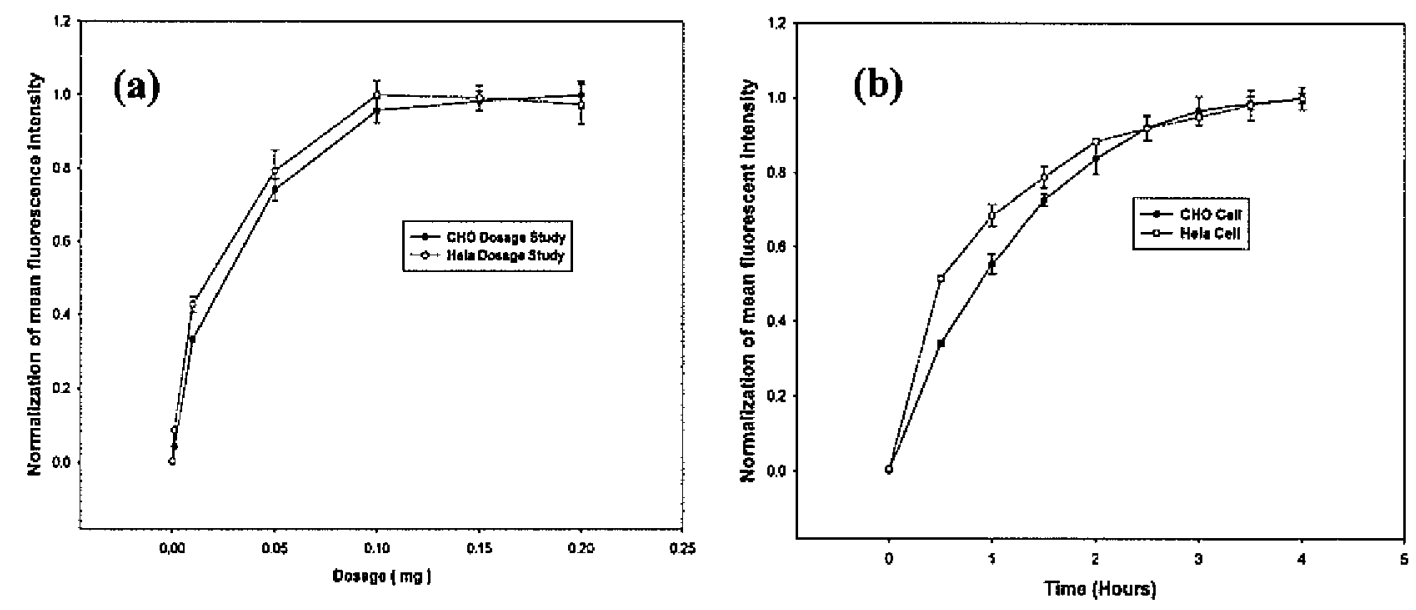

Figure 7-5. F-MSN internalization. Dosage study (a); Tíme dependence study (b)

In the case of cancer cells, whose cell cycle is very short, the carrier particles have to be shared during mitosis, to ensure a continuum in delivery. In order to study if the MSNs own these characteristic, we treated HeLa and CHO cells with Fluorescein doped MSNs and monitor their evolution by confocal microscopy. We observed that the cells are able to distribute the material evenly and share between daughter cells following mitosis.

Drug Delivery. As the biocompatibility of the MSNs was demonstrated, we directed our attention to intracellular delivery applications. Intracellular delivery presents three major 
challenges: 1. transmembrane trafficking, involving the ability of MSN to penetrate the membrane while carrying a loading; 2. release of the "cargo" and 3 . drug action, encompassing the amount and effectiveness of release inside the cell.

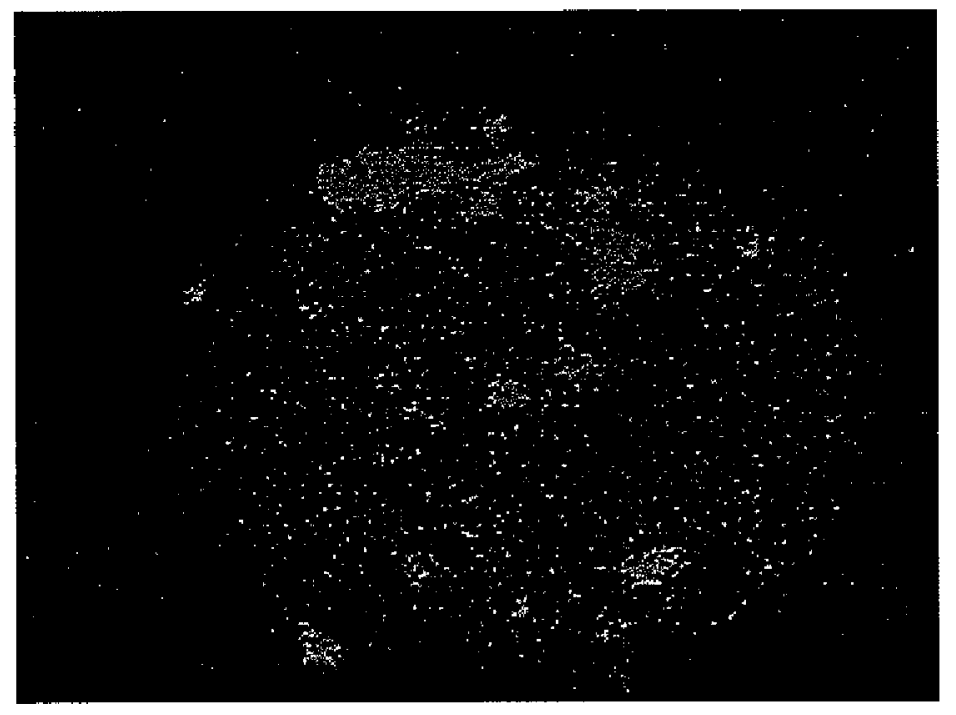

Figure 7-6. Fluorescent MSNs after endocytosis and cell mitosis - a dividing HeLa cell

The first intracellular delivery application that we are proposing here is related to cancer therapy and involves the delivery of an antineoplastic antibiotic, Doxorubicin, to HeLa cancer cells. In current cancer therapy, Doxorubicin (Adriamycin $($ ) is normally administered intravenously with dramatic side effects in the body. When pure Doxorubicin is released in the cells, the drug is accumulating inside their nuclei, triggering an apoptotic death mechanism. In our approach, Doxorubicin is encapsulated inside the mesopores of MSNs having the opening of the channels capped with bio-friendly PAMAM dendrimers of generation G4.5. The caps are covalently attached through a chemically cleavable disulfide linker. To demonstrate that this carrier has the ability to effectively deliver the drug to the cells we had to answer the three aforementioned challenges. The transmembrane trafficking of Doxorubicin loaded Dox-MSNs, was monitored by TEM, ss showed in Figure 7-7. 


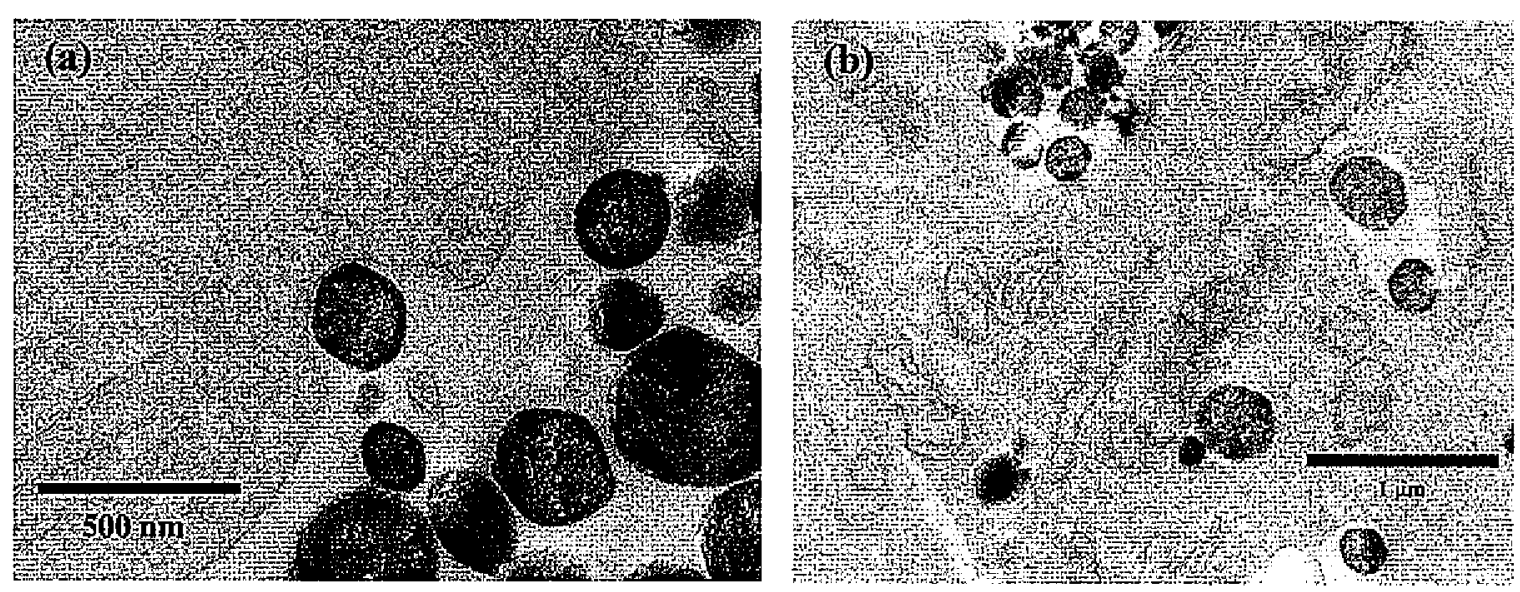

Figure 7-7. Cellular application of F-MSN (a) F-MSN engaged in endocytosis. (b) F-MSNs inside of a HeLa cell.

In this way, besides the proof brought by earlier presented flow cytometry investigations, we evidenced that the MSN are not only engulfed by the cells but also that they are not disturbing cellular homeostasis. The ability of MSN to penetrate the membrane while carrying a loading does not make them yet a drug delivery carrier. The second problem to be addressed is the release of the drug inside the cytosol. To achieve this goal, the dendrimer caps used for drug encapsulation were attached through a disulfide bond that can be cleaved in the intensely reducing environment inside the cells. The confocal images in Fig. 7-7 illustrate the red fluorescent nuclei of HeLa cells that are demonstrating that the doxorubicin has been released from the MSNs mesopores after $12 \mathrm{~h}$ of incubation of the Dox-MSNs with the cells. As a benchmark, we performed the same experiment with a water solution of Doxorubicin that was deposited on the cells. Doxorubicin mechanism of action consists of DNA intercalation with blocking of replication. For this reason, any cell that is undergoes Doxorubicin uptake will show red fluorescent nuclei. Fter fixation, the cells were counterstained with DAPI - a fluorescent dye that is also a DNA intercalator. As showed in the confocal image, no nuclei were available for DAPI staining, the Doxorubicin having 
occupied the chromosome. The localization of the drug in the nuclei in both cases proves that our release followed the same killing mechanism as the direct administration.

(a)
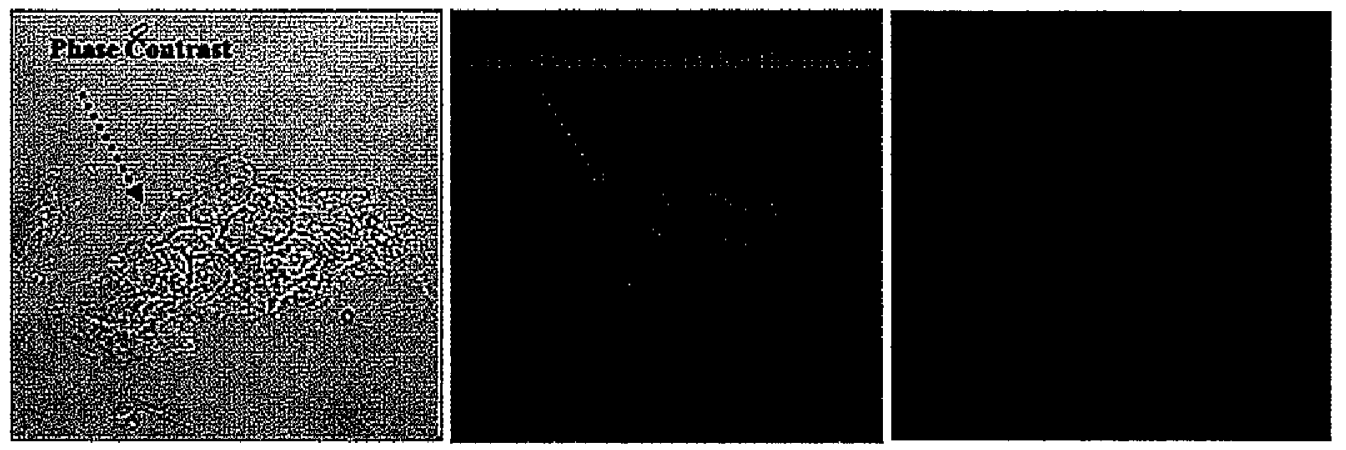

(b)
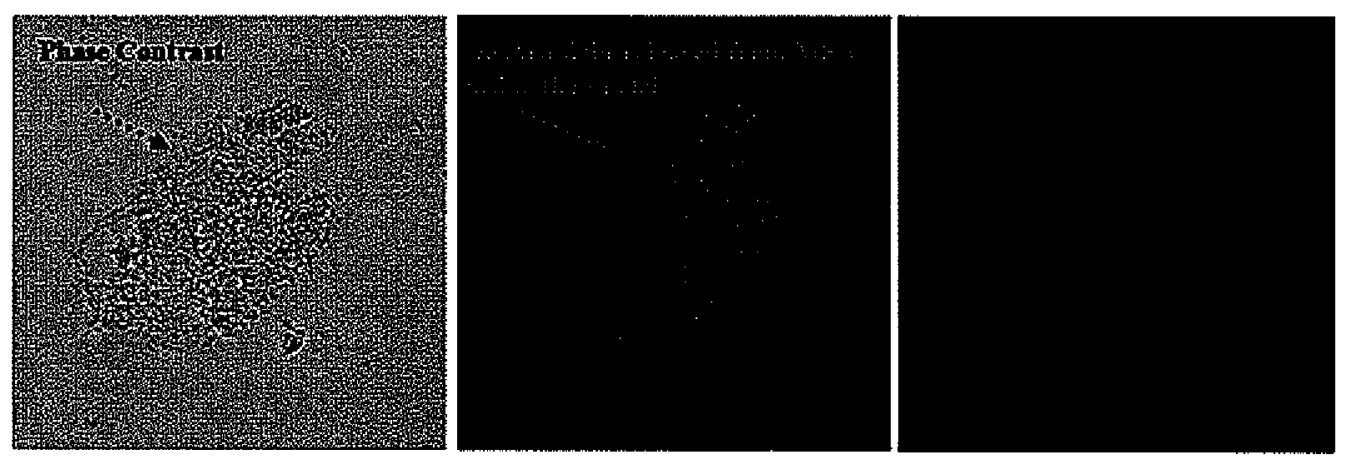

Figure 7-8. Doxorubicin delivery: Free doxorubicin delivered to HeLa Cells (a); MSN Encapsulated doxorubicin delivery in HeLa Cells (b)

The release mechanism is not clear, however, the reducing media of the cytosol might be responsible of disulfide bond cleavage. To attest that the Doxorubicin release is originated from uncapped mesopores and not from any physiabsorbed drug, we performed a control experiment where the disulfide linker in Dox-MSN was replaced by a non-cleavable urea bond to give Dox-ISP-MSN. The urea bond was generated by reacting the amine termini of generation G4 PAMAM dendrimers with MSN-surface-bounded isocyanate groups. The Doxorubicin entrapped in the mesopores could be visualized by examining the confocal images of the cells after treatment with Dox-ISP-MSN where the red spots can be easily observed. The striking evidence is brought by nuclei staining (Figure. 7-9). 
(a)
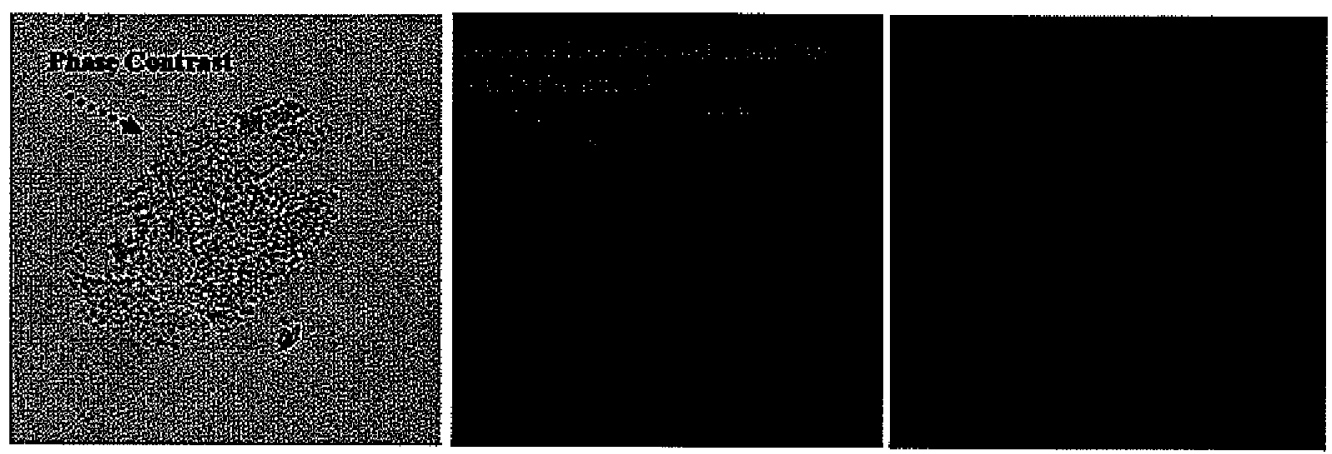

(b)
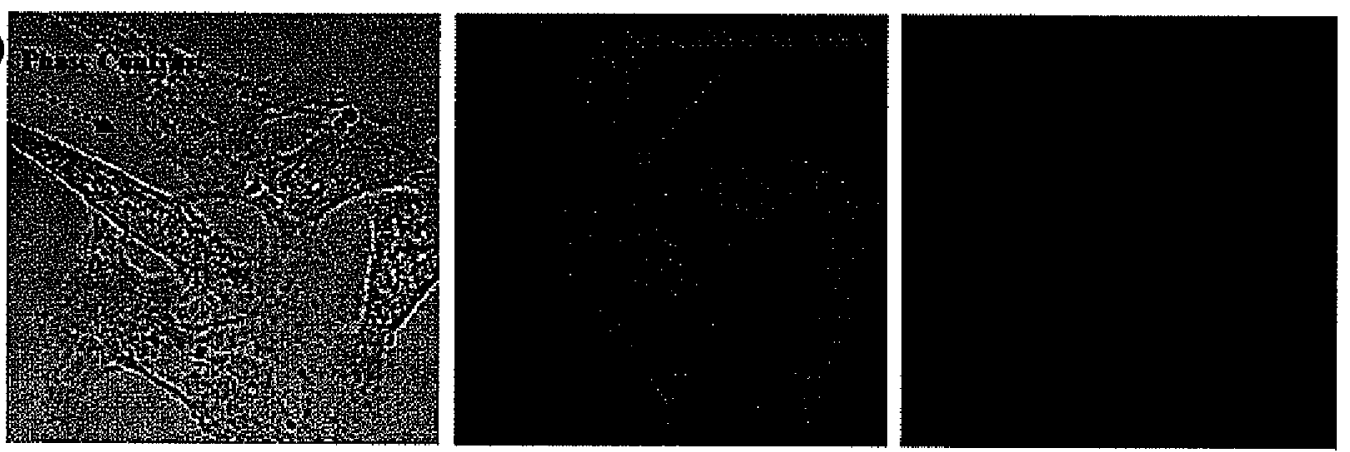

Figure. 7-9 Cleavable versus non-cleavable caps: Cells incubated with Dox-MSNs: release of Doxorubicin visualized by confocal microscopy (a); Cells incubated with Dox-ISP-MSNs: No release is observed, DAPI stain resides in the nuclei.

By contrast with the Dox-MSNs, the noncleavable caps do not allow Doxorubicin release and consequently, the cells are surviving for many days, as showed in the biocompatibility section. Furthermore, the nuclei are stained with DAPI that demonstrates that the nuclear DNA was not interfered by any Doxorubicin. Any possibility of Doxorubicin physiabsorbtion was eliminated by extensive washes of the loaded MSNs followed by a filtration and fluorescent examination of the supernatant for any residual Doxorubicin in both Dox-MSN and Dox-ISP-MSN.

The third factor in evaluating a drug carrier is the drug action after release. This includes the amount and consequently the effectiveness of the release. To observe the fate of cells after dox-MSN application, a kinetic study was performed and confocal microscopy images were collected at intervals of four h (Figure. 7-11). The cells started to change their 
shapes after $8 \mathrm{~h}$ but at this stage only few of them had incorporated the Doxorubicin in the nuclei. After $12 \mathrm{~h}$, all cells had the drug in the nuclei. After another $12 \mathrm{~h}$, the culture was completely destoyed and only some debris could be observed on light microscope. Althoug we have a visual proof of effectiveness of the release, the quantitative data are important for trying to evaluate the mechnism. The amount of potential drug release of MSNs was evaluated by high performance liquid chromatography (HPLC). The loaded Dox-MSNs, after extensive wash, were suspended in phosphate buffer at physiological $\mathrm{pH}(7.4)$ and the release was triggerd using dithiothreitol, a well known disulfide reducing reagent. The release profile is represented in Figure. 7-10. The amount of released drug is evaluated as $300 \mathrm{nmoles} / \mathrm{mg}$ MSNs. ${ }^{10}$ The G4.5-capped MSN nanoparticles with Doxorubicin (10.00 mg) material were dispersed in $1.50 \mathrm{~mL}$ of PBS buffer ( $\mathrm{pH}$ 7.4), followed by repeating wash/sonication/centrifugation cycles for five times to remove physisorbed, uncapped Doxorubicin molecules on the exterior surface of the material. The purified MSN/drug composite was redispersed in $3.50 \mathrm{~mL}$ of PBS buffer (pH 7.4). Aliquots were taken every $4 \mathrm{~h}$ over a time period of $12 \mathrm{~h}$ from the MSN/PBS buffer suspension and injected to an analytical HPLC system (Hitachi LC/3DQMS with a reverse phase C18 column (Vydac), $0.4 \mathrm{~cm} \times 25$ $\mathrm{cm})$ to monitor the leaching of the mesoporous channel encapsulated Doxorubicin molecules. ${ }^{10}$ After $12 \mathrm{~h}$, dithiothreitol (DTT, $18.50 \mathrm{mM}$ ) was added to the suspension to cleave the disulfide linkage between the G4.5 dendrimers and the MSN. The kinetic profiles of the DTT-induced release of Doxorubicin were monitored by following two literaturereported HPLC separation conditions. ${ }^{10}$ The peaks/areas at $254 \mathrm{~nm}$ were monitored/integrated for the quantitative analysis of amounts of released Doxorubicin.in of mixing, the suspension was centrifuged and the individual concentrations of dopamine and glutamic acid in the 
supernatant were analyzed by HPLC. Flow rate of mobile phase was $1 \mathrm{~mL} / \mathrm{min}$. separation was obtained with the following linear gradient of water (A)-acetonitrile (B), both containing $0.1 \%$ (v/v) CF3COOH: from $25 \% \mathrm{~B}$ to $30 \% \mathrm{~B}$ in $10 \mathrm{~min}$, and then up to $80 \% \mathrm{~B}$ in $5 \mathrm{~min}$, finally elution was maintained isocratic for the next $15 \mathrm{~min}$ to return to the initial condition and re-equilibrate. The column temperature was set at room temperature and the injection volume of samples was $25 \mu \mathrm{L}$ for all analyses.

Transfection. As described in the introductory part, the material can prove universal carrier properties by transporting molecules not only inside the mesoporous channels but also, for large molecules, on the outer surface.

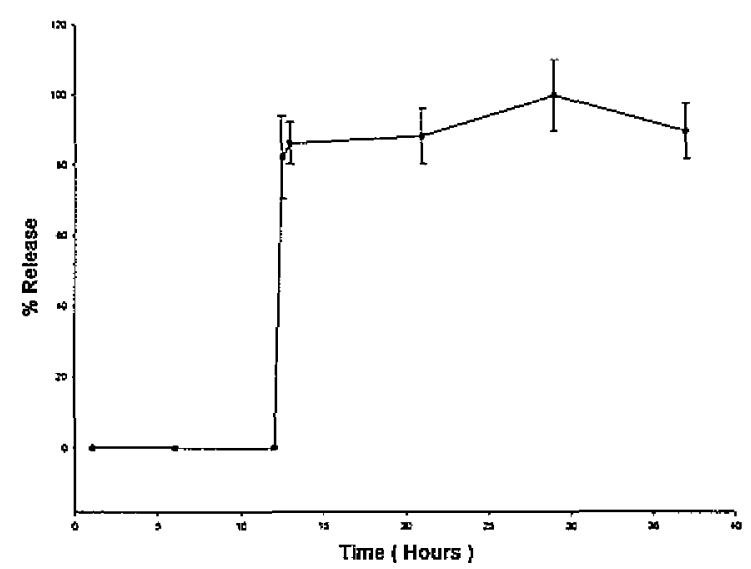

Figure 7-10. HPLC study of Doxorubicin release from Dox-MSNs.

It was demonstrated in our previously published work that MSNs, after derivatization with a cationically charged molecule on the external surface, can complex and delivery plasmid DNA to cancer cells such as HeLa and CHO at a superior efficiency than commercially available vectors. 
(a)
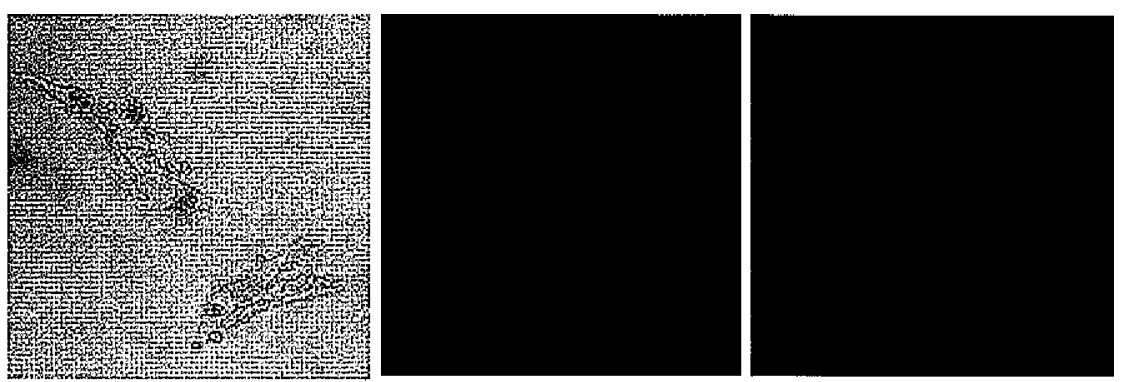

(b)
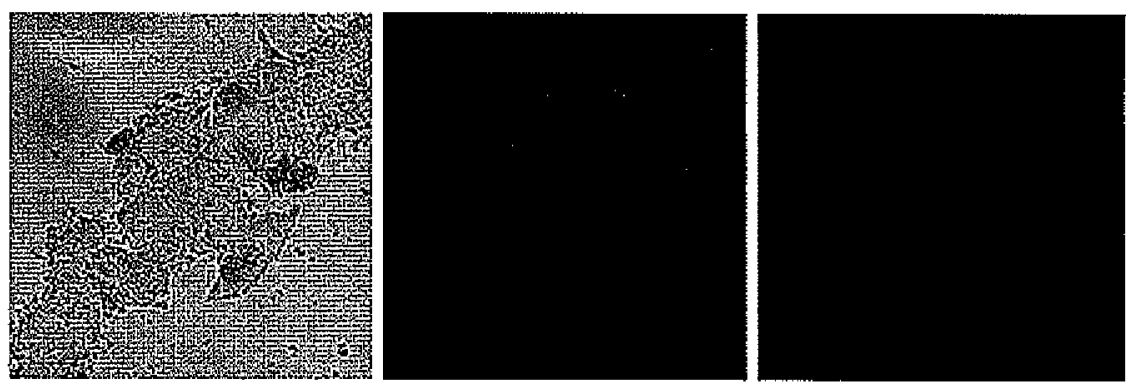

(c)
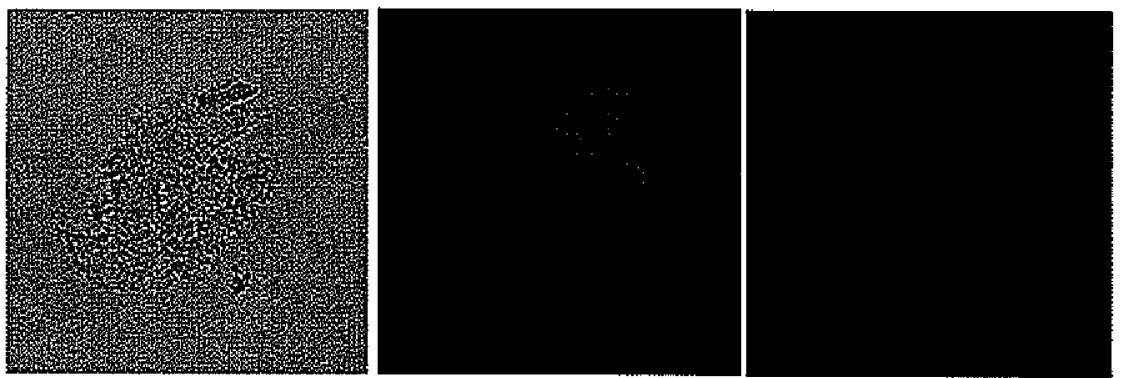

Figure 7-11. Kinetic study of Doxorubicin release: the Dox-MSNs were applied to cell cultures and monitored every four $h$ : after $4 \mathrm{~h}(\mathrm{a})$; after $8 \mathrm{~h}(\mathrm{~b})$; after $12 \mathrm{~h}$ (c)

As the modularity of our system permits multiple functionalities, Texas Red doped MSNs were used for transfection of HeLa cells following the same derivatization/complexation/delivery pathway used in our previous work. Confocal imaging was used for analyzing the cells after gene expression. The visual inspection of the sections, recorded at a thickness of $0.5 \mu \mathrm{m}$, supplies a rapid method for investigating the internalization of the material.

The application of MSNs in cancer gene therapy is important but there are many other diseases that can take advantage of gene therapy utilizing this nanocomposite. In the present work, we disclose a breakthrough in gene delivery, as the system is able to transfect primary 
cells such as neural glia (astrocytes) at an unprecedented efficiency. Our MSN-based gene delivery nanodevice was applied to living cells in vitro. The nanocomposite comprises the core module--MSN, an exterior surface module for DNA complexation and an internal pore surface module as buffer capacity enhancer. In our approach, the external surface of MSN materials was modified with G2-PAMAM dendrimers, covalently attached through a surface anchored linker. The interior surface of the mesopores is functionalized with imidazole group. The positive surface has ability to complex plasmid DNA as it was demonstrated in our previously work. ${ }^{3}$ As a proof of principle we condensed and transfected pEGFP-Cl-plasmid that is encoding for green fluorescent protein--to different types of cell lines as well as primary cells. The transfection of HeLa and CHO cells with pEGFP using MSNs was published elsewhere. However, the efficiency of the method was not satisfactory when applied to astrocytes and therefore required further optimization. One of the impediments in cells transfection is represented by endosomal escape of the DNA. The $\mathrm{pH}$ inside the endosome reach values around 5 , suggesting that by fine-tuning the $\mathrm{pH}$ one can manipulate the carrier fate.

The concept of "proton sponge" was introduced by Plank et al. ${ }^{9}$ and is related to the buffer capacity of the carrier. This feature is enhancing the efficiency of gene transfection by causing endosomal burst and consequent escape of DNA. Because of the large surface area of the MSNs, they can be modified with functional groups to provide a strong buffer capacity to these gene carriers and thus enhancing endosomal escape thus increasing the efficacy of transfection. Anchoring dihydroimidazole functionality in the mesopores--via our previously published co-condensation reaction--proved to be the key of this optimization process. The 
transfection efficiency for astrocytes was considerably increased in this way from $1-2 \%$ to $12.4 \%$ which is unprecedented for primary cells when using other non-viral vectors.

(a)
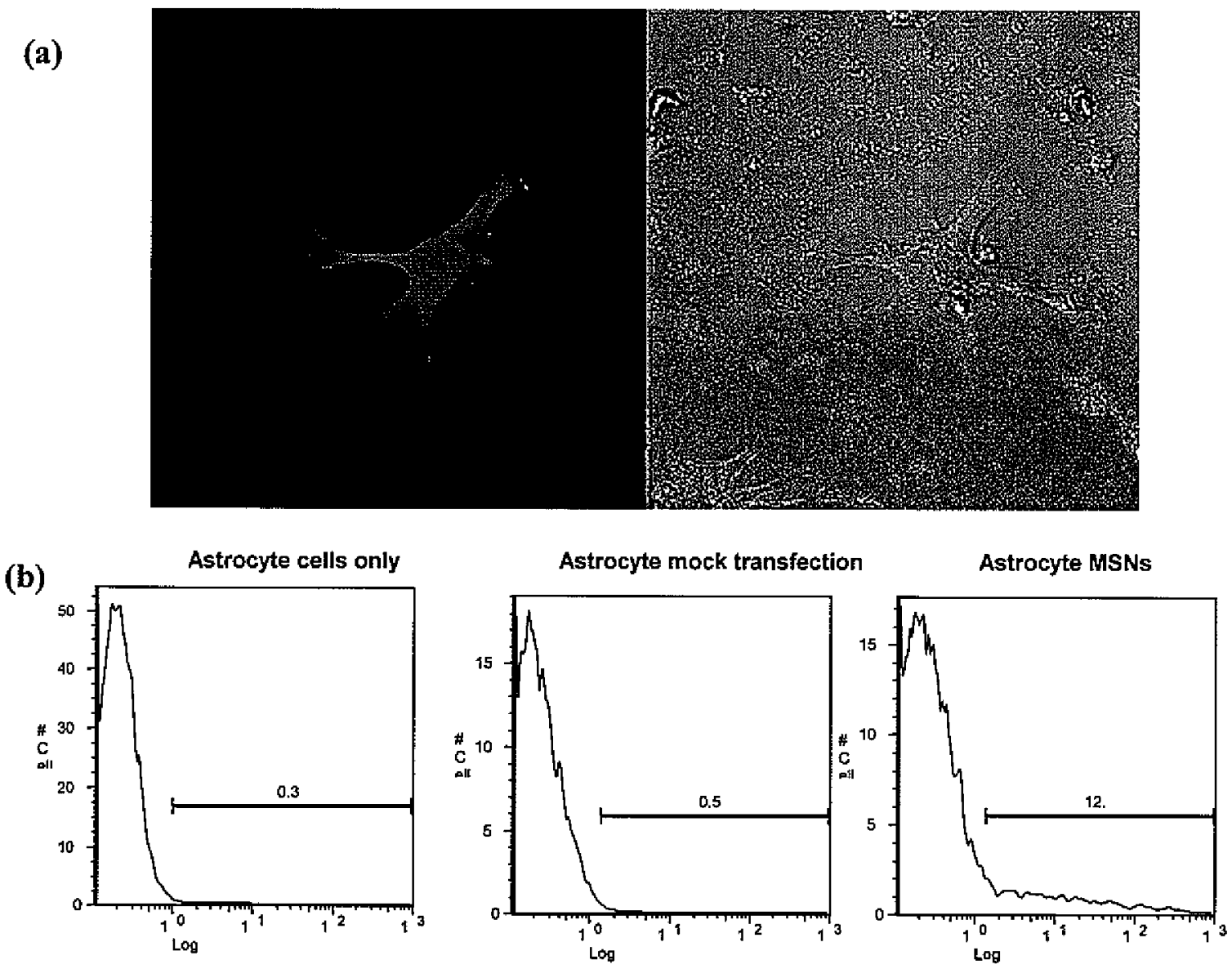

Figure 7-12. Transfection of neural glia (astrocytes) with pEGFP utilizing G2-MSN as a transfection vector (a) Confocal microspy images (b) Flow cytometry results

Cotransfection of two different types of plasmids. The transfection of different types of cells with plasmid pEGFP offers a proof of principle for applicability in MSN-based transfection for one particular gene. However, one of the major challenges for therapeutic gene transfection is to develop a method for fast response detection of the encoded protein expression. 
This is possible for a gene encoding a signal such as fluorescence (pEGFP) but most of therapeutic genes have as a single result, the protein that is expressed. One of the solutions of the problem is the engineering of a marker gene--such as the one encoding for GFP--inside the plasmid of choice. The expression of the marker is representing a benchmark for the expression of the desired gene. However, the genetic engineering is tedious; besides, as the size of the plasmid increases, eventually the whole transfection process can be compromised. The alternative is represented by cotransfection of two plasmids: one encoding for the therapeutic gene and one encoding for the marker gene. For the later choice, the ideal gene carrier would be able to deliver both plasmids, in a known ratio, so that the expression of the marker can be correlated with the extent of the therapeutic gene expression.

In order to test if our system can achieve the aforementioned task, we used two plasmids that encode for different gene fluorescent proteins: pEGFP-C1 and DsRed-N1. The ratio between the two plasmids in the transfection experiments was $1: 1$ for all experiments. Since we have chosen plasmids that encode for fluorescent proteins, the level of expression could be monitored by flow cytometry. The most interesting finding was that within a cell culture there is no mixed population of transfected cells, i.e. there were no cells transfected only with one type of the two plasmids. The same observation is illustrated by the confocal images in Figure. 7-14. The efficiency of cotransfection is similar with the transfection efficiencies that we reported for transfection of pEGFP in HeLa and CHO cells in Figure 715. The TEM micrographs bring further evidence of particle internalization shown in Figure 7-13. 


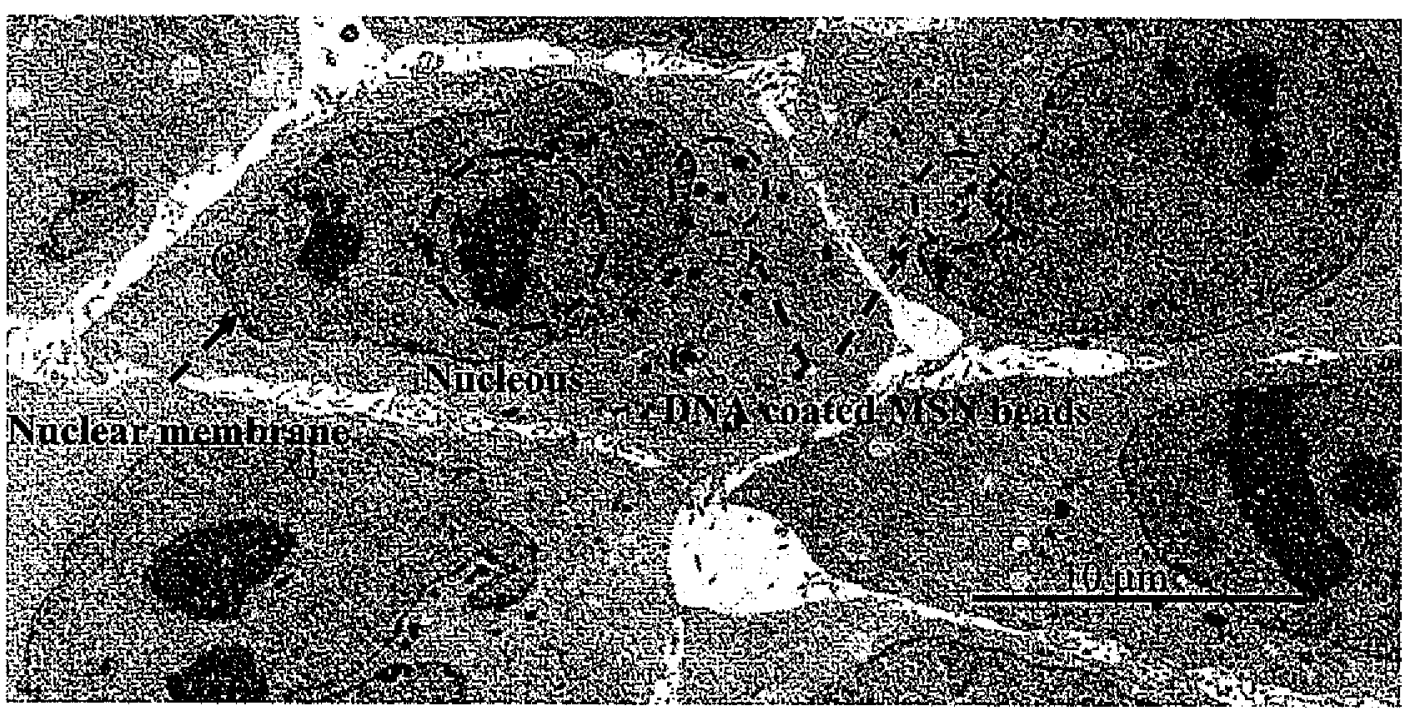

Figure 7-13. TEM micrograph of cotransfected HeLa cells

a) Hela Cells

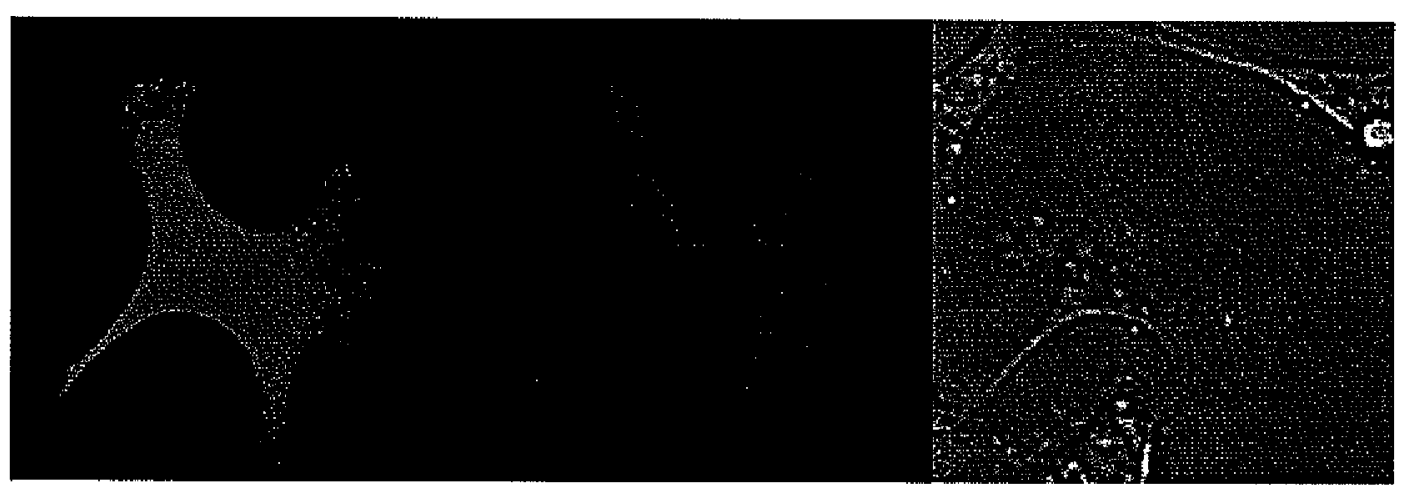

b) CHO Cells

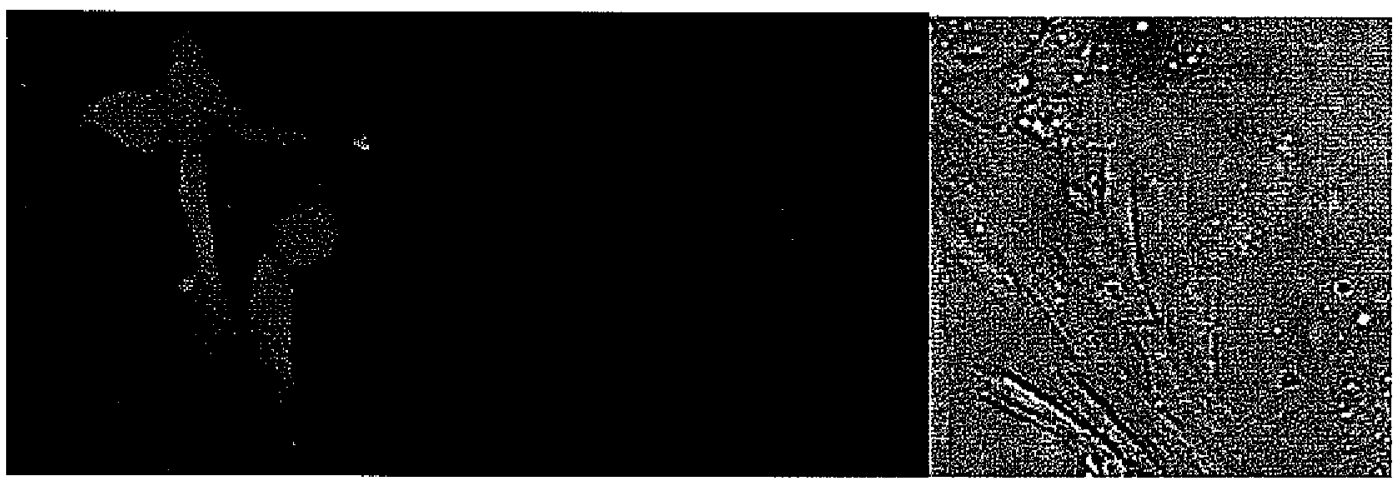

Figure. 7-14. Confocal fluorescence images and phase contrast images of HeLa cells (a) and CHO cells(b). 


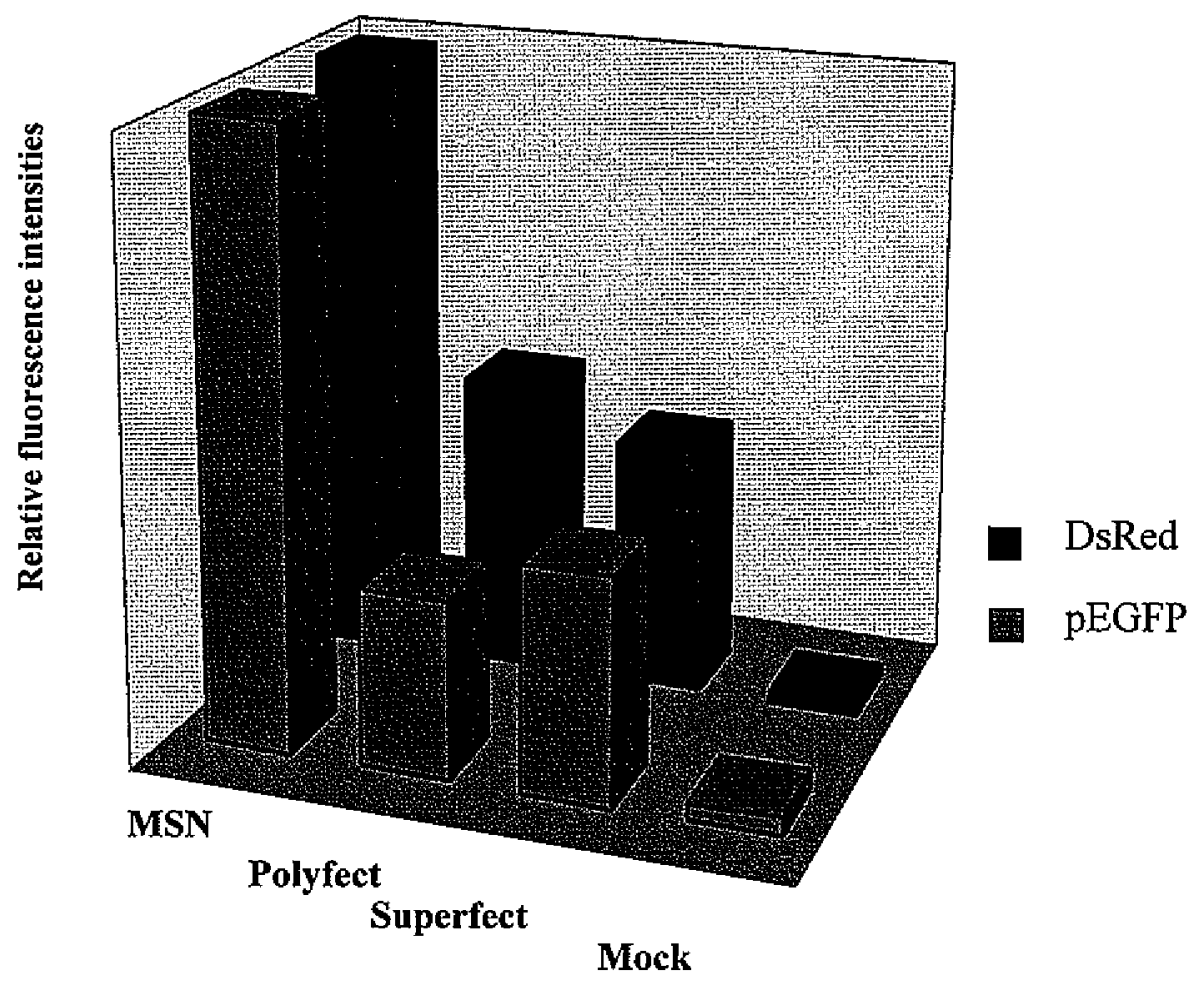

Figure. 7-15. Relative transfection efficiencies between several transfection reagents: G2-MSN, Polyfect and Superfect. Mock transfection (beads without plasmids) was also performed to demonstrate that there is no fluorescent signal detected in the absence of DNA complexed MSNs.

\section{Conclusions}

The potential of MSN in drug and gene delivery was demonstrated. Possible combinations of the two approaches can be easily envisioned. In future applications the MSNs can serve as gene carriers using the outer surface while carrying gene up- or downregulator molecules inside the mesopores. On the other hand, one of the methods proposed in the biocompatibility study was utilizing fluorescent doped MSNs in flow cytometry, demonstrating a possible utility in flow cytometry measurements. We can envision that by further outer surface derivatization of fluorescence MSN particles with cell targeting 
moieties, one can perform cellular sorting, the damaged cells being labeled and selected. In an extreme approach, all three elements of MSN: silica matrix, the nanochannels and the outer surface could be exploited at the same time, the device being endowed with both carrier and tracking abilities.

\section{Acknowledgements}

The authors thank Dr. Janice Buss, Dr. Louisa Tabatabai and Dr. Marit NilsenHamilton for their helpful suggestions. The authors would like to acknowledge the cell and hybridoma facilities personnel of ISU for their assistance.

\section{References}

(1). (a) Uhrich, K. E.; Cannizzaro, S. M.; Langer, R. S.; Shakesheff, K. M. Chem. Rev. 1999, 99, 3181. (b) Langer, R. Acc. Chem. Res. 1993, 26, 537 and references therein.

(2). (a) Luo, D.; Saltzman, W. M. Nat. Biotechnol. 2000, 18, 893. (b) Kneuer, C.; Sameti, M.; Bakowsky, U.; Schiestel, T.; Schirra, H.; Schmidt, H.; Lehr, C.-M. Bioconjugate Chem. 2000, 11, 926. (c) He, X.-X.; Wang, K.; Tan, W.; Liu, B.; Lin, X.; He, C.; Li, D.; Huang, S.; Li, J. J. Am. Chem. Soc. 2003, 125, 7167. (d) Luo, D.; Han, E.; Belcheva, N.; Saltzman, W. M. J. Controlled Release 2004, 95, 333. (e) Vallet-Regi, M.; Ramila, A.; del Real, R. P.; Perez-Pariente, J. Chem. Mater. 2001, 13, 307. (f) Munoz, B.; Ramila, A.; Perez-Pariente, J.; Diaz, I.; 
Vallet-Regi, M. Chem. Mater. 2003, 15, 500. (g) Ramila, A.; Munoz, B.; PerezPariente, J.; Vallet-Regi, M. J. Sol.-Gel Sci. Technol. 2003, 26, 1199.

(3). (a) Lin, V. S. Y.; Lai, C.-Y.; Huang, J.; Song, S.-A.; Xu, S. J. Am. Chem. Soc. 2001, 123, 11510-11511. (b) Radu, D. R.; Lai, C.-Y.; Wiench, J. W.; Pruski, M; Lin, V. S. Y. J. Am. Chem. Soc. 2004, 126, 1640. (c) Radu, D. R.; Lai, C.-Y.; Jeftinija, K.; Rowe, E. W.; Jeftinija, S.; Lin, V. S.-Y. J. Am. Chem. Soc. 2004; I26, 13216.

(4). Lai, C.-Y.; Trewyn, B. G.; Jeftinija, D. M.; Jeftinija, K.; Xu, S.; Jeftinija, S.; Lin, V. S.-Y. J. Am. Chem. Soc. 2003, 125, 4451.

(5). (a) Radu, D. R.; Lai, C.-Y.; Jeftinija, K.; Rowe, E. W.; Jeftinija, S.; Lin, V. S.-Y. J. Am. Chem. Soc. 2004; 126, 13216. (b) See chapter 8 of this dissertation for details and references therein.

(6). Marjan, B; Olavi, S; Egon, M. Journal of Colloid and Interface Science, 2002, 254,274 and references therein.

(7). (a) Yao, Y; Zhang, M; Shi, J; Gong, M; Zhang, H; Yang, Y. Materials Letters, 2001, 48, 44. (b) Onida, B.; Bonelli, B.; Borello, L.; Fiorilli, S.; Bodoardo, S.; Penazzi, N.; Arean, C. Otero; Palomino, G. Turnes; Garrone, E. Studies in Surface Science and Catalysis 2003, 146, 379.

(8). (a) Rohloff L., Andreas Wiesner and Peter Götz, Journal of Insect Physiology, 1994, 40, 1045. (b) Chok P. Wan, Choon S. Park and Benjamin H. S. Lau, Joumal of Immunological Methods, 1993, 162, 1. 
(9). (a) Plank, C., Zatloukal, K., Cotton, M., Mechtler, K., Wagner, E. Bioconjugate Chem. 1992, 3, 533. (b) Plank, C., Oberhauser, B., Mechtler, K., Koch, C., \& Wagner, E. J. Biol. Chem. 1994, 269, 12918. (c) Wagner, E., Plank, C., Zatloukal, K., Cotton, M., \& Birnstiel, M. L. Proc. Natl. Acad. Sci. 1992, 89, 7934. (d) Behr, J.-P. Chimica , 1997, 51, 34. (e) Boussif, O., Lezoualc'h, F., Zanta, M. A., Mergny, M. D., Scherman, D., Demeneix, B., \& Behr, J.-P. Proc. Natl. Acad. Sci. 1995, 92, 7297. (f) Pack, D., Putnam, D., \& Langer, R. Biotechnol. Bioeng, 2000, 67, 217. (g) Midoux, P. \& Monsigny, M. Bioconjugate Chem. 1999, 10, 406.

(10). (a) Zhao,P.; Dash, A.K. Journal of Pharmaceutical and Biomedical Analysis, 1999, 20, 543. (b) E. Configliacchi, G. Razzano, V. Rizzo, A. Vigevani, Journal of Pharmaceutical and Biomedical Analysis, 1996, 123. 
CHAPTER 8. A POLYAMDOAMINE DENDRIMER-CAPPED MESOPOROUS SILICA NANOSPHERE-BASED GENE TRANSFECTION REAGENT

A paper published in the Journal of American Chemical Society, $2004,126,13216-13217$

Daniela R. Radu, Cheng-Yu Lai, Ksenija Jeftinija, Eric W. Rowe, Srdija Jeftinija, and Victor S.-Y. Lin

Department of Chemistry and Department of Medical Sciences, Iowa State University, Ames, Iowa

\begin{abstract}
We synthesized a MCM-41 type mesoporous silica nanosphere (MSN) based gene transfection system, where second generation (G2) PAMAMs were covalently attached to the surface of MSN. The G2-PAMAM-capped MSN material (G2-MSN) was used to complex with a plasmid DNA (pEGFP-C1) that is encoding for an enhanced green fluorescence protein. The gene transfection efficacy, uptake mechanism, and biocompatibility of the G2MSN system with various cell types, such as neural glia (astrocytes), human cervical cancer (HeLa), and Chinese hamster ovarian (CHO) cells were investigated.
\end{abstract}

\title{
Introduction
}

Recent reports in the literature have demonstrated that polyamidoamine (PAMAM) dendrimers can serve as non-viral gene transfection reagents.' However, only those 
PAMAMs of high generations $(G>5)$ have been shown to be efficient in gene transfection. ${ }^{\text {la }}$ The required procedures for the synthesis and purification of these high G PAMAMs are usually tedious and low-yield. In contrast, the low G PAMAMs $(\mathrm{G}<3)$ are nontoxic and easy to be synthesized. Despite the benefits, the smaller molecular sizes and the limited surface charges of the low G PAMAMs prohibit efficient complexation with plasmid DNAs in solution due to the entropy penalty. ${ }^{\text {la }}$ Herein, we report a novel gene transfection system, where second generation (G2) PAMAMs were covalently attached to the surface of a MCM41 type mesoporous silica nanosphere (MSN) $)^{2}$ material as depicted in Figure 8-1.
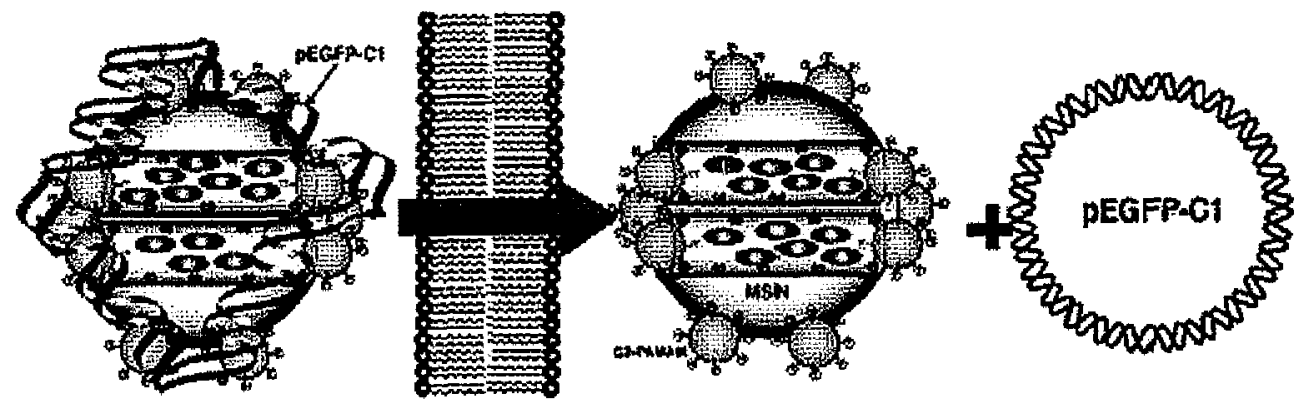

Figure 8-1. Schematic representation of a non-viral gene transfection.

\section{Materials and Methods}

\section{Experimental}

\subsection{Synthesis of ICP-MSN}

$N$-Cetyltrimethylammonium bromide (CTAB, $1.00 \mathrm{~g}, 2.74 \mathrm{mmol}$ ) was dissolved in $480 \mathrm{~mL}$ of nanopure water. Sodium hydroxide aqueous solution $(2.00 \mathrm{M}, 3.50 \mathrm{~mL})$ was introduced to the CTAB solution and the temperature of the mixture was adjusted to $80{ }^{\circ} \mathrm{C}$. Tetraethoxysilane (TEOS, $5.00 \mathrm{~mL}, 22.4 \mathrm{mmol}$ ) was added dropwise to the surfactant solution under vigorous stirring. The mixture was allowed to react for $2 \mathrm{~h}$ to give rise to a 
white precipitate. This solid crude product was filtered, washed with deionized water and methanol, and dried in air to yield the as-synthesized MSN. To remove the surfactant template (CTAB), $1.50 \mathrm{~g}$ of the as-synthesized MSN was refluxed for $24 \mathrm{~h}$ in a methanolic solution of $9.00 \mathrm{~mL}$ of $\mathrm{HCl}(37.4 \%)$ in $160.00 \mathrm{~mL}$ methanol. The resulting material was filtered and extensively washed with deionized water and methanol. The surfactant-free MSN material was placed under high vacuum to remove the remaining solvent from the mesopores. MSN $(1.00 \mathrm{~g})$ was refluxed for $20 \mathrm{~h}$ in $80.00 \mathrm{~mL}$ of anhydrous toluene with $0.25 \mathrm{~mL}(1.00$ mmol) of 3-isocyanatopropyltriethoxysilane to yield the 3-isocyanatopropyl-functionalized MSN (ICP-MSN) material.

\subsection{Synthesis of G2-MSN without Texas Red}

The purified ICP-MSN $(0.15 \mathrm{~g})$ was added to anhydrous ethanol $(3.00 \mathrm{~mL})$. A second-generation (G2) polyamidoamine dendrimer (PAMAM, $2.00 \mathrm{~mL}, 0.11 \mathrm{mmol}$ ) was then added to the ICP-MSN ethanol solution. The amino groups of the G2-PAMAM were allowed to react with the ICP functional groups present on the surface of MSN for $20 \mathrm{~h}$ at room temperature to yield the G2-PAMAM-capped MSN material (G2-MSN). The resulting G2-MSN material was filtered and washed thoroughly with ethanol, methanol and acetone and dried under high vacuum.

\subsection{Synthesis of Texas Red-loaded G2-MSN}

The purified ICP-MSN $(0.15 \mathrm{~g})$ was added to an anhydrous ethanol solution $(3.00 \mathrm{~mL})$ of Texas $\operatorname{Red}^{\mathrm{TM}}$ (5.00 mM, Molecular Probe). The solution mixture was stirred at room temperature for $20 \mathrm{~h}$ to allow the Texas Red to be encapsulated by the ICP-MSN. A secondgeneration (G2) polyamidoamine dendrimer (PAMAM, $2.00 \mathrm{~mL}, 0.11 \mathrm{mmol}$ ) was then added to the ICP-MSN/Texas Red solution. The amino groups of the G2-PAMAM were 
allowed to react with the ICP functional groups present on the surface of MSN for $20 \mathrm{~h}$ at room temperature to yield the Texas Red-loaded, G2-PAMAM-capped MSN material (Texas Red-loaded G2-MSN). The resulting G2-MSN material was filtered and washed thoroughly with ethanol, methanol and acetone and dried under high vacuum. To ensure the complete removal of Texas Red molecules physisorbed on the exterior surface of the G2-MSN, a Soxhlet extraction in ethanol was performed for $20 \mathrm{~h}$. The resulting solid was filtered and dried in air.

\section{Characterization of ICP-MSN and G2-MSN}

\subsection{Powder X-Ray Diffraction}

Powder XRD experiments were performed on a Scintag XDS 2000 diffractometer using a $\mathrm{Cu} \mathrm{Ka}$ radiation source. Low angle diffraction with a $2 \theta$ range of 1 to $10^{\circ}$ was used to investigate the long-range order of the materials.

\subsection{Nitrogen adsorption/desorption isotherms}

The surface area and median pore diameter were measured using $\mathrm{N}_{2}$ adsorption/desorption measurements in a Micromeritics ASAP 2000 BET surface analyzer system. The data were evaluated using the Brunauer-Emmett-Teller (BET) and BarrettJoyner-Halenda (BJH) methods to calculate the surface area and pore volumes/pore size distributions, respectively. Samples were prepared by degassing at $90^{\circ} \mathrm{C}$ for $1 \mathrm{~h}$ and then at $150{ }^{\circ} \mathrm{C}$ for $4 \mathrm{~h}$. 


\subsection{Solid-state ${ }^{13}$ C CP-MAS NMR}

Solid-state ${ }^{13} \mathrm{C}$ CP-MAS NMR spectra were obtained at $75.47 \mathrm{MHz}$ on a Bruker MSL300 spectrometer equipped with Bruker 4mm rotor MAS probe. Magic-angle sample spinning rate was maintained at $10 \mathrm{KHz}$ for ${ }^{13} \mathrm{C}$ in order to minimize the spin band due to the high anisotropic chemical shifts of aromatic carbons. The NMR spectra consisted of 5,000 to 20,000 acquisitions with cross polarization times of $3 \mathrm{~ms}\left({ }^{13} \mathrm{C}\right)$ and pulse repetition times of $15 \mathrm{~s}\left({ }^{13} \mathrm{C}\right)$. All chemical shifts reported are referenced to liquid $\mathrm{Me}_{4} \mathrm{Si}$ (TMS).

\subsection{Scanning and Transmission Electron Micrographs (SEM and TEM) of G2-} MSN

Particle morphology of these materials was determined by scanning electron microscopy (SEM) with $10 \mathrm{kV}$ accelerating voltage and $0.005 \mathrm{nA}$ of beam current for imaging. For transmission electron microscopy (TEM) studies, a small aliquot was taken from a suspension of methanol and placed in a lacey carbon-coated TEM grid, which was pulled through the suspension and allowed to dry in air. Thin sections of samples embedded in epoxy resin were obtained with ultramicrotomy $(60-80 \mathrm{~nm})$. The resulting sample was examined with a Philips model CM-30 TEM operated at $300 \mathrm{kV}$. The specimen was given no further treatment, as it appeared stable under beam bombardment.

\section{Gene Transfection Experiments of DNA-coated G2-MSNs}

\subsection{Experimental}

Human cervical cancer (HeLa) and Chinese Hamster Ovarian (CHO) cell lines were obtained from American Tissue Culture Collection (ATCC). HeLa and CHO cells were maintained in T75 flasks using DMEM (Dulbbecco's modified Eagle's medium) 
supplemented with $10 \% \mathrm{CS}$ serum, $2 \mathrm{mM} \mathrm{L-glutamine,} 100 \mathrm{U} / \mathrm{mL}$ penicillin, $100 \mu \mathrm{g} / \mu \mathrm{L}$ streptomycin, and $1 \mu \mathrm{g} / \mu \mathrm{L}$ gentamycin. All cells were passaged every 2-3 days. A redshifted variant of GFP expressed from pEGFP-Cl (Clontech, Palo Alto, CA) was used as reporter protein. All plasmids were amplified in the E. coli strain $\mathrm{DH} 5 \alpha$ and purified according to the manufacturer's protocol (Qiagen, USA). The isolated DNA was resuspended in Tris-EDTA (pH 8.0) at a concentration of $1 \mu \mathrm{g} / \mu \mathrm{L}$.

HeLa cells were first seeded onto $24-$ well plates $\left(6 \times 10^{4}\right.$ cells per well, in $0.6 \mathrm{~mL}$ growth medium) and 6-well plates ( $2 \times 10^{5}$ cells per well, in $1.5 \mathrm{~mL}$ growth medium) $24 \mathrm{~h}$ prior to the experiment. The former plating (24-well) was used for transfection efficiency measurements. The 6-well plating was used for imaging studies.

In a typical transfection experiment, $1 \mu \mathrm{g}$ of plasmid DNA encoding GFP was added to $10 \mu \mathrm{g}$ of G2-MSN suspension obtained by dispersing the nanosphere material in $30 \mu \mathrm{L}$ of HEPES buffer solution (10 mM HEPES, pH 7.4). The complex mixture was incubated for 2 $\mathrm{h}$ at $4{ }^{\circ} \mathrm{C}$. A solution of $30 \mu \mathrm{L}$ of $100 \mathrm{mM} \mathrm{CaCl}_{2}$ (aq) was added to the G2-MSN-DNA complex solution and allowed to incubate for another $2 \mathrm{~h}$. The $50 \mathrm{mM} \mathrm{Ca}^{2+}$ was to enhance/stabilize the complexation between DNA and G2-MSN and protect the surfacebound DNA from enzymatic degradation as described in recent literature. The entire $60 \mu \mathrm{L}$ of the G2-MSN-DNA suspension was added to cells cultured on 24-well plates. Given that each well contained $0.6 \mathrm{~mL}$ DMEM, the addition of the suspension resulted in a final $\mathrm{Ca}^{2+}$ concentration of $4.5 \mathrm{mM}$. After incubation for 4 hours at $37^{\circ} \mathrm{C}$, the transfection mixture containing residual G2-MSN-DNA complexes was removed by washing the transfected cells with PBS buffer and cultured with DMEM supplemented with $10 \%$ calf serum (CS) and 
antibiotics. The cultures were maintained for 2 days to monitor gene expression. The transfected cells were then washed with PBS buffer and cultured with DMEM $+10 \%$ calf serum (CS) medium and antibiotics for 2 days for gene expression analysis or image studies. To compare the transfection efficiency of our G2-MSN system with other commercially available transfection reagents, three different reagents, PolyFect ${ }^{(B)}$, SuperFect ${ }^{(B)}$ (Qiagen, Valencia, California) and Metafectene ${ }^{\circledR}$ (Biontex, Germany), were used to transfect the aforementioned cell types under the same experimental condition. First, 8 and $5 \mu \mathrm{L}$ of the stock solutions of PolyFect ${ }^{\boxplus}(2 \mathrm{mg} / \mathrm{mL})$ and SuperFect ${ }^{\boxplus}(3 \mathrm{mg} / \mathrm{mL})$, respectively, were added to a $30 \mu \mathrm{L}$ of serum-free medium (DMEM) containing $1 \mu \mathrm{g}$ DNA. The solutions were incubated at room temperature for $15 \mathrm{~min}$ to allow the formation of stable complexes between DNA molecules and transfection reagents. The complexes were then added to a culture of HeLa cells in a 24 well plate with a cell density of $6 \times 10^{4}$ cells/well that contained $350 \mu \mathrm{I}$ of pre-warmed DMEM $+10 \% \mathrm{CS}$ medium and antibiotics. After $4 \mathrm{~h}$ of incubation, the transfection medium was discarded and replaced with fresh growth medium (DMEM + $10 \% \mathrm{CS}$ medium and antibiotics). The cells were evaluated for expression of the enhanced green fluorescent protein (EGFP) by flow cytometry after $48 \mathrm{~h}$ post-transfection.

For Metafectene ${ }^{\circledR}$, the protocol involved the addition of $5 \mu \mathrm{L}$ stock solution of

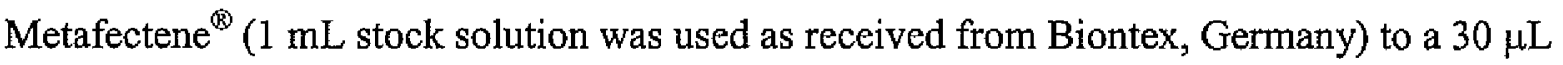
of serum-free medium (DMEM) containing $1 \mu \mathrm{g}$ DNA. This solution was incubated at room temperature for $15 \mathrm{~min}$ to allow complex formation before the addition to the cells. The complexes were added to the aforementioned HeLa cell wells that contained $350 \mu \mathrm{L}$ of prewarmed, serum-free DMEM. After $4 \mathrm{~h}$ of incubation, the transfection medium was discarded 
and replaced with fresh growth medium (DMEM $+10 \% \mathrm{CS}$ medium and antibiotics). Cells were evaluated for expression of the enhanced green fluorescent protein (EGFP) by flow cytometry after $48 \mathrm{~h}$ post-transfection.

\subsection{Stability Studies of pEGFP-C1 DNA and G2-MSN-DNA Complex}

DNA was released from the G2-MSN particles by vigorous agitation in $2 \mathrm{M} \mathrm{NaCl}$ at $50{ }^{\circ} \mathrm{C}$ for $30 \mathrm{~min}$. The supernatant was collected by micro-centrifugation at $14000 \mathrm{rpm}$ at 4 ${ }^{\circ} \mathrm{C}$ for 15 min. After ethanolic precipitation, the DNA was resuspended in TE buffer and loaded in the gel.

\subsection{Flow Cytometry Analysis of Transfection Efficiencies of G2-MSN and Other Reagents}

Flow cytometric measurements were performed immediately after collection of cultured cells. All cells were trypsinized and resuspended in $0.5 \mathrm{~mL}$ of PBS before the FACS analysis. Positive and negative control experiments utilizing cultures of untransfected cells (HeLa cells only) and "mock"-transfected cells (cells incubated with MSNs without pEGFP-CI plasmid) were measured with an EPICS-ALTRA flow cytometer (Beckman Coulter, Miami, FL), using a $488 \mathrm{~nm}$ laser for GFP excitation. GFP fluorescence was detected using PMT2 in conjunction with a $525 \mathrm{~nm}$ band-pass filter. An electronic gate was set around cells based on the forward and side scatter properties of the population, and a minimum of 10,000 gated events per sample were collected and stored in list mode files. Data analysis was performed with FlowJo software (Tree Star, Ashland, OR). Scatter-gated events are displayed herein as single parameter histograms of logarithmic GFP fluorescence. All experiments were performed in quadruplicate. Untransfected cells were used for 
background calibration. The average transfection efficiencies of different transfection reagent systems on HeLa cells were summarized in Table 8-3.

\subsection{Confocal Microscopy Imaging of Transfected Cells}

HeLa cells were grown on coverslips in a 6-well culture plate. All of the samples were washed three times with PBS buffer and fixed with formaldehyde in PBS (3.7\%). The samples were excited by an argon laser $\left(\lambda_{\mathrm{ex}}=488 \mathrm{~nm}\right)$ and the images were subject to a longpass filter $(\lambda=515 \mathrm{~nm})$. Images were captured on an inverted Nikon Eclipse microscope connected to a Prairie Technologies (Middleton, WD) Scanning Laser Confocal Microscope controlled by Prairie Technologies software. Images were analyzed using Metamorph software (Universal Imaging, West Chester, PA).

\subsection{Transmission Electron Micrographs of G2-MSN transfected Cells}

To study the endocytosis of G2-MSN-DNA complexes, post-transfection cells on coverslips were fixed at selected time-points with $2 \%$ glutaraldehyde and $2 \%$ paraformaldehyde in PBS buffer, $\mathrm{pH} 7.2$, at $4{ }^{\circ} \mathrm{C}$ for $48 \mathrm{~h}$. The samples were then washed in PBS followed by washing in $0.1 \mathrm{M}$ cacodylate buffer, $\mathrm{pH} 7.2$, and post-fixed in $1 \%$ osmium tetroxide in $0.1 \mathrm{M}$ cacodylate buffer for 1 hour at room temperature. The samples were then washed briefly in $\mathrm{dH} 2 \mathrm{O}$ and dehydrated through a graded ethanol series and cleared using ultra pure acetone and infiltrated and embedded with EPON epoxy resin (EmBed 812, Electron Microscopy Sciences, Ft. Washington, PA). Coverslips were embedded by inverting the slips (cell side down) onto upright beem capsules and polymerized at $60^{\circ} \mathrm{C}$ for 24 hand $70{ }^{\circ} \mathrm{C}$ for $24 \mathrm{~h}$. The coverslips were removed from the resin with liquid nitrogen. Thin sections were made using a Reichert Ultracut S ultramicrotome (Leica, Deerfield, IL) and collected onto copper grids and stained with $4 \%$ uranyl acetate in $50 \%$ methanol followed by 
Sato's lead stain. Images were collected using a JEOL 1200 EXII scanning and transmission electron microscope (Japan Electron Optics Laboratory, Peabody, MA.) at $80 \mathrm{kV}$ with a Megaview III digital camera and SIS Pro software (Soft Imaging System, Corp., Lakewood, $\mathrm{CO})$.

\subsection{Cell Growth Studies}

To further demonstrate the in vitro biocompatibility of the G2-MSN, growth studies were performed for HeLa and $\mathrm{CHO}$ cells. Two series of experiments were designed for both types of cells: one series studied the natural cells growth (without MSNs) and the other was monitored after MSNs application. All experiments were performed in triplicate. To ensure enough space and media for cell growing, the cells were seeded in T-25 flasks. In the experiments without MSNs, 18 flasks were loaded with the same amount of cells for each cell type. After allowing $24 \mathrm{~h}$ for cell adhesion, the cells were analyzed everyday ( 3 flasks per day) for 6 days. The cells were trypsinized and counted by using a Guava ViaCount $($ assay (Guava Technologies, Inc, USA). In the experiments with G2-MSNs, the cells were seeded for $24 \mathrm{~h}$ prior to the incubation with MSNs at $0.1 \mathrm{mg} / \mathrm{mL}$ concentration in DMEM + $10 \% \mathrm{CS}$ (calf serum) and antibiotics for $4 \mathrm{~h}$. After the $4 \mathrm{~h}$ incubation, the cells were washed twice with PBS buffer and incubated for another 6 days. The aforementioned cell counting procedures were followed. All experiments were performed in triplicate ( 3 flasks /day). During the 6-day growth period, the cells were periodically examined under a phase contrast microscope. The cells were added with fresh media every other day or upon $\mathrm{pH}$ fluctuations (Phenol Red dye was used as $\mathrm{pH}$ indicator). The doubling times of the cell density of HeLa cells without and with MSNs were calculated from the semilog plots to be $20 \mathrm{~h}$ and $24 \mathrm{~h}$, respectively. The doubling times of CHO cells without and with MSNs were calculated to be 
$21 \mathrm{~h}$ and $24 \mathrm{~h}$, respectively. $\left(\mathrm{R}^{2}>97 \%\right.$ in the case of HeLa cells, whereas $\mathrm{R}^{2}>97.6 \%$ for CHO cells).

\section{Results and Discussions}

The G2-PAMAM-capped MSN material (G2-MSN) was used to complex with a plasmid DNA (pEGFP-C1) that codes for an enhanced green fluorescence protein. ${ }^{3}$ We have investigated the gene transfection efficacy, uptake mechanism, and biocompatibility of the G2-MSN with neural glia (astrocytes), human cervical cancer (HeLa), and Chinese hamster ovarian (CHO) cells.

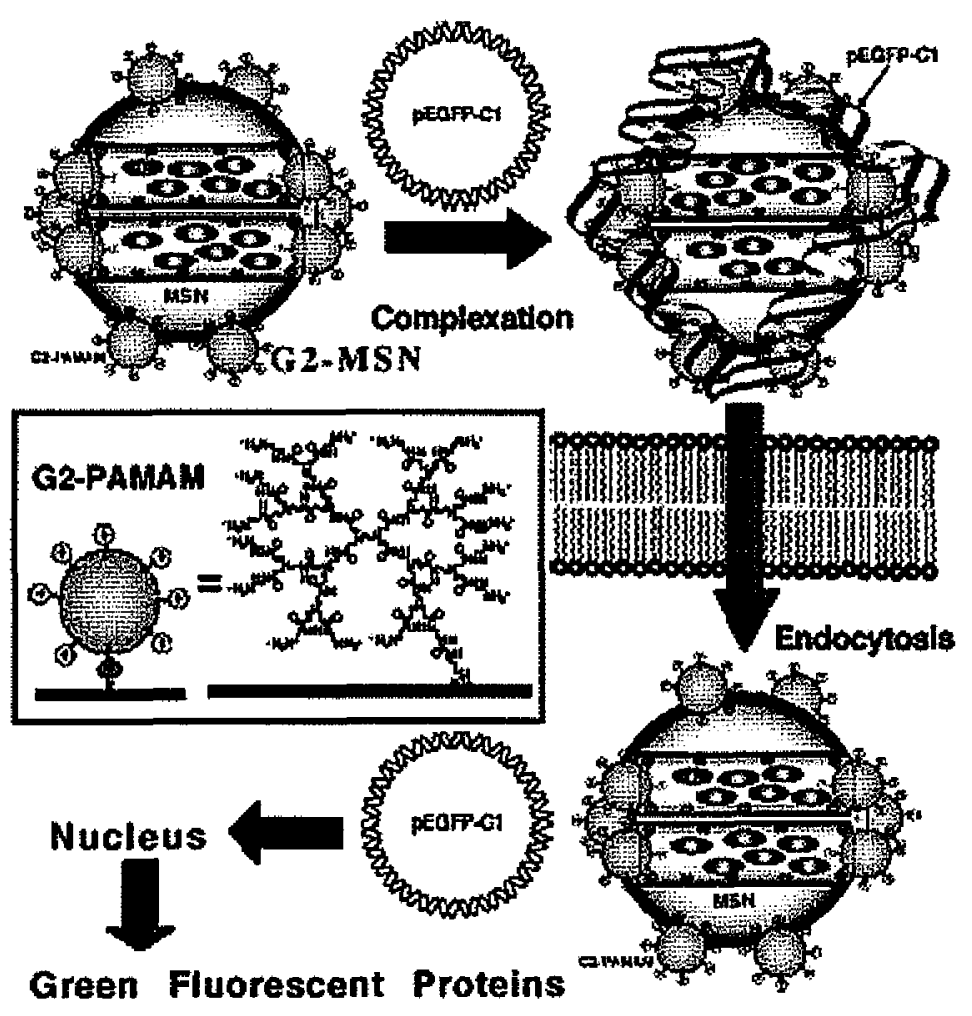

Figure 8-2. Schematic representation of a non-viral gene transfection system based on a Texas Red. (TR)loaded, G2-PAMAM dendrimercapped MSN material complexed with an enhanced green fluorescence protein (Aequorea victoria) plasmid DNA (pEGFP-C1). 
In contrast to other recently reported silica nanoparticle-based gene transfer systems, ${ }^{4}$ the mesoporous structure of the MSN allows membrane impermeable molecules, such as pharmaceutical drugs and fluorescent dyes, to be encapsulated inside the MSN channels. ${ }^{2,5}$

The system renders the possibility to serve as a universal transmembrane carrier for intracellular drug delivery and imaging applications. To the best of our knowledge, no uptake study of MCM-41 type mesoporous silicas into eukaryotic cells have been reported before.

To construct the G2-MSN gene transfer system, a MSN material with an average particle size of $250 \mathrm{~nm}$ (avg. pore diameter $=2.7 \mathrm{~nm}$ ) was synthesized via our previously reported method. $^{2}$ 3-Isocyanatopropyltriethoxysilane $(0.25 \mathrm{~mL}, 1 \mathrm{mmol})$ was grafted onto the pore surface of the MSN $(1 \mathrm{~g})$ in $80 \mathrm{~mL}$ of toluene for $20 \mathrm{~h}$ to yield the isocyanatopropylfunctionalized MSN (ICP-MSN) material.

To visualize the interaction of MSNs and cells, we prepared a G2-MSN material loaded with a fluorescent dye (Texas Red $\left.{ }^{\mathrm{TM}}\right)$. ICP-MSN $(0.15 \mathrm{~g})$ was added to an anhydrous ethanol solution of Texas Red ${ }^{\mathrm{TM}}(5 \mathrm{mM})$, and stirred for $20 \mathrm{~h}$. The amine-terminated G2PAMAMs were used as caps to encapsulate Texas Red molecules inside the porous channels of ICP-MSN. An ethanol solution of G2-PAMAM $(0.11 \mathrm{mmol})$ was added to the MSN/Texas Red solution for $20 \mathrm{~h}$ to form urea linkage between amines of PAMAM and ICP groups of MSN (Figure 8-1,2 inset). The structure of G2-PAMAM-capped, Texas Red-encapsulated MSN were scrutinized by XRD, SEM, TEM, $\mathrm{N}_{2}$ sorption isotherms, and ${ }^{13} \mathrm{C}$ CP.MAS NMR spectroscopy and also summaried in the following (Figure 8-3 to 5) ${ }^{6}$. 


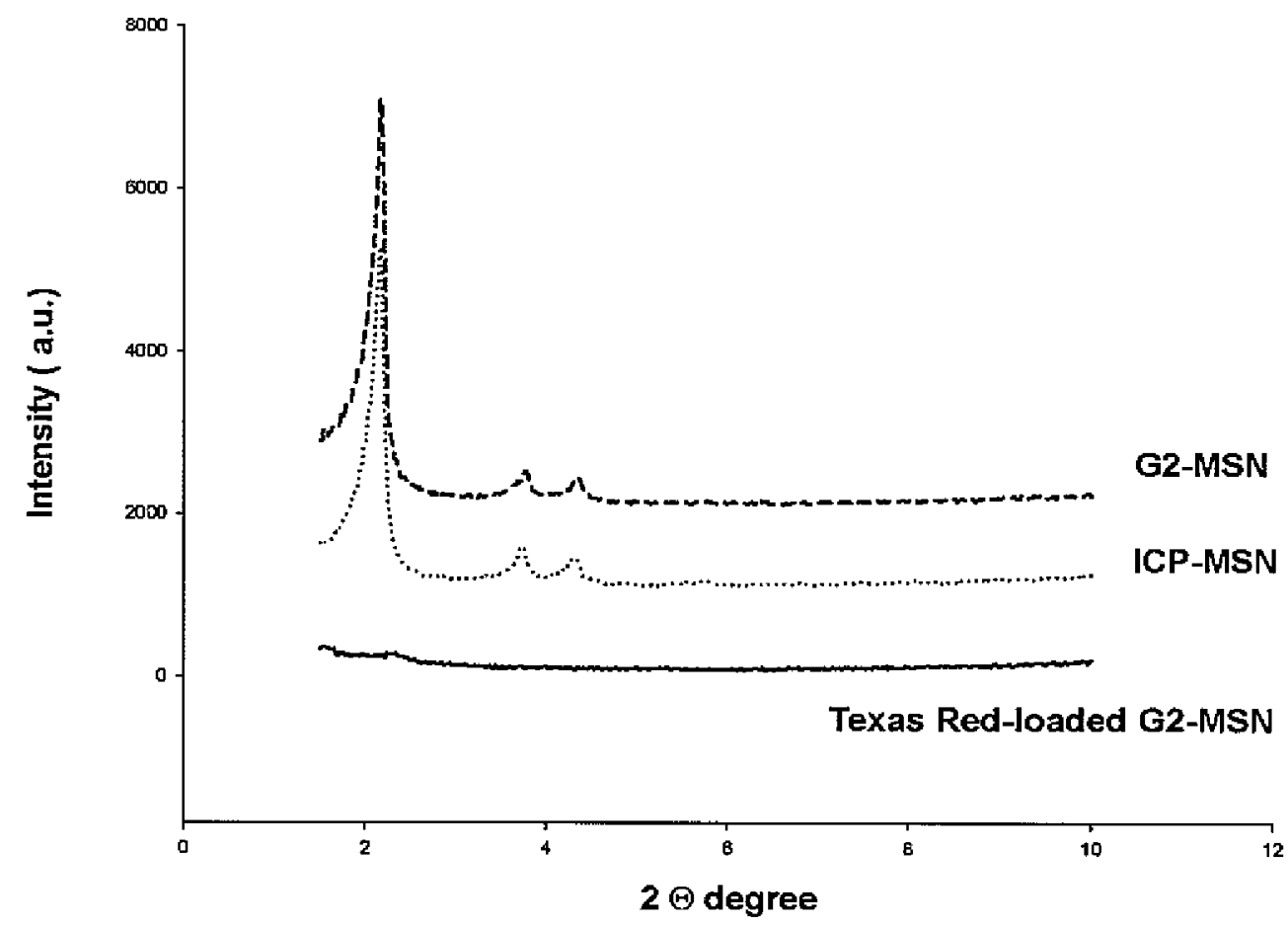

Figure 8-3. Powder X-Ray diffraction patterns of purified ICP-MSN, G2-MSN, and Texas Red-loaded G2MSN materials. Both ICP-MSN and G2-MSN materials exhibit the typical diffraction patterns of MCM-4I type mesoporous silica with hexagonal symmetry. The changes in the Tex Red-loaded G2-MSN diffraction pattern might be caused by pore filling effect.

Table 8-1. Powder X-Ray diffraction patterns

\begin{tabular}{|c|c|c|c|}
\hline \multirow{2}{*}{ Sample } & \multicolumn{3}{|c|}{ Powder XRD Diffraction } \\
& $d_{100}(\AA)$ & $d_{110}(\AA)$ & $d_{200}(\AA)$ \\
\hline ICP-MSN & 40.88 & 23.61 & 21.05 \\
\hline G2-MSN & 40.88 & 23.48 & 21.05 \\
\hline
\end{tabular}



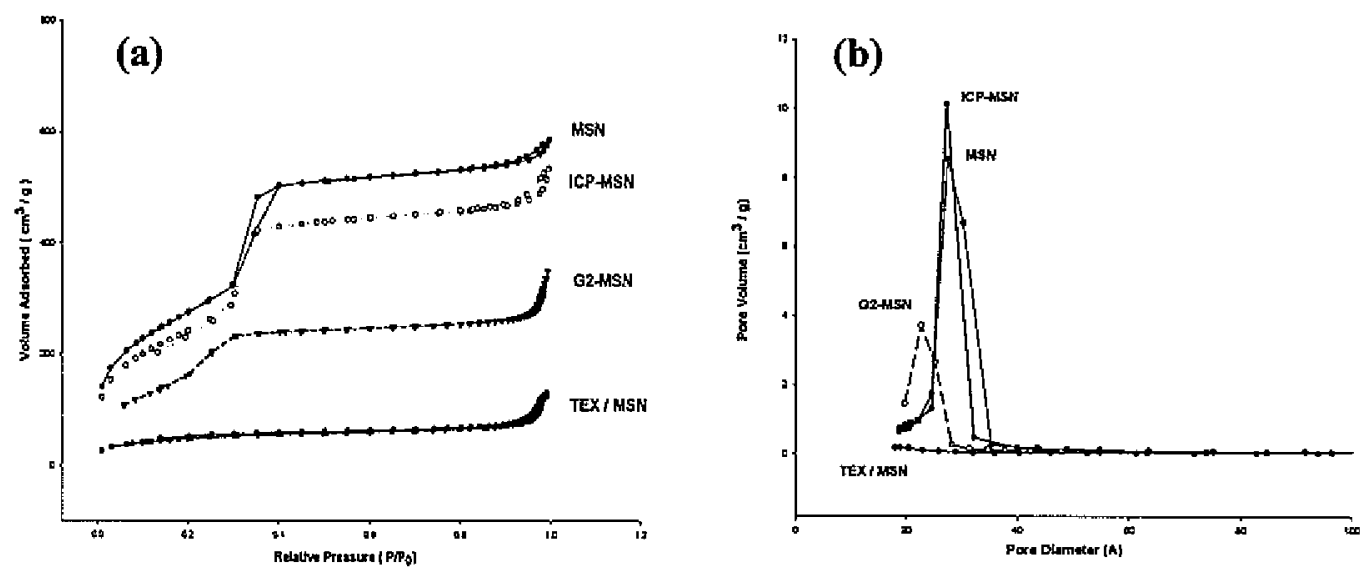

Figure 8-4. BET nitrogen adsorption/desorption isotherms (a) and BJH pore size distributions (b) of MSN, ICP-MSN, G2-MSN, and Texas Red-loaded G2-MSN materials. The BET isotherms of ICP-MSN and G2-MSN materials didn't exhibit any hysteresis indicated that there was no xerogel formation on the exterior surface of the MSN upon surface functionalization.

Table 8-2. BET and BJH parameters

\begin{tabular}{|c|c|c|c|}
\hline \multirow{2}{*}{ Sample } & \multicolumn{3}{|c|}{ Nitrogen Sorption Isotherms } \\
& BET Surface Area & BET Pore Volume & BJH Pore diameter \\
& $\left(\mathrm{m}^{2} / \mathrm{g}\right)$ & $(\mathrm{mL} / \mathrm{g})$ & 27.3 \\
\hline MSN & 959 & 0.865 & 27.2 \\
\hline ICP-MSN & 842 & 0.755 & 22.6 \\
\hline G2-MSN & 568 & 0.481 & 18.8 \\
\hline Texas Red-loaded & 167 & 0.190 & \\
\hline G2-MSN & & & \\
\hline
\end{tabular}



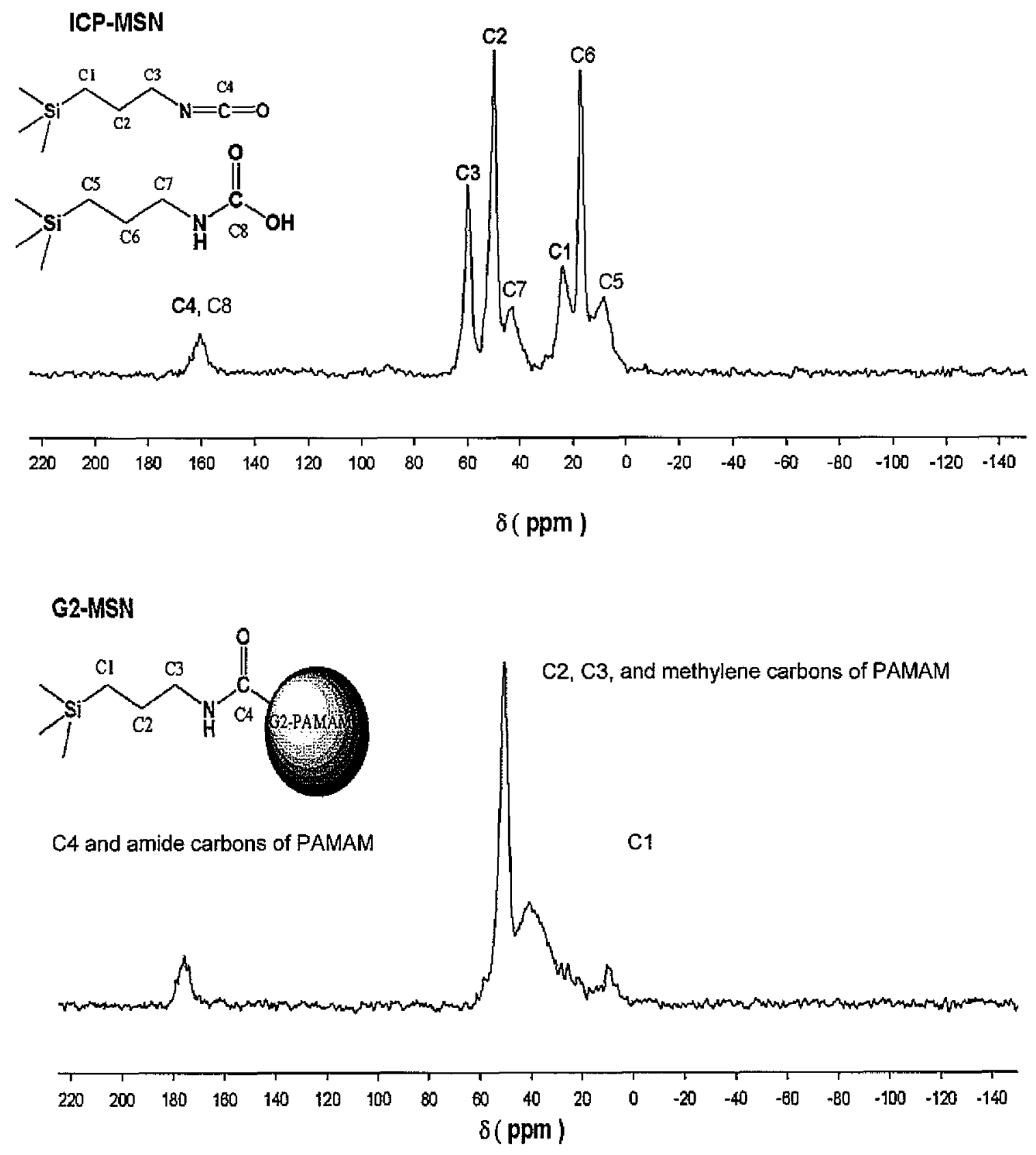

Figure $8-5 .{ }^{13} \mathrm{C}$ solid state CP-MAS NMR spectra of the ICP-MSN (top) and G2-MSN (bottom) materials. Propyl-carbamic acid impurity from the hydrolyzed isocyanopropyl groups of the ICP-MSN was also observed in the spectrum of ICP-MSN. 

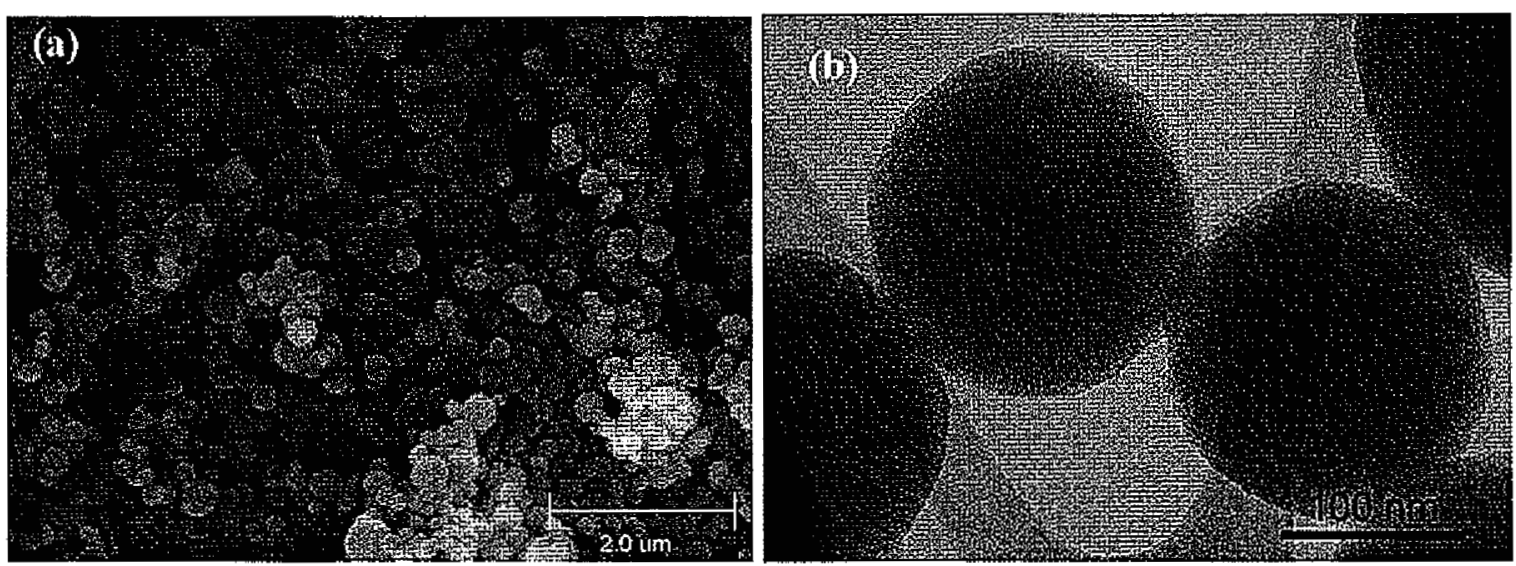

Figure 8-6. SEM (a) and TEM (300 kV) micrographs of the G2-MSN (b). The spherical shape of the silica particles is illustrated in the SEM image (a). The MCM-41 type of mesoporous channel structure of the G2MSN is visualized by the parallel stripes shown in the micrograph (b).

To study the complexation between the pEGFP-C1 DNA and G2-MSN in different weight ratios at physiological $\mathrm{pH}$, agarose gel electrophoresis $(0.8 \%, 45 \mathrm{mM}$ TBE buffer) of pEGFP-C1 in the presence of G2-MSNs was performed for $3.5 \mathrm{~h}$ at $155 \mathrm{~V}$.

Figure 8-7a shows the electrophoretic shifts for pEGFP-C1 in the absence (lane 2) of G2-MSN and presence of increasing amounts (lane 3-8) of G2-MSN. The results demonstrated that the G2-MSN could bind with plasmid DNA to form stable DNA-MSN 1:5, as illustrated by the retention of pEGFP-C1 around the sample wells (lane 6-8). Similar to the high G PAMAMs with large numbers of positive surface charges, each G2-MSN particle was covered with numerous covalently anchored G2PAMAMs. Thus, the resulting polycationic G2-MSN could complex with the polyanionic pEGFP-C1 efficiently without paying a large entropy penalty as in the case of free G2 PAMAMs complexing with plasmid DNAs. ${ }^{\text {la }}$ To examine whether the G2-MSN are efficient in protecting pEGFP-C1 DNA against enzymatic cleavage, a restriction endonuclease ( $B a m \mathrm{H} \mathrm{I}, 2$ units) was introduced to the DNA and the stable G2-MSN-DNA complexes containing $1 \mu \mathrm{g}$ of DNA. 

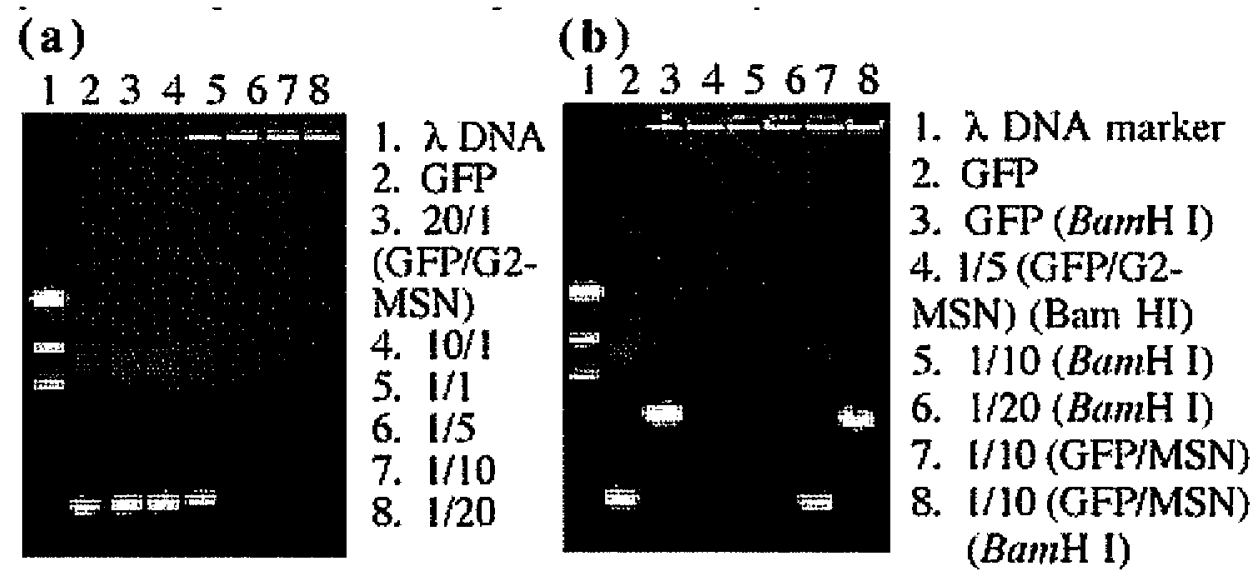

Figure 8-7. Complexation of G2-MSN with pEGFP-C1 DNA (GFP). (a)Electrophoretic gel shifts of GFP in the absence (lane 2) and increasing amounts of G2-MSN (lane 3-8). (b) Electrophoretic gel shifts of GFP complexed with la and uncapped MSN (MSN). Lane 2 is undigested free GFP, whereas lane 3 is the GFP digested with BamH I endonuclease. Lane 4-6 are GFP complexed with different ratios of G2- MSN and treated with BamH I. Lane 7 and 8 are the GFP complexed with uncapped MSN untreated and treated with BamH I respectively.

The samples were incubated for $2 \mathrm{~h}$ at $37^{\circ} \mathrm{C}$, followed by deactivation of enzyme at $70{ }^{\circ} \mathrm{C}$ for $15 \mathrm{~min}$. As shown in Figure 8-7b, free pEGFP-C1 (lane 2) was digested and cleaved by BamH I, whereas the DNAs when complexed with MSNs (lane 4-6) were not cleaved by the enzyme under the same condition. We also extracted the pEGFP-Cl from the

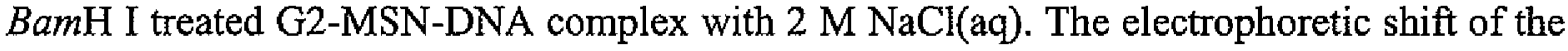
extracted DNA was the same as that of the free pEGFP-C1 suggested that the G2-MSN-DNA complex could protect DNA from enzymatic degradation. ${ }^{6}$ Interestingly, pEGFP-CI DNA was digested by BamH I in the presence of MSN without PAMAM caps (Figure 8-7b, lane 8). 


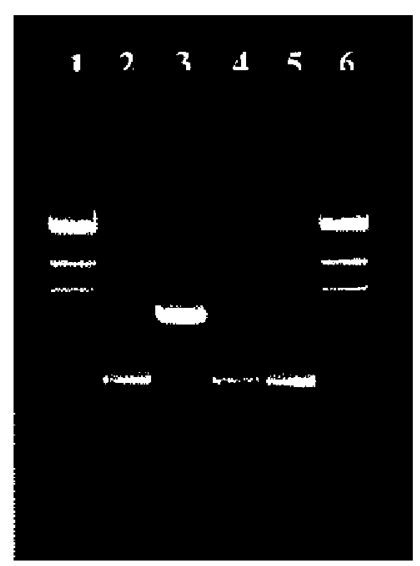

Figure 8-8. Electrophoretic gel shifts of stability Studies of pEGFP-Cl DNA and G2-MSN-DNA Complex after Bam H1 treatment. Lanes 1 and 6: DNA marker ( $\lambda$ DNA). Lanes 2 and 5: Undigested free plasmid DNA

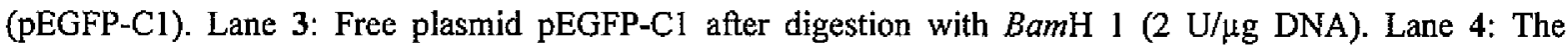

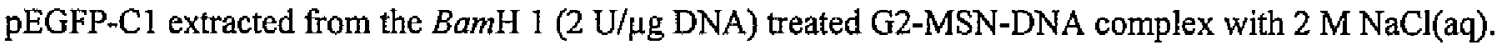

The result indicated that the G2-MSN-DNA complex could protect pEGFP-C1 DNA from enzymatic degradation (Figure 8-9).
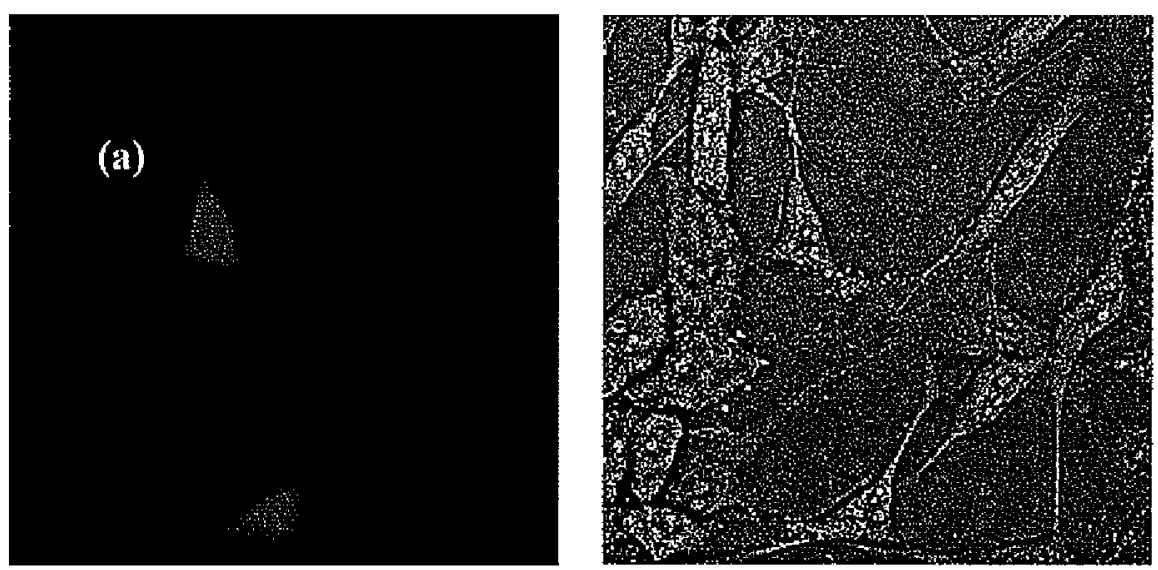

Figure 8-9. Fluorescent microscopy images of HeLa cells treated with G2-MSN-DNA complexes that have first been exposed to $B a m H$ I. (a) HeLa cells with green fluorescent proteins expressed. (b) Phase contrast image of the same region of interest. 
To investigate the transfection efficacy of our system, G2-MSNs without Texas Red $(10 \mu \mathrm{g})$ were mixed with $1 \mu \mathrm{g}$ of pEGFP-C1.6 The MSN/DNA suspension $(60 \mu \mathrm{L} /$ well $)$ was further added to the cells on 24 -well plates $(6 \times 104$ cells per well, in $0.6 \mathrm{~mL}$ growth medium) and incubated for 4 hours at $37^{\circ} \mathrm{C}$. The cells were then washed with PBS buffer and cultured with DMEM $+10 \%$ calf serum (CS) medium and antibiotics for 2 days. The transfected cells were trypsinized and resuspended in $0.5 \mathrm{ml}$ of PBS for direct flow cytometric analysis to evaluate the expression of GFP.3 Control experiments utilizing cultures of untransfected cells and "mock"-transfected cells (cells incubated with MSNs without pEGFP-C1) were measured with an EPICS-ALTRA flow cytometer. As shown in Figure 8-10 and Table 8-3, significant GFP-expression was observed. To compare the transfection efficiency of G2MSN with other commercial transfection reagents, we conducted pEGFP-C1 transfection experiments on HeLa cells with PolyFect, SuperFect, and Metafectene under the same experimental conditions. ${ }^{6}$ Flow cytometry analyses on the $48 \mathrm{~h}$ post transfection cells showed efficiencies of $35 \pm 5 \%$ (G2-MSN), $15 \pm 2 \%$ (PolyFect), $10 \pm 2 \%$ (SuperFect), and $16 \pm 2 \%$ (Metafectene). ${ }^{6}$

Table 8-3. Transfection Efficiency of different transfection reagents on HeLa cells.

\begin{tabular}{ccc}
\hline Transfection Reagent & $\begin{array}{c}\text { Population } \\
(\%)\end{array}$ & X mean Intensity \\
\hline G2-MSN & $35 \pm 5$ & $129 \pm 13$ \\
PolyFect $^{\text {(6) }}$ & $15 \pm 2$ & $312 \pm 4$ \\
Superfect $^{(3)}$ & $10 \pm 2$ & $250 \pm 50$ \\
Metafectene $^{\text {(2) }}$ & $16 \pm 2$ & $248 \pm 20$ \\
\hline
\end{tabular}


(a) Naked DNA

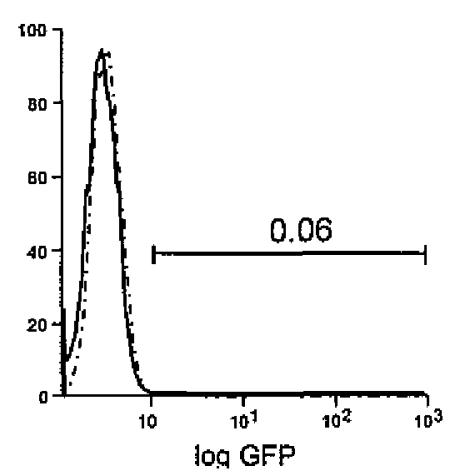

(d) Polyfect ${ }^{\mathrm{rM}}$

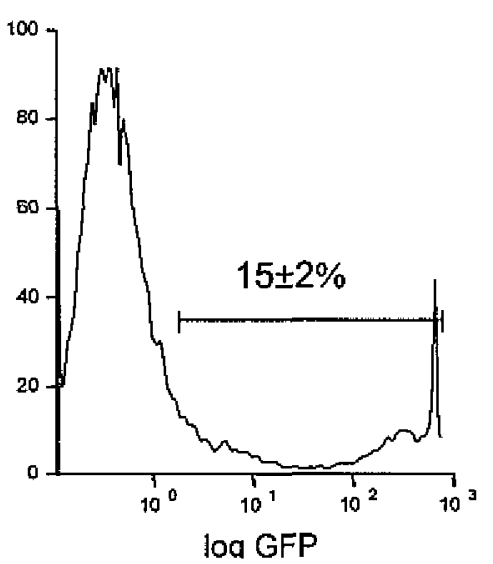

(b) Mock

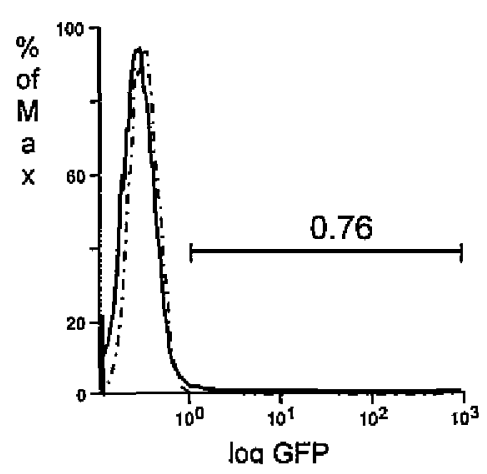

(e) Metafectene $\mathrm{T}^{\mathrm{TM}}$

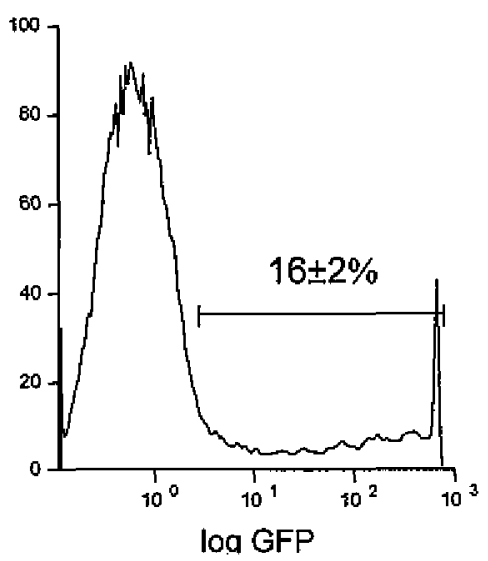

(c) DNA coated G2-MSN

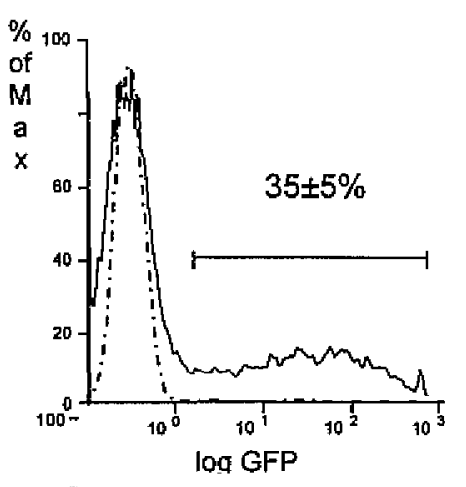

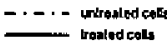

(f) Superfect ${ }^{\mathrm{TM}}$

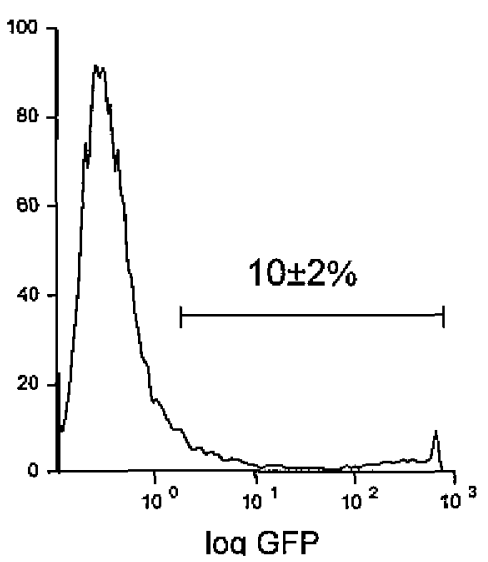

Figure 8-10. Flow cytometry analysis of the transfection of pEGFP in HeLa cells with G2-MSN. The flow cytometry histograms show distribution of events on the green (FL1) channel. (a) Nontransfected control experiment: HeLa cells (dashed line) and HeLa cells treated with pEGFP-CI DNA (solid line). (b) "Mock" transfection control experiment: HeLa cells (dashed line) and HeLa cells treated with MSNs without DNA (solid line). (c) G2-MSN transfection results: HeLa cells (dashed line) and HeLa cells treated with pEGFP-C1 DNA-coated G2-MSNs. HeLa cells transfected different commercially available transfection reagents (d), (e), and (f). 
The transfection enhancement of the G2-MSN could be attributed to the particle sedimentation effect as previously reported by Luo et al ${ }^{4 \mathrm{a}, \mathrm{d}}$ To examine the mammalian cell membrane permeability, Texas Red-loaded G2-MSNs were introduced to GFP-transfected rat astrocytes. The confocal fluorescence micrograph (Figure 8-11b) clearly illustrated that the G2-MSNs (red fluorescent dots) entered into the cytoplasm of a green fluorescent neural glia cell.
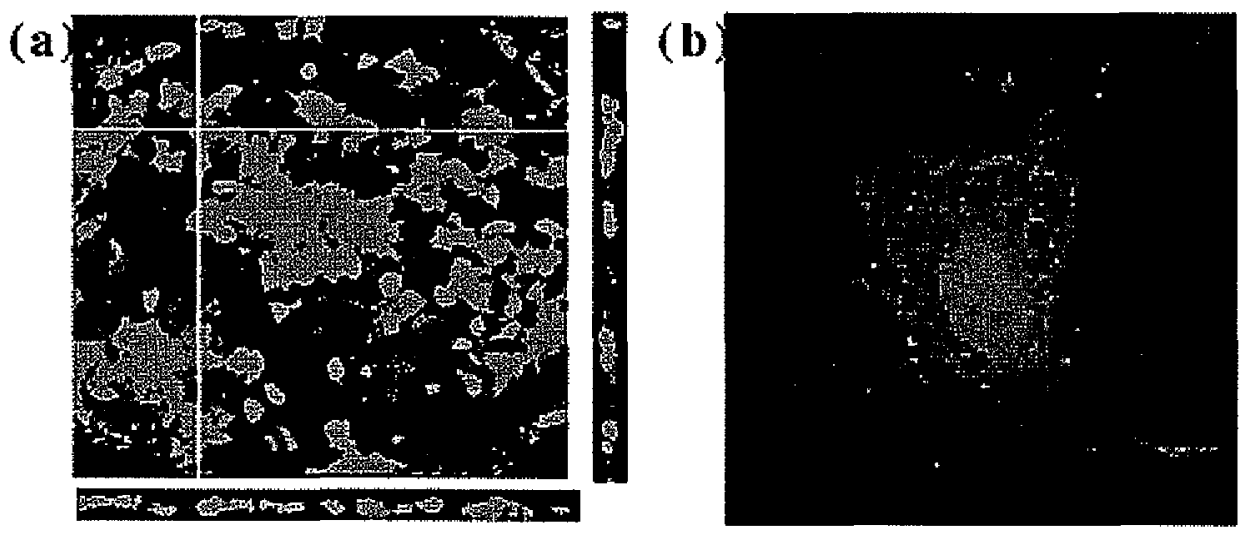

Figure 8-11. Fluorescence confocal micrographs of cells transfected by pEGFP-C1-coated G2-MSN system (a) GFP transfected HeLa cells showing cross-sections through a cell layer. Orthogonal images indicated the monolayer packing of cells. (b) Texas Red-loaded G2-MSNs inside a GFP-transfected rat neural glia cell (astrocyte).

Transmission electron micrographs of the posttransfection cells also provided direct evidence that a large number of G2-MSN-DNA complexes were endocytosed by all three types of cells (Figure 8-12). It is noteworthy that many subcellular organelles, such as mitochondria and Golgi, were observed with MSNs nearby as shown in Figure 8-12b, $c$ and d. Given the fact that these organelles disappear rapidly upon cell death, the result strongly suggested that the MSNs were not cytotoxic in vitro. 


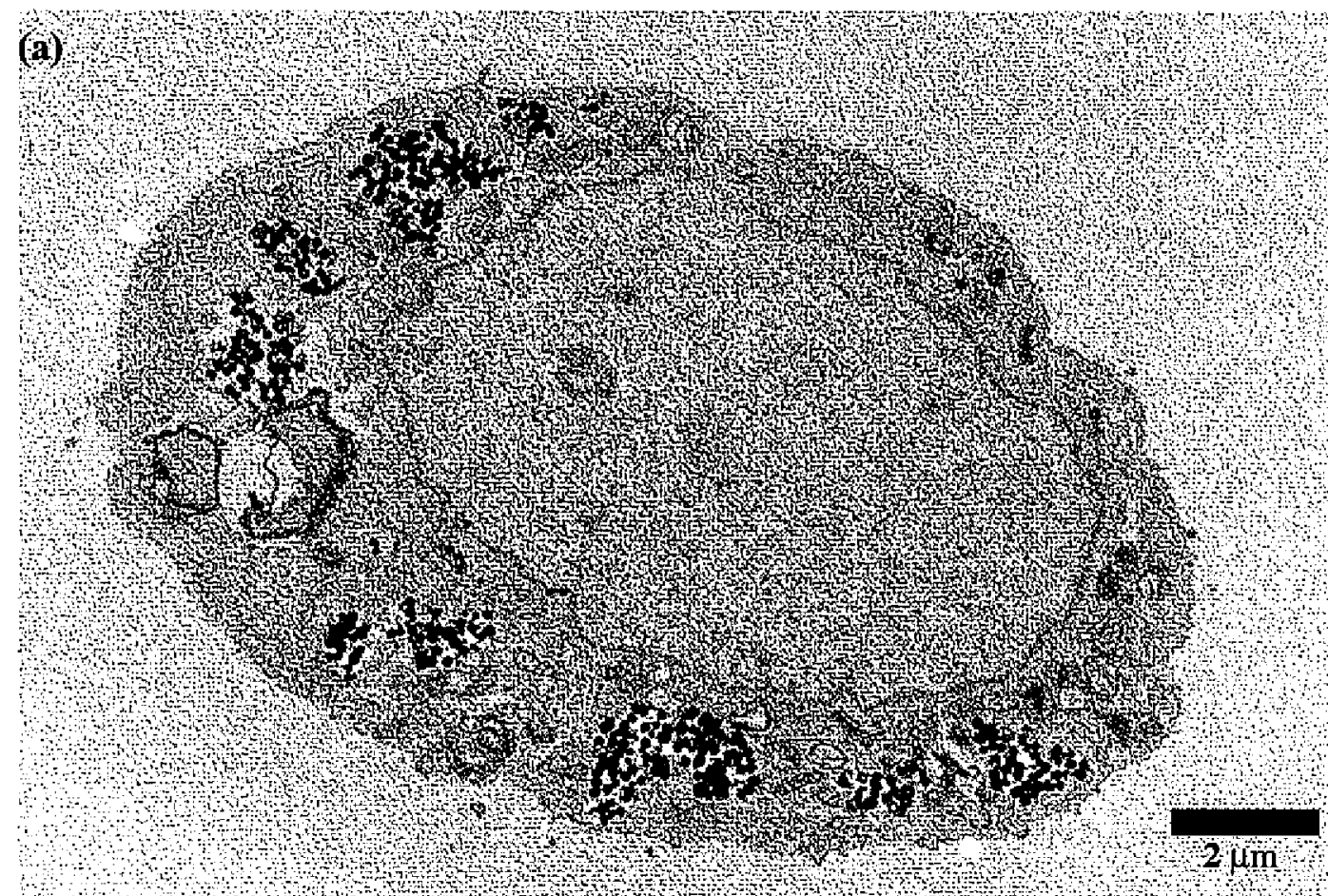

(b)

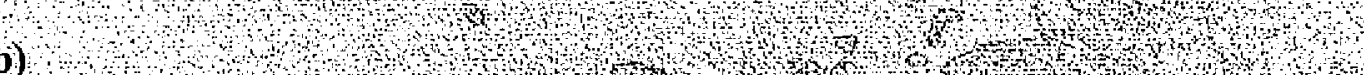
- m-

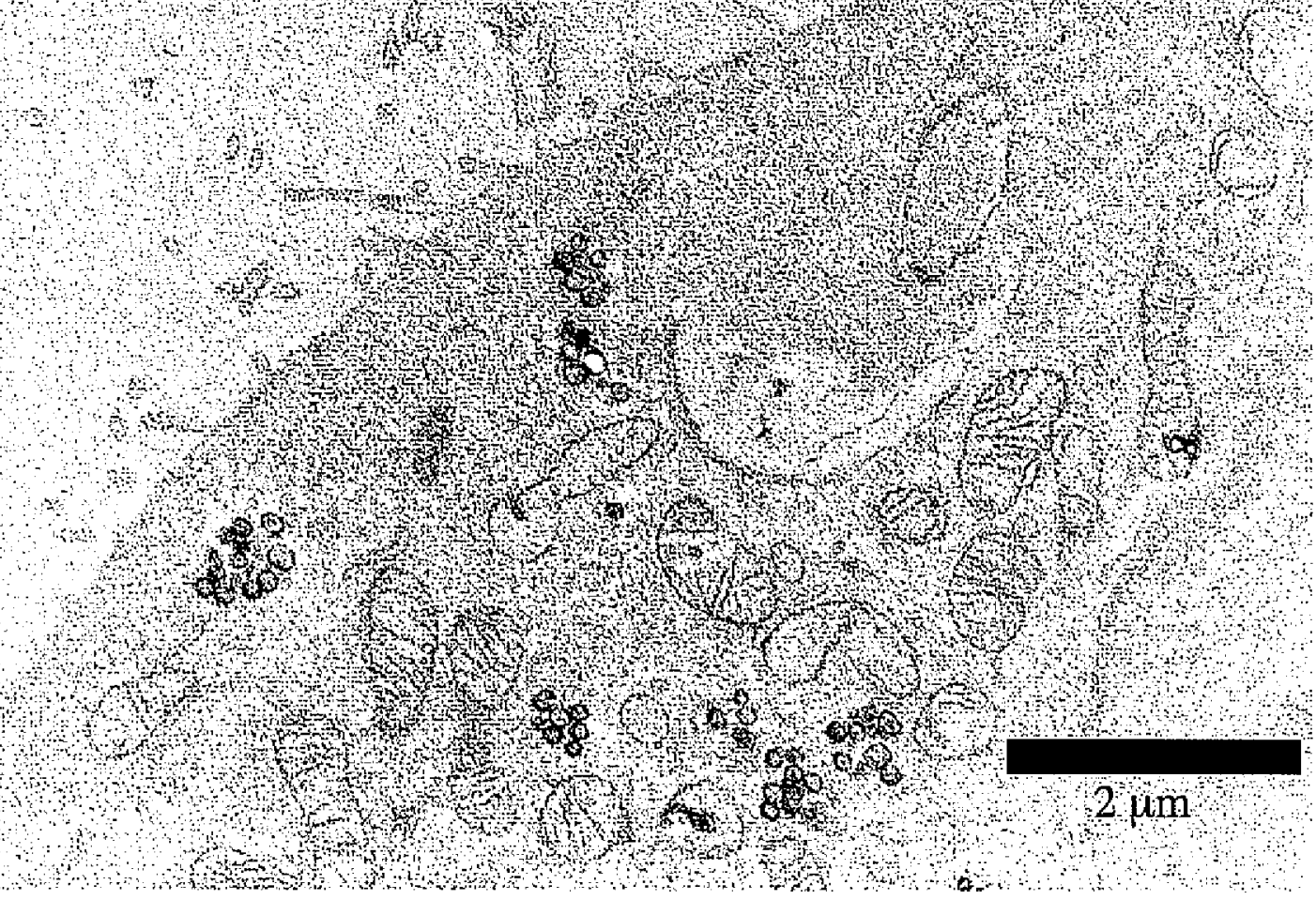



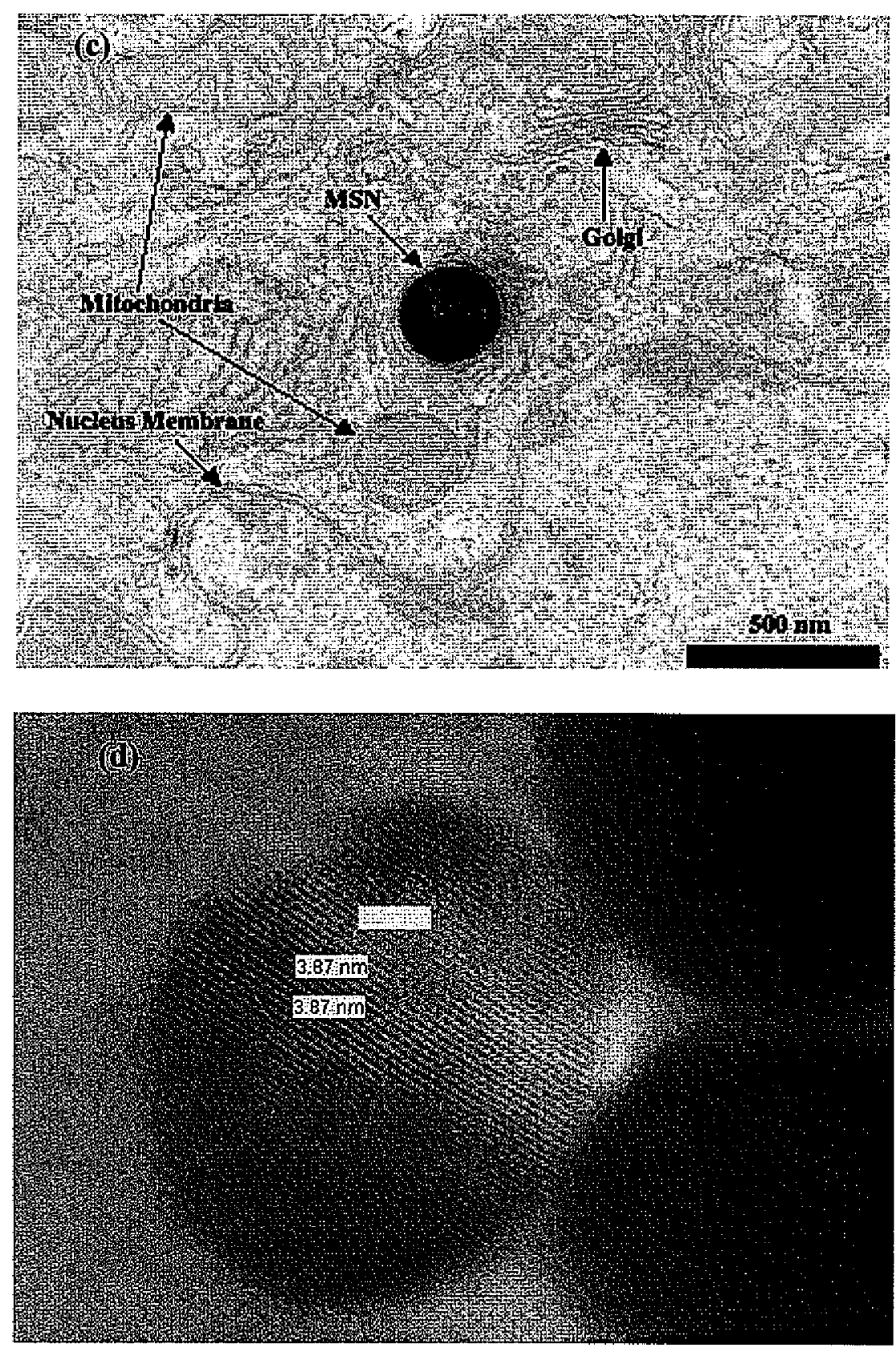

Figure 8-12. TEM micrographs of G2-MSN-DNA complexes (black dots) endocytosed by Chinese hamster ovarian (CHO) (a), human cervical cancer (HeLa) (b), and neural glia (astrocytes) (c) cells. Subcellular organelles, e.g., mitochondria and Golgi, were observed with MSNs nearby (b) and (c). The measured distance between channels (d) (including the pore walls) is consistent with the BJH average pore diameter of 3-4 nm from $\mathrm{N}_{2}$ sorption isotherms of the MSN material alone. 
To further investigate the biocompatibility of G2-MSN, we compared the cell growth profiles of HeLa cultures without and with G2-MSNs $(0.1 \mathrm{mg} / \mathrm{mL})$. The numbers of cells from cultures with and without G2-MSNs were counted daily for 6 days. ${ }^{6}$ The doubling times of the cell density of HeLa cells without and with MSNs were calculated from the semilog plots to be $20 \mathrm{~h}$ and $24 \mathrm{~h}$, respectively. The doubling times of CHO cells without and with MSNs were calculated to be $21 \mathrm{~h}$ and $24 \mathrm{~h}$, respectively. $\left(\mathrm{R}^{2}>97 \%\right.$ in the case of HeLa cells, whereas $\mathrm{R}^{2}>97.6 \%$ for $\mathrm{CHO}$ cells)

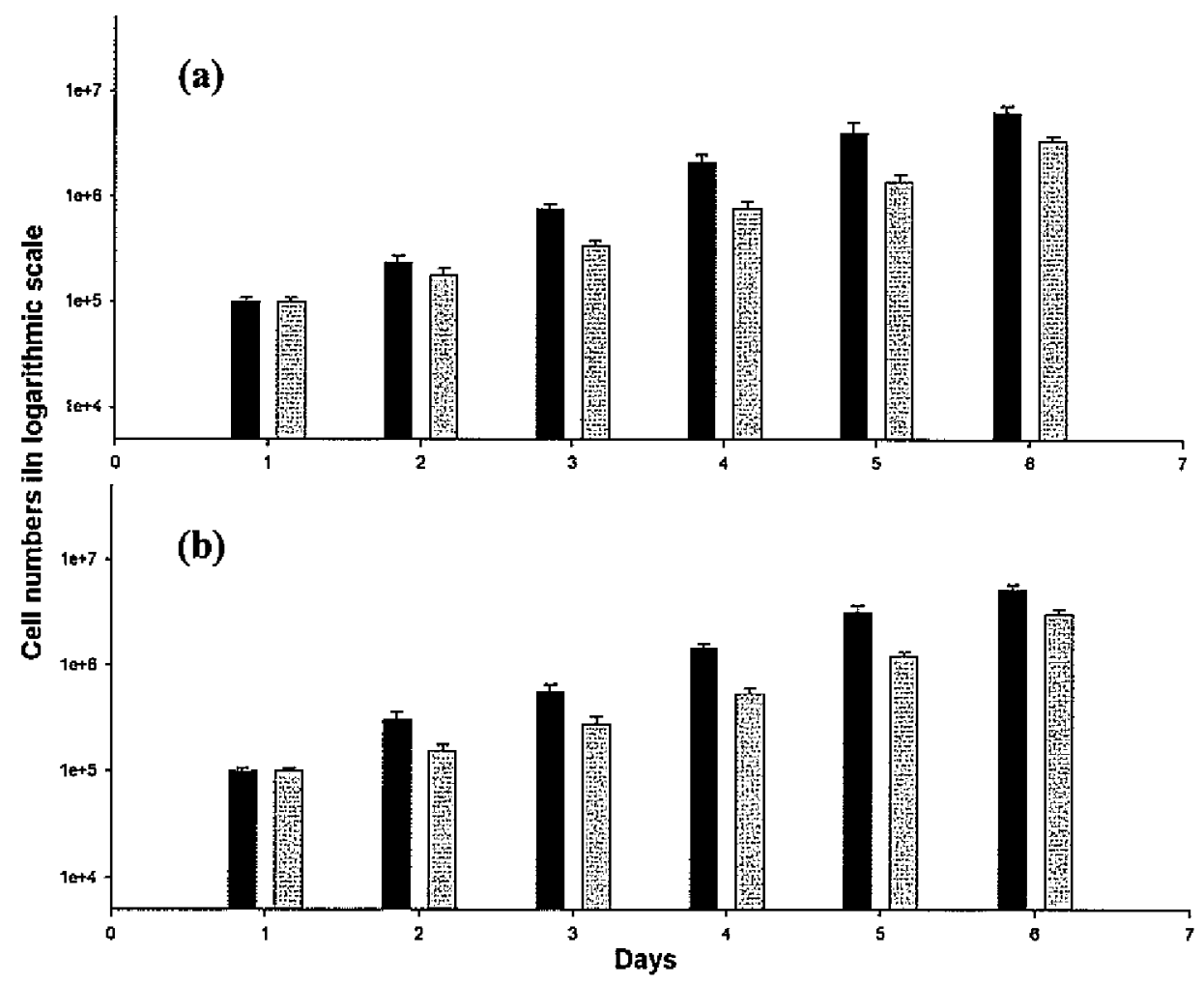

Figure 8-13. Cell growth of (a) HeLa and (b) CHO cells in the presence of G2-MSN (gray bars) and in the absence of G2-MSN (black bars).

Shown in Figure 8-13, the slopes of the cell growth curves from those cultures with and without G2-MSNs were very similar indicated that the increase of numbers of cells was 
not hindered by the presence of G2-MSNs. We envision that the G2-MSN material could serve as a new transmembrane delivery system for many biotechnological applications.

\section{Conclusions}

The mesoporous structure of the MSN material shows exogeneous biomolecules such as DNA or membrane impermeable molecules, such as pharmaceutical drugs and fluorescent dyes, to be encapsulated inside the MSN channels. The system renders the possibility to serve as a universal transmembrane carrier for intracellular therapeutic gene therapy, drug delivery and imaging applications.

\section{Acknowledgement}

This research was supported by the NSF (CHE-0239570). The authors thank Dr. Robert Doyle and the cell and hybridoma facilities of ISU for their assistance.

\section{References}

(1). Dennig, J.; Duncan, E. Rev. Mol. Biotechnol. 2002, 90,339 and the references therein. (b) Esfand, R.; Tomalia, D. A. Drug Discovery Today 2001, 6, 428.

(2). Lai, C.-Y.; Trewyn, B. G.; Jeftinija, D. M.; Jeftinija, K.; Xu, S.; Jeftinija, S.; Lin, V. S.-Y. J. Am. Chem. Soc. 2003, 125, 4451.

(3). Subramanian, S.; Srienc, F. J. Biotechnol. 1996, 49, 138.

(4). (a) Luo, D; Saltzman, W. M. Nat. Biotechnol. 2000, 18, 893. (b) Kneuer, C.; Sameti, M.; Bakowsky, U.; Schiestel, T.; Schirra, H.; Schmidt, H.; Lehr, C.-M. Bioconjugate Chem. 2000, 11, 926. (c) He, X.X.; Wang, K.; Tan, W.; Liu, B.; 
Lin, X.; He, C.; Li, D.; Huang, S.; Li, J. J. Am. Chem. Soc. 2003, 125, 7168. (d) Luo, D.; Han, E.; Belcheva, N.; Saltzman, W. M. J. Controlled Release 2004, 95, 333.

(5). Mal, N. K.; Fujiwara, M.; Tanaka, Y. Nature (London) 2003, 421, 350. 


\section{CHAPTER 9. GENERAL CONCLUSIONS}

\section{General Conclusions}

In this dissertation, I have presented the research accomplished during my doctoral studies. Each chapter is comprised by a journal article that was published or submitted for publication in specialized literature. The central theme of the thesis is represented by mesoporous silica nanospheres and their applications. The thesis contains eight chapters discussing in detail morphological and structural aspects of the material and their modification to embrace a suitable form for various applications such as: catalysis, biosensing, drug delivery and gene delivery.

Chapter 1 presented a general introduction of Mesoporous Silicates MCM-41, regarding the synthesis and material characterizations as well as a forecast of potential applications.

Chapter 2 introduced a new method for fine tuning the amount of chemically accessible organic functional groups on the pores surface of MCM-41 type mesoporous silica nanosphere (MSN) materials by matching the electrostatic interactions between surfactant head group and the organoalkoxysilane precursors at the micelle-water interface.

Chapter 3 discussed the design and synthesis of a well-defined, monodispersed mesoporous silica nanosphere (MSN) as a catalytic system which could serve as synthetic scaffolds to direct the polymerization of 1,4-diacetynil-benzene inside the mesopores. The catalytic function is played by a $\mathrm{Cu}^{2+}$ chelated by ethylenediamine groups anchored on the pore surface.

Chapter 4 presented organosulfonic acid-functionalized mesoporous silicas synthesized in a one-step approach of co-condensing inorganic-organic reagents in the presence of different surfactant templates with in situ oxidation of the thiol groups to the sulfonic acid groups. The resulting materials were tested for their catalytic performance in the esterification of fatty acid with methanol to produce methyl esters.

Chapter 5 demonstrated the modification of a MSN with a poly(lactic acid) layer as a gatekeeper to regulate the diffusion of molecules in the nanoscale pores of the material (PLA-MSN). We successfully select the molecular recognition events between several 
structurally simple neurotransmitters, i.e., dopamine, tyrosine, and glutamic acid and a pore surface-anchored o-phthalic hemithioacetal (OPTA) group.

In chapter 6, we applied a luciferase-catalyzed chemiluminescence technique to the study of ATP release from mesoporous silica nanospheres end-capped with CdS nanocrystals and PAMAM dendrimers. By changing the capping molecules as well as the uncapping triggers, we concluded that the release profile of a drug of interest can be fine-tuned.

Chapter 7 presented an intracellular MSN-based shuttle, obtained by properly engineering the inner surface or external surface of the particle. The study demonstrated the feasibility of these nanocomposites in applications such s drug delivery, gene transfection or fluorescent cellular marker.

Chapter 8 has shown a de novo synthesized gene shuttle, polyamidoamine dendrimercapped mesoporous silica nanosphere-based gene transfection reagent, providing high transfection efficiencies in different types of cells.

In sum, the MSNs showed versatility in a wide range of applications. In terms of catalysis, a wide range of reactions that can take advantage of the novel "gate keeping effect" can be approached.

The research presented herein also opens new dimensions for expanding the biotechnological potential of MSNs in particular and mesoporous silicas in general. We can envision that in the future, the MSN-based drug delivery and gene delivery carriers can combine in a nanocomposite with multiple destinations in the cell that can serve as a real investigator of different cell functions.

As a general conclusion, the research presented here represents a significant contribution to the beginning of a new era in mesoporous materials chemistry. 
Iowa State University

Dissertation Abstract

Student name: Daniela Rodica Radu

Dissertation Title: Mesoporous silica nanomaterials for applications in catalysis, sensing, drug delivery and gene transfection

Major Professor: Dr. Victor Shang-Yi Lin

The central theme of this dissertation is represented by the versatility of mesoporous silica nanomaterials in various applications such as catalysis and bio-applications, with main focus on biological applications of Mesoporous Silica Nanospheres (MSN). The metamorphosis that we impose to these materials from catalysis to sensing and to drug and gene delivery is detailed in this dissertation. First, we developed a synthetic method that can fine tune the amount of chemically accessible organic functional groups on the pores surface of MSN by exploiting electrostatic and size matching between the cationic alkylammonium head group of the CTAB surfactant and various anionic organoalkoxysilane precursors at the micelle-water interface in a base-catalyzed condensation reaction of silicate.

Aiming nature imitation, we demonstrated the catalytic abilities of the MSNs. We utilized an ethylenediamine functional group for chelating $\mathrm{Cu}^{2+}$ as a catalytic functional group anchored inside the mesopores. Thus, a polyalkynylene-based conducting polymer (molecular wire) was synthesized within the Cu-functionalized MSNs silica catalyst.

For sensing applications, we have synthesized a poly(lactic acid) coated mesoporous silica nanosphere (PLA-MSN) material that serves as a fluorescence sensor system for 
detection of amino-containing neurotransmitters in neutral aqueous buffer. We exploited the mesoporosity of MSNs for encapsulating pharmaceutical drugs. We examined bio-friendly capping molecules such as polyamidoamine dendrimers of generations $G 2$ to $G 4$, to prevent the drug leaching. Next, the drug delivery system employed MSNs loaded with Doxonubicin, an anticancer drug. The results demonstrated that these nano-Trojan horses have ability to deliver Doxorubicin to cancer cells and induce their death.

Finally, to demonstrate the potential of MSN as an universal cellular transmembrane nanovehicle, we anchored positively charged dendrimers on the surface of MSN and utilize them to complex cationic DNA. The p-EGFP-C1 gene-coated MSN nanocomposite was able to transfect cancer cell lines, such as human HeLa and CHO cancer cell lines. The gene carrier ability of MSNs was further proved by transfecting primary cells and cotransfecting of two different genes in cancer cell lines.

In sum, MSN are versatile partners in several types of applications, as demonstrated in the 164 pages of my dissertation. 